\title{
EXPLORING THE INTERDEPENDENCIES OF RESEARCH FUNDERS IN THE UK
}

\author{
REPORT BY THE OHE AND SPRU \\ Prepared for \\ CANCER RESEARCH UK \\ March 2014
}

Authors:

OHE: Shah, K., Sussex, J., Hernandez-Villafuerte, K. and Garau M.

SPRU: Rotolo, D., Hopkins, M.M., Grassano, N., Crane, P., Lang, F., Hutton, J., Pateman, C., Mawer, A., Farrell, C. and Sharp, $\mathrm{T}$.

For further information please contact:

Jon Sussex

jsussex@ohe.org

Office of Health Economics

Southside, 105 Victoria Street

London SW1E 6QT

United Kingdom

Tel: +44207 7471412 or +447789435855 


\section{CONTENTS}

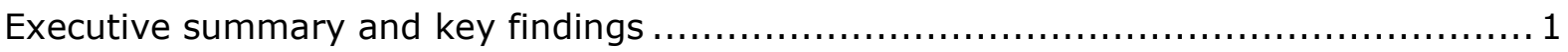

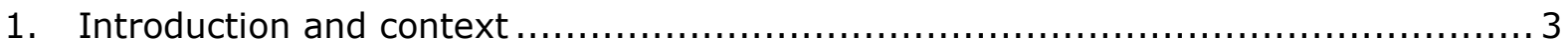

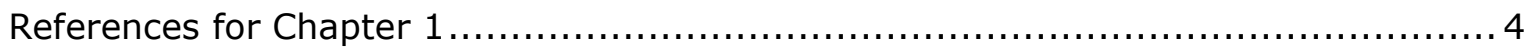

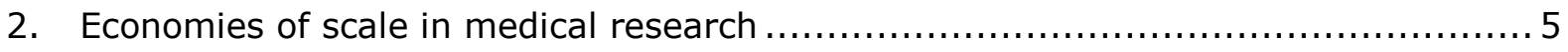

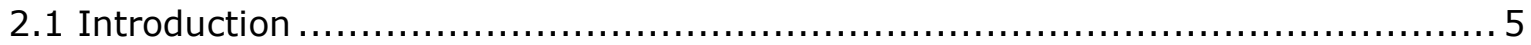

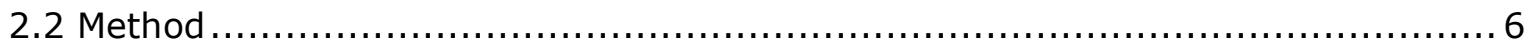

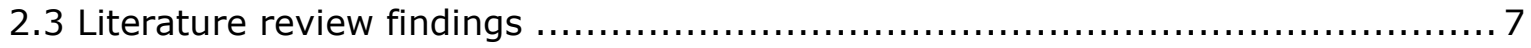

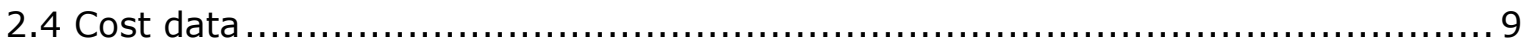

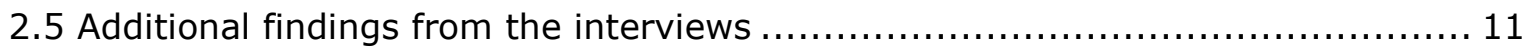

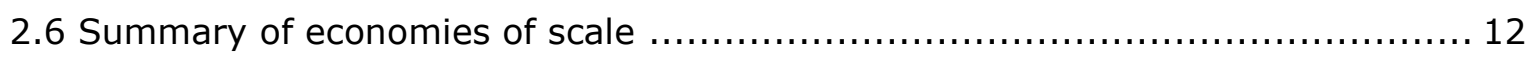

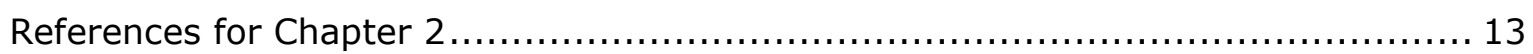

3. Funding interdependencies in neoplasms research .............................. 15

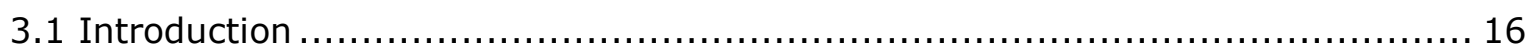

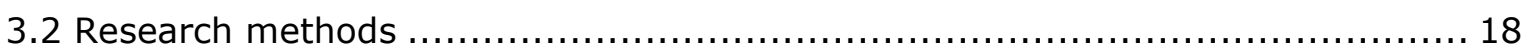

3.2.1 Limitations of the dataset construction for analysis and interpretation......... 19

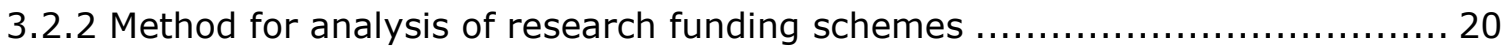

3.2.3 Method for case studies of leading researchers................................ 20

3.3 Scientometric analysis results: Contextual descriptive statistics .................... 21

3.3.1 Publication numbers and outlets .............................................. 21

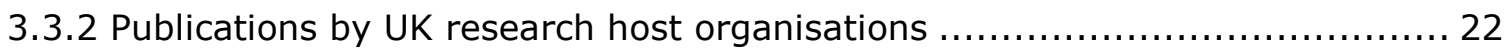

3.4 Scientometric analysis: Interdependencies in neoplasm research .................. 25

3.4.1 Collaborations among authors and interdependent host organisations .......... 25

3.4.2 The interdependence of funding organisations .................................. 32

3.5 Scientometric analysis: Complementarities in neoplasms research ................ 40

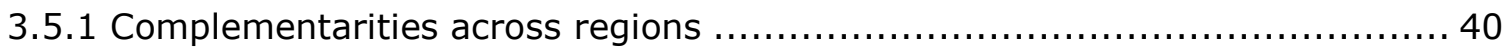

3.5.2 Funder complementarities at research host organisation level ................. 44

3.5.3 Complementarities across MESH codes within neoplasms ...................... 44

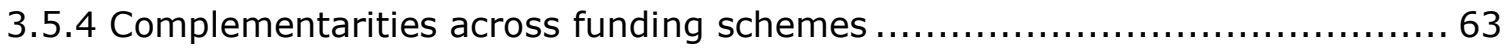

3.5.5 Researchers use of complementary funding schemes over time.................69 69

3.6 Scientometric analysis: Diversity in neoplasm research ......................... 75

3.6.1 Diversity of funders and host organisations across scientific disciplines ........ 75

3.6.2 Diversity of funders and host organisations across medical areas ............... 79

3.7 Scientometric analysis: Additional perspectives .................................. 84

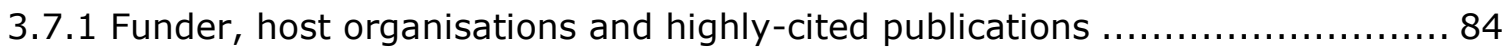

3.7.2 Funder, host organisations and intensity of international collaboration ....... 868 


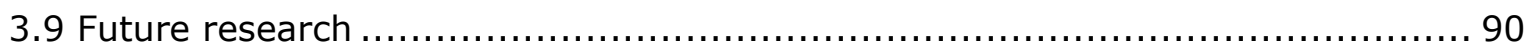

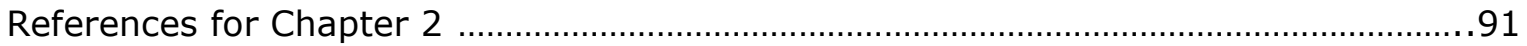

4. Complementarity/substitutability of government and charity funding of cancer

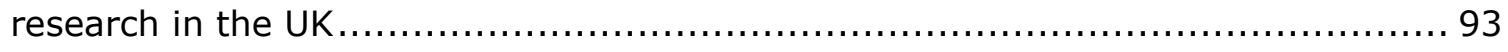

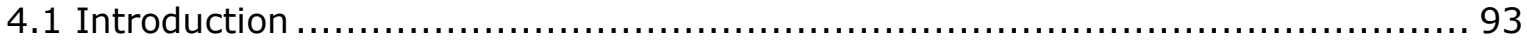

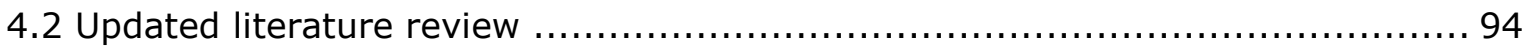

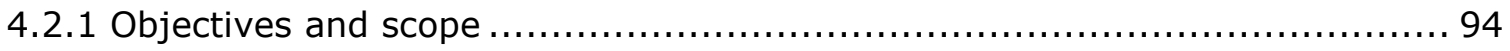

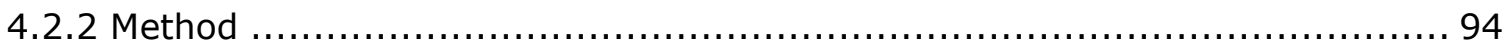

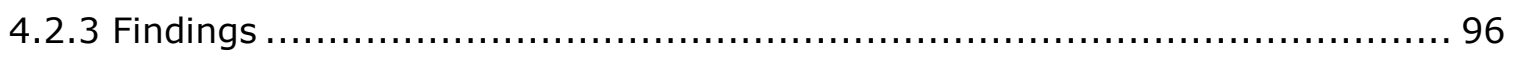

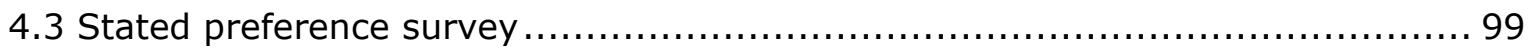

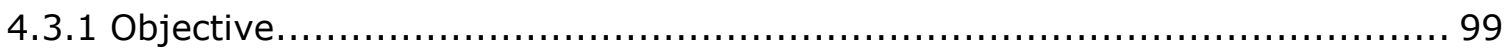

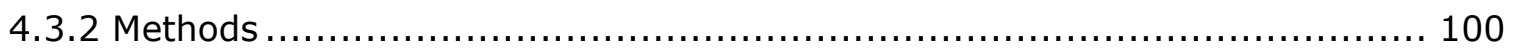

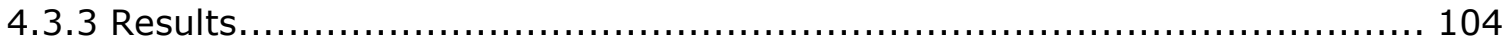

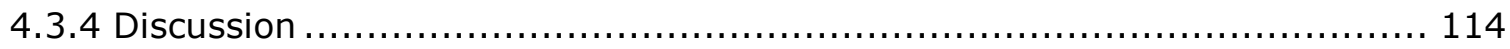

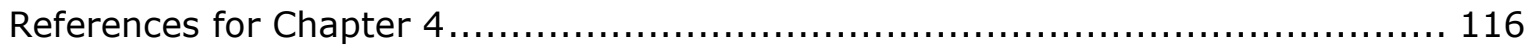

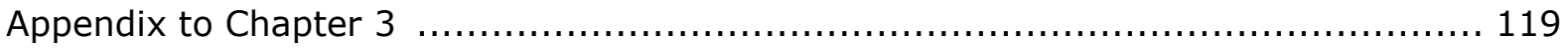

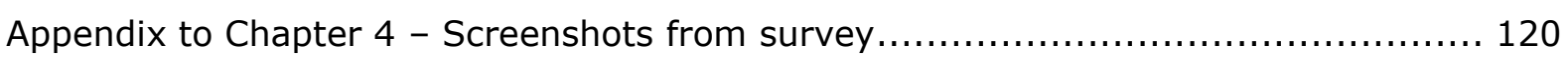




\section{EXECUTIVE SUMMARY}

Investment in medical research is vital to the continuing improvement of the UK's health and wealth. It is through research that we expand our understanding of disease and develop new treatments for patients. Medical research charities currently contribute over $£ 1$ billion annually to medical research in the UK, of which over $£ 350$ million is provided by Cancer Research UK. Many charities, including Cancer Research UK, receive no government funding for their research activity.

Cancer Research UK is engaged in a programme of work in order to better understand the medical research funding environment and demonstrate the importance of sustained investment. A key part of that is the Office of Health Economics" (OHE) 2011 report "Exploring the interdependency between public and charitable medical research". This study found that there are substantial benefits, both financial and qualitative, from the existence of a variety of funders and that reductions in the level of government financial support for medical research are likely to have broader negative effects.

This contributed to other evidence which found that the activities and funding of the charity, public and private sectors respectively are complementary, i.e. mutually reinforcing, rather than duplicative or merely substituting for one another.

"Exploring the interdependencies of research funders in the UK" by the Office of Health Economics (OHE) and SPRU: Science and Technology Policy Research at the University of Sussex, represents a continued effort to build the evidence base around the funding of medical research.

This report uncovers the extent to which funders of cancer research are interdependent, nationally and internationally. Key figures show that two thirds of publications acknowledging external support have relied on multiple funders, while just under half benefited from overseas funding, and almost a fifth are also supported by industry. In addition the analysis shows that the general public would not want tax funding of cancer research to be reduced, but would not donate enough to charities to compensate for any such reduction.

Exploring the interdependencies between different medical research funders, particularly in cancer, provides us with a striking picture of the extent to which research funders contribute together to produce world class research. The findings provide a compelling case for why investment - by all sectors - is needed to allow the UK to continue to punch above its weight in terms of research outputs. 


\section{KEY FINDINGS}

\section{ECONOMIES OF SCALE IN MEDICAL RESEARCH}

A cut in research funding by a research funder might cause a slightly disproportionate fall in research activity, demonstrating a small effect of economies of scale.

- However, beyond the short term, economies of scale appear to be exhausted at small sizes of research teams and research projects.

- There are exceptions of a few projects that entail expensive and highly specific equipment, IT systems or buildings that demonstrate the existence of economies of scale.

\section{FUNDING COMPLEMENTARITIES AND INTERDEPENDENCIES IN NEOPLASMS RESEARCH}

The UK produced almost $7 \%$ of global research publications on neoplasms ${ }^{1}$ in 2011 . To achieve this, scientists' host organisations and their funders worked in an interdependent and complementary way.

- Over 1,000 UK organisations contributed to neoplasms research papers, and in doing so collaborated with co-authors in over 5,000 non-UK organisations.

- Funding acknowledgements appear in half of all publications and reveal that these papers by UK researchers benefited from the support of over 650 distinct UK funders and over 1,500 non-UK funders, as well as over 300 private organisations (many of them multinational).

- These publications were supported by an average of more than three funders per publication.

- Major funders strongly focus on pathology and genetics while surgery is relatively neglected.

- Minor UK funders are complementary to major UK funders as they focus on distinct neoplasm types.

\section{COMPLEMENTARITY/SUBSTITUTABILITY OF GOVERNMENT AND CHARITY FUNDING OF CANCER RESEARCH IN THE UK}

Most of the public's decisions about how much to donate to cancer research or other medical research charities are unaffected by government decisions on funding cancer or other medical research.

- The vast majority of respondents stated that their out-of-pocket donations to cancer research and other medical research charities would not be affected by changes in government funding levels or by being given the opportunity to allocate $£ 100$ of their income tax to these charities.

\footnotetext{
${ }^{1}$ Neoplasms are abnormal masses of tissue arising from an abnormal proliferation of cells. This term covers all forms of cancer research.
} 


\section{INTRODUCTION AND CONTEXT}

The UK makes a disproportionately strong and successful contribution to the global medical research effort. An important element of this is the role of medical research charities alongside the public sector and private industry. Charities currently contribute over $£ 1$ billion annually to medical research in the UK (AMRC, 2013), about one third of which is provided by Cancer Research UK.

The public, charity and private sectors bring different strengths and emphases. The evidence is that the three sectors' activities and funding are complementary, i.e. mutually reinforcing, rather than duplicative or merely substituting for one another (Cancer Research UK, 2011; HERG et al., 2008; OHE, 2009; OHE, 2011). Taken together, this combined medical research effort generates not only health benefits to people all over the world, but also important economic gains to the UK (HERG et al., 2008).

The Government's June 2013 Spending Round maintained public funding of science research, including medical research, in cash terms until 2015/16, implying a gradual squeeze in real terms given expected inflation (as measured by the GDP deflator) of $2 \%$ per year (HM Treasury, 2013). The period of austerity and consequent pressure to constrain public expenditure is likely to continue beyond then.

Cancer Research UK was interested in gaining further understanding of the following:

a) What is the difference between the diverse research activities supported by funders in the UK? Do these research activities complement one another? How interdependent are these research activities?

b) If there was a cut in government funding for life sciences would other funders (private and public) be able to continue to support research activities? What would be the impact on the life sciences output in the UK?

In March 2013 Cancer Research UK awarded a grant to the Office of Health Economics (OHE) and SPRU: Science and Technology Policy Research at the University of Sussex to help answer these questions. This report sets out our work and has the following main elements:

- A high level investigation of the likely extent of economies of scale in charity- and publicly-funded medical research in the UK. It is based on a review of academic and grey literature on economies of scale in medical research, and a programme of interviews with major UK medical research funders plus analysis of cost data provided by them. This part of our work is reported in Chapter 2.

- Scientometric analysis (that is the science of measuring scientific research) was undertaken to establish the interdependencies and the differences between the diverse research activities supported by different funders of cancer research in the UK. This is reported in Chapter 3. We looked at research publications and tracked back to the funders identified 
through these outputs. Our strategy made no a priori judgements on where UK researchers obtain funding and the results show the relative importance of all funders named or acknowledged in papers, including non-UK funders and industry.

- A study of the complementarity or substitutability of government and charity funding of cancer research in the UK, including a literature review. The main focus of this strand of our research is an internet survey of a sample of the UK general population. We use a stated preference design, informed by a prior focus group workshop, to assess how a change in Government funding of cancer research might affect public willingness to donate to cancer research charities. This part of our work is presented in Chapter 4.

\section{References for Chapter 1}

AMRC (Association of Medical Research Charities). (2013) Charity funded research. AMRC member research expenditure for 2012. London: AMRC.

Cancer Research UK. (2011) Building the ideal environment for medical research. London: Cancer Research UK.

HERG, OHE, RAND Europe. (2008) Medical research: what's it worth? London: Medical Research Council, Wellcome Trust, Academy of Medical Sciences.

HM Treasury. (2013) Spending round 2013. Cmnd 8639. London: Her Majesty's Treasury.

OHE (Office of Health Economics). (2009) Forward together: complementarity of public and charitable research with respect to private research spending.

Cambridge: Alzheimer's Research UK.

OHE (Office of Health Economics). (2011) Exploring the interdependency between public and charitable medical research. London: Cancer Research UK. 


\section{ECONOMIES OF SCALE IN MEDICAL RESEARCH}

\section{Key Points}

- There is some evidence in the literature of the existence of economies of scale in research but it is from a nearly 20 -year old US study and is not specific to medical research.

- In the short term, cost data from UK medical research funders suggests a hypothetical $1 \%$ cut in research funding might initially cause an approximately $1.3 \%$ fall in research activity, but in the medium to long term the impact would be more proportionate.

- Beyond the short term, economies of scale appear to be exhausted at small sizes of research teams and research projects, with the exception of a few projects that entail expensive and highly specific equipment, IT systems or buildings.

- But even temporary cuts in funding can have long lasting consequences: reduced funding means less work for researchers in the UK, meaning that some will either leave the country or change careers, and not all would return to the UK or to research were funding to be increased again later.

\subsection{Introduction}

The impact on the output of medical research in the UK of a hypothetical cut in government funding depends on the answers to two questions:

- would changes in government funding affect the general public's donations to medical research charities?

- to what extent are there economies of scale in medical research? If economies of scale are significant then a $1 \%$ cut in medical research spending would reduce the outputs from that research by more than $1 \%$.

We address the first of these questions in Chapter 4. Answering the second question is the subject of the remainder of the present chapter.

The presence (or not) of economies of scale is detected by measuring marginal costs relative to average costs. If marginal costs are below average costs then there are economies of scale: increasing the amount of activity would reduce the average cost of that activity; and conversely, reducing the amount of activity would raise the average cost of that activity.

Economies of scale are generated by the existence of fixed costs. In the short run, e.g. within a year, many costs may be 'fixed': not only the costs of buildings and equipment used but also overhead costs such as those of IT and information services, finance, personnel and general management staff. Over time many of the costs that are fixed in the short term become variable: overheads can be 
scaled down or up; buildings and equipment can be turned to other uses, sold off, or simply not replaced when they wear out. Some costs may never be variable though. These are the 'sunk costs' associated with highly specific capital: physical capital such as specialised buildings or equipment (e.g. a synchrotron may have no other use than medical research, or no use that is nearly as valuable as medical research); and human capital, i.e. the specialised training and experience embodied in researchers that would not be nearly so valuable if those people had to find other employments.

Thus the existence and magnitude of economies of scale is dependent on the timescale under consideration. In the absence of sunk costs, all costs are ultimately variable and in that case economies of scale are a short to medium term phenomenon. We have attempted, therefore, to distinguish between short and long term effects.

To quantify precisely the magnitude of economies of scale in medical research would require access to, and detailed discussion and analysis of, disaggregated cost data from a representative range of organisations and individuals undertaking medical research in the UK. It is not clear that such data are currently available. RCUK and UUK noted in their review of the impact of 'full economic costing' of research that "The absence of robust cost data had led many institutions to underestimate the costs of research" (RCUK and UUK, 2009).

Separately identifying the costs of medical research is far from straightforward given that research is usually jointly produced (in higher education institutions) with teaching undergraduate and graduate students, and (in hospitals) with provision of health care services to patients. Allocating costs, e.g. between undergraduate education, postgraduate education and research at a university, is to some extent arbitrary. Plus there are very many different areas of research, which may share costs. Thus in a 'multi-product enterprise' such as a university there is a distinction between 'ray economies of scale' and 'product-specific economies of scale'. Ray economies of scale assume that the composition of output remains constant, while its scale is allowed to expand or contract. This gets round the multi-product nature of the enterprise by assuming that the quantity of teaching, say, is increased pro rata with the quantity of research. But a multi-product enterprise may expand outputs of different products nonproportionally, in which case ray economies of scale are not applicable. In such an environment, estimation of product-specific economies of scale allows a better understanding of the organisation's cost structure.

A further complication is that empirical studies of economies of scale need to measure not only the quantity of research outputs (which is itself not straightforward but is commonly proxied by numbers of research publications), but also should allow for the quality of those outputs (which is very difficult in practice), as a $1 \%$ cut in finding might lead to lower quality research as corners are cut, not just to less research.

\subsection{Method}

Thus, an empirical analysis of economies of scale in medical research would be a major undertaking. It would, furthermore, depend on the willingness of research 
organisations (i.e. the recipients of research funding) to open their books to scrutiny of their costs. Such a study would have been well beyond the scope of the budget available for the current project. We therefore agreed with Cancer Research UK to undertake instead a high level assessment of the magnitude of economies of scale in medical research, based on:

- a review of economic and grey literature on economies of scale in medical research outside industry. There is a considerable literature on R\&D in industry, especially in pharmaceutical companies, but our focus was rather on that research which is funded by the Government and/or charities. The review comprised: (a) a search (as at $6^{\text {th }}$ August 2013) by title and (if warranted by the title) abstract of the first 100 hits found via Google Scholar and Google respectively using the search terms "economies of scale" AND ("medical" AND "research"); (b) obtaining grey literature on the subject of medical research funding in the UK, including literature recommended by interviewees; and (c) checking apparently relevant references in the bibliographies of relevant publications;

- interviews with senior representatives of the MRC, NIHR and OSCHR, the Wellcome Trust and Arthritis Research UK. The interviewees provided an overview of the fixed versus variable costs of the research funded by their organisations and indicated how their organisations might be expected to respond to reduced or increased funds for medical research;

- a group interview with five managers at Cancer Research UK with responsibilities related to allocation of funds to different types of research activity;

- analysis of cost data provided by interviewees on the balance between fixed and variable costs in medical research.

\subsection{Literature review findings}

All of the handful of relevant references found among the first 100 hits of the Google Scholar search were summarised in a book chapter by Cohn and Cooper (2004). These references discuss economies of scale in the production of university research, including medical research, in the context of empirical studies of economies of scale in higher education institutions. They are all econometric analyses and have as their main focus the measurement of economies of scale in university teaching but they also offer evidence (or appear to) on economies of scale in research as one of the products of universities seen as multi-product enterprises.

Dundar and Lewis (1995) examined econometrically the production of hours of student teaching and the number of research publications of 118 departments of 18 public research universities in the USA. They report finding, at the department level, both ray and product-specific economies of scale in undergraduate teaching, graduate teaching and research publications. In other words, the cost per research publication fell the larger the scale/funding of the university department, both when teaching and research are increased together in constant proportions and when research is increased by itself. 
The only UK studies were by Johnes (1997 and 1998) and Izadi et al. (2002). Johnes (1997 and 1998) used academic year 1994/95 data for 99 UK universities to estimate a multi-product cost function with research as one of the products. 'Research' was not limited to medical or natural sciences research but covered all areas including humanities and social sciences. 'Research' was measured as the value of research grants. The results appear to show significant unexploited economies of scale in research overall at the then current average scale of UK universities. Izadi et al. (2002) analysed the same data as Johnes but used a different econometric approach. They also appeared to find economies of scale in research. Each of the UK studies concerns 'product-specific' economies of scale where the 'product' is the value of research grants won. In other words, larger universities win disproportionately more research grants, and smaller universities disproportionately few. Unfortunately, however, these UK studies say nothing about the outputs of the research carried out with those grants and hence nothing about what happens to the cost per research output as research funding is increased or reduced.

The Google review revealed two references of interest from the grey literature.

Vonortas and colleagues (2011) undertook an analysis for DG Research and Information of the European Commission of the economies of scale and scope at the project level in European Commission funded research. They analysed econometrically survey data from 1,172 organisations participating in 676 research projects funded by the $5^{\text {th }}$ and $6^{\text {th }}$ Framework Programmes for Research and Technological Development of the EU. This includes medical research but along with much non-medical research. The complex econometric analysis showed no statistically significant relationships between project size and outputs for publicly and charity funded research. Economies of scale were exhausted at small project sizes "well below the ... average project sizes that we observe". In summary they found that: "Taken overall, the econometric results indicate that increasing scale does not seem to improve project performance, with the notable exception of firms which seem to benefit from increasing scale in terms of their own funding, showing a positive effect mainly on commercial impacts." (Vonortas et al., 2011; both quotes taken from page 4).

In a review for the UK Government Office of Science and Technology, von Tunzelmann et al. (2003) looked at the impact of the size of research units on their research performance. The review was not limited to medical research. The studies they reviewed included the Dundar and Lewis (1995) and Johnes (1997) articles discussed above. Von Tunzelmann and colleagues concluded overall that:

"the key unit would appear to be the group or team, rather than the department or the university"

and

"there is reasonably convincing evidence of a size effect in the form [of] a 'critical mass' threshold. In many scientific fields, productivity seems to rise as the team size increases to about six or eight persons, above which there is usually little or no extra gain per capita." 
This suggests that if a hypothetical cut in research funding were met by cutting discrete small teams rather than shaving resources from many more of them, the loss of research output would be proportionate to the funding cut rather than disproportionate.

Finally, one of the interviewees identified a 2009 report by the management consultants McKinsey (2009) of being of some relevance to the discussion of economies of scale. McKinsey sought to identify the distinguishing characteristics of high productivity medical research laboratories, based on interviews with "12 world-class academic innovators" and their own analysis of practices in 15 research laboratories in industry with different levels of performance and "several more academic laboratories". They identified five areas that distinguished high productivity labs: strategy decisions, talent management, portfolio and project management, problem solving, collaboration. The inclusion of portfolio and project management in the list implies a possible role for economies of scale, though more so for economies of scope: "The top labs design their portfolios of projects to be interlinked, so that they are both additive, in that the lab reaps benefits from their intellectual scale, and synergistic, in that each project might uncover insights that prove valuable to another." (McKinsey \& Company, 2009).

Overall the literature is largely unhelpful about identifying the existence or not of economies of scale in medical research, in terms of research output per research pound spent. Such economies of scale as there are appear to be exhausted at small scales of research units. Consequently, if a hypothetical cut in medical research spending were met by closing down whole, albeit small, research teams rather than by squeezing across the board, the loss of research output might only be proportionate to the funding cut, rather than disproportionately damaging.

\subsection{Cost data}

Medical research in the UK is funded, indirectly as well as directly, from a variety of sources. This, plus the previously noted tendency for research to be conducted in institutions that are jointly producing research and teaching (and sometimes health care), from some or all of the same people and facilities, makes it problematic to determine the balance between variable and fixed costs incurred in the production of medical research. However, a review of literature on UK research funding arrangements, combined with information obtained in the interview programme, allows the following impressionistic picture to be constructed.

Some of the infrastructure necessary for universities to conduct medical research is paid for by "Quality Related (QR)" funding that UK universities receive from the higher education funding councils of the four countries of the UK in recognition of the quality and quantity of the research they achieve across all subject areas (UKCRC, 2012). Some of the infrastructure, including some staff costs, is also in effect paid for out of non-research funding streams received by universities. The 2010 Wakeham Report found that UK higher education institutions were reporting in $2008 / 09$ a deficit of $£ 2.187$ billion (24\%) of research funding versus research costs. 
The funding arrangements currently in place in the UK assume that $20 \%$ of full economic costs of research (whether medical research or any other kind) are met from QR and other underlying funding streams. The remaining $80 \%$ of full economic costs are supposed to be funded by research council and NIHR grants, and by grants from charities topped up by the tax-funded Charity Research Support Fund. Charities generally fund around $60 \%$ of full economic costs of research at universities. The interviewees from MRC and NIHR confirmed that this $20 / 80$ split of funding of full economic costs was not based on any assessment of the split between fixed and variable costs of research, but was rather a political agreement.

The Wakeham Report recommended incentivising universities to improve efficiency in indirect costs, which are essentially overhead costs and which across all research councils (not just the Medical Research Council) were estimated to represent $30 \%$ of total research project costs. Direct costs were estimated at $61 \%$ of total research project costs, with estates costs making up the remaining $9 \%$. (Estates costs are more usually included under the heading of indirect or overhead costs, but the Wakeham Report treated them separately as it explicitly did not propose cutting spending on that part of total research costs).

Information provided by Cancer Research UK implies a rather higher percentage of medical research costs are direct, i.e. short-term variable, costs than the Wakeham Report states for all (not just medical) research councils. An analysis of data provided by Cancer Research UK, of $£ 155$ million of research grants ( 110 grants) awarded by them with start dates between June 2012 and May 2013 inclusive, shows that the costs of those projects have the following average split:

- directly incurred costs $=54 \%(\min 20 \% ; \max 93 \%)$

- $\quad$ directly allocated costs $=22 \%(5 \% ; 56 \%)$

- $\quad$ indirect costs $=24 \%(2 \% ; 45 \%)$

Thus there is wide variation from project to project but overall, short term variable costs (i.e. the direct costs) appear to average $76 \%$ of the total and indirect costs (overheads etc.) $24 \%$.

Other data provided by Cancer Research UK shows the annual budgets of the five research institutes they fund. Out of total costs of $£ 122$ million, $78 \%$ are identified as research staff costs and other research running expenses, which may be thought of as broadly equivalent to 'variable' costs. The other $22 \%$ were overhead costs, including administrative and support staff (e.g. information systems staff) and corresponding operating expenses, plus the annuitised costs of property and capital equipment.

Data provided by the MRC showed that of the total of $£ 372$ million that the MRC committed in 2012/13 to fund grants and fellowships, $78 \%$ went on 'direct costs' (including 'exceptions', which are direct costs funded at $100 \%$ of 'full economic costs') and $22 \%$ on 'indirect costs'.

In summary, the 78/22 direct/indirect cost split for the MRC grants and fellowships matches the 78/22 direct/indirect split for Cancer Research UK's institutes, and is similar to the 76/24 direct/indirect split for Cancer Research UK's grants. 
Taking a 78/22 or $76 / 24$ split to represent the balance of variable versus short term fixed costs: a hypothetical $1 \%$ cut in research funding falling entirely on direct/variable costs would imply an approximately $1.3 \%$ cut in the short term in the amount of research activity.

However, in the medium to long term it would be possible to reduce the scale of infrastructure slightly so that research capacity and use of that capacity are once more brought into balance. To the extent that resources have been invested in highly specific human capital - specialist trained and experienced researchers and highly specific fixed capital, meaning that the specialised skills/experience and equipment have much higher value in their current uses than in their next best alternative uses, then those economies of scale will persist even in the long run. Those costs are 'sunk', meaning that if that human and physical capacity is used less than fully then there will be irrecoverable waste. However, it is not possible on the basis of the information we found to determine what percentage of costs fall into the 'sunk' category.

\subsection{Additional findings from the interviews}

We asked the interviewees at Arthritis Research UK, MRC, NIHR, OSCHR and the Wellcome Trust how significant, if at all, they would expect short run and longer run economies of scale to be, and how they would expect a marginal reduction or increase in funds available for medical research to be allocated.

Three of the four interviewees who felt able to comment considered that although there might be economies of scale in medical research in the short run - because research capacity and overhead support functions cannot be created or abandoned immediately - in the longer run capacity could and would be adjusted in response to sustained increases or cuts in funding. The fourth interviewee largely agreed with this view but with the qualification that a minority of medical research in the UK is capital intensive, and furthermore that the physical capital involved was highly specific, implying substantial sunk costs and hence some long lasting economies of scale. Examples are: the Diamond Light Source synchrotron at Harwell; cancer biobanking; and research requiring high cost IT and imaging equipment.

When considering the likely impact of marginal reductions or increases in funding, an essential distinction is whether the changed funding level is expected to be a temporary aberration or a permanent feature. Temporary increases in funding would be expended on short duration projects, to avoid creating commitments that might not be sustainable beyond the current year. Temporary reductions would be met by delaying the starts of new projects or by attempting to squeeze efficiencies out of research activity already under way.

One particular issue, raised by two of the interviewees, was that temporary cuts in funding can have long lasting negative consequences. The fixed costs of educating and training researchers, combined with the international nature of labour markets for highly trained and expert people, mean that the funding 'tap' causes problems immediately it is turned off and these problems take time to be overcome even if the tap is turned back on again subsequently. When reduced funding means less work for researchers to do, they leave the country or leave 
research for other careers. If funding were then to be increased again, not all of them would return to the UK or to research. Thus even temporary funding cuts cause long term damage. In general, planned cuts with advance warning (giving time to plan for them) are less damaging than sudden unexpected cuts.

Changes to funding levels that are expected to persist would generally prompt qualitatively different responses by research funders. The initial response to a cut in funds available might still involve attempting to squeeze efficiencies from research units and projects already being funded. One interviewee said that their organisation would not push too hard for further efficiencies for fear of the damage that might cause. A more general short term response would be to raise the quality 'bar' for funding new projects: i.e. fewer projects would be initiated. This would in effect mean less research produced from the existing research capacity. Given the earlier discussion of fixed/indirect and variable/direct costs, a $1 \%$ cut in funds might in the short term therefore be expected to have the effect of a greater than $1 \%$ cut in the amount of research activity funded.

However, over the medium to longer term a sustained cut in funds would lead to reduced capacity too, bringing research capacity and use of that capacity back into balance. In other words, capital would be sold off or not replaced and overhead staff and costs would also be cut. Thus over a period of a few years a $1 \%$ cut in funding would imply, broadly speaking, a $1 \%$ reduction of research activity. This view is borne out by the literature on economies of scale in medical research, as discussed earlier.

The response to a sustained increase in funds available might, even in the short term, be to increase research capacity as well as to make more use of such capacity. A common theme in the interviews was that capacity for medical research is issue/field specific. Consequently, funders' decisions about how much of any increase to invest in capacity would depend on which fields were considered to be the highest priorities for more research and whether they already had sufficient capacity or whether they were high priorities to build up.

\subsection{Summary of economies of scale}

The published academic literature offers little evidence on whether there are economies of scale in medical research outside industry. A study of 18 public research universities in the USA found that the cost per research publication produced (not specifically medical research, but all types of research) fell as the scale/funding of the university department increased, both when teaching and research are increased in step together and when research is increased by itself (Dundar and Lewis, 1995). Studies using data for 99 UK universities for the academic year 1994/95 also appeared to find economies of scale in research (again not specifically medical research), but they used research grants won as their measure of 'research', which begs the question what happened to the scale of outputs from research (Johnes, 1997 and 1998; and Izadi et al., 2002). An EU study found economies of scale in research projects (again, not specifically medical research) to be exhausted at small project scales (Vonortas et al., 2011) and von Tunzelmann and colleagues concluded that further economies of scale 
would not be realised once research teams went beyond eight or so members (von Tunzelmann et al., 2003).

Data from Cancer Research UK and the MRC show direct (arguably short term variable) costs to be around $76 \%-78 \%$ of total costs, and indirect costs (arguably more fixed costs in the short term) around $22 \%-24 \%$ of total costs. This suggests that in the first year or so after a change in funding, when only direct costs can be varied, a hypothetical $1 \%$ cut in funding would lead to a $1.3 \%$ reduction in medical research activity.

The views of the interviewees imply that this short term consequence would not last in the medium to longer term as over a period of a few years it would be possible to adjust research capacity too. Thus economies of scale appear to be only short term. The one exception to that is a minority of medical research that involves high cost and highly specialised equipment, IT or biobanks. Furthermore, temporary cuts in funding can have long lasting negative consequences: reduced funding means less work for researchers in the UK, meaning that some will either leave the country or change careers, and not all would return to the UK or to research if funding were to be increased again later.

Thus, in summary, there is some evidence of the existence of economies of scale in research but it is from a nearly 20 -year old US study and is not specific to medical research. Beyond the short term, economies of scale appear to be exhausted at small sizes of research teams and research projects, with the exception of the small number of projects that entail expensive and highly specific equipment, IT systems or buildings.

\section{References for Chapter 2}

Cohn, E. and Cooper, S.T. (2004) Multi-product cost functions for universities: economies of scale and scope. In Johnes, G. and Johnes, J. eds. International handbook on the economics of education. Cheltenham: Edward Elgar Publishing Ltd. 579-612.

Dundar, H. and Lewis, D.R. (1995) Departmental productivity in American universities: economies of scale and scope. Economics of Education Review. 14(2), 119-144.

Izadi, H., Johnes, G., Oskrochi, R. and Crouchley, R. (2002) Stochastic frontier estimation of a CES cost function: the case of higher education in Britain. Economics of Education Review. 21(1), 63-71.

Johnes, G. (1997) Costs and industrial structure in contemporary British higher education. The Economic Journal. 107, 727-737.

Johnes, G. (1998) Corrigendum. The Economic Journal. 108, 1275. 
McKinsey \& Company. (2009) Pharma R\&D compendium. The secret of high productivity in the research lab. London: McKinsey \& Company.

RCUK (Research Councils UK) and UUK (Universities UK). (2009) RCUK/UUK review of the impact of full economic costing on the UK higher education sector. Swindon: RCUK.

UKCRC (UK Clinical Research Collaboration) (2012) UK health research analysis 2009/10. London: UKCRC.

Vonortas, N., Polt, W., Fisher, R., Spanos, Y., Dinges, M., Ipektsidis, B. and Pateraki, M. (2011) Economies of scale and scope at the research project level. Report for the European Commission Directorate-General for Research and Innovation. Brussels: European Commission.

von Tunzelmann, N., Ranga, M., Martin, B. and Geuna, A. (2003) The effects of size on research performance: a SPRU review. Report for the Office of Science and Technology, Department of Trade and Industry. Brighton: SPRU Science and Technology Policy Research, University of Sussex.

Wakeham, W. (2010) Financial sustainability and efficiency in full economic costing of research in UK higher education institutions. Report of the RCUK/UUK Task Group chaired by Sir William Wakeham. Swindon: RCUK. 


\section{FUNDING INTERDEPENDENCIES IN NEOPLASMS RESEARCH}

\section{Key Points}

\section{Descriptive statistics}

- The UK produced $6.9 \%$ of global research publications on neoplasms in 2011.

- This research was produced by authors from 1,159 UK organisations and coauthors from 5,077 non-UK research host organisations.

- Publications by UK authors acknowledged financial support from 2,621 organisations, of which 663 were UK based, excluding 307 private sector organisations.

- 26 host organisations ( $2 \%$ of the total) contribute to $72 \%$ of the publications output.

\section{Interdependency - Strong interdependencies exist among research hosts and among research funders}

- $67 \%$ of publications relied on collaboration among research hosting institutions and $43 \%$ involved international collaborators.

- The 113 leading UK research organisations collaborate in publications more with international partners than with their UK neighbours.

- Where publications acknowledge funding, multiple funders are acknowledged $64 \%$ of the time, with a mean of 3.3 funders acknowledged per publication.

- Industry contributed to over $14 \%$ of UK neoplasm publications in 2011 and $18 \%$ of those acknowledging funders acknowledge industry support. These papers were more highly cited than expected.

\section{Complementarity - The research funding of different organisations is complementary, particularly between large funders and small funders}

- The major funders of research on neoplasms support scientific publications that have co-authors across almost the entire UK, but centre their efforts in the Cambridge, London and Oxford areas.

- Smaller funders focus primarily on London but often have a secondary and focus on other regions, which makes them complementary to the major funders in geographic terms.

- The top-three UK funders of neoplasms research - Cancer Research UK, the UK Departments of Health and MRC - focused mainly on "Neoplasms, Glandular and Epithelial", "Digestive System Neoplasms" and "Urogenital Neoplasms", while smaller funders are complementary as they often focus on other neoplasm types.

- Funding schemes provided by the major charity and government funders provide UK researchers with a broad choice of grants, making the UK an attractive funding environment for leading scientists who rely on multiple grants simultaneously to build their groups and sustain promising new research lines. 


\section{Diversity - The major research funders and host organisations differ considerably in terms of supported scientific disciplines and research domains}

- Of the major funders, Cancer Research UK and the Departments of Health (including NHS and NIHR) BBSRC and EPSRC support the broadest range of research.

- Major funders strongly focus on pathology and genetics, while surgery is relatively neglected.

\section{Additional Perspectives - Research quality and international collaborations}

- Major UK funders support a higher proportion of highly cited publications than minor UK funders. Papers with more funders also have higher citations.

- Publications supported by industry are significantly more highly cited than those without industry support.

\subsection{Introduction}

The UK biomedical research community benefits from a broad range of public sector, private sector and charitable funders that play a key role in supporting their work. Yet, the extent to which funders play complementary roles in this support is less understood. The analysis undertaken for this project provides evidence of a highly interdependent and complementary funding system, based on an in-depth study of the portion of the UK's research base focused on neoplasms.

Prior studies that attempt to ascertain the nature of funding landscapes have often begun by exploring the stated funding activities of selected, large UK-based funders (e.g. HERG et al. 2008; Morgan-Jones and Grant 2011, OHE 2011). Our approach complements the established ones with an additional 'search mode'. Specifically, starting from the one of the main outputs of research activity, that is publications, we map the funders as they are acknowledged in publications. This empirical approach has an advantage in that it makes no a priori judgements on which funding bodies supported the UK researchers. It allows a comprehensive picture to be produced of the diverse and complex constellation of all funders that supported publications in the selected domain, i.e. the approach is not biased towards the large funding bodies. Publications and the relative databases containing the bibliographic data of these publications can be analysed to reveal much about the way researchers make use of their funding environment. Publications can be used as a starting point to explore questions such as:

a) How interdependent are the research activities that funders support?

b) How do funders support research activities in ways that complement one another?

c) How is the broad and diverse range of research activities in the UK supported by the different funders?

From an analytical perspective these are broad questions. Using scientometric analysis, terms such as interdependence, complementarity, and diversity can be 
explored from a number of different informative perspectives (Rotolo et al. 2013). The analysis therefore has to begin by addressing even more fundamental questions concerning the involvement of funders in supporting biomedical research:

- Which public and private bodies fund UK researchers in cancer and which support more publications?

- What are the differences in the geographic and institutional coverage of each funder's investments?

- Which funders support rapidly cited works, or works in high quality journals?

- Which funders support international collaborations or public/private collaborations?

- Which funders support more interdisciplinary research?

- Which funders support particular approaches such as clinical trials of therapeutics and diagnostics? (These are derived from the Medical Subject Headings (MeSH) classifications).

- What is the diseases focus (within cancer) of different funders?

Additional insights into the complementarities of funders are provided by a qualitative analysis of the types of award schemes offered by grant funders and their characteristics.

Finally, the interdependency of research funded through different means and complementarities between funders is explored using case studies drawn from interviews with four leading UK researchers to illustrate how researchers working in diverse areas of biomedicine have used funding schemes funding in order to achieve significant research milestones.

The data analysis is arranged in sections according to address questions $A, B$ and $C$ above, with additional sections discussing further findings, distributed according to the following working definitions of key terms:

- Research host organisations - Primarily undertake research

- Major UK host organisations - UK research host organisations that contribute to at least 2\% of the UK research output in neoplasms in 2011

- External funding organisations - Primarily sponsor research undertaken externally

- Major UK funders - UK funders that supported at least $2 \%$ of the UK research publications in neoplasms in 2011

- Interdependency - Where two or more research hosts or external funders support a single output (i.e. publication)

- Complementarity - Where different research hosts and external funders support activities that collectively address a wider range of activities than individual organisations contributing to more potential synergies across the research system.

- Diversity - Variety in the characteristics, scope and balance of research activities that individual research hosts undertake or that individual external funders support 


\subsection{Research methods}

Two systematic approaches are possible to undertake a comprehensive analysis of a research funding landscape over a given time period. One starts upstream with the funders and then traces the research outputs they have supported (the 'top down' approach). The other starts with the research outputs and traces the funders that supported these (the 'bottom up' approach). Both approaches have limitations and so with limited resources, analysts must be aware of these and make pragmatic choices (McLean et al. 1998).

Collection of data from funders requires that, inter alia, all relevant funders can be identified and that these organisations are transparent about the research they support, use common definitions and similar reporting styles to ensure relevant inputs, and their outputs, can be identified (Hopkins and Siepel 2013). Efforts to develop a 'top down' approach have been advanced by UK research funders and are becoming increasingly sophisticated (for example see UKCRC 2012). However many smaller funders are not included in such funding statistics, nor are international funders.

The 'bottom up' approach requires that all relevant research outputs can be identified and that authors of outputs are transparent about who has funded their research, with funding data reported in a style that is accessible and amenable to analysis. Although much research is published and accessible through highly indexed and structured databases which aids searching, some organisations, particularly in industry, do not publish all of their research (Rafols et al. 2012, Goldacre 2012). This is a substantial limitation because in the UK at least, estimates suggest industry funds the majority of biomedical research (MorganJones and Grant 2011) However this limitation is also likely to be a problem for the top down approach (Hopkins and Siepel 2013).

This study develops a 'bottom up' strategy to map all papers written by authors working in the UK and related to the neoplasms domain in order to map the funding landscape. The required information is not readily available from one database and so a multi-stage process is required to identify relevant papers and collect data across the required fields for a broad analysis. Full details of the steps undertaken to create the dataset are provided in the Appendix to this chapter. The following paragraphs provide just a summary of this more detailed account.

For the purposes of identifying a sample of UK papers from which to generate a 'snapshot' of the UK research system a search was undertaken of PubMed/MEDLINE using the Medical Subject Headings (MeSH) code 'Neoplasms'. This is a broad term encompassing cancerous and pre-cancerous growths. All papers with at least one UK author on neoplasms published in 2011 where identified. Of the 7,922 records identified, electronic access was possible for $94.8 \%$ of the sample $(7,510$ publications $)$.

These 7,510 publications were scanned for acknowledgements to funders, with 3,914 publications disclosing at least one funder. Robustness checks confirmed that those publications not acknowledging funders were more likely to be shorter, less cost intensive categories of publication (such as editorials or comments) and

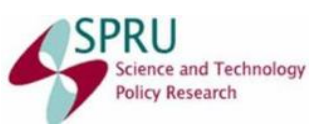


that those not acknowledging funders were most often funded only by their employer (already captured for this analysis through identification of all author affiliated host organisations). These findings are consistent with prior research on UK biomedical publications data which found that $39 \%$ of papers did not acknowledge funders, with the primary reason being that the papers were funded by the organisation or organisations that the authors were affiliated with (Lewison et al. 1995).

As discussed in Chapter 2, most grants by UK research councils and charities do not fully reimburse organisations hosting research for their costs. Therefore in identifying the funders of neoplasm research in the UK it is appropriate to discuss the research host organisations and their external funders. These are considered as two distinct perspectives in the analysis presented here - a single combined approach being problematic because of heterogeneity in the origin of funding supporting research host organisations that not externally grant funded.

\subsubsection{Limitations of the dataset construction for analysis and interpretation}

A key limitation is that although publications record author affiliations and in many cases report funding sources, it is frequently the case that publications do not disclose which authors or affiliated organisations have benefitted from specific funders. Figure 3.1 illustrates the structure of the data records under ideal and actual conditions, and shows how the resulting data analysis focuses on either the publications host organisations produce, or the publications funders support. 
Figure 3.1: Ideal and actual funding disclosure reconstruction

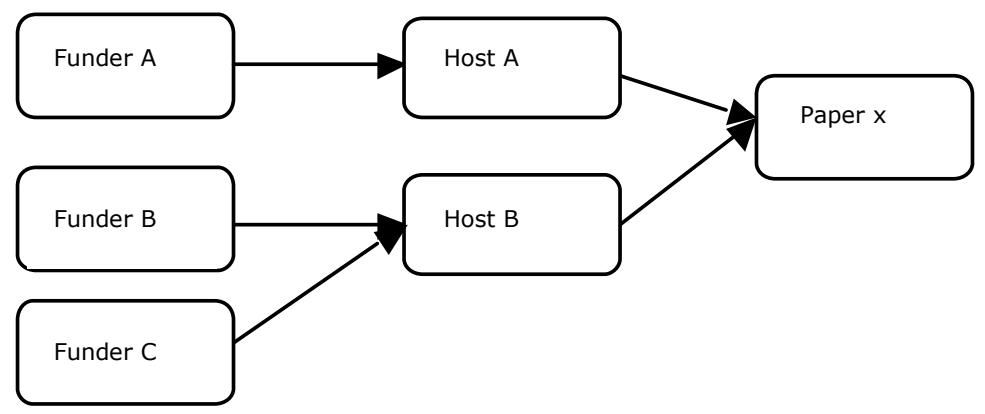

(ideal funding disclosure reconstruction)

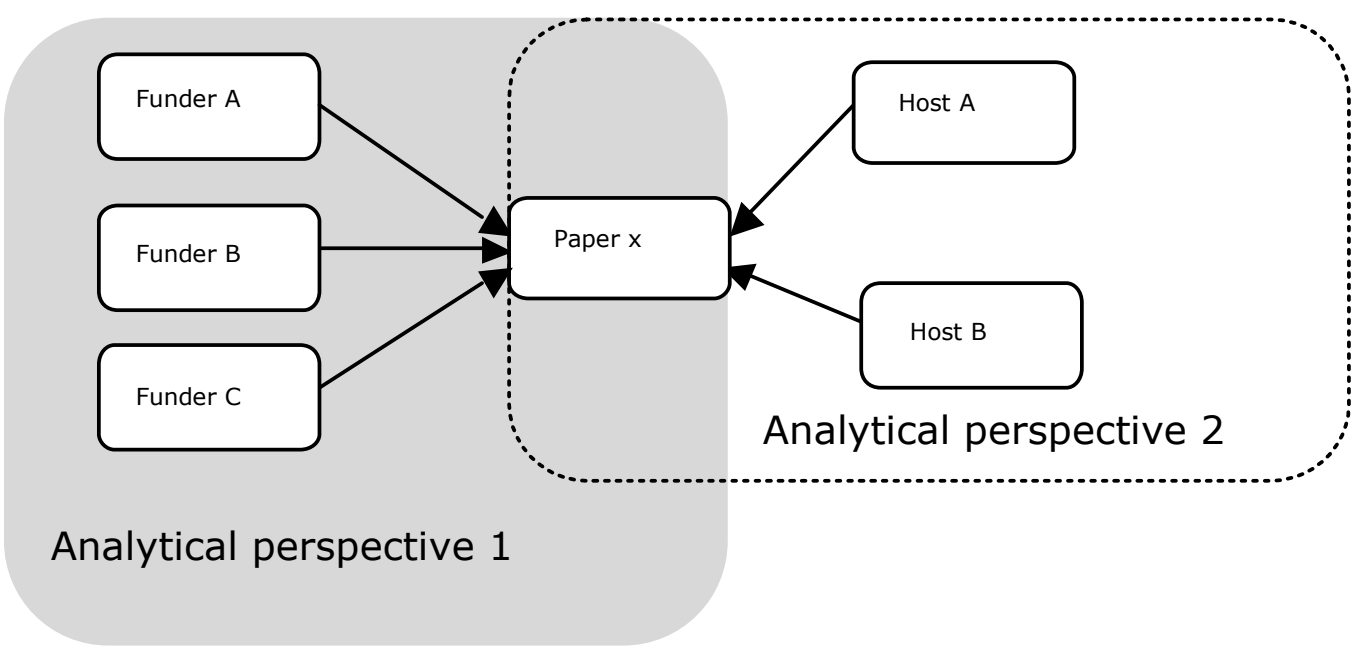

(actual funding disclosure reconstruction)

\subsubsection{Method for analysis of research funding schemes}

In order to understand how the major research funders provide complementary or overlapping funding schemes for the research community it was necessary to identify the leading funders, using the data from publication acknowledgements sections. Those funders contributing to $>1 \%$ of publications were selected for investigation (10 UK-based funders and three non-UK based funders). Funders' websites and key documents such as annual reports for the most recent period were examined to determine whether these schemes were open to researchers working in the UK. A qualitative comparative analysis based on similarities and differences between the funders' different schemes was then undertaken.

\subsubsection{Method for case studies of leading researchers}

The scientometric analysis of publications in 2011 and the description of the top funders funding schemes both provide system-wide snapshots of the landscape of UK biomedicine in the neoplasms field. To explore how researchers navigate through this landscape and also to give a dynamic view of how different funding 
schemes may be complementary or interdependent, case studies of leading researchers were undertaken.

Case study subjects were selected from a sample of convenience provided by Cancer Research UK and so cannot be described as scientifically selected. Five individuals were approached in mid 2013 with four responding and contributing. The case study sample over-selects highly successful scientists funded by Cancer Research UK, but with this bias understood these cases can be used to inform the scientometric analysis by providing insight into the writing of acknowledgement sections and the role of international partners. These case studies also to provide some (non-comprehensive) illustrations of the ways in which different funding sources funding can be used over time to advance an avenue of research.

\subsection{Scientometric analysis results: Contextual descriptive statistics}

\subsubsection{Publication numbers and outlets}

Of the 115,101 publications in 2011 classified as related to neoplasms according to the MeSH coding system, 7,922 had at least one UK-based author. The UK was therefore involved in the generation of $6.9 \%$ of the global output of publications on neoplasms in 2011. These papers are distributed across 1,480 journal titles. The analysis focuses on a sample of $94.8 \%$ of these papers, based on 7,510 publications across 1,350 journal titles.

Concentration is low with only 13 journals containing $>1 \%$ of these publications and the top 17 journals accounting for just $20 \%$ of total publications (see Figure 3.2). The most frequently targeted journals within the sample are the British Journal of Cancer (2.9\%), highlighted in green, the European Journal of Cancer $(1.6 \%)$, highlighted in blue, joint in third place, highlighted in orange, the International Journal of Cancer (1.5\%) and the Journal of Clinical Oncology $(1.5 \%)$. 
Figure 3.2: Leading journals of 2011 UK publications on neoplasms and distribution journal-number of publications

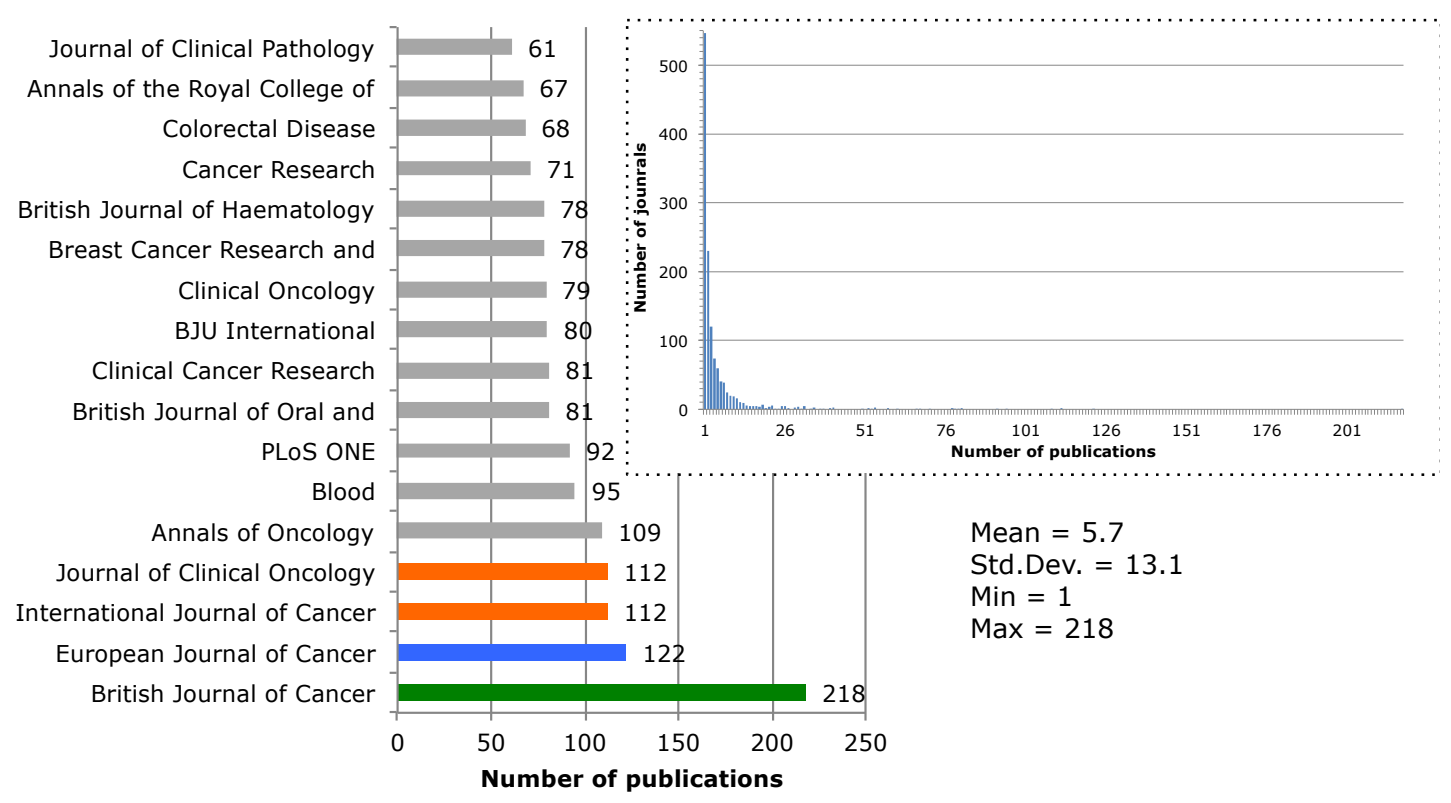

\subsubsection{Publications by UK research host organisations}

Table 3.1 reports the top-50 UK organisations publishing in neoplasms (62 host organisations are listed). It is notable that a large proportion of the organisations contributing to more than 100 publications per year are clusters of institutions linked by association to a university hospital or NHS Trust. This makes direct comparisons to smaller organisations somewhat problematic, but pragmatically is necessary as staff in these clusters will frequently work between sites and have dual affiliations.

Figure 3.3 shows the distribution of publishing output in the field of neoplasms across the population of host organisations, dividing these into three groups according to their contribution to the publication output: (i) less than $0.1 \%$, (ii) from $0.1 \%$ to $1 \%$, and (iii) more than $1 \%$. These three groups accounts for 951 , 182 , and 26 organisations that contributed respectively to 1,433, 2,933, 5,394 publications,. This suggests that although neoplasm research in the UK was undertaken in a large number of organisation (1,159 organisations), a core of 26 host organisations ( $2 \%$ ) contributed to $\sim 72 \%$ of the publication output. 
Table 3.1: Top-50 ranking of UK organisations (62 organisations listed) publishing on neoplasms research

\begin{tabular}{|c|c|c|}
\hline & Organisation & $\begin{array}{l}\text { Number of } \\
\text { publications }\end{array}$ \\
\hline 1) & $\begin{array}{l}\text { Institute of Cancer Research, London } \\
\text { (including the following organisation or name variations: Royal Marsden NHS Foundation Trust) }\end{array}$ & 699 \\
\hline 2) & $\begin{array}{l}\text { University College London, London } \\
\text { (including the following organisation or name variations: University College London Hospitals NHS } \\
\text { Trust, UCL Cancer Institute, National Hospital for Neurology and Neurosurgery, Royal Free } \\
\text { Hampstead NHS Trust) }\end{array}$ & 630 \\
\hline 3) & $\begin{array}{l}\text { Imperial College, London } \\
\text { (including the following organisation or name variations: Imperial College Healthcare NHS Trust, } \\
\text { Hammersmith Hospital, Charing Cross Hospital) }\end{array}$ & 567 \\
\hline 4) & $\begin{array}{l}\text { University of Cambridge, Cambridge } \\
\text { (including the following organisation or name variations: Cancer Research UK Cambridge Research } \\
\text { Institute, Hutchison/MRC Research Centre, Cambridge Biomedical Research Centre, Addenbrooke's } \\
\text { University Hospital, Cambridge University Hospital NHS Trust) }\end{array}$ & 556 \\
\hline 5) & $\begin{array}{l}\text { Oxford University, Oxford } \\
\text { (including the following organisation or name variations: Gray Institute, John Radcliffe Hospital, } \\
\text { Oxford Radcliffe Hospitals NHS Trust, United Kingdom) }\end{array}$ & 548 \\
\hline 6) & $\begin{array}{l}\text { King's College London, London } \\
\text { (including the following organisation or name variations: King's College Hospital NHS Trust, Guy's } \\
\text { and St Thomas NHS Trust, Guy's Hospital, Western General Hospital) }\end{array}$ & 529 \\
\hline 7) & $\begin{array}{l}\text { University of Leeds, Leeds } \\
\text { (including the following organisation or name variations: Leeds Cancer Research UK Centre, St } \\
\text { James's University Hospital, Leeds Teaching Hospitals NHS Trust, Leeds General Infirmary) }\end{array}$ & 395 \\
\hline 8) & $\begin{array}{l}\text { University of Manchester, Manchester } \\
\text { (including the following organisation or name variations: Cancer Research UK Paterson Institute, } \\
\text { Christie Hospital) }\end{array}$ & 389 \\
\hline 9) & $\begin{array}{l}\text { Queen Mary University of London, London } \\
\text { (including the following organisation or name variations: St Bartholomew's Hospital) }\end{array}$ & 323 \\
\hline 10) & $\begin{array}{l}\text { University of Edinburgh, Edinburgh } \\
\text { (including the following organisation or name variations: Edinburgh Cancer Research Centre, Western General Hospital) }\end{array}$ & 282 \\
\hline 11) & $\begin{array}{l}\text { University of Glasgow, Glasgow } \\
\text { (including the following organisation or name variations: NHS Greater Glasgow and Clyde, Gartnaval } \\
\text { General Hospital, Glasgow Royal Infirmary, Western Infirmary) }\end{array}$ & 278 \\
\hline 12) & $\begin{array}{l}\text { University of Newcastle, Newcastle Upon Tyne } \\
\text { (including the following organisation or name variations: Northern Institute of Cancer Research, } \\
\text { Newcastle upon Tyne Hospitals NHS Trust, Royal Victoria Infirmary, Freeman Hospital) }\end{array}$ & 243 \\
\hline 13) & University of Birmingham, Birmingham & 219 \\
\hline 14) & $\begin{array}{l}\text { University of Sheffield, Sheffield } \\
\text { (including the following organisation or name variations: Weston Park Hospital, Sheffield Children's } \\
\text { NHS Trust, Sheffield Teaching Hospitals NHS Trust) }\end{array}$ & 212 \\
\hline 15) & $\begin{array}{l}\text { Cardiff University, Cardiff } \\
\text { (including the following organisation or name variations: Velindre NHS Trust) }\end{array}$ & 191 \\
\hline 16) & $\begin{array}{l}\text { University of Southampton, Southampton } \\
\text { (including the following organisation or name variations: Southampton General Hospital) }\end{array}$ & 170 \\
\hline 17) & University of Liverpool, Liverpool & 166 \\
\hline 18) & $\begin{array}{l}\text { St George's Hospital NHS Trust, London } \\
\text { (including the following organisation or name variations: St George's Hospital, St George's, } \\
\text { University of London) }\end{array}$ & 132 \\
\hline 19) & $\begin{array}{l}\text { Queen's University, Belfast } \\
\text { (including the following organisation or name variations: Belfast City Hospital) }\end{array}$ & 128 \\
\hline 20) & University of Nottingham, Nottingham & 115 \\
\hline 21) & University of Aberdeen, Aberdeen & 104 \\
\hline 22) & University of Bristol, Bristol & 100 \\
\hline 23) & University of Leicester, Leicester & 87 \\
\hline 24) & Mount Vernon Hospital, Northwood & 81 \\
\hline 25) & London Research Institute, London & 79 \\
\hline 26) & Ninewells Hospital and Medical School, Dundee & 77 \\
\hline 27) & AstraZeneca, Macclesfield & 75 \\
\hline 27) & Royal Liverpool and Broadgreen University Hospitals NHS Trust, Liverpool & 75 \\
\hline 28) & Great Ormond Street Hospital for Children, London & 72 \\
\hline 28) & Queen's Medical Centre, Nottingham & 72 \\
\hline 29) & Churchill Hospital, Headington & 70 \\
\hline 29) & Nottingham University Hospitals NHS Trust, Nottingham & 70 \\
\hline 30) & London School of Hygiene and Tropical Medicine, London & 69 \\
\hline 30) & University of Dundee, Dundee & 69 \\
\hline 31) & Royal Surrey County Hospital, Guildford & 58 \\
\hline 32) & Queen Elizabeth Hospital, Birmingham & 57 \\
\hline 33) & Nottingham City Hospital, Nottingham & 56 \\
\hline 34) & University Hospital of Wales, Cardiff & 54 \\
\hline 35) & Leicester Royal Infirmary, Leicester & 52 \\
\hline 35) & University of Sussex, Brighton & 52 \\
\hline 36) & Medical Research Council, London & 49 \\
\hline 37) & University of Warwick, Warwick & 48 \\
\hline \multicolumn{3}{|c|}{$\begin{array}{l}\text { Office of } \\
\text { Health } \\
\text { Economics } \\
\text { Research \& Consulting }\end{array}$} \\
\hline
\end{tabular}




\begin{tabular}{llc}
\hline & Organisation & $\begin{array}{c}\text { Number of } \\
\text { publications }\end{array}$ \\
\hline 38$)$ & University Hospital Southampton NHS Trust, Southampton & 46 \\
$39)$ & Beatson Institute for Cancer Research, Glasgow & 44 \\
$40)$ & University of York, York & 42 \\
$40)$ & Welcome Trust Sanger Institute, Cambridge & 42 \\
$41)$ & Aberdeen Royal Infirmary, Aberdeen & 41 \\
$41)$ & St. Mary's Hospital, London & 41 \\
$42)$ & Queen Alexandra Hospital, Portsmouth & 40 \\
$42)$ & Royal Infirmary of Edinburgh, Edinburgh & 40 \\
$43)$ & University of East Anglia, Norwich & 39 \\
$44)$ & St Mary's Hospital, Manchester & 38 \\
$45)$ & Birmingham Women's Hospital, Birmingham & 36 \\
$46)$ & Birmingham Children's Hospital, Birmingham & 35 \\
$46)$ & Royal Hallamshire Hospital, Sheffield & 35 \\
$46)$ & Royal National Orthopaedic Hospital, London & 35 \\
$47)$ & Norfolk and Norwich University Hospital, Norwich & 34 \\
$48)$ & Royal Brompton Hospital, London & 33 \\
$48)$ & University of Surrey, Guildford & 33 \\
$49)$ & University Hospitals Bristol NHS Trust, Bristol & 32 \\
50) & Manchester Royal Infirmary, Manchester & 31 \\
50) & Royal Devon and Exeter Hospital, Exeter & 31 \\
\hline
\end{tabular}

Figure 3.3: Number of organisation by contribution to the 2011 UK publications in neoplasms

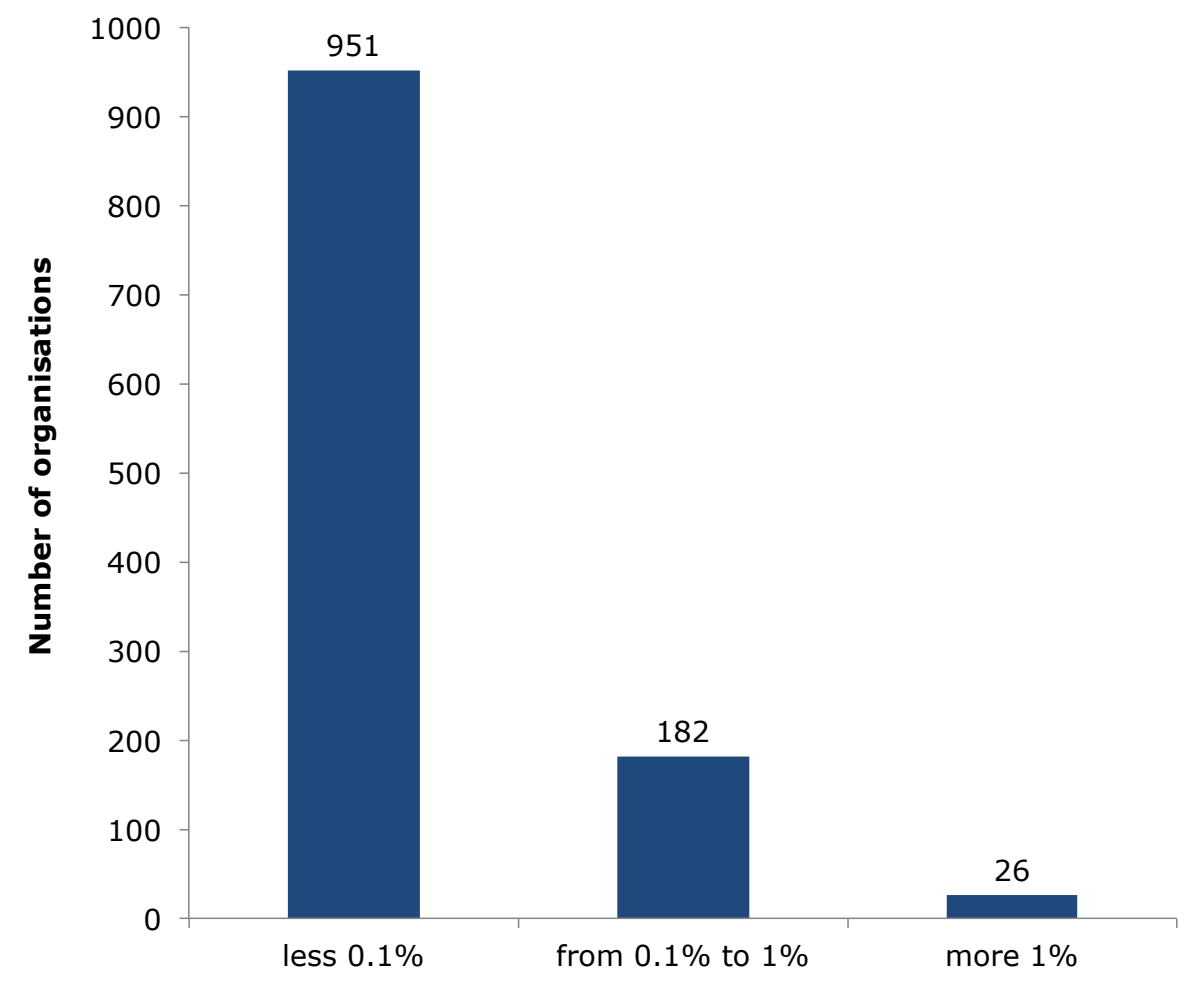




\subsection{Scientometric analysis: Interdependencies in Neoplasm Research}

This section aims to address the question 'How interdependent are these research activities that funders support?'. In this context, interdependency is understood as situations where two or more research hosts or external funders support a single research output (publication).

Host organisations may therefore be seen as interdependent when they work with other host organisations to produce research publications. Funders can be described as interdependent on other funders when the publications that their mission depends on are produced in conjunction with those funders. Analysis of these two perspectives (illustrated in Figure 3.1) form the basis of this section with the analysis of the authors' affiliations on 7,510 publications and the analysis of external funders based on acknowledgements in 3,914 publications. It is a presumption that in most cases publications produced with charitable funding or funding from research councils are the result of interdependencies between hosts and external funders due to the practice of not funding $100 \%$ of full economic costs (as discussed in Chapter 2). However, the analysis presented here does not explore this third perspective.

\subsubsection{The interdependence of research host organisations}

Analysis of the sample of 7,510 publications reveals that neoplasms research is a highly collaborative enterprise between research host organisations. Figure 3.4 shows the distribution of publications by authorship, revealing that very few $(<6 \%)$ publications are sole authored, and of these fewer are cost intensive 'articles'. Figure 3.5 shows the distribution of publication by number of authors' affiliations per paper, revealing that $67 \%$ of publications result from crossorganisational collaboration, indicating that research host organisations are highly interdependent on each other to produce research publications.

Figure 3.4: Number of authors per publication and types of publications

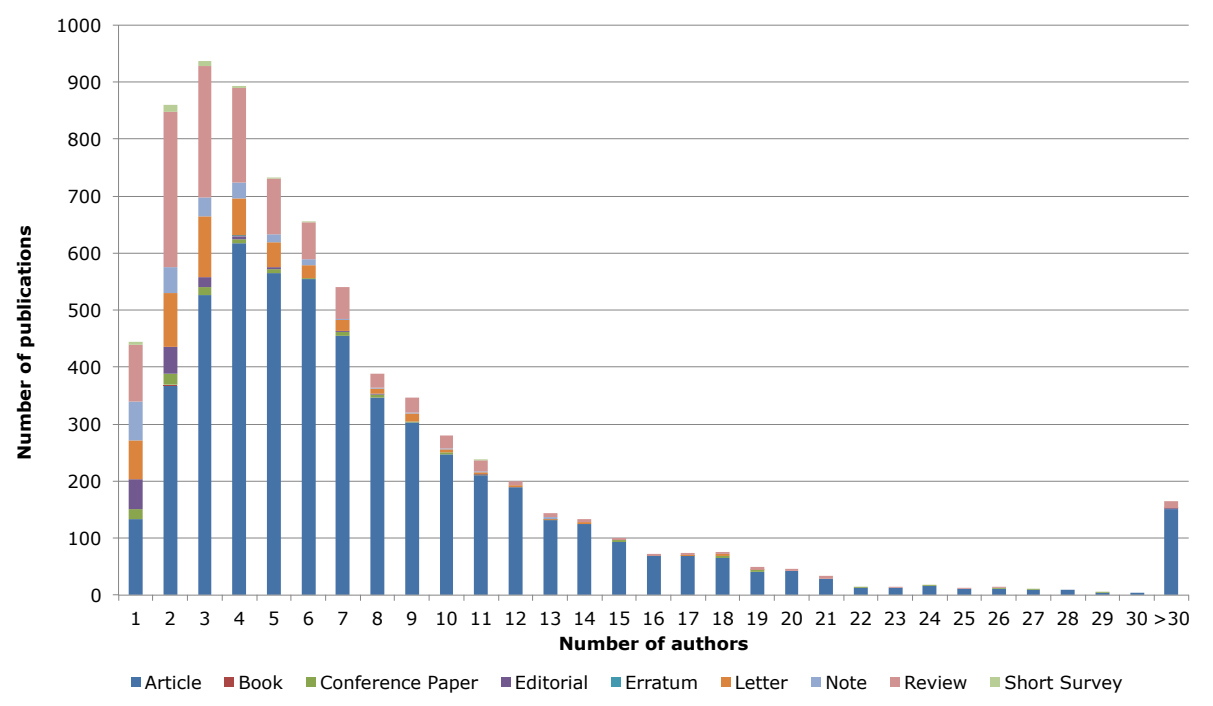


Figure 3.5: Number of affiliations per publication and types of publications

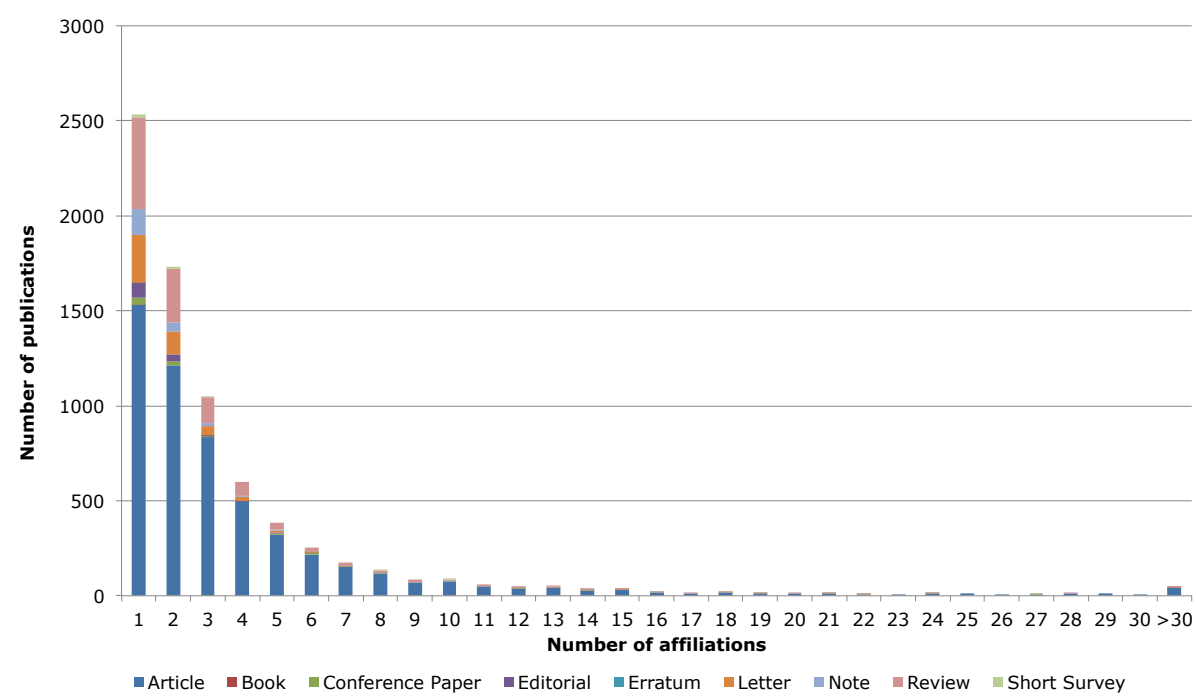

Table 3.2 shows that publications have a mean of 7.7 authors (although Figure 3.5 shows the mode is 3 for all publications and 4 if considering just the more cost intensive articles) and involves a mean of 3.8 host organisations (although Figure 3.6 shows the mode is 1 , even for the cost-intensive research articles, this is because of the wide distribution of the data).

Overall, Table 3.2 shows that the sample of 7,510 publications has 1,159 UK host organisations publishing on neoplasms and co-authoring with researchers at 5,077 non-UK host organisations.

Research on neoplasms involves much international collaboration with $43.3 \%$ of publications having at least one co-author based outside the UK. This implies that over two fifths of the UK neoplasms publication output is dependent on international host organisations, with the average international 'publication' relying on a mean of 2.1 non-UK organisations. Table 3.3 reveals the top-50 ranking (containing 68 organisations) non-UK host organisations (excluding industry) that contribute co-authors to publications with UK co-authors. The high proportion of US collaborators in this list (18/68), implies that UK research on neoplasms is most interdependent on the US funding system for co-author funding. Other strong ties are evident with Italian and Dutch (both 8/68), German (6/68), Swedish (5/68) and Spanish (5/68) research systems. 
Table 3.2: Descriptive statistics on the publication sample $(\mathrm{N}=7,510)$

\begin{tabular}{|c|c|}
\hline Number of author-publication pairs & 57,988 \\
\hline \multicolumn{2}{|l|}{ Number of authors per publication } \\
\hline Mean & 7.7 \\
\hline Standard Deviation & 11.4 \\
\hline Min & 1 \\
\hline Max & 303 \\
\hline \multicolumn{2}{|l|}{ Number of affiliation-publication pairs } \\
\hline before names' harmonisation process & 34,732 \\
\hline after names' harmonisation process & 28,834 \\
\hline Number of distinct affiliations & 6,402 \\
\hline UK & 1,159 \\
\hline Non-UK & 5,077 \\
\hline \multicolumn{2}{|l|}{ Number of affiliations per publication } \\
\hline Mean & 3.8 \\
\hline Standard Deviation & 5.9 \\
\hline Min & 1 \\
\hline Max & 141 \\
\hline \multicolumn{2}{|l|}{ Number of UK affiliations per publication } \\
\hline Mean & 1.7 \\
\hline Standard Deviation & 1.5 \\
\hline Min & 1 \\
\hline Max & 30 \\
\hline \multicolumn{2}{|l|}{ Number of publications involving } \\
\hline at least one non-UK affiliation & 3,253 \\
\hline only UK affiliations & 4,257 \\
\hline \multicolumn{2}{|l|}{ Number of non-UK affiliations per publication } \\
\hline Mean & 2.1 \\
\hline Standard Deviation & 5.3 \\
\hline Min & 1 \\
\hline Max & 111 \\
\hline \multicolumn{2}{|l|}{$\begin{array}{r}\text { Number of countries per publication } \\
\text { (excluding UK) }\end{array}$} \\
\hline Mean & 1.1 \\
\hline Standard Deviation & 1.1 \\
\hline Min & 0 \\
\hline Max & 24 \\
\hline
\end{tabular}


Table 3.3: Top 50 Ranking of non-UK organisations (68 organisations listed) collaborating with UK organisations

\begin{tabular}{|c|c|c|}
\hline & Organisation & $\begin{array}{l}\text { Number of } \\
\text { publications }\end{array}$ \\
\hline 1) & Karolinska Institutet, Sweden & 164 \\
\hline 2) & National Institutes of Health, United States & 146 \\
\hline 3) & University of California, United States & 144 \\
\hline 4) & University of Texas, United States & 129 \\
\hline 5) & Umea University, Sweden & 124 \\
\hline 6) & Fondazione IRCCS Istituto Nazionale dei Tumori, Italy & 123 \\
\hline 7) & Harvard University, United States & 122 \\
\hline 8) & International Agency for Research on Cancer, France & 120 \\
\hline 9) & Utrecht University, Netherlands & 116 \\
\hline 10) & University of Toronto, Canada & 114 \\
\hline 11) & German Cancer Research Center, Germany & 113 \\
\hline 12) & Erasmus University Medical Center, Netherlands & 103 \\
\hline 13) & Paris South University, France & 98 \\
\hline 14) & Mayo Clinic, United States & 97 \\
\hline 15) & Catalan Institute of Oncology (ICO), Spain & 96 \\
\hline 16) & AMC Amsterdam, Netherlands & 91 \\
\hline 17) & Leiden University Medical Center, Netherlands & 89 \\
\hline 18) & Lund University Hospital, Sweden & 85 \\
\hline 19) & Aahrus University, Denmark & 83 \\
\hline 20) & Danish Cancer Society, Denmark & 82 \\
\hline 21) & Katholieke Universiteit Leuven, Belgium & 82 \\
\hline 21) & Memorial Sloan-Kettering Cancer Center, United States & 82 \\
\hline 21) & Radboud University, Netherlands & 82 \\
\hline 22) & Dana Farber Cancer Institute, United States & 81 \\
\hline 23) & CIBER-BBN, Spain & 76 \\
\hline 23) & University of Montreal, Canada & 76 \\
\hline 24) & University of Copenhagen, Denmark & 74 \\
\hline 25) & Queensland Institute of Medical Research, Australia & 72 \\
\hline 26) & University of Melbourne, Australia & 71 \\
\hline 27) & University of Pennsylvania, United States & 70 \\
\hline 28) & Istituto Toscano Tumori, Italy & 69 \\
\hline 28) & University of Washington, United States & 69 \\
\hline 29) & University of Heidelberg, Germany & 68 \\
\hline 30) & University of Sydney, Australia & 65 \\
\hline 31) & Federico II University, Italy & 64 \\
\hline 32) & University of Athens, Greece & 63 \\
\hline 33) & Netherlands Cancer Institute, Netherlands & 61 \\
\hline 34) & University of Torino, Italy & 60 \\
\hline 35) & University of Southern California, United States & 58 \\
\hline 35) & Uppsala University, Sweden & 58 \\
\hline 36) & Azienda Ospedaliera Civile MP Arezzo, Italy & 55 \\
\hline 37) & National Institute for Public Health and the Environment, Netherlands & 54 \\
\hline 37) & University of Leuven, Belgium & 54 \\
\hline 38) & Johns Hopkins University, United States & 53 \\
\hline 39) & European Institute of Oncology, Italy & 51 \\
\hline 40) & Andalusian School of Public Health, Spain & 50 \\
\hline 40) & German Institute of Human Nutrition, Germany & 50 \\
\hline 41) & University of Padua, Italy & 49 \\
\hline 42) & University of Tromso, Norway & 48 \\
\hline 43) & Human Genetic Foundation (HuGeF), Italy & 47 \\
\hline 43) & Peter MacCallum Cancer Centre, Australia & 47 \\
\hline 43) & Stanford University, United States & 47 \\
\hline 44) & University of Michigan, United States & 46 \\
\hline 45) & Maastricht University Medical Center, Netherlands & 45 \\
\hline 45) & Mount Sinai Medical Centre, United States & 45 \\
\hline 45) & Health and Health Care Services Council, Spain & 45 \\
\hline 45) & University of Gotherburg, Sweden & 45 \\
\hline 45) & World Health Organisation, Worldwide & 45 \\
\hline 46) & Navarre Public Health Institute, Spain & 44 \\
\hline 47) & Charité Berlin, Germany & 42 \\
\hline 47) & Charles University, Czech Republic & 42 \\
\hline 47) & Fred Hutchinson Cancer Center, United States & 42 \\
\hline 47) & Ulm University, Germany & 42 \\
\hline 48) & Duke University, United States & 41 \\
\hline 49) & Massachusetts General Hospital, United States & 40 \\
\hline 50$)$ & Universite Paris Descartes, France & 39 \\
\hline 50) & Hannover Medical School, Germany & 39 \\
\hline 50) & University of North Carolina, United States & 39 \\
\hline
\end{tabular}


Figures 3.6 and 3.7 explore the co-authorship network of host organisations. The complete network is a highly complex structure due to the large number of organisations and ties connecting those organisations. Specifically, the network involves $>6,000$ organisations connected by $>95,000$ co-authorships in publications. The complete network is depicted in Figure $3.6(a) .^{2}$ Despite this complexity the complete co-authorship network is informative for the analysis of interdependencies in neoplasms research. For example, the largest component i.e. the largest set of connected nodes (Wassermann and Faust 1994) - includes $97.4 \%$ of the nodes, which is notably high and suggests those organisations in the field are highly interdependent. Further evidence of the intensity of interorganisational research activities is provided by the degree centrality measure, that is the number of ties connecting a node to other nodes in the network (Freeman 1979). On average an organisation is connected to 30.8 other organisations (with the maximum being 1,286 organisations).

The analysis of a core of the co-authorship network provides an additional informative perspective but can only be undertaken by subjectively imposing conditions (i.e. there is no objectively definable 'core'). We identify a core imposing the following conditions:

a) Organisations that contributed to at least $0.1 \%$ (at least seven publications) of the UK research output are included in the set of nodes

b) The strongest $5 \%$ of co-authorship ties are included as connections (connections are shown between two organisations if they are connected by co-authorship in at least five publications)

This imposing of these conditions is necessary to visualise the most central organisations. The core network is depicted in Figure 3.6 (b). It involves 575 organisations connected by 5,039 ties. We focus only on organisations in the largest component of the network. This reduces the network to 387 nodes, i.e. 188 organisations are working in smaller clusters isolated by imposing the above mentioned conditions. The set of 387 organisations is composed of $113(\sim 29 \%)$ UK organisations, $263(\sim 69 \%)$ non-UK organisations, and 11 ( 2\%) organisations located in multiple countries including UK (where multinational firms are placed).

Analysis of the core highlights one of the key features of UK research in neoplasms, which is the strong role international collaborations play. Despite the bias in sample collection created by focusing only on papers with UK authors (as defined by the sample strategy adopted to meet the main aims of this report) the centre of the network is dominated by international research host organisations. In the international core network, an organisation is on average connected with 17.5 other organisations (degree centrality) up to a maximum of 197 organisations. Figure 3.7 provides a more detailed picture of this core. The strong interdependency between UK organisations and international actors is also depicted in Figure 3.6 (c) which by removing the non-UK organisations from previous core networks, identifies the UK core network. In the UK core network an organisation is on average connected with 7.5 other organisations (degree centrality) up to 53 organisations.

\footnotetext{
${ }^{2}$ Gephi 0.8.2 was used to produce the network figures. 
Figure 3.6: Co-authorship network. The nodes' colours are assigned as in the followings: UK organisations (green), non-UK organisations (blue), organisation located in multiple countries including UK (yellow). The size of nodes is proportional to the $\log _{2}$ of the number of publications the given actors contributed to.

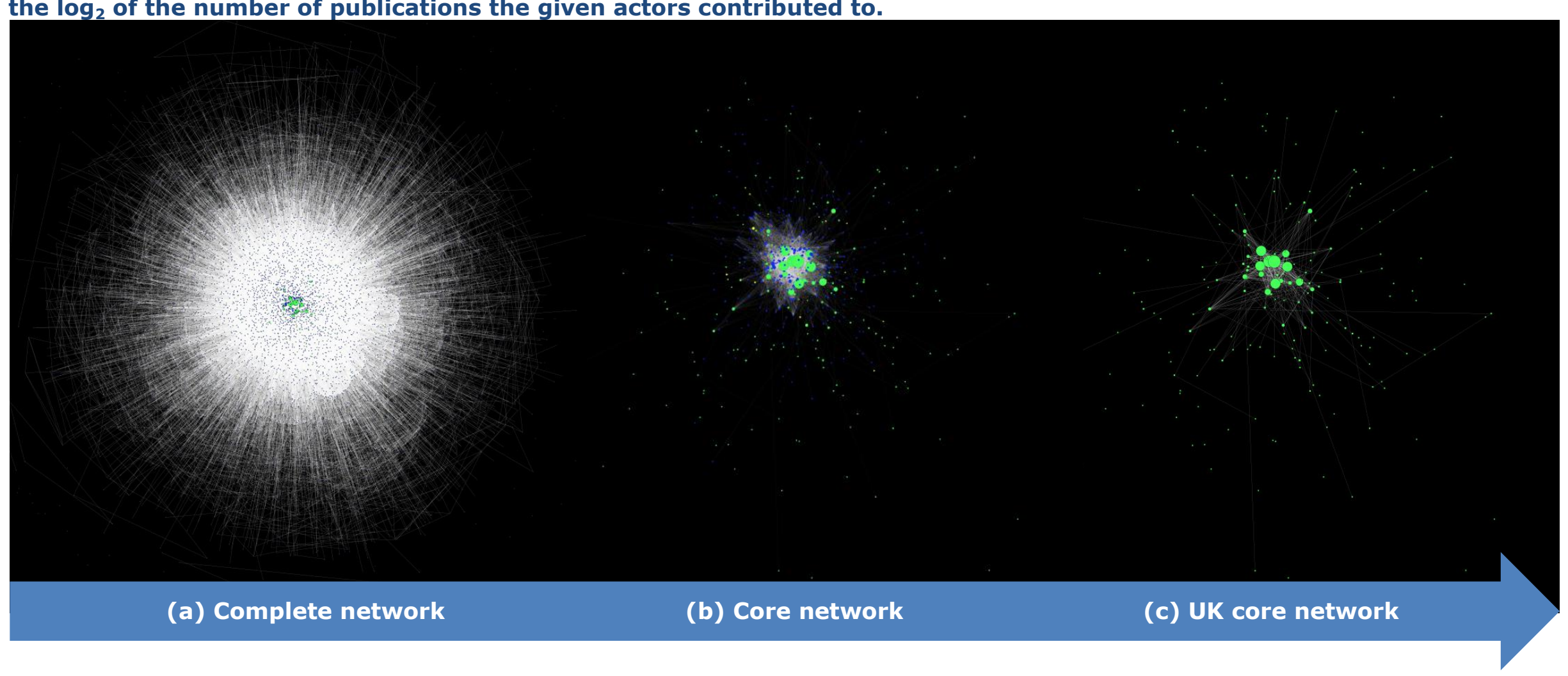


Figure 3.7: Focus on the core co-authorship network in neoplasms. The nodes' colours are assigned as in the followings: UK organisations (green), non-UK organisations (blue), organisation located in multiple countries including UK (yellow). The size of nodes is proportional to the $\log _{2}$ of the number of publications the given actors contributed to.
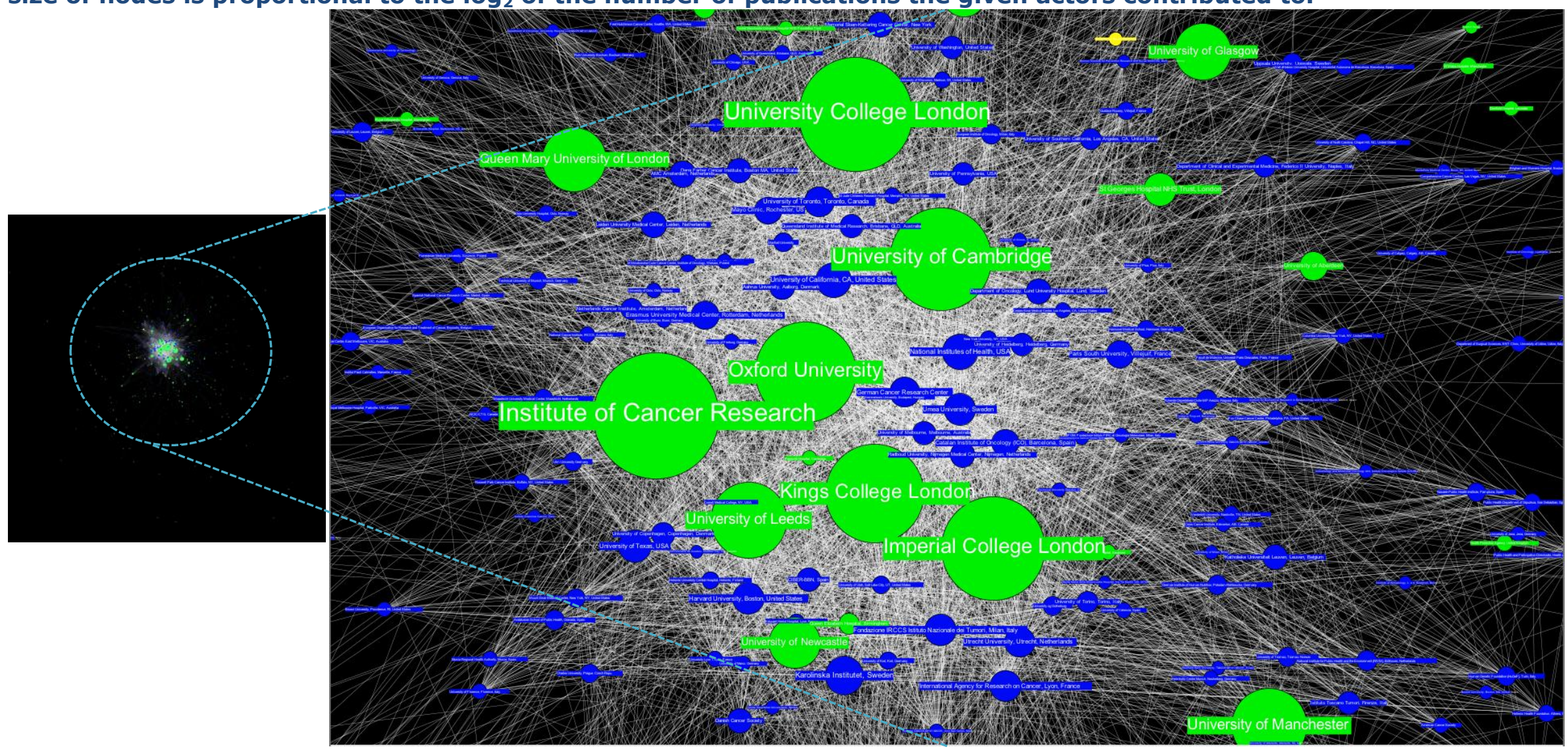


\subsubsection{The interdependence of funding organisations}

Publications in the sample acknowledged support from over 2,500 organisations. While 663 funders are based in the UK (excluding private sector organisations), 1,591 non-UK funders are acknowledged, as well as a further 307 private sector organisations (see Table 3.4).

Table 3.4: Funding data and publications $(\mathrm{N}=3,914)$

\begin{tabular}{|c|c|}
\hline \multicolumn{2}{|l|}{ Number of distinct funders } \\
\hline UK & 663 \\
\hline Non-UK & 1,579 \\
\hline Industrial actors & 307 \\
\hline \multicolumn{2}{|l|}{ Number of funders per publication } \\
\hline Mean & 3.3 \\
\hline Standard Deviation & 5.0 \\
\hline Min & 1 \\
\hline Max & 78 \\
\hline \multicolumn{2}{|l|}{$\begin{array}{r}\text { Number of UK funders per publication } \\
\text { (excluding industrial actors) }\end{array}$} \\
\hline Mean & 1.4 \\
\hline Standard Deviation & 1.5 \\
\hline Min & 0 \\
\hline Max & 11 \\
\hline \multicolumn{2}{|l|}{ Number of industrial funders per publication } \\
\hline Mean & 0.3 \\
\hline Standard Deviation & 1.5 \\
\hline Min & 0 \\
\hline Max & 50 \\
\hline
\end{tabular}

Where publications acknowledge funding, only in $36 \%(1,420 / 3,914)$ of the cases the research depended on a single funder. Those papers acknowledging financial support had a mean of 3.3 funders.

To gain an insight into the reasons why papers acknowledge multiple funders, it is useful to draw on the case study interviews. Although only four individuals were interviewed, the resulting case studies follow research undertaken by Principal Investigators (PIs) over at least a decade each, thereby following multiple projects per investigator and giving an insight into the funding support behind several hundred papers. In a complex funding ecosystem, research is often not funded by a single organisation. The interviewees reveal three broad types of co-contribution:

1. Host + external funder - UK funders will generally not support the full economic cost of research and will require the host organisation to make a financial contribution. Host organisations will often meet this cost through cross-subsidising activities, for example with teaching revenues supporting research infrastructure and/or staff costs.

2. Sharing funding by cost type - funders contribute to different types of cost, perhaps at different times such as when one funder finances a facility (externally) and another provides for staff costs related to the particular 
project. Additionally, others may provide significant support, as when industrial partners provide expensive drugs for a trial.

3. Joint funding - researchers or funders can anticipate the need for joint funding of a project or scheme in advance with costs being shared in a number of ways, such as by geography, institution or overall contribution. In other cases once a project is established, researchers may be opportunistic by working with other groups as projects progress if this allows projects to advance more efficiently. Joint publications are therefore also jointly funded by the authors' financial supporters.

These categories are not mutually exclusive, with some or all applying to a given publication. Interpreting the contribution of a given funder is challenging as publications often have multiple authors from multiple organisations, and acknowledge multiple funders. Indeed from the information provided in the acknowledgements sections of publications it is generally not possible to identify which mode of support a funder is being acknowledged for, or even which author or organisation a given funder is supporting. Resolving this without speaking to one or more of the research paper's authors is therefore not possible. A further limitation of the approach is that publications may (strategically or mistakenly) also acknowledge funders that have not supported a given paper.

Where the outputs of a research study depend on multiple sources of funding, the funders are described here as being interdependent, in that their funding support has required additional input from at least one other funder to yield the published output. It is important to acknowledge that this does not necessarily mean that no research would have been possible without all of the funders, but rather that the observed output would not have been possible in its exact form. One researcher interviewed said "I would strongly say that my research is not dependent on other people's funding at all" but said also that they did collaborate widely on papers for "scientific reasons". Another suggested that ad hoc collaborations were an efficient way of proceeding because it saved "re-inventing the wheel". Thus interdependency can be weak or strong.

An example of strong interdependency of funders that would fall within each of the three conditions above is described in Case study 1.

\section{Case Study 1: Interdependency of funders in large scale clinical oncology trials}

Tim Maughan is Professor of clinical oncology and Department Director of the MRC/ CR-UK Gray Institute for radiation oncology and biology, within the Department of Oncology at the University of Oxford. He is also honorary consultant at the Churchill Hospital, Oxford. Over the last decade, Professor Maughan has played a leading role in the design and execution of several large clinical trials of cancer treatments that have depended on funding from multiple sources. In particular his work has focused on advancing the stratification of therapeutic treatment by studying the effectiveness of different drug combinations against colorectal cancers, with the hope that in the future biomarker tests will be able to guide clinical treatment choices by molecular categorisation of tumour type.

Clinical research demands a much larger cost to answering a given research question than laboratory research. However, Maughan has been able to obtain

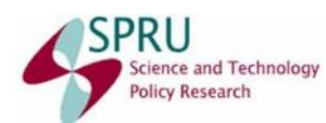


support for large and sophisticated multi-arm studies designed to answer different questions simultaneously. Phase 2 and Phase 3 trials designed by Maughan have be supported though combinations of CRUK, MRC and NIHR funding, as well as with contributions by industry and other charities.

A recent example is the COIN trial (results reported in Maughan et al 2011, and Adams et al. 2011) which compared three treatment regimes in patients with advanced colorectal cancer. Continuous or intermittent use of Oxaliplatin and fluoropyrimidine (in combination) were compared to assess whether breaks in chemotherapy reduced the toxic side effects suffered by patients. Another arm of the trial compared the use of cetuximab in combination with oxaliplatin and capecitabine to see if this was superior to the other regimes.

The COIN trial is an example of a large Phase III trial design that changed in form according to the availability of new research findings and collaborations even as it commenced. The initial idea for the COIN trial emerged from an NCRI study group - a group of experts that are funded to meet regularly to discuss research proposals. Maughan was encouraged by colleagues to design a study to explore the relative benefits of different drug combinations against advanced colorectal cancer, including to assess variants of a treatment protocol (Oxaliplatin with fluoropyrimidine) widely used outside the UK, but not yet approved by NICE.

The great expense of large trials such as COIN (with $>1600$ patients) means these are often prohibitively expensive without industrial support in other parts of Europe. However with the availability of government and charitable core funding it is possible to undertake independent academic investigator led trials in the UK. This has the advantage that the data is publicly owned and publication is unhindered by commercial interests. The core cost of the COIN trial was supported by a CRUK Clinical Trials Advisory and Awards Committee grant, with the MRC clinical trials unit providing infrastructural support and acting as the formal trial sponsor. Additionally the trial also relied on industry partners to supply drugs and additional funding.

Before the trial could commence the costs of Oxaliplatin had to be met. This drug was not yet NICE approved for NHS use, and so funding for this was underwritten by the NIHR. However NICE subsequently issued an approval before the trial commenced, and so this funding was not drawn on - the drug being purchased through routine NHS clinical provision. Several firms were invited to contribute to the study but some declined to join. However the team were successful in attracting Merck, a major German Pharmaceutical firm, to make a $£ 500$ perpatient contribution to trial costs and to supply around $£ 10 \mathrm{M}$ worth of the MAb therapy, Cetuximab. Other contributions in the form of discounted drugs were made by Baxter, Wyeth, Sanofi. During the trial data was collected by staff funded through the National Cancer Research Networks

As the trial progressed, newly published data emerged suggesting that mutations in the KRAS gene might affect treatment outcomes in patients receiving epidermal growth factor receptor targeted antibodies such as Cetuximab. Arrangements had already been made to have a team at UCL hospitals undertaking biomarker testing for EGFR-status of tumours, and now plans were rapidly made to incorporate into the study the genotyping of patient tumours for KRAS status, which involved obtaining additional funding from Merck and CRUK, in the form of a Biomarkers and Imaging Discovery and Development Committee (BIDD) grant. This work was undertaken by a laboratory at Cardiff University where a doctoral research student, supported by local charity Cancer Research Wales, genotyped over 2000 tumour samples. The work was subsequently 
validated by another laboratory in Leuven, in turn supported by the Institute for the promotion of Innovation through Science and Technology in Flanders.

The COIN trial made important contributions by showing that the addition of Cetuximab to oxaliplatin and fluoropyrimidine chemotherapy was not of benefit to patients regardless of tumour KRAS status, and that intermittent chemotherapy was not inferior to continuous chemotherapy, allowing oncologists to adjust treatments to reduce toxic side effects in selected patients with advanced colorectal cancer.

Figure 3.8 shows the interdependence of UK funders, where two or more UK funders are acknowledged in the same publication. Figure 3.8 reveals at least 250 UK-based public sector and charitable external funders that support more than one publication on neoplasms per year. The most commonly interdependent funders are also the largest - namely the MRC, Cancer Research UK and the UK's Departments of Health (including the NIHR). Figure 3.8 excludes private sector funders, non-UK funders and UK-based funders acknowledged in less than two publications in 2011. The majority of the funders shown are external to the host organisation undertaking the research, however a small proportion of these are host organisations that also appear to support neoplasms research through internal funds beyond the standard contribution to salary and infrastructure costs of staff needed to bring research council or charity grants up to full economic costs (although some authors do acknowledge such contributions, authors generally do not acknowledge their employer as a funder, but it is not possible to exclude these where they do occur).

By reading the symmetric matrix (in Figure 3.8 above) by row the top-3 'cofunders' for each funder can be identified (highlighted green), e.g. Wellcome Trust co-funds papers most often with MRC (86), Cancer Research UK (83) and the Departments of Health (75).

Beyond interdependencies at the national level, there is interdependence of national research systems and their funders, as explored in the previous section. This interdependence is further confirmed by assessing the numbers of UK publications that acknowledge non-UK funders: see Figure 3.9, which shows all funders acknowledged in more than $2 \%$ of publications in the sample. This reveals that of the top 17 funders of neoplasms papers with UK authors, nine are UK based and eight are non-UK.

Notably, the top five contains two non-UK funders: the NIH and the European Commission. The NIH is acknowledged almost as much as the MRC, while the contributions to UK publication output of the Swedish Cancer Society or Italian Association for Cancer Research is comparable to that of Leukaemia and Lymphoma Research, Breakthrough Breast Cancer or the Breast Cancer Campaign. However it must be recognised that these funders are not supporting UK researchers directly, but rather their co-authors in other countries. An exception is the European Commission which does directly support UK researchers through its funding programmes. With acknowledgements to the European Commission in 384 papers, this suggests that the European 
Commission supports UK researchers in neoplasms more frequently than does the Wellcome Trust. However, this finding should be interpreted with caution because an unknown number of these acknowledgements will support non-UK collaborators of UK authors more often than is likely to be the case for the more UK-focused Wellcome Trust. Figure 3.9 also confirms the key importance to UK scientists of funding for non-UK co-authors in the USA, Italy Sweden, Australia, Germany and France.

Figure 3.8: Co-funding of UK funders that were acknowledged in at least in two publications (excluding industry) and co-occurrence matrix for the funders that acknowledged in at least $2 \%$ of the publication sample

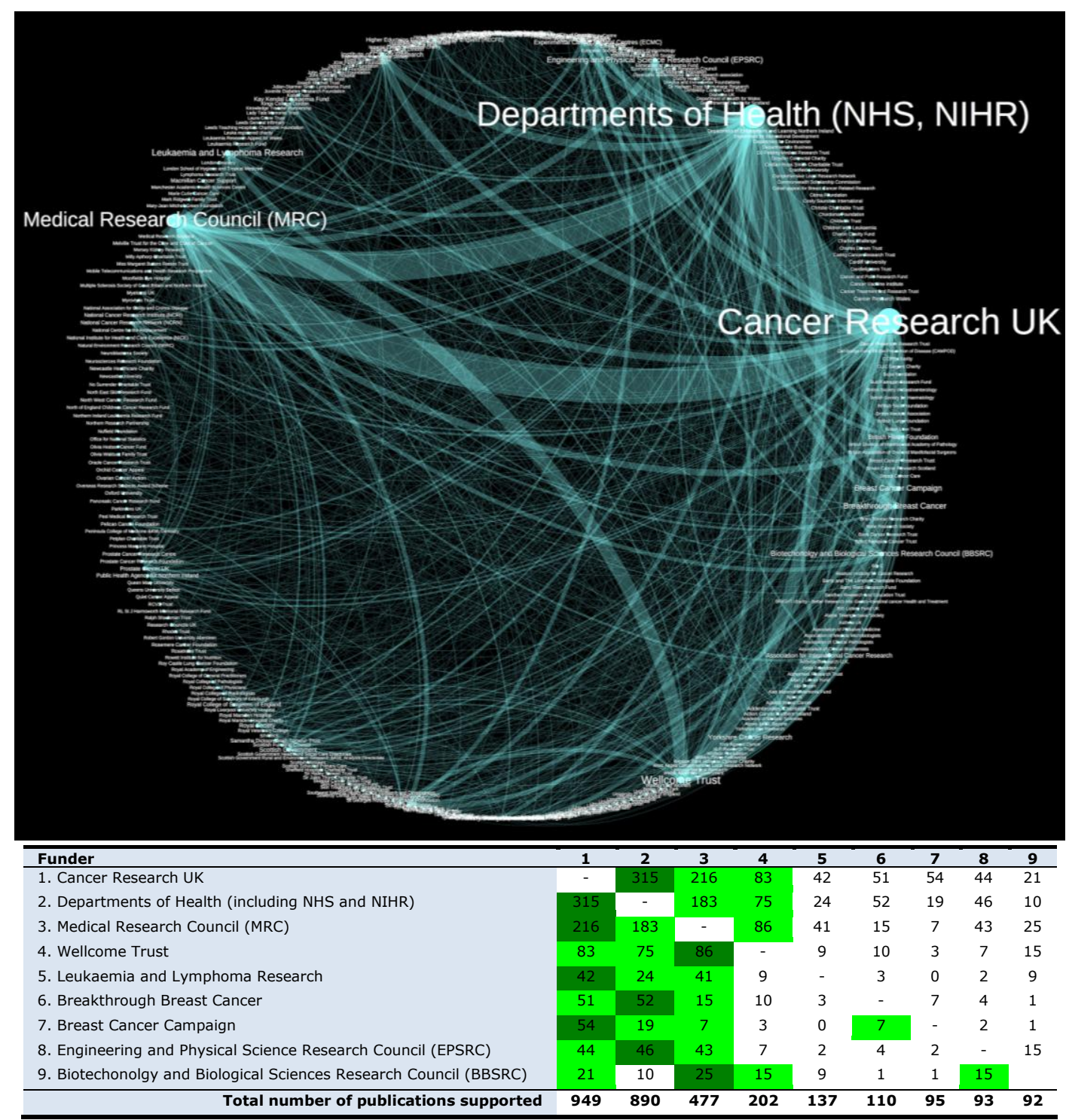

These findings are highly contextual to neoplasms research and generalisations cannot be made outside the field of neoplasms because the sample of papers captured for this study excludes many papers that are funded by host organisations and external funders. Those funders that are more specialised on neoplasms will have a greater proportion of their activities included within the analysis. All tabulations of data should therefore be interpreted with this in mind. 
This is a selective lens that focuses on neoplasms, and organisations' activities beyond neoplasms are excluded.

Figure 3.9: UK (red), EU (blue), and non-EU (green) funding organisations acknowledged in at least $2 \%$ of the publication sample ( $N$ $=3,914)$. The chart excludes private actors.

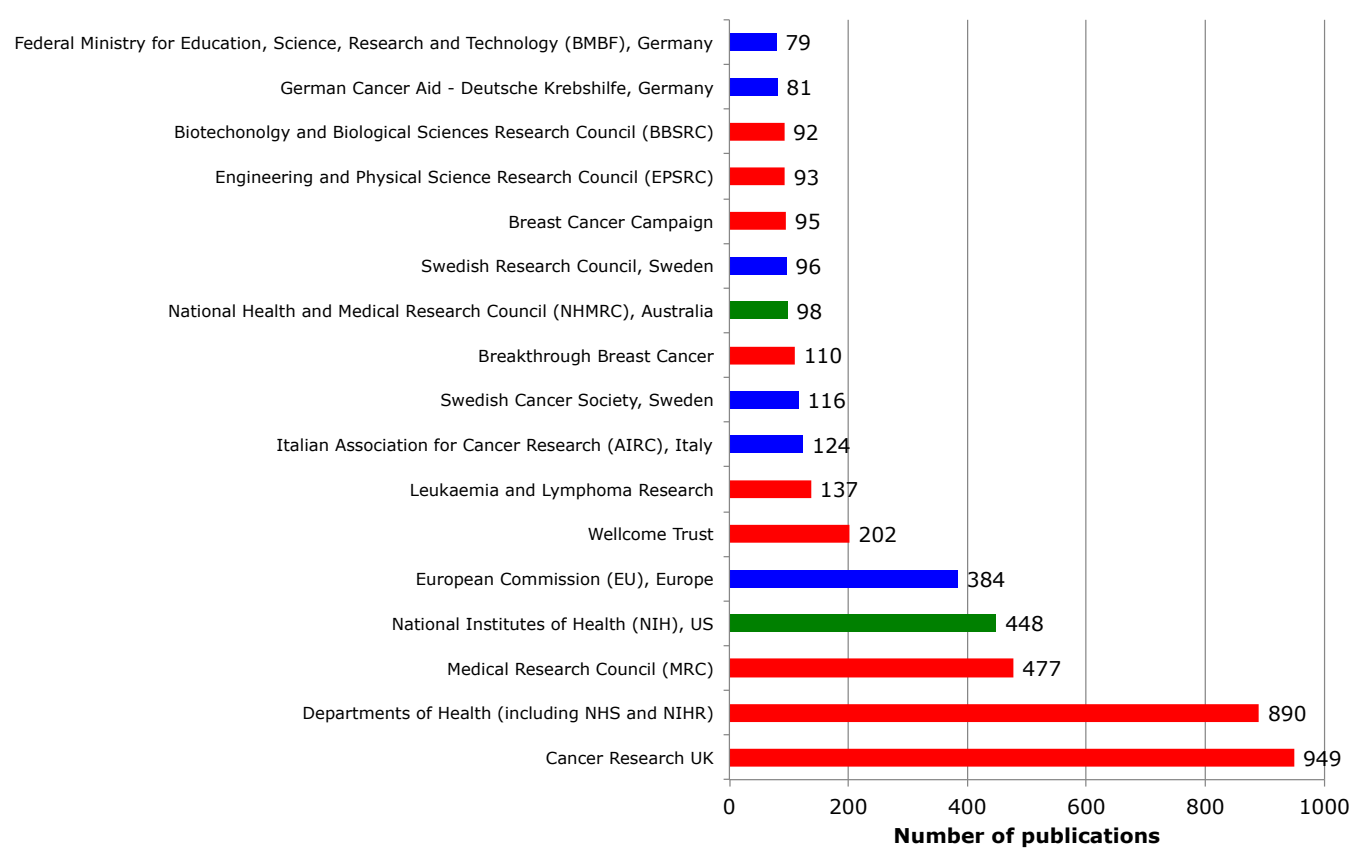

Table 3.5 and Figure 3.10 demonstrate that articles acknowledging external funding are more likely to involve more international organisations (as measured by the number of distinct countries in the list of host organisations). This suggests that external funders provide support for authors to collaborate internationally and that one consequence of such international collaboration is a leveraging of national research funding as UK authors' publications benefit from the financial support of their co-authors' funders.

\section{Table 3.5: Availability of funding data and number of countries}

\begin{tabular}{lcccc}
\hline & \multicolumn{3}{c}{ Number of countries } \\
\cline { 2 - 4 } Type of publication & Mean & Std.Dev. & Min & Max \\
\hline $\begin{array}{l}\text { Publication with funding data in acknowledgement } \\
\text { sections }\end{array}$ & 2.5 & 2.5 & 1 & 25 \\
$\begin{array}{l}\text { Publications with no acknowledgements sections or } \\
\text { no funding data in acknowledgement sections }\end{array}$ & 1.6 & 1.4 & 1 & 20 \\
\hline
\end{tabular}

Notes. The t-test on mean ( $t=20.31, p<0.001)$ confirmed that publications providing funding data in acknowledgement sections involves on average more countries than those that do not. This result is confirmed also when running the test on the sample of "Article" type of publication. 
Figure 3.10: Numbers of publications and countries involved

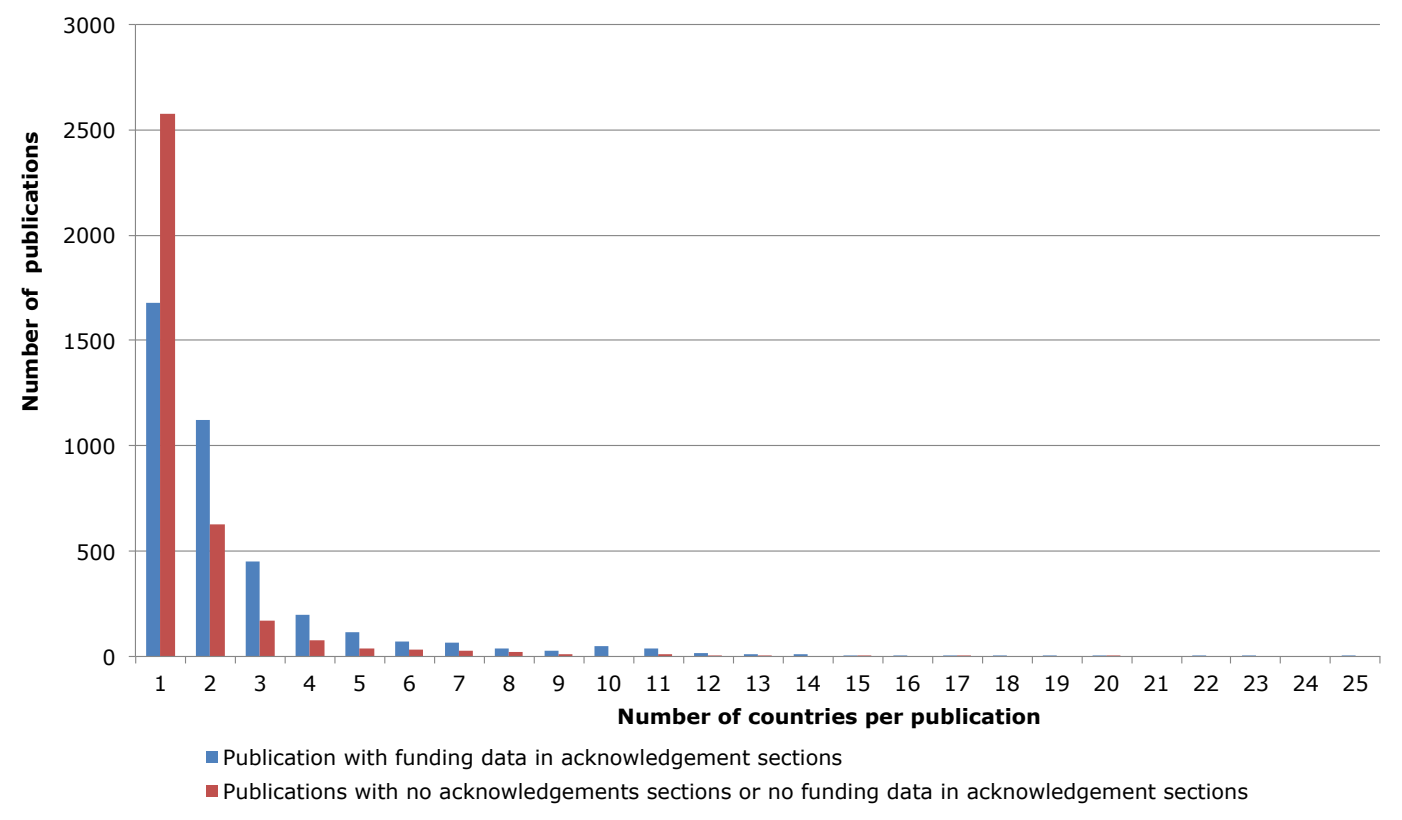

Figure 3.11: Number of funders per publication and types of publications

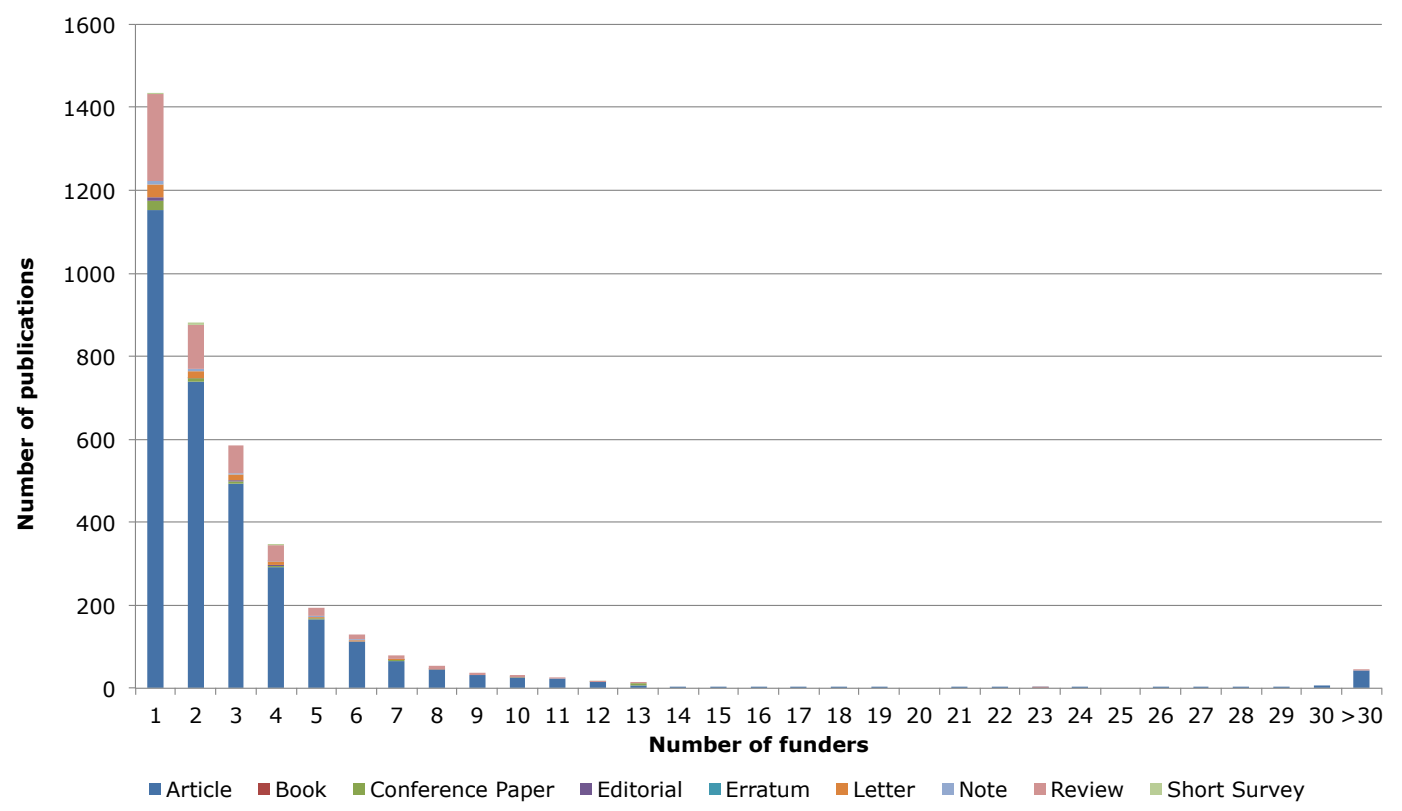

Figure 3.11 shows that the it is most common for papers acknowledging funders to be supported by one funder, however $64 \%$ of papers have more than one funder, with the mean number of funders acknowledged per paper being 3.3.

Industry plays a significant role in UK neoplasms research, with 698/3,914 publications acknowledging funders including a private organisation (17.8\%). By comparison, industry co-authors less frequently, with $647 / 7,510$ publications having a co-author at a private organisation (8.6\%). However combining these categories reveals that industry supports $1,084 / 7,510$ publications (14.4\%). A minority (261) of industry-supported papers provides a co-author and acknowledged funding. Figure 3.12 shows the private organisations that most 
frequently co-author publications with UK authors. The largest publisher is shown in green (Pfizer), the second largest in blue (AstraZeneca) and the third largest in orange (Novartis).

\section{Figure 3.12: Private organisation acknowledged in at least $1 \%$ of the publication sample $(\mathrm{N}=3,914)$}

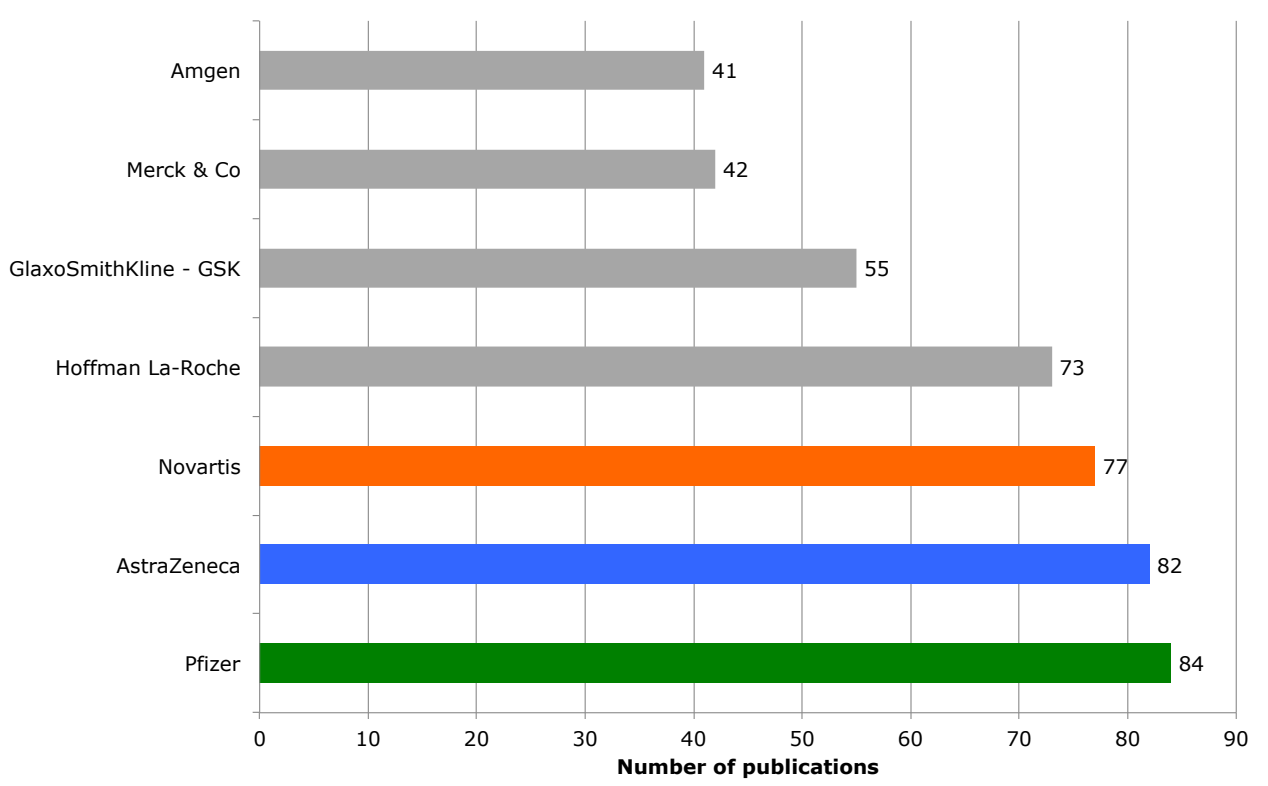

As reported in Figure 3.13, on average $\sim 17 \%$ of the publications supported by major UK funders involve industry - from a minimum of $\sim 8 \%$ for Breast Cancer Campaign to a maximum of $\sim 23 \%$ for MRC.

\section{Figure 3.13 Proportion of industry publications supported by major UK} funders.

Biotechonolgy and Biological Sciences Research Council (BBSRC)

Engineering and Physical Science Research Council (EPSRC)

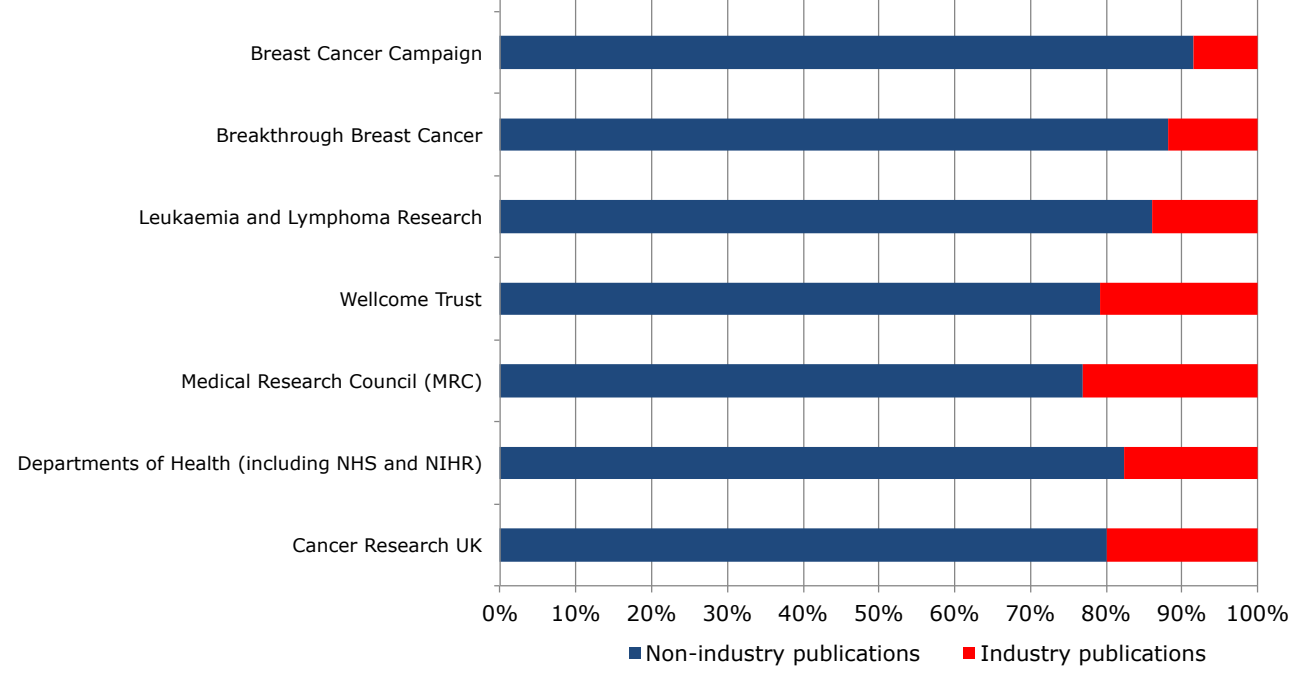




\subsection{Scientometric analysis: Complementarities in neoplasms research}

Complementarities in research funding are regarded here as where the activities of funders and/or research host organisations support research in distinct areas rather than wholly overlapping (or being similar) in the activities that they support. For example, research grant funding can also be used to support projects that are complementary to each other by aiding the creation of multidisciplinary groups, so broadening a research effort. A series of grants can also be used to lengthen the duration of a research effort, such that these are complementary in their use to develop a line of research towards application.

\subsubsection{Complementarities across regions}

One of the most basic complementarities is revealed in the exploration of how hosts and funders are active across the geography of the UK. In order to divide geographies up into regions, the 'Nomenclature of territorial units for statistics' is adopted, using the Level 2 codes (NUTS-2 divides the UK into 36 regions, vs. only 12 for NUTS-1). ${ }^{3}$ Table 3.7, Figure 3.13 and Figure 3.14 divide the UK into NUTS2 regions. Table 3.7 demonstrates that all regions of the UK are active in neoplasms research to some extent.

Table 3.7: UK regions (NUTS-2) and number of publications

\begin{tabular}{|c|c|c|c|}
\hline & NUTS-2 Code & Region & Number of publications \\
\hline 1) & UKI1 and UKI2 & Inner London and Outer London & 3124 \\
\hline 2) & UKH1 & East Anglia & 720 \\
\hline 3) & UKJ1 & Berkshire, Buckinghamshire and Oxfordshire & 713 \\
\hline 4) & UKD3 & Greater Manchester & 540 \\
\hline 5) & UKM2 & Eastern Scotland & 495 \\
\hline 6) & UKG3 & West Midlands & 485 \\
\hline 7) & UKE4 & West Yorkshire & 452 \\
\hline 8) & UKM3 & South Western Scotland & 395 \\
\hline 9) & UKD7 & Merseyside & 322 \\
\hline 10) & UKK1 & Gloucestershire, Wiltshire and Bristol/Bath area & 313 \\
\hline 11) & UKF1 & Derbyshire and Nottinghamshire & 307 \\
\hline 12) & UKC2 & Northumberland and Tyne and Wear & 291 \\
\hline 13) & UKJ3 & Hampshire and Isle of Wight & 286 \\
\hline 14) & UKL2 & East Wales & 278 \\
\hline 15) & UKE3 & South Yorkshire & 269 \\
\hline 16) & UKF2 & Leicestershire, Rutland and Northamptonshire & 203 \\
\hline 17) & UKNO & Northern Ireland & 195 \\
\hline 18) & UKM5 & North Eastern Scotland & 130 \\
\hline 19) & UKJ2 & Surrey, East and West Sussex & 120 \\
\hline 20) & UKK4 & Devon & 107 \\
\hline 21) & UKD4 & Lancashire & 97 \\
\hline 22) & UKD6 & Cheshire & 96 \\
\hline 23) & UKE2 & North Yorkshire & 78 \\
\hline 24) & UKL1 & West Wales and The Valleys & 69 \\
\hline 25) & UKJ4 & Kent & 58 \\
\hline 26) & UKE1 & East Yorkshire and Northern Lincolnshire & 57 \\
\hline 27) & UKK2 & Dorset and Somerset & 54 \\
\hline 28) & UKH2 & Bedfordshire and Hertfordshire & 47 \\
\hline 29) & UKH3 & Essex & 41 \\
\hline 30) & UKC1 & Tees Valley and Durham & 37 \\
\hline 31) & UKG2 & Shropshire and Staffordshire & 30 \\
\hline 32) & UKG1 & Herefordshire, Worcestershire and Warwickshire & 27 \\
\hline 33) & UKF3 & Lincolnshire & 12 \\
\hline 34) & UKK3 & Cornwall and Isles of Scilly & 12 \\
\hline 35) & UKD1 & Cumbria & 7 \\
\hline 36) & UKM6 & Highlands and Islands & 7 \\
\hline
\end{tabular}

${ }^{3}$ http://epp.eurostat.ec.europa.eu/portal/page/portal/nuts_nomenclature/introduction 
Figure 3.14 shows how co-author ties generate a collaborative network that reflects some of the geospatial relationship of towns the UK, with remote, sparsely populated regions at the margins of the map. Figure 3.13 also shows that the UK is highly dependent on research in London, Cambridge and Oxford areas as $4,032 / 7,510$ publications ( $~ 54 \%$ of the sample) were produced with at least one co-author in "Inner and Outer London", "East Anglia" or "Berkshire, Buckinghamshire and Oxfordshire". However, the remaining 46\% of the output has no co-author from a research host organisation from these regions. Vosviewer software identifies clusters within this co-authorship network, highlighting how authors in "Inner and Outer London", "East Anglia" or "Berkshire, Buckinghamshire and Oxfordshire" are more closely linked with "West Yorkshire" "Herefordshire, Worcestershire and Warwickshire" and "Surrey, East and West Sussex" than other parts of the country. See Figure 3.14. The Scottish regions also form a notably distinct cluster, as does the North West of England.

Table 3.8 shows funding by the funders acknowledged in at least $2 \%$ of the publications combined with region of the UK identified from host organisations' addresses. A strong limitation of the data is that publications do not consistently reveal which host organisations obtain support from specific funders in multi-host multi-funder papers. However, it is possible to demonstrate regions where no publications supported by a given funder have a host organisation in a particular region. In this way it is possible to show that eight NUTS-2 regions received funding from fewer than half of the top nine funders. These include "Cornwall \& the Isles of Scilly" "Cumbria", "Devon", "Essex", "Kent", "Hertfordshire, Worstershire and Warwickshire", "Lincolnshire", "Tees Valley \& Durham", and "West Wales and the Valleys".

Cancer Research UK, the Departments of Health and the MRC provide the most comprehensive geographic coverage by regional funding, which is unremarkable given the size of their funding portfolios. However, these funders and the Wellcome Trust are notable in focusing the most research funding in London, East Anglia and Berkshire, Buckinghamshire and Oxfordshire - the so-called 'Golden Triangle' of London, Cambridge and Oxford. While the smaller funders shown also generally have the core focus of their research on London, they more often have a secondary geographical focus outside the 'Golden Triangle'. For example Leukaemia and Lymphoma Research appears to focus in "Northumberland, and Tyne and Wear", and "West Yorkshire", while Breakthrough Breast Cancer supports research in "Greater Manchester" and "Eastern Scotland".

This suggests that there is complementarity between the large national funders that focus on the South East and smaller, perhaps more regionally oriented, charities that focus elsewhere as well as in London. Examples outside the top nine include Yorkshire Cancer Research, Scottish Funding Council, Cancer Research Wales, Northwest Cancer Research Fund and the Newcastle Healthcare Charity. There are also many smaller charities that also focus their funding efforts in the Golden Triangle, so this is not to say that small funders offset the focus demonstrated by the large funders. 
Figure 3.14: Co-authorship between UK NUTS-2 regions. Network and relative clusters are produced using VOSviewer Version 1.5.4

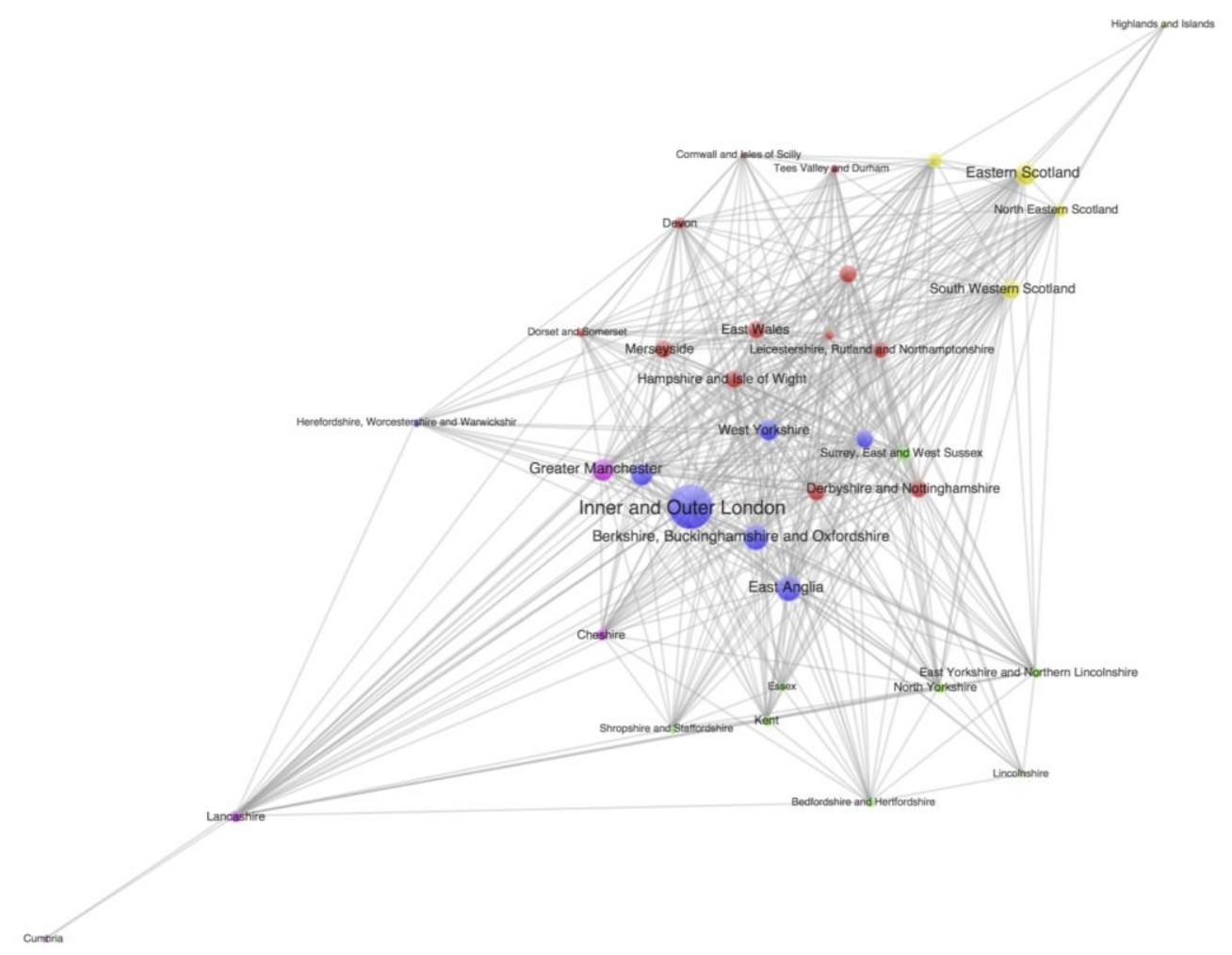

(a) Network view

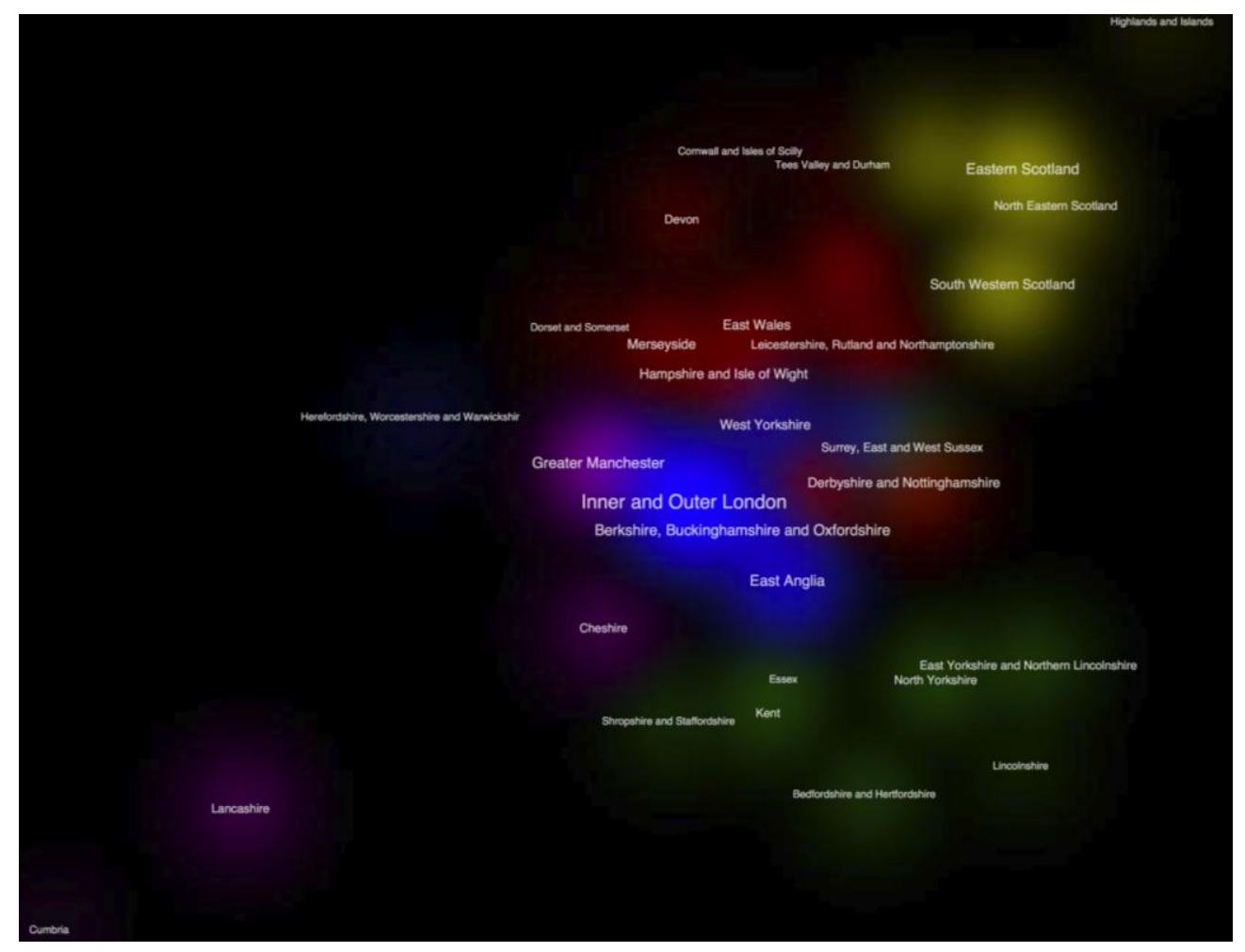

(b) Cluster view 
Table 3.8: UK funding organisations acknowledged in at least $2 \%$ of the publication sample by directly or indirectly supported regions (NUTS-2)

\section{Regions}

Tees Valley and Durham

Northumberland and Tyne and Wear Cumbria

Greater Manchester

Lancashire

Cheshire

Merseyside

East Yorkshire and Northern Lincolnshire

North Yorkshire

South Yorkshire

West Yorkshire

Derbyshire and Nottinghamshire

Leicestershire, Rutland and Northamptonshire

Lincolnshire

Herefordshire, Worcestershire and Warwickshire

Shropshire and Staffordshire

West Midlands

East Anglia

Bedfordshire and Hertfordshire

Essex

Inner London and Outer London

Berkshire, Buckinghamshire and Oxfordshire

Surrey, East and West Sussex

Hampshire and Isle of Wight

Kent

Gloucestershire, Wiltshire and Bristol/Bath area

Dorset and Somerset

Cornwall and Isles of Scilly

Devon

West Wales and The Valleys

East Wales

Eastern Scotland

South Western Scotland

North Eastern Scotland

\begin{tabular}{|c|c|c|c|c|c|c|c|c|}
\hline \multicolumn{9}{|c|}{ Funders } \\
\hline 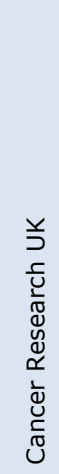 & 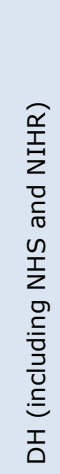 & 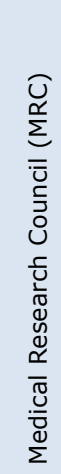 & 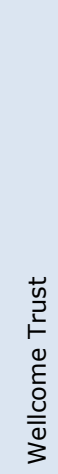 & 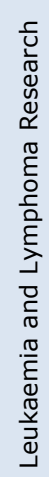 & 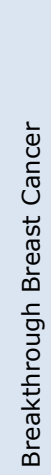 & 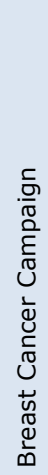 & 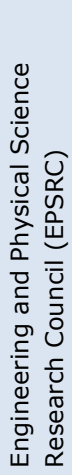 & 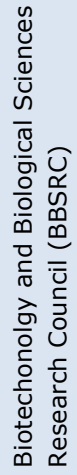 \\
\hline 6 & 6 & 3 & 1 & 0 & 0 & 0 & 0 & 0 \\
\hline 54 & 46 & 32 & 8 & 19 & 3 & 2 & 2 & 6 \\
\hline 0 & 0 & 0 & 0 & 0 & 0 & 0 & 0 & 0 \\
\hline 102 & 89 & 35 & 11 & 9 & 24 & 8 & 7 & 13 \\
\hline 5 & 7 & 3 & 1 & 0 & 0 & 0 & 1 & 0 \\
\hline 8 & 5 & 4 & 1 & 0 & 0 & 0 & 2 & 2 \\
\hline 42 & 39 & 20 & 6 & 2 & 1 & 1 & 0 & 8 \\
\hline 2 & 6 & 4 & 1 & 1 & 0 & 0 & 1 & 1 \\
\hline 5 & 7 & 4 & 1 & 7 & 0 & 0 & 1 & 1 \\
\hline 40 & 42 & 14 & 3 & 4 & 6 & 12 & 6 & 5 \\
\hline 88 & 60 & 40 & 10 & 18 & 1 & 6 & 2 & 7 \\
\hline 38 & 32 & 19 & 1 & 1 & 3 & 9 & 4 & 5 \\
\hline 24 & 28 & 15 & 5 & 7 & 1 & 5 & 0 & 1 \\
\hline 0 & 0 & 1 & 0 & 0 & 0 & 0 & 0 & 0 \\
\hline 0 & 3 & 1 & 0 & 0 & 0 & 0 & 0 & 0 \\
\hline 2 & 2 & 0 & 0 & 0 & 0 & 1 & 1 & 1 \\
\hline 85 & 54 & 45 & 11 & 15 & 1 & 7 & 7 & 5 \\
\hline 224 & 177 & 115 & 70 & 19 & 8 & 22 & 5 & 8 \\
\hline 1 & 2 & 2 & 0 & 1 & 0 & 1 & 1 & 0 \\
\hline 2 & 1 & 0 & 0 & 0 & 0 & 0 & 0 & 0 \\
\hline 518 & 613 & 274 & 113 & 62 & 78 & 41 & 47 & 26 \\
\hline 185 & 168 & 128 & 57 & 17 & 10 & 7 & 18 & 13 \\
\hline 14 & 16 & 7 & 3 & 2 & 1 & 1 & 1 & 1 \\
\hline 50 & 35 & 17 & 5 & 16 & 2 & 7 & 1 & 4 \\
\hline 3 & 4 & 0 & 0 & 0 & 0 & 1 & 0 & 0 \\
\hline 48 & 53 & 36 & 13 & 10 & 1 & 4 & 2 & 3 \\
\hline 9 & 5 & 7 & 0 & 7 & 1 & 0 & 0 & 0 \\
\hline 1 & 2 & 1 & 0 & 0 & 0 & 0 & 0 & 0 \\
\hline 20 & 27 & 10 & 3 & 0 & 1 & 0 & 0 & 0 \\
\hline 11 & 5 & 3 & 0 & 0 & 0 & 0 & 1 & 0 \\
\hline 39 & 36 & 23 & 9 & 14 & 2 & 2 & 4 & 5 \\
\hline 73 & 43 & 55 & 23 & 5 & 18 & 6 & 7 & 8 \\
\hline 75 & 29 & 37 & 20 & 6 & 3 & 1 & 2 & 4 \\
\hline 14 & 25 & 10 & 3 & 0 & 1 & 4 & 1 & 3 \\
\hline
\end{tabular}

Around half of the organisations working on neoplasms in the UK produced work through international collaboration, while the remaining 576 worked alone or with national co-authors. Most such organisations (426) produced only one publication on neoplasms in 2011. This is a highly diverse group of organisations, including hospitals (157) government offices or organisations (34), industry (47) and charities (33). A further 152 - the majority of which were hospitals (116) produced between 1 and 15 publications in 2011. This suggests there may also be a complementarity between institutions that have an international focus and those addressing national-level research agendas. However this requires further investigation to confirm. 
It is possible that the national-level, low volume publishing organisations are producing distinct types of output to the high volume, highly international publishers. This remains to be investigated.

\subsubsection{Funder complementarities at research host organisation level}

Following from the discussion above, it is possible to explore the coverage of the UK research host organisations by the major funders to understand the number of distinct UK organisations directly or indirectly supported by them. As noted in Figure 3.1, it is not possible to distinguish between direct benefit (where a host organisation has funding) and indirect benefit (where host organisations and funders support a single publication). The funders shown in Table 3.9 supported (directly or indirectly) in total 430 UK organisations (out of 699 organisations involved in those publications with acknowledgment sections).

Table 3.9: Number of research host organisations involved in papers supported by major UK funders

\begin{tabular}{llc}
\hline & Funder & $\begin{array}{c}\text { Number of } \\
\text { organisations }\end{array}$ \\
\hline 1) & UK Departments of Health (inc. NHS, NIHR) & 330 \\
2) & Cancer Research UK & 259 \\
3) & Medical Research Council & 175 \\
4) & Wellcome Trust & 91 \\
5) & Breast cancer Campaign & 68 \\
6) & Engineering and Physical Sciences Research Council & 60 \\
7) & Leukaemia and Lymphoma Research & 59 \\
8) & Biotechnology and Biological Sciences Research Council & 49 \\
9) & Breakthrough Breast Cancer & 48 \\
\hline
\end{tabular}

\subsubsection{Complementarities across MESH codes within neoplasms}

Complementarity of funders and host organisations can be investigated by analysing the specific focus of the research that these organisations are pursuing. This allows the relative focus of research on neoplasms at national and organisational level to be studied, and identification of relatively neglected areas.

We use the MeSH descriptors under the 'parent' descriptor "Neoplasms" to profile the research of these organisations. Table 3.10 shows that the publications in our sample were classified by descriptors belonging to the sub-branches "Neoplasms by Site" and "Neoplasms by Histologic Type" which hold 68\% and $43 \%$ of the sample respectively (see Table A2 in the appendix for more details on the MeSH classification system). Table 3.11 reports the descriptors of these 'sub-branches' at the next level of detail (the third MESH level) with the corresponding number of publications. The three areas with most publications are "Neoplasms, Glandular and Epithelial", "Digestive System Neoplasms", and "Urogenital Neoplasms". 
Table 3.10: "Neoplasms" MeSH Descriptors at level $2(\mathrm{~N}=7,510)$.

\begin{tabular}{lcc}
\hline Descriptor & Tree number & $\begin{array}{c}\text { Number of } \\
\text { publications }\end{array}$ \\
\hline Neoplasms by Site & C04.588 & 5,137 \\
Neoplasms by Histologic Type & $\mathrm{C} 04.557$ & 3,252 \\
Neoplastic Processes & $\mathrm{C} 04.697$ & 970 \\
Cysts & $\mathrm{C} 04.182$ & 175 \\
Neoplasms, Experimental & $\mathrm{C} 04.619$ & 158 \\
Neoplastic Syndromes, Hereditary & $\mathrm{C} 04.700$ & 112 \\
Precancerous Conditions & $\mathrm{C} 04.834$ & 109 \\
Tumor Virus Infections & $\mathrm{C} 04.925$ & 106 \\
Neoplasms, Multiple Primary & $\mathrm{C} 04.651$ & 56 \\
Neoplasms, Radiation-Induced & $\mathrm{C} 04.682$ & 50 \\
Paraneoplastic Syndromes & $\mathrm{C} 04.730$ & 44 \\
Neoplasms, Second Primary & $\mathrm{C} 04.692$ & 40 \\
Pregnancy Complications, Neoplastic & $\mathrm{C} 04.850$ & 37 \\
Neoplasms, Hormone-Dependent & $\mathrm{C} 04.626$ & 24 \\
Hamartoma & $\mathrm{C} 04.445$ & 23 \\
Neoplasms, Post-Traumatic & $\mathrm{C} 04.666$ & 0 \\
\hline
\end{tabular}

Note: More than one descriptor can be assigned to a publication. The publication count includes also the lower levels of the MeSH tree. 1,126 publications (14.99\%) are classified as "Neoplasms" at the first level of the MeSH tree, i.e. no additional MeSH descriptors at second or lower level are reported.

Table 3.11: "Neoplasms by Site" and "Neoplasms by Histologic Type" MeSH Descriptors at level 3.

\begin{tabular}{|c|c|c|}
\hline Descriptor & Tree number & No. of pubs \\
\hline Neoplasms, Glandular and Epithelial & C04.557.470 & 1,633 \\
\hline Digestive System Neoplasms & C04.588.274 & 1,253 \\
\hline Urogenital Neoplasms & C04.588.945 & 1,017 \\
\hline Breast Neoplasms & C04.588.180 & 1,008 \\
\hline Head and Neck Neoplasms & C04.588.443 & 663 \\
\hline Neoplasms, Germ Cell and Embryonal & C04.557.465 & 652 \\
\hline Neoplasms, Nerve Tissue & C04.557.580 & 614 \\
\hline Endocrine Gland Neoplasms & C04.588.322 & 565 \\
\hline Thoracic Neoplasms & C04.588.894 & 533 \\
\hline Leukemia & C04.557.337 & 435 \\
\hline Nervous System Neoplasms & C04.588.614 & 373 \\
\hline Neoplasms, Connective and Soft Tissue & C04.557.450 & 328 \\
\hline Lymphoma & C04.557.386 & 302 \\
\hline Skin Neoplasms & C04.588.805 & 287 \\
\hline Bone Neoplasms & C04.588.149 & 236 \\
\hline Nevi and Melanomas & C04.557.665 & 229 \\
\hline Neoplasms, Plasma Cell & C04.557.595 & 132 \\
\hline Neoplasms, Vascular Tissue & C04.557.645 & 115 \\
\hline Neoplasms, Complex and Mixed & C04.557.435 & 62 \\
\hline Soft Tissue Neoplasms & C04.588.839 & 62 \\
\hline Eye Neoplasms & C04.588.364 & 61 \\
\hline Hematologic Neoplasms & C04.588.448 & 60 \\
\hline Abdominal Neoplasms & C04.588.33 & 46 \\
\hline Mammary Neoplasms, Animal & C04.588.531 & 23 \\
\hline Pelvic Neoplasms & C04.588.699 & 13 \\
\hline Neoplasms, Gonadal Tissue & C04.557.475 & 11 \\
\hline Lymphatic Vessel Tumors & C04.557.375 & 10 \\
\hline Histiocytic Disorders, Malignant & C04.557.227 & 5 \\
\hline Splenic Neoplasms & C04.588.842 & 5 \\
\hline Odontogenic Tumors & C04.557.695 & 1 \\
\hline Anal Gland Neoplasms & $\mathrm{C} 04.588 .83$ & 1 \\
\hline
\end{tabular}

Notes. More than one descriptor can be assigned to a publication. Publications to which multiple descriptors belonging to the same branch (at the third level of the MeSH tree) are assigned are not double counted. The third level of the MeSH tree allows classifying 6,174 publications (82.2\%). 
Major UK research host organisations (17) and funders (9) are profiled according to the most frequently occurring $25 \mathrm{MeSH}$ descriptors in Figure 3.14 and Figure 3.15 , respectively. These figures report two types of information for each major UK host organisation and funder. The radar chart on the left of each page depicts the proportion of research that a host organisations produced or a funder supported in a given neoplasm domain relatively to overall number of publications that they produced/supported in neoplasms. The radar chart on the right of the page normalises the organisations' profiles by comparing the proportion of publications a host organisation produced or a funder supported in a given neoplasm domain versus the expected value of publications in that domain. The expected value (number) of publications in the neoplasms domain is calculated as the average number of publications per organisation in that domain. This allows an organisation's research contribution by neoplasm domains in relation to the overall activity in those domains and to the organisation's output. For example, if a domain is indicated to have a value higher than 1 , then the focal organisation is contributing to that domain more than expected. ${ }^{4}$

Figure 3.15 explores how the research of the major host organisation is distributed over the major neoplasm domains (as reported in Table 3.11). The Figure 3.15 indicates that major UK host organisations (except for Cardiff University and University of Southampton) contributed at least $20 \%$ of their research output to the "Neoplasms, Glandular and Epithelial" domain. At least $20 \%$ of the research output of University College London, Imperial College, Oxford University, University of Leeds, and University of Glasgow is focused on "Digestive System Neoplasms". Finally, the Institute of Cancer Research, University of Cambridge, Oxford University, Queen Mary University of London, and Cardiff University focused more than $20 \%$ of their research output on "Urogenital Neoplasms". Overall the top-9 major host organisations' research profiles are relatively similar. However the radar charts suggest that University of Edinburgh and University of Sheffield are particularly focused on "Breast Neoplasms" domains to which they contribute $\sim 30 \%$ of their neoplasms research outputs. Other distinctive features include a relative focus at University of Liverpool on "Head and Neck Neoplasms" and at Cardiff University and University of Southampton on "Leukemia".

Additional information on the host organisations' research profile is provided by the radar charts on the right of each page in Figure 3.15, which show output relative to other organisations nationally. The charts reveal that while all UK major host organisations (except for Cardiff University and University of Southampton) contributed to the "Neoplasms, Glandular and Epithelial" domain with at least $20 \%$ of their research output in neoplasms, none of these organisations is contributing more than expected to this neoplasm domain, which is a major focus at the national level.

Similarly University College London, Imperial College, Oxford University, University of Leeds, and University of Glasgow undertake a high proportion of

\footnotetext{
${ }^{4}$ An alternative normalisation approach could consider the incidence ratio of different neoplasms on UK population. However, the available statistics do not fully match the MeSH classification making this type of normalisation possible only for certain types of neoplasms. This would provide partial statistics. We therefore deemed it more suitable to undertake a normalisation based on publication count. 
their neoplasms research on "Digestive System Neoplasms". However, only Oxford University, University of Leeds, and University of Glasgow are contributing more than expected to this domain. Finally, the Institute of Cancer Research, University of Cambridge, Oxford University, Queen Mary University of London, and Cardiff University focus more than $20 \%$ of their research output in "Urogenital Neoplasms" and are also contributing more than expected to this type of neoplasm research.

The charts also reveal major contributions to relatively smaller neoplasms domains. For example, the Institute of Cancer Research, University of Leeds, University of Newcastle, University of Birmingham are contributing at least twice as much as is expected to "Neoplasms, Plasma Cell". In addition, University of Newcastle and University of Cardiff produced more publications than expected in "Leukemia". 
Figure 3.15a: Major UK research host organisations in "Neoplasms" area and distribution of publications across the different types of cancer. Left charts report the percentage of research host organisations' total publications in different neoplasm domains. Right charts report whether research host organisations are more $(>1.0)$ or less $(<1.0)$ active in each domain than expected.
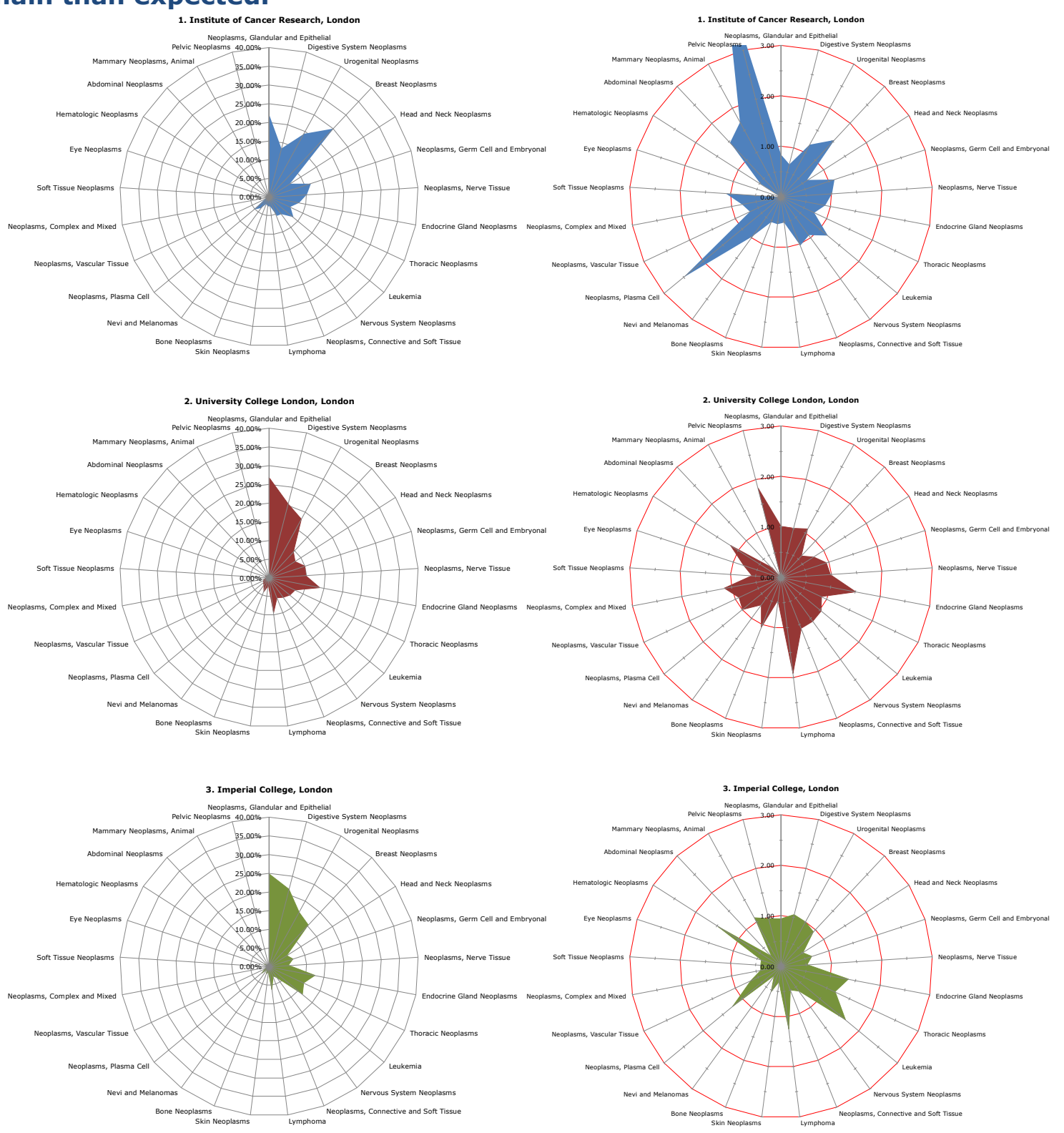
Figure 3.15b: Major UK research host organisations in "Neoplasms" area and distribution of publications across the different types of cancer. Left charts report the percentage of research host organisations' total publications in different neoplasm domains. Right charts report whether research host organisations are more $(>1.0)$ or less $(<1.0)$ active in each domain than expected.
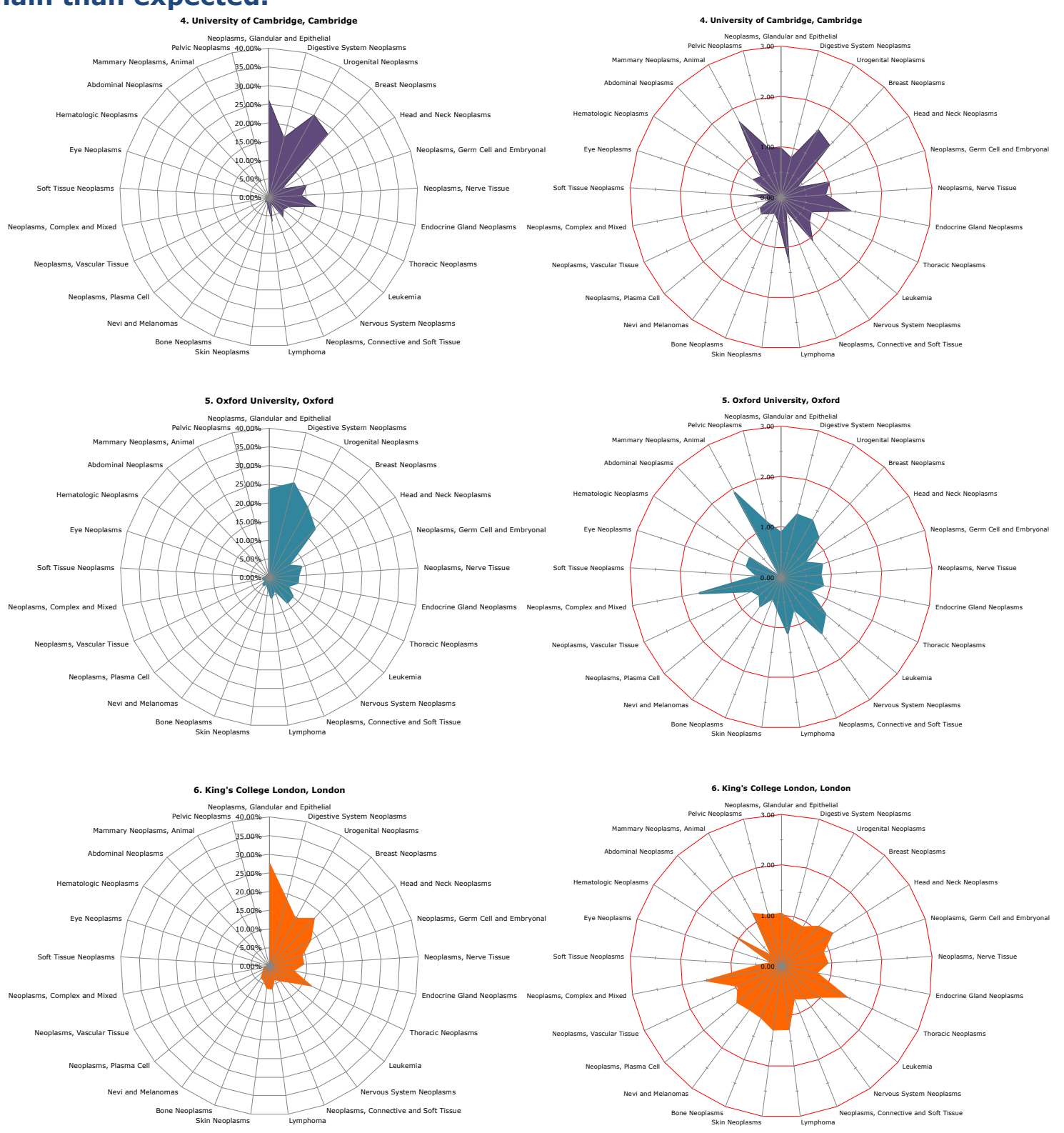
Figure 3.15c: Major UK research host organisations in "Neoplasms" area and distribution of publications across the different types of cancer. Left charts report the percentage of research host organisations' total publications in different neoplasm domains. Right charts report whether research host organisations are more $(>1.0)$ or less $(<1.0)$ active in each domain than expected.
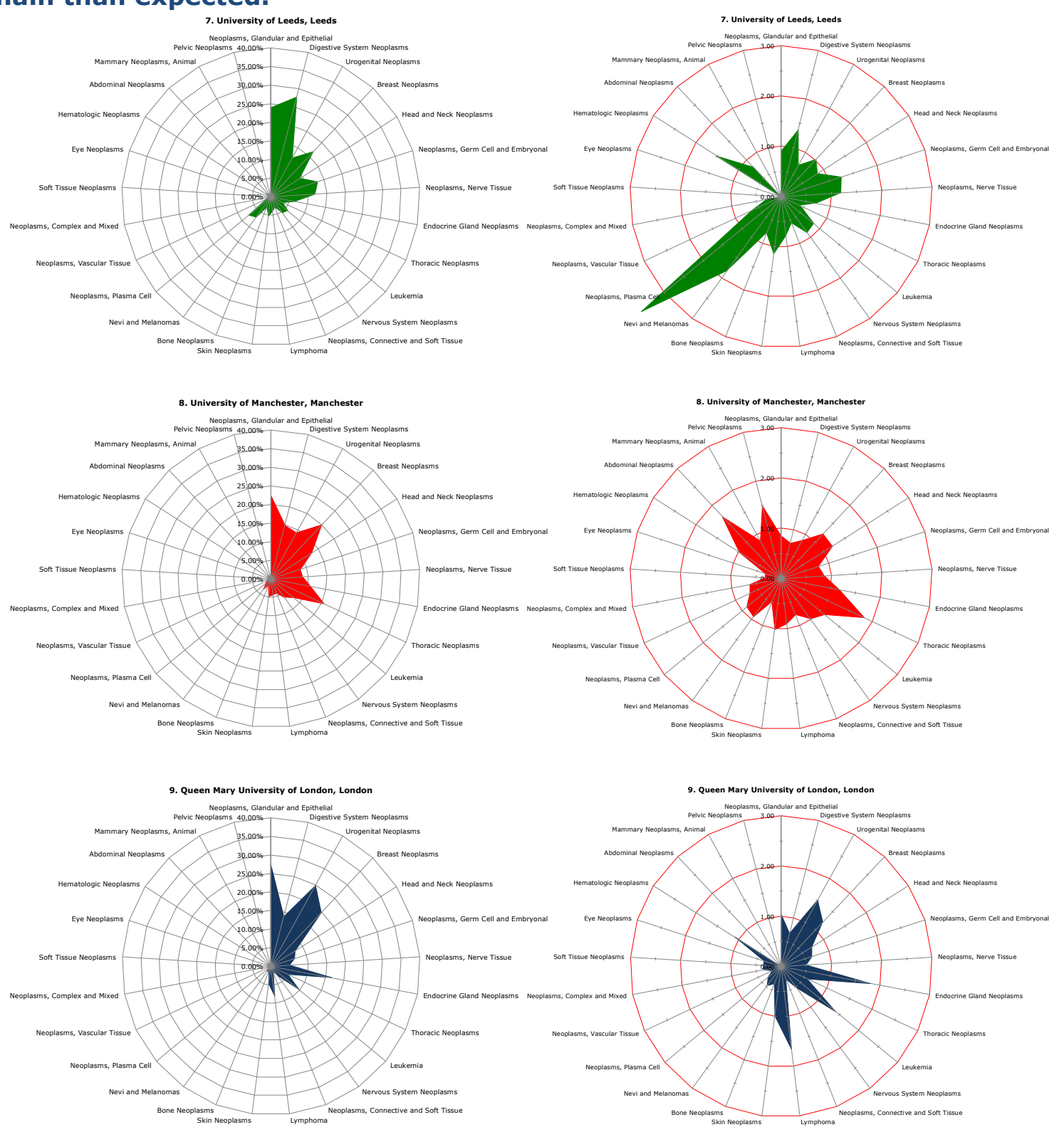
Figure 3.15d: Major UK research host organisations in "Neoplasms" area and distribution of publications across the different types of cancer. Left charts report the percentage of research host organisations' total publications in different neoplasm domains. Right charts report whether research host organisations are more $(>1.0)$ or less $(<1.0)$ active in each domain than expected.
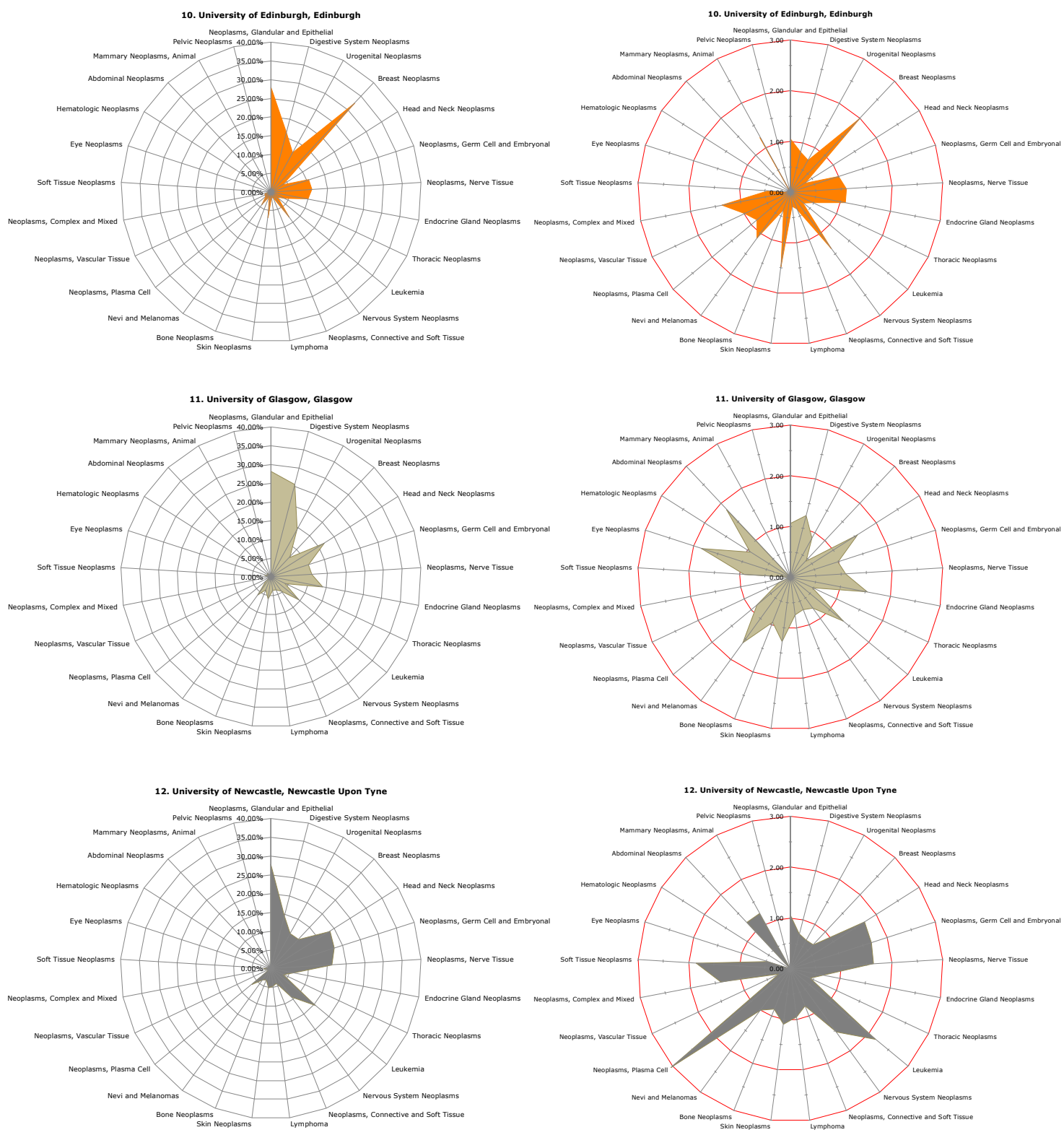
Figure 3.15e: Major UK research host organisations in "Neoplasms" area and distribution of publications across the different types of cancer. Left charts report the percentage of research host organisations' total publications in different neoplasm domains. Right charts report whether research host organisations are more $(>1.0)$ or less $(<1.0)$ active in each domain than expected.
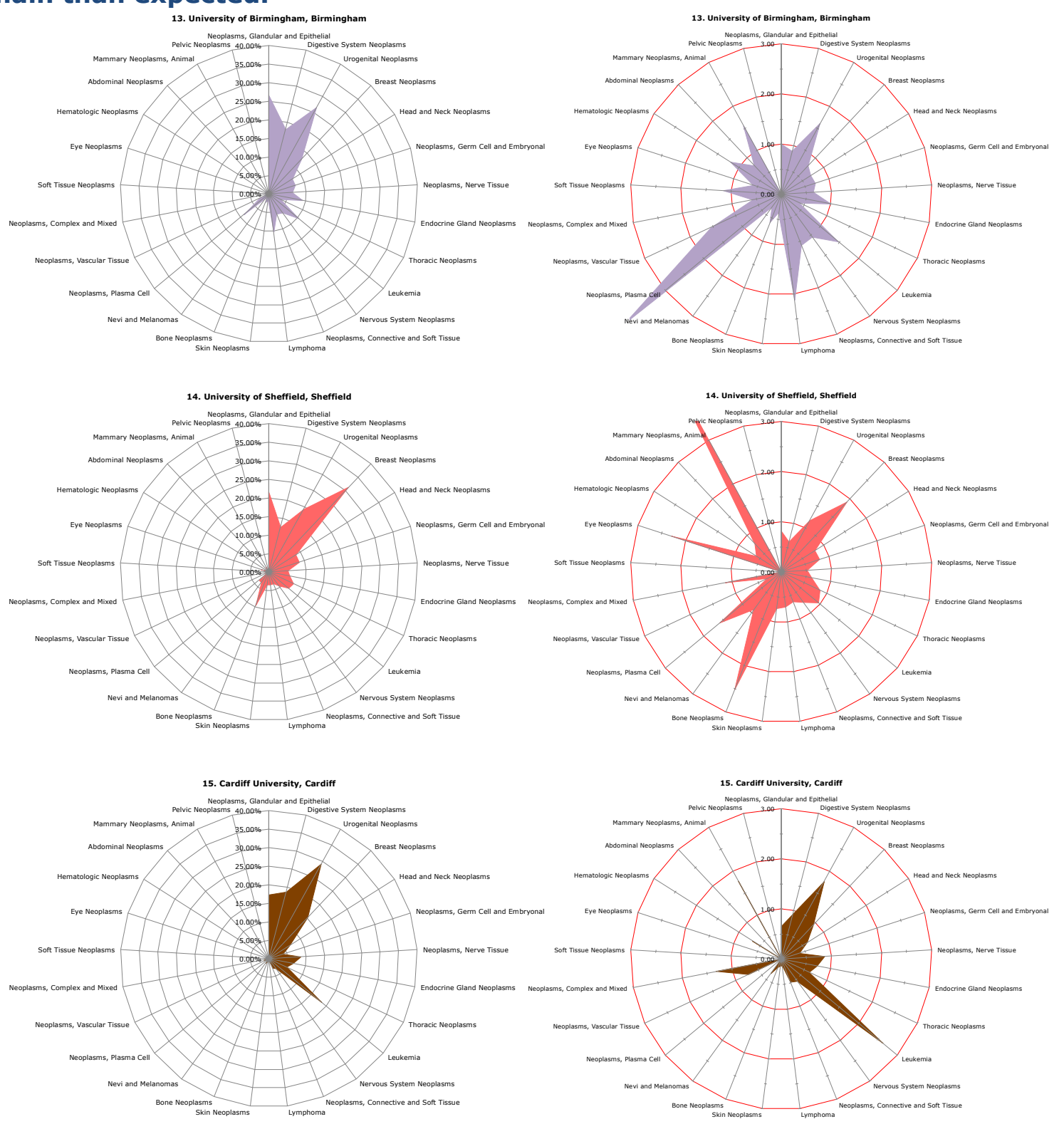
Figure 3.15f: Major UK research host organisations in "Neoplasms" area and distribution of publications across the different types of cancer. Left charts report the percentage of research host organisations' total publications in different neoplasm domains. Right charts report whether research host organisations are more $(>1.0)$ or less $(<1.0)$ active in each domain than expected.

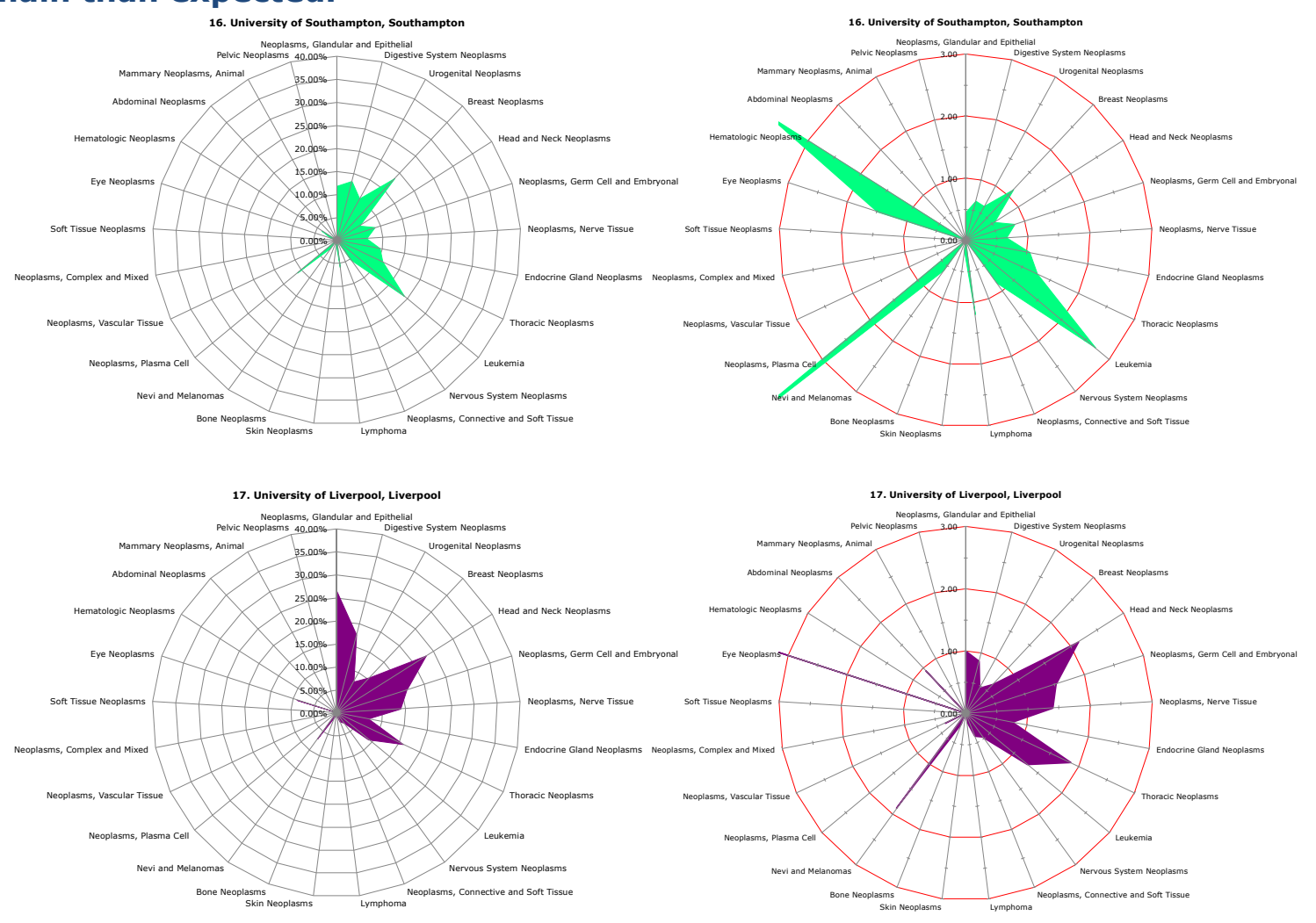

Figure 3.16 shows that the top three external research funders (CR-UK, DH and MRC) also mainly focus on "Neoplasms, Glandular and Epithelial", "Digestive System Neoplasms", and "Urogenital Neoplasms". The remaining funders have a more specialised research profile across the neoplasms domains. For instance, $\sim 80 \%$ of the publications supported by Breakthrough Breast Cancer or Breast Cancer Campaign are classified as "Breast Neoplasms". Leukaemia and Lymphoma Research support paper mainly related to "Leukemia" and "Lymphoma" domains. The Wellcome Trust and BBSRC are relatively more focused on "Neoplasms, Germ Cell and Embryonal" and "Neoplasms, Nerve Tissue" domains. While the top-3 funders' research profiles are relatively similar in the neoplasms domains that they support, it is worth noting that relatively 'minor' neoplasm sites such as eye, bone, skin and soft tissue are neglected by these funders. However, the remaining major funders seem to complement this. For example, BBSRC and EPSRC are contributing more than expected to eye, bone, skin and soft tissue domains (see charts on the right in Figure 3.15). 
Figure 3.16a: Major UK funders acknowledged in "Neoplasms" area and distribution of publications across the different types of cancer. Left charts report the percentage of funders' total publications in different neoplasm domains. Right charts report whether funders are more $(>1.0)$ or less $(<1.0)$ active in each domain than expected.

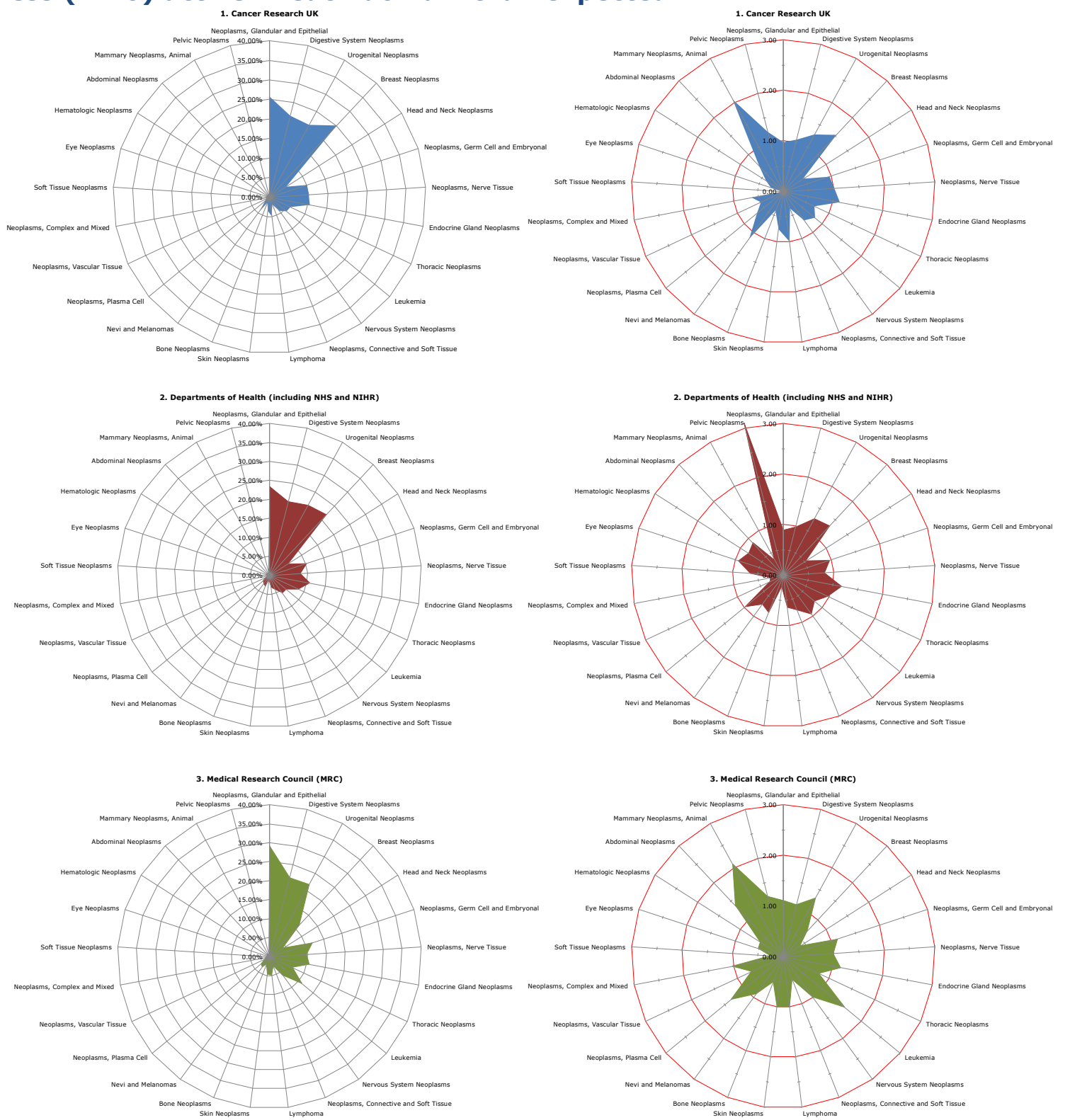


Figure 3.16b: Major UK funders acknowledged in "Neoplasms" area and distribution of publications across the different types of cancer. Left charts report the percentage of funders' total publications in different neoplasm domains. Right charts report whether funders are more $(>1.0)$ or less $(<1.0)$ active in each domain than expected.

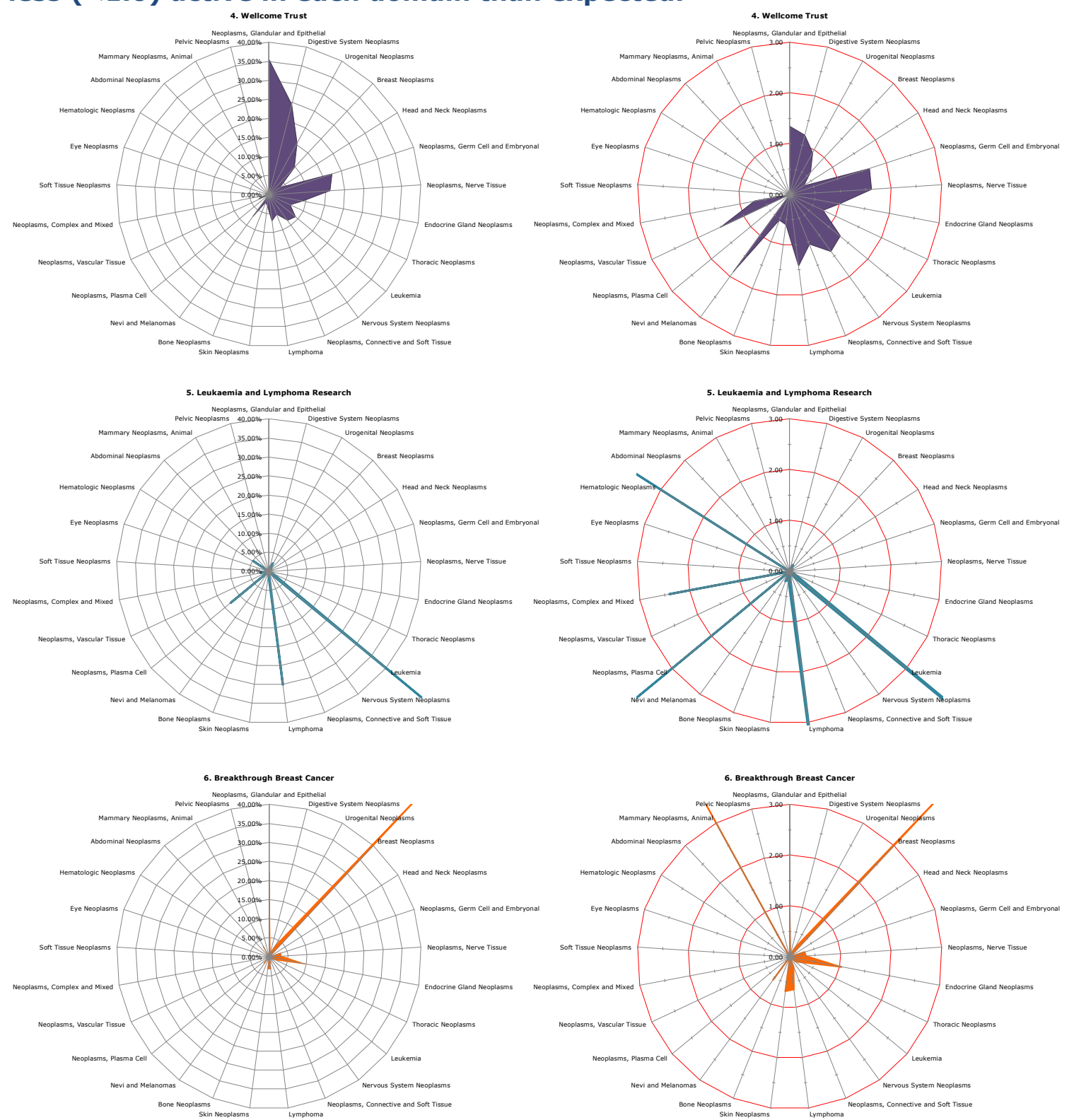


Figure 3.16c: Major UK funders acknowledged in "Neoplasms" area and distribution of publications across the different types of cancer. Left charts report the percentage of funders' total publications in different neoplasm domains. Right charts report whether funders are more $(>1.0)$ or less $(<1.0)$ active in each domain than expected.

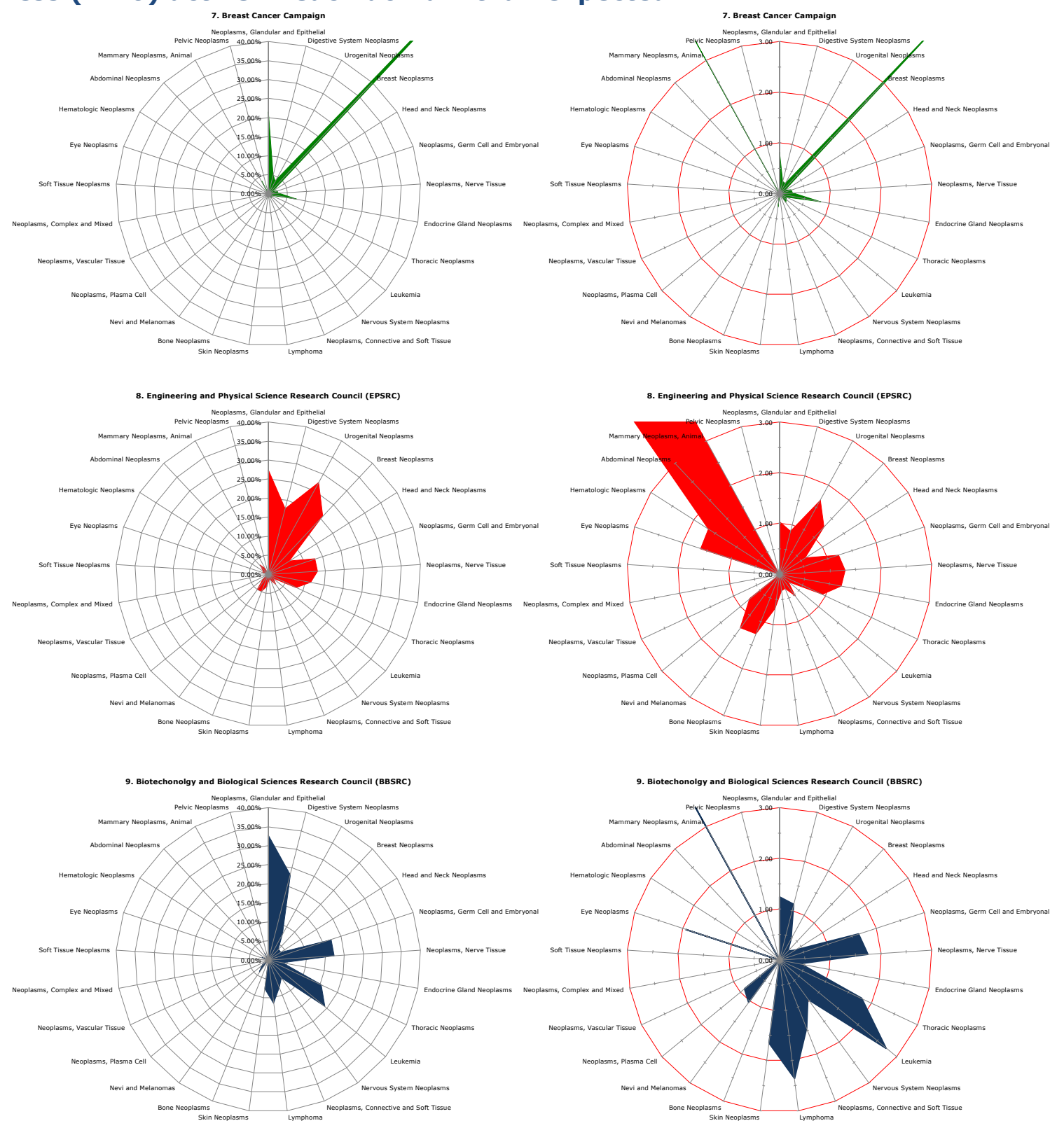

The analysis also compares the major UK funders collectively (defined as those supporting at least $2 \%$ of the research output) with the remaining research funders that are more minor by funding activity in neoplasms research. To facilitate comparisons at the aggregate level, we first to chart the interdependence between different types of funders and set out the overall contributions by each set of funders individually and with other funders by group. To do so, we defines three categories of funder as in the followings:

- Major UK funders: UK funders acknowledged in at least $2 \%$ of the publications reporting acknowledgment sections 
- Minor UK funders: UK funders acknowledged in less than $2 \%$ of the publications (however these are not necessarily small funders by size).

- Other Funders and Industry: all other funders not falling in the previous categories including industrial actors

A publication may be supported by one of these categories of funders or by combinations of these. We represent the possible combinations in Figure 3.17 and report the number of publications supported by each combination of funders.

Figure 3.17: Conceptualising the co-funding

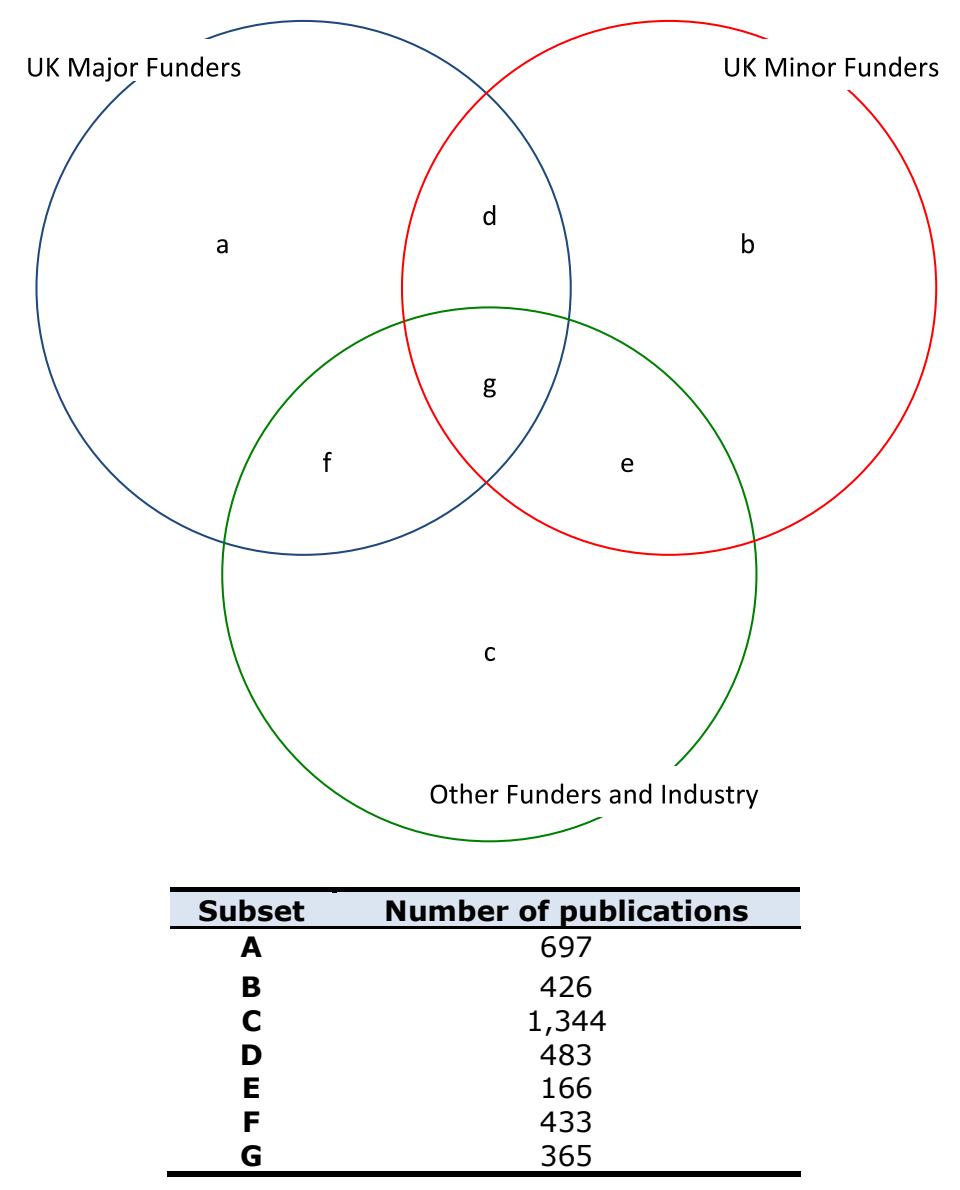

The analysis reveals that 697 publications (17.8\%) are exclusively supported by one or more UK major funders, 466 publications (10.9\%) are exclusively supported by one or more UK minor funders, and 1,344 publications (34.3\%) are exclusively supported by other funders and industry. Adopting the same radar chart approach used to profile the research produced by major UK host organisations or supported by the major UK funders, we profile the publications according to the combination of categories of funders that supported them. This analysis is reported in Figure 3.17.

Publications supported only by major UK funders (a) are mainly focused on "Neoplasms, Glandular and Epithelial", "Digestive System Neoplasms", "Urogenital Neoplasms", and "Breast Neoplasms" while "Head and Neck Neoplasms", "Neoplasms, Germ Cell and Embryonal", "Neoplasms, Nerve Tissue", "Endocrine Gland Neoplasms", and "Thoracic Neoplasms" are relatively neglected when compared to research outputs supported only by minor UK funders (b). This 
finding is confirmed also when the observed number of publications is compared with the expected one (see right radar charts in Figure 3.18b). Interestingly, the subset of publications supported by UK minor funders and other funders including industry (e) is unevenly distributed across neoplasms domains when it is compared to the subset of publications supported by other funders' combinations (left charts). The combination of minor UK funder and other funders including industry is also disproportionally contributing to specific neoplasms domains (right charts) such as "Breast Neoplasms", "Neoplasms, Germ Cell and Embryonal", "Thoracic Neoplasms", "Bone Neoplasms", and "Nevi and Melanomas".

Figure 3.18a: Funders acknowledged in "Neoplasms" area and distribution of publications across the different types of cancer. Left charts report the percentage of funders' total publications in different neoplasm domains. Right charts report whether funders are more $(>1.0)$ or less $(<1.0)$ active in each domain than expected.
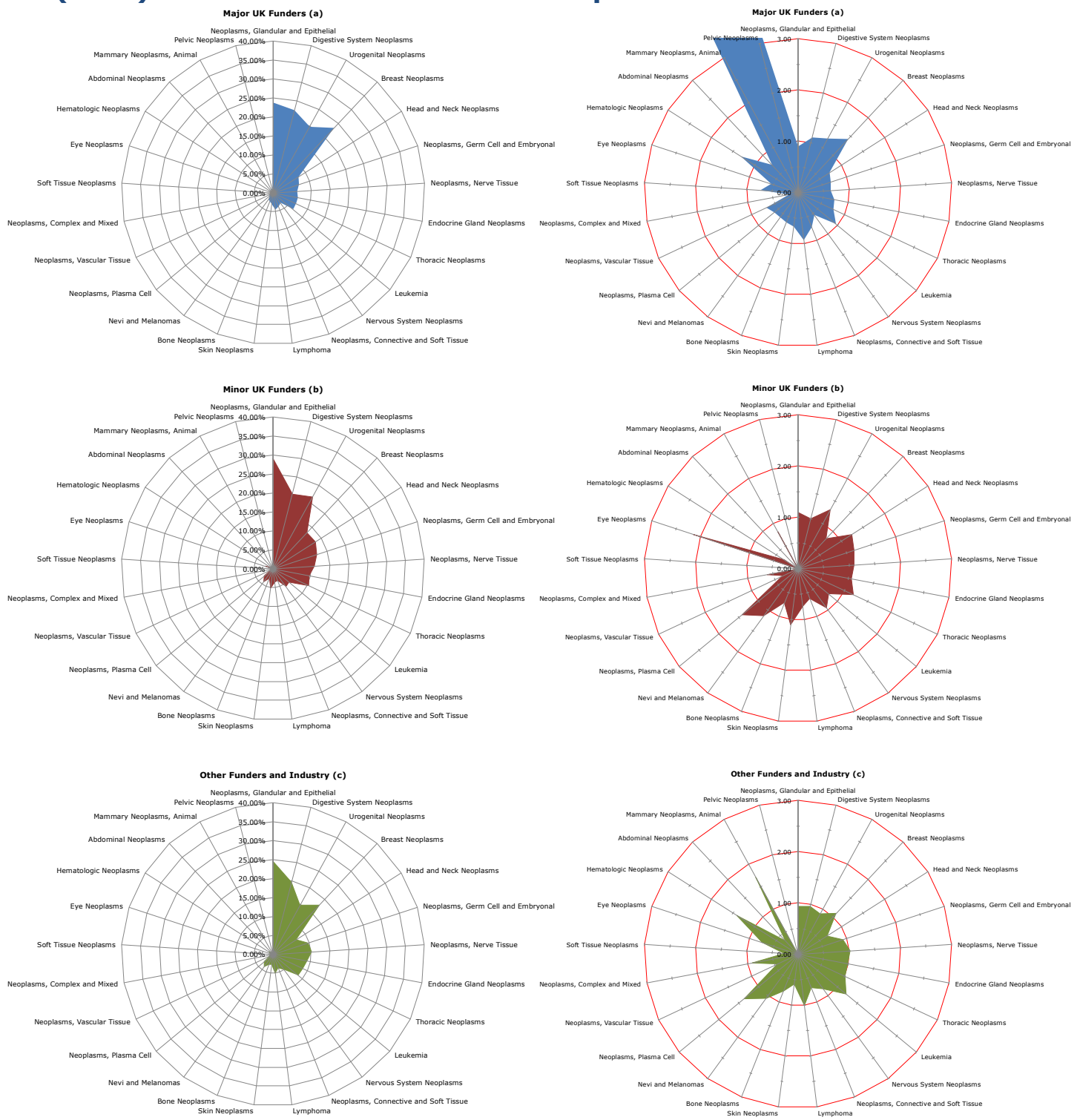
Figure 3.18b: Funders acknowledged in "Neoplasms" area and distribution of publications across the different types of cancer. Left charts report the percentage of funders' total publications in different neoplasm domains. Right charts report whether funders are more $(>1.0)$ or less $(<1.0)$ active in each domain than expected.
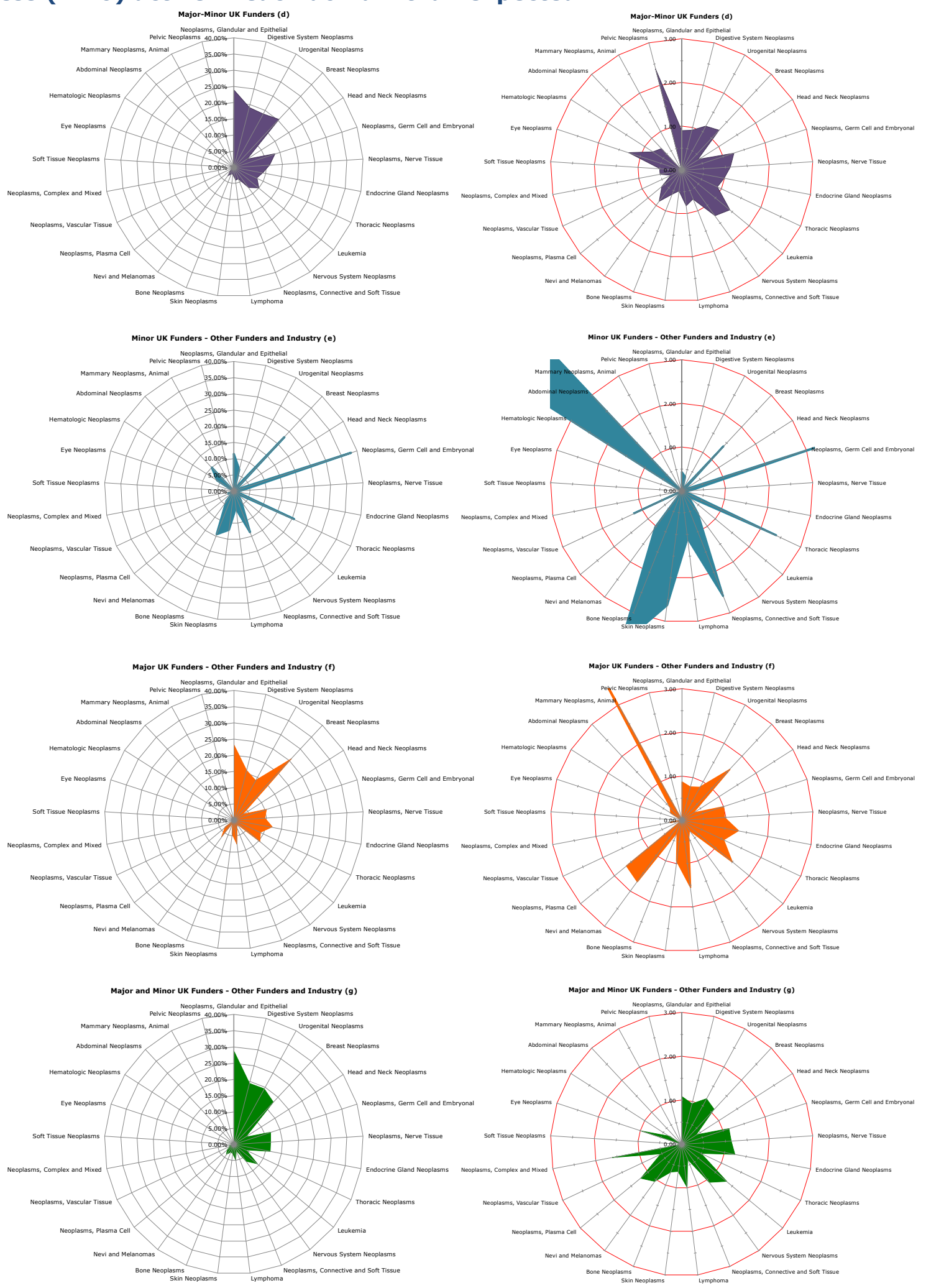
Figure 3.19 summarizes how different categories of funders contribute to the neoplasms domains independently or in combination - based only publications reporting funding sources in the acknowledgement section. Results shows that the proportion of publications supported exclusively by major UK funders (blue) or minor UK funders (red) is very similar across a number of domains such as "Head and Neck Neoplasms", "Neoplasms, Nerve Tissue", "Thoracic Neoplasms", and "Skin Neoplasms". Major UK funders are more active than minor UK funders in domains such as "Digestive System Neoplasms", "Urogenital Neoplasms", "Breast Neoplasms", "Neoplasms, Vascular Tissue", "Soft Tissue, Neoplasms", and "Pelvic Neoplasms". As there are only nine major funders this suggests funding is relatively more concentrated in these domains. Publications supported exclusively by "Other Funders and Industry" (green) are relatively equally distributed across the different neoplasms domains (except for "Abdominal Neoplasms", "Mammary Neoplasms, Animal" and "Pelvic Neoplasms") showing that industrial funders and non-UK funders support on average $\sim 33 \%$ of publications across the neoplasms domains.

Figure 3.19: Funders acknowledged in "Neoplasms" area and distribution of publications across the different types of neoplasms $(N=3,914)$

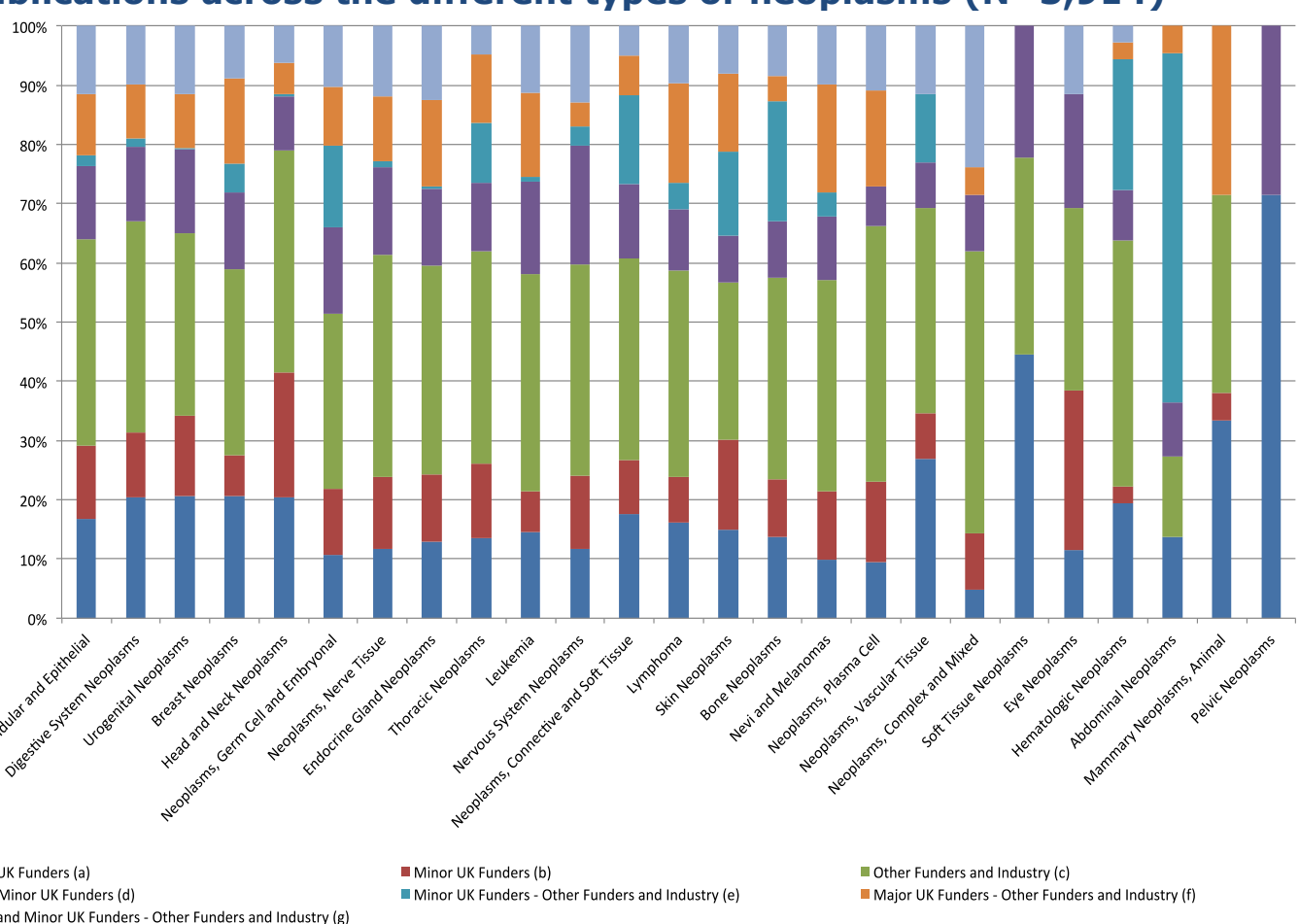

Figure 3.20 further explore this by combining the different categories in three overlapping groups, i.e. publications supported at least by one major UK funder $(a+d+f+g)$, publications supported by at least one minor UK funder $(b+d+e+g)$, and publications supported at least by one 'other' funder or industry $(c+e+f+g)$. While the three groups have a relative similar research profile when compared in term of proportion of publications supported in a given neoplasms domains (top charts in Figure 3.20), the charts comparing the observed number of publication with the expected one in each domains provide evidence of the diversity of research profiles of the three groups. Publications supported by at least one UK minor funder seems to be more evenly spread across the neoplasms domains, i.e. 
the number of publications is close to the expected one in many domains, when compared to the distribution of publications supported by at least one major UK funder. The analysis also shows that publications supported at least by one funder not falling to the other two groups or industry are concentrated more than expected in a number of neoplasms domains such as "Neoplasms, Plasma Cell", "Nevi and Melanomas", "Hematological Neoplasms", and "Abdominal Neoplasms". 
Figure 3.20: Comparing major and minor UK funders acknowledged in "Neoplasms". Upper charts report the percentage of funders' total publications in different neoplasm domains. Lower charts report whether funders are more ( $>1.0)$ or less $(<1.0)$ active in each domain than expected.

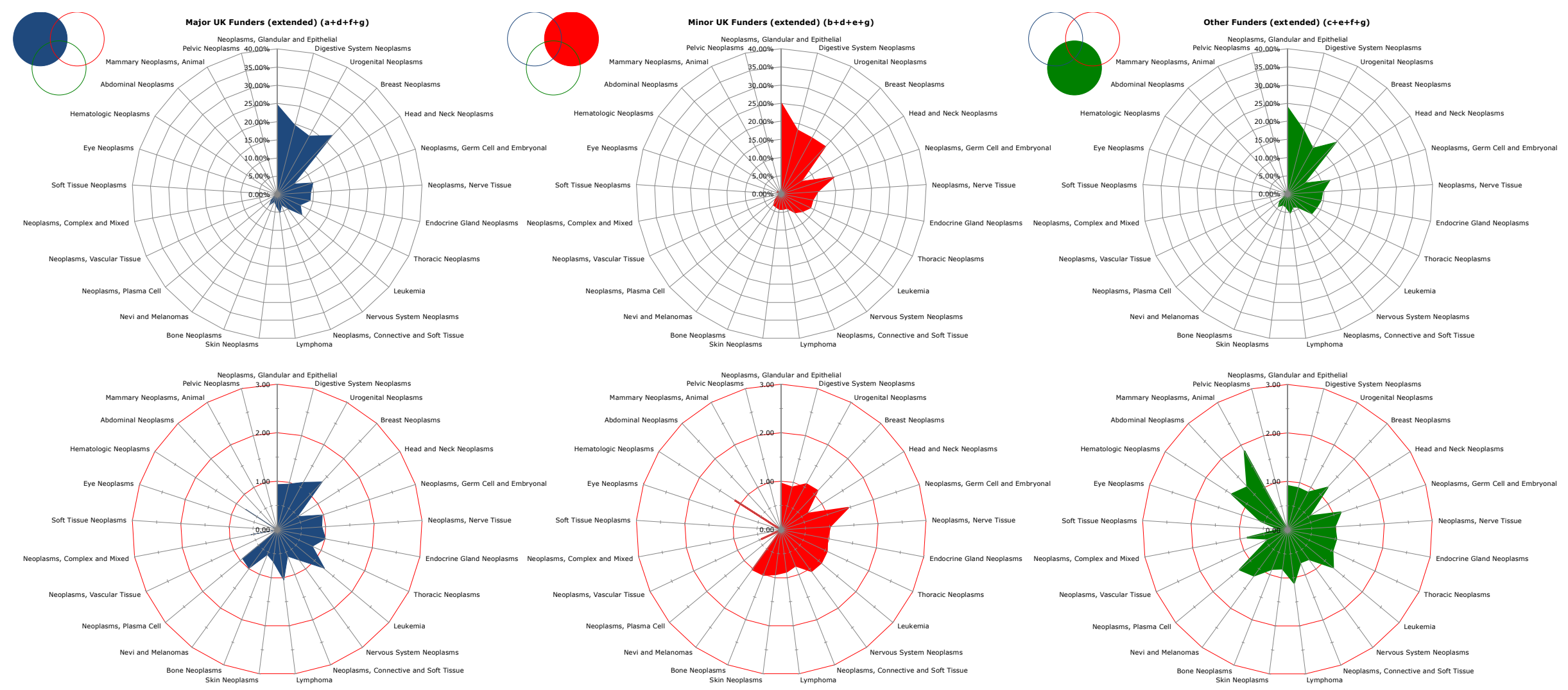




\subsubsection{Complementarities across funding schemes}

For the purpose of this study we identify complementary funders' schemes as being those that collectively support a wider range of research activity than individual funders, and by doing so facilitate researchers to obtain funding throughout their career for different types of research, rather than a narrower range of activity. In order to explore how funding schemes might be complementary, the top public funders in neoplasms were identified by publication counts, and data regarding the funding schemes they support gathered from their websites and their most recent annual reports.

The top funders were: Cancer Research UK, the UK Departments of Health (DH, subdivided into NHS and NIHR), the Medical Research Council (MRC), the National Institutes for Health (NIH, USA), The Wellcome Trust, Breast Cancer Campaign (BCC), Biotechnology and Biological Sciences Research Council (BBSRC), Yorkshire Cancer Research (YCR), Economic and Physical Sciences Research Council (EPSRC), Leukaemia and Lymphoma Research (LLR), European Union (EU, under Framework Programme 7 (FP 7) and European Commission Department of Health and Consumers (DG SANCO).

The data collected from these funders covered the purpose, duration and amount of the funding, in addition to an idea of the people who would be eligible to apply. A subjective interpretation has been made to develop a classification system in an attempt to overcome the issues associated with the diversity of terminology used by different funding bodies (see Table 3.12). The terminology used by funders to describe their schemes may vary from the description here.

Table 3.12: Classification system to enable the categorisation of the different types of funding available from the top funders of UK research in neoplasms

\begin{tabular}{|c|c|c|c|}
\hline Type of funding & Purpose & Scale of award & Duration \\
\hline Fellowships & $\begin{array}{l}\text { To set up research groups, provide further } \\
\text { training or to further academic career } \\
\text { development. Anything after completion of } \\
\text { doctoral studies }\end{array}$ & $\begin{array}{l}\text { Usually covers } \\
\text { salary for the } \\
\text { duration }\end{array}$ & $\begin{array}{l}\text { Can be } \\
\text { anything } \\
\text { from } 1-6 \\
\text { years }\end{array}$ \\
\hline Studentships & $\begin{array}{l}\text { To fund academic development of fund } \\
\text { further formal training (up to and including } \\
\text { PhD training). Mainly stand-alone } \\
\text { studentships (i.e. excluding studentships } \\
\text { written into Programme or Project grant } \\
\text { proposals). }\end{array}$ & $\begin{array}{l}\text { Usually covers } \\
\text { salary and tuition } \\
\text { fees for the } \\
\text { duration }\end{array}$ & 3-4 years \\
\hline Projects & $\begin{array}{l}\text { To fund a defined piece of work with } \\
\text { clearly state and achievable objectives }\end{array}$ & $\begin{array}{l}\text { Some have no fixed } \\
\text { limits but tend to } \\
\text { range from } £ 25,000 \\
\text { up to } £ 1 \mathrm{~m} \text { per year }\end{array}$ & $1-5$ years \\
\hline Programmes & $\begin{array}{l}\text { To provide long term support for larger } \\
\text { research groups that aim to answer an } \\
\text { interrelated set of questions and utilise a } \\
\text { multidisciplinary team }\end{array}$ & $\begin{array}{l}\text { Often with no pre- } \\
\text { defined funding } \\
\text { limit but usually } \\
\text { multi-million pound }\end{array}$ & $5-7$ years \\
\hline
\end{tabular}


Other types of funding categorised but not shown include funding specifically for infrastructure (sometimes including equipment and resources) or travel. The summary table of funding schemes offered by top funders is presented below (Table 3.13).

Table 3.13: A summary overview of the different types of funding available from the top public funders of UK cancer research

\begin{tabular}{|c|c|c|c|c|c|c|}
\hline \multirow[b]{2}{*}{ Funder } & \multicolumn{6}{|c|}{ Type of project funding } \\
\hline & 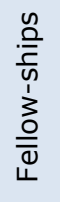 & 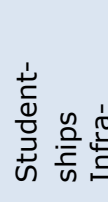 & 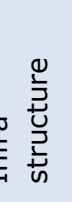 & 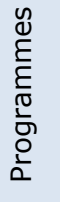 & $\begin{array}{l}\frac{n}{0} \\
0 \\
0 \\
0 \\
0\end{array}$ & $\begin{array}{l}\bar{\Phi} \\
\stackrel{0}{\mathbb{N}} \\
\vdash\end{array}$ \\
\hline Cancer Research UK & $\checkmark$ & & $\boldsymbol{V}$ & $\boldsymbol{V}$ & $\checkmark$ & $\checkmark$ \\
\hline $\mathrm{DH}(\mathrm{NHS})$ & & $\checkmark$ & & & & \\
\hline NIHR & $\boldsymbol{v}$ & $\boldsymbol{r}$ & $\boldsymbol{v}$ & $\boldsymbol{v}$ & $\boldsymbol{r}$ & \\
\hline Medical Research Council (MRC) & $\checkmark$ & $\checkmark$ & & $\checkmark$ & $\checkmark$ & \\
\hline National Institutes of Health (NIH) & $\boldsymbol{v}$ & & & $\boldsymbol{v}$ & $\boldsymbol{v}$ & $\boldsymbol{v}$ \\
\hline Wellcome Trust & $\checkmark$ & $\checkmark$ & $\boldsymbol{v}$ & $\checkmark$ & $\checkmark$ & $\boldsymbol{v}$ \\
\hline Breast Cancer Campaign & $\boldsymbol{v}$ & $\boldsymbol{\sim}$ & & & $\boldsymbol{\sim}$ & \\
\hline Biotechnology and Biological Sciences Research Council (BBSRC) & $\checkmark$ & $\checkmark$ & & $\boldsymbol{\sim}$ & $\checkmark$ & $\checkmark$ \\
\hline Yorkshire Cancer Research (YCR) & $\boldsymbol{\sim}$ & $\checkmark$ & & $\boldsymbol{v}$ & $\checkmark$ & $\boldsymbol{v}$ \\
\hline Engineering and Physical Science Research Council (EPSRC) & $\boldsymbol{V}$ & $\boldsymbol{\sim}$ & & $\boldsymbol{r}$ & $\boldsymbol{\sim}$ & $\boldsymbol{v}$ \\
\hline Leukaemia and Lymphoma Research & $\boldsymbol{v}$ & $\checkmark$ & & $\boldsymbol{\sim}$ & $\checkmark$ & $\checkmark$ \\
\hline European Commission (FP7) & $\boldsymbol{V}$ & & $\boldsymbol{v}$ & $\boldsymbol{v}$ & $\boldsymbol{V}$ & \\
\hline European Commission DG SANCO & & & $\boldsymbol{v}$ & & $\checkmark$ & $\boldsymbol{v}$ \\
\hline
\end{tabular}

\section{PhD Studentships}

PhD Studentships in cancer research represent a subset of the studentships categorised above. There are two reasons for this: 1$)$ studentships in general was taken to include schemes such as internships for undergraduates, summer research placements, funding for masters programmes, 'in-practice' fellowships and funding for specific training for doctoral students, and 2) only those studentships that provided a full stipend and coverage of tuition fees are discussed further here. These studentships were available from seven of the top funders including BBSRC, BCC, EPSRC, LLR, MRC, NIHR and The Wellcome Trust. This shows that the UK funding system provides significant choice for prospective PhD students seeking funding.

Interestingly, the top two funders in the UK, Cancer Research UK and the DH (NHS division), do not appear on this list, principally because the NHS only provides bursaries for tuition fees, and not stipends to students and Cancer Research UK fund studentships within PI led projects rather than awarding directto-student funding.. Of the studentships available, it notable that the three UK research councils offering studentships, the BBSRC, EPSRC and MRC, all offer a stream of funding available for research to be carried out in collaboration with industry partners. Termed CASE (Collaborative Awards in Science and Engineering) studentships, these provide students with research training experience and an opportunity to take their research into the private sphere. 


\section{Early Career Researchers}

For a more detailed analysis of the funding available for early career researchers, we take a subset of the fellowships category, as defined in Table 3.11. For these purposes we take the threshold for 'early' career funding opportunities to be any available to researchers who completed their PhD less than five years prior to application ${ }^{5}$. Included under this categorisation are fellowships open to postdoctoral researchers, where the funding is specifically aimed at early career researchers, or where there is no specification of career stage. Only fellowships supporting awardees salary are included. ${ }^{6}$ Nine of the major funding bodies provide early career fellowships including the BBSRC, Cancer Research UK, EPSRC, EU (under FP7), LLR, MRC, NIHR, The Wellcome Trust and YCR. The UK funding system therefore benefits from a wide range of funding options for early career researchers.

One common characteristic of these fellowships is that there are many that are collaborative in nature and involve cooperation between more than one type of institution or funder, be it in terms of sector, discipline or geographic location. For instance, all three fellowships offered by BBSRC are funded in partnership with another funding body (the Food Standards Agency, Royal Society of Edinburgh and Royal Society/EPSRC/NERC and Rolls Royce) with one requiring the establishment or strengthening of corporate ties between industry and academia. Other funders tend to encourage clinical/academia links with fellowships offering clinicians academic research training or lectureships (LLR, MRC and NIHR). In terms of encouraging research outside the biological and chemical sciences the MRC, Cancer Research UK and Wellcome show some focus towards social science disciplines such as health economics, population studies, biomedical informatics and public health, whereas the NIHR and Wellcome have fellowships in transitional/translational research areas, emphasising the shift from basic to clinical science. The EPSRC support a scheme focusing high risk research. In terms of fellowships that encourage geographic movement, the EU (FP7) presents several outgoing (and ingoing - although these were not specifically included in this analysis due to the lack of salary funding) fellowships in collaboration with Marie Curie, and the support of training networks, that allow networks to bring early career researchers in directly. In addition, Wellcome has a collaborative fellowship with the Massachusetts Institute of Technology (MIT) that allows researchers time in both a UK (host) institution and at MIT.

\section{Projects}

Project grants represent the most common pathway to funding from the sample of funders we assessed: 12 of the 13 funding bodies analysed showed opportunities for project funding. The only funder that shows no availability of project funding was the NHS, which is likely explained by the responsibility for this type of funding for the DH being taken on by the NIHR. As with fellowships there are distinctions between the ways organisations approach the distribution of

\footnotetext{
${ }^{5}$ Fellowships aimed at clinicians with professional qualifications were not deemed to be 'early career'. ${ }^{6}$ This inclusion criterion, therefore excludes schemes such as the CRUK Career Establishment Award, which aims to help researchers develop an independent career in cancer research by establishing a research group, as it does not fund the award holders salary. 
funding for projects. Since the period studied, Cancer Research UK has withdrawn the availability of project grants.

Table 3.14: Summary of the different types of project funding available from the top public funders of UK cancer research

\begin{tabular}{|c|c|c|c|c|c|c|c|}
\hline \multirow[b]{2}{*}{ Funder } & \multicolumn{7}{|c|}{$\begin{array}{c}\text { Targeting of project } \\
\text { funding schemes }\end{array}$} \\
\hline & 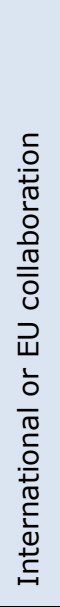 & 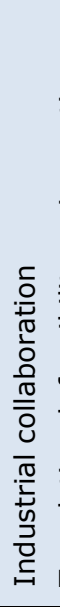 & 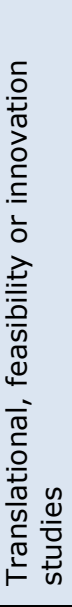 & 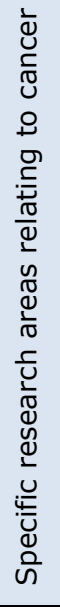 & 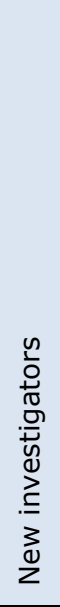 & 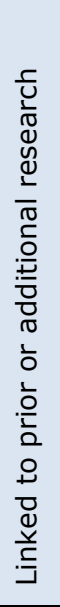 & 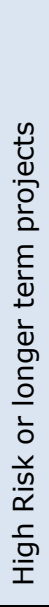 \\
\hline Cancer Research UK & & & $\boldsymbol{V}$ & $\checkmark$ & & & \\
\hline NIHR & & & $\boldsymbol{\sim}$ & $\boldsymbol{\nu}$ & & & \\
\hline Medical Research Council (MRC) & & & $\boldsymbol{v}$ & & & $\boldsymbol{v}$ & \\
\hline National Institutes of Health (NIH) & & & $\boldsymbol{\sim}$ & & & $\boldsymbol{V}$ & \\
\hline Wellcome Trust & & $\boldsymbol{\sim}$ & $\boldsymbol{\gamma}$ & $\boldsymbol{V}$ & & $\boldsymbol{V}$ & \\
\hline Breast Cancer Campaign & & & & $\boldsymbol{V}$ & & & \\
\hline Biotechnolgy and Biological Sciences Research Council (BBSRC) & $\checkmark$ & $\boldsymbol{V}$ & $\boldsymbol{\sim}$ & & $\boldsymbol{v}$ & & \\
\hline Yorkshire Cancer Research (YCR) & & & $\boldsymbol{\sim}$ & & & & \\
\hline Engineering and Physical Science Research Council (EPSRC) & & $\boldsymbol{v}$ & & & $\boldsymbol{v}$ & & $\boldsymbol{\sim}$ \\
\hline Leukaemia and Lymphoma Research & & & & $\boldsymbol{V}$ & & & \\
\hline European Commission (FP7) & $\boldsymbol{\nu}$ & $\boldsymbol{V}$ & & & $\checkmark$ & $\boldsymbol{v}$ & $\checkmark$ \\
\hline European Commission DG SANCO & $\boldsymbol{V}$ & & & & & & \\
\hline
\end{tabular}

The diverse range of project grants available from the top public cancer funders is summarised in Table 3.14. Whilst some of these categories are straightforward, others show a large amount of variation. For instance, funding for translational, feasibility or innovation purposes can range from translation of research from lab to clinic (BBSRC, MRC, Wellcome, YCR), drug discovery (Cancer Research UK, YCR) and innovation of medical technologies more broadly (NIHR) to pilot or feasibility studies (NIH). However, this category does not include grants specifically aimed at proving funding for clinical trials (discussed in a separate section below). In addition, the project funding categorised under specific research covers general funding for particular subtypes of cancer (as in the cases of BCC or LLR) and the various disciplinary approaches to cancer research (e.g. Cancer Research UK funds specific projects relating to tobacco advisory groups, population research and biomarkers; NIHR funds more patient-related research such as health services and delivery, public health, health technology assessment, efficacy and mechanism evaluation and patient benefit; and Wellcome funds initiatives towards sustaining health). Projects that are linked to prior or additional research has been indicated where a funding body sets out project grants for research projects that may lead to programme grants (MRC), 
grants linked to a renewal of a previous project (NIH), strategic grants that add value to existing research groups ${ }^{7}$ (Wellcome) or for the support for recently created teams (EU FP7). In addition to these variations within groups there are also distinct strategies for project funding that do not fit into any of the above categories. For instance, the NIH offer more general and exploratory options for the direction of their project funding, as well as projects that encourage cooperation between itself (the NIH) and the research groups. In addition the MRC have a stream of project funding that focuses on the development of methods for research.

\section{Programmes}

Ten of the 13 funders support large, multidisciplinary programme grants. These are BBSRC, Cancer Research UK, EPSRC, EU (FP7), LLR, MRC, NIH, NIHR, Wellcome and YCR. Most of these programme grants lack specified directions, where most simply require a proposal that identifies an integrated but multidisciplinary research stream. Some do, however, specify particular research area interests, such as the Cancer Research UK Population Research Committee Programme Grants, the MRC Experimental Medicine Challenge Grant (focusing on disease pathophysiology), the NIH Specialised Centre, supporting specific disease areas, and the Wellcome/EPSRC Innovative Engineering for Health scheme which focuses on biomedical engineering. The LLR Specialist Programme grant and the NIHR Programme Development Grant also show a distinction from other initiatives, where the LLR scheme provides further support existing grant holders, and the NIHR supports the preparation of programme grants.

\section{Clinical trials}

Schemes that explicitly support clinical trials are available from four of the 13 funding bodies in this analysis: Cancer Research UK, LLR, MRC and NIH. Cancer Research UK have three such grant options, ranging from small project grants for feasibility studies (allowing for $£ 25,000$ per annum to be obtained for a maximum of four years) to larger scale Phase III Clinical Trial Grants, which appreciate how costly and time consuming this later stage of development can be by offering $£ 100,000$ per annum for 10 years. The charity's New Agents Committee Trials Funds also claims to provide a process for selecting new treatments and diagnostics and allowing them to enter early clinical trials (offering $£ 40,000$ per annum for two years). LLR also offer Clinical Trial awards for Phase I/II trials of new therapy options, however the financial and duration limitations are not publicly disclosed. The MRC (in collaboration with the Technology Strategy Board (TSB)) offer $£ 250,000$ as a minimum for clinical projects under their Biomedical Catalyst: Developmental Pathway Funding Scheme. Finally the NIH offer a smaller amount, up to $\$ 100,000$ for $1-3$ years to support the planning of clinical trials as part of their Clinical Trial Planning Grant Program.

\footnotetext{
${ }^{7}$ Note that this stream shows possible overlap with the type of funding provided by CRUK in their Senior Cancer Research Fellowship which supports the establishment or further development of an independent research group. 


\section{Industry}

There are several ways in which funders seem to be encouraging collaboration between academic and industrial research. One is through the industrial fellowships where researchers from industry are encouraged to bring their skills into an academic context (run by BBSRC). Other schemes involve encouraging partnerships between industry and academia (EPSRC/TSB and MRC), while some of these entail the expectation that the industrial partner will contribute some funding towards the collaboration (BBSRC). The EU (FP7) shows support for industry through their collaborative projects and Industry-Academia Partnerships and Pathways (under the Marie Curie Actions), that encourage industry/academia consortia, and support for industry directly through a Risk-Sharing Finance Facility and Small and Medium Size Enterprises (SMEs) initiatives.

\section{Non-UK-based funding bodies}

The analysis major funders of UK neoplasm research identified five funding bodies based outside the UK ${ }^{8}$. The NIH (National Institutes of Health in the USA), was included in the main analysis due to the apparent wide-ranging coverage of their project and programme funding and its availability to institutions from other countries outside the USA, ranging from public or private, non-profit or for-profit. It is therefore justifiable to conclude that researchers based in the UK may be gaining access to funding streams from the NIH. The remaining foreign funding bodies, which include the Swedish Cancer Society (SCS), the Italian Association for Cancer Research (AIRC), German Cancer Aid (GCA) and Australia's National Health and Medical Research Council (NHMRC), generally limit the amount of funding available to UK researchers/institutions and focus on domestic institutions. For the NHMRC, the general rules of eligibility are that the chief (principal) researchers should be Australian citizens or have permanent residency, however other listed researchers on grants can be of any nationality.

In light of this there are two potential explanations for the inclusion of these foreign funding bodies in the top funders of UK cancer research. One is that the data shows a large amount of international collaboration, where UK researchers are working alongside non-UK researchers, and the funding patterns of all collaborating authors are being picked up by our methods. The other explanation is that researchers based in the UK may have dual institutional affiliations or have undertaken visits abroad and therefore have had some funding from non-UK/EU funding sources.

\section{Summary on complementarities of funding schemes}

This analysis shows that the funding opportunities available to researchers from the funding bodies most active in supporting cancer research in the UK are both overlapping and complementary.

The most overlap is seen with fellowships (including those for early career researchers) and project grants. Studentships are also readily available from a number of these funders, with particular significance lying in the existence of an

\footnotetext{
${ }^{8}$ This is with exception of the European Union FP7 and DG SANCO (EC) which are included in the analysis. 
emphasis, from the UK research councils, on collaborative studentships with industrial partners.

Funders of UK research are particularly complementary to each other in the area of project grants where there are a broad range of different types of scheme available to suit the diverse needs of researchers.

Where there is least opportunity for support is in the later stages of the development spectrum in the area of clinical trials and industrial funding, opportunities are less broad particularly where studies require large amounts of funding over longer term. Exceptions include the Cancer Research UK Phase III Clinical Trial Grants and the MRC/TSB Biomedical Catalyst Developmental Pathways Funding Scheme being the only later stage development funding available from these sources. This implies that, despite the relatively well-funded area of translational studies, there are limitations to the extent to which public funding can provide the necessary funding for bodies of research to be taken towards commercialisation, creating a bottleneck with a smaller number of funders. Furthermore, despite the support for industry-academia links, there seems relatively little direct support for industry research from public funding bodies.

\subsubsection{Researchers use of complementary funding schemes over time}

As described in the previous section, diverse funding schemes are available to UK researchers studying neoplasms. This section uses interviews to explore case studies of how researchers can use a series of funding schemes to develop a line of research over a period of years or even over a decade. As the examples discussed illustrate, this is often necessary to achieve significant breakthroughs. Such breakthroughs may depend on bringing together and sustaining multidisciplinary teams or organisations with diverse missions, meaning that complementary types of funding scheme need to be accessed. Case studies drawing on the experiences of three scientists leading programmes of research are presented here, followed by discussion of common themes.

\section{Case study 2: Research on DNA-repair mechanisms leads to promising drug candidates}

Professor Steve Jackson heads a laboratory at The Gurdon Institute, University of Cambridge, exploring the molecular pathways controlling DNA repair. DNA repair mechanisms are of particular interest because drugs that inhibit the body's cells' ability to repair damaged genes are considered a promising avenue to inhibit cancer growth. Jackson's laboratory has spun out two biotech firms, KuDOS Pharmaceuticals and MISSION Therapeutics, to aid translation of this fundamental biological science into commercial drug programmes. KuDOS attracted more than $£ 40$ million in private sector investment mainly from Venture Capital, before it was acquired for over $£ 120$ million by AstraZeneca in 2005 . The resulting drugs are now in clinical trials.

What kinds of funding allowed Jackson's work to develop to the stage where it attracted large scale commercial investment? 
Jackson, originally from Nottingham, conducted his early work on DNA repair during a post-doc in the USA in the late 1980s where he was funded by a Lucille P. Markey Fellowship and the Howard Hughes Medical Institute as well as the Leukaemia Society of America. He was offered further funding to stay in the USA and might not have returned: "I would not come back to the UK just to be scratching around for smaller grants" Jackson said. One substantial opportunity Jackson pursued was an application for a Cancer Research Campaign programme grant, which he won. This gave Jackson five years of funding. Jackson recalls "[For] me having a starting point where you can hire 2-3 individuals and form a coherent group is important and that was fundamental for me to come back to the UK." Returning to the UK in 1991, Jackson's laboratory was founded and hosted in an institute jointly funded by the Wellcome Trust and the Cancer Research Campaign. In what was then a new funding model, these charities provided research infrastructure, but the hosted scientists had to find their own additional grant funding to support researchers' salaries and the direct costs of their projects. The five-year CRC programme grant allowed Jackson considerable flexibility, which retrospectively can be seen as having allowed him to exploit the emerging promise of DNA repair enzymes: "A lot of good science comes along as unexpected. So way back to $1990-1992$, I had no idea that my lab was going to be focusing on DNA repair... since then...almost all my publications, nearly a couple of hundred, have been on DNA repair and I set up two companies. That was not planned. So I think best science and the best opportunities are often through doing cutting edge studies in a good environment with good people and following your nose as much anything else."

The CRC programme grant became a platform from which to expand the team from 3-4 to around eight scientists. Jackson suggests that "In order to get a grant you need to have preliminary data to have a compelling case for your proposal and [there is] momentum... if you have an existing grant ongoing ... data can be used as starting point for applying to further grants." These extra grants were necessary to expand the group to fully develop the emerging research lines. Through the early and mid-1990s, Jackson's laboratory had additional funding support from the Medical Research Council, the Leverhulme Trust, the A-T Medical Trust, the Kay Kendall Leukaemia Research Fund, European Union funding schemes, and CRC project grants. Each extra grant would cover at least one additional post-doc's salary. Jackson laments these bolt-on awards are more difficult obtain now that Cancer Research UK focuses on distributing Programme grants and no longer offers stand-alone project grants. This makes it difficult to expand existing groups and also it concentrates resources so that some investigators in less well established groups will not get an opportunity to investigate their novel ideas: "we spend $£ 2000$ a day just for reagents and that does not include the salaries. Proper cell and molecular biology science in [the] lab is expensive. UK universities would not be able to do science without external funding... and that is just a matter [of] how science is done now."

As DNA repair became a major area of interest for researchers in the field, Jackson's laboratory has collaborated widely. Co-authorship patterns on Jackson's papers show a particularly strong link with an MRC centre at the University of Sussex. Jackson notes that the MRC investment here was also leveraged in supporting research that led to the founding of KuDOS. However, perhaps 
surprisingly the grants that have facilitated these interactions have generally not been formal collaborative grants. Jackson suggests "[this area of] science isn't like assembling an airbus... where you can plan several years in advance... It is perhaps more preferable from the scientists' point of view that scientists are funded in a manner so that they can afford to collaborate in a spontaneous way". In this manner, dozens of funders can be identified as supporting Jackson's publications mainly by funding his co-authors.

It took almost a decade of activity from Jackson's first paper on DNA repair mechanisms in 1988 to the founding of KuDOS in 1997 and then several more years to the development of pharmaceutical candidates known as PARP inhibitors. During this time not only was much fundamental science explored through an international network, but also the build-up of skills and knowledge in a single location, allowed KuDOS to be founded. Multiple charities and government grants were important to support this work, and CRC continued to support Jackson's work as an early investor in facilities for KuDOS. Jackson has also played an active role in stewarding the commercial R\&D, although as Chief Scientific Officer of KuDOS and now MISSION, he is concerned not to allow industrial influence to shape the scientific agenda.

\section{Case study 3: Controversial hypotheses yield results with long term support}

Fran Balkwill is a Professor of Cancer Biology at Barts Cancer Institute, Queen Mary University of London, where she leads the Centre for Cancer and Inflammation and the Cytokine and Cancer group. Balkwill's research began at the Imperial Cancer Research Fund laboratories at Lincoln's Inn Fields, London (now Cancer Research UK's London Research Institute). Balkwill has long been interested in translational research, exploring the therapeutic potential of cytokines such as tumour necrosis factor (TNF) and interferons.

Until the early 1990s TNF was largely characterised as an anti-cancer agent (Balkwill 2009). However during this period it began to be appreciated, by Balkwill's group and others that under certain circumstances TNF may actually encourage tumour growth. Balkwill recalls a "eureka moment" when she took inspiration from a talk about the application of anti-TNF to treat Rheumatoid Arthritis, in which clinical activity was first shown in 1994: "I heard Mark Feldmann talk about how anti-TNF inhibited inflammatory cytokine production, inhibited the leukocyte infiltrate into the joint, inhibited angiogensis and inhibited matrix metalloproteinases, and I thought, well that's what you want to do in the tumour microenvironment". At the time this was a particularly controversial view as prior evidence dating back to the $19^{\text {th }}$ century suggested that TNF would inhibit cancer and subsequent clinical findings leading to the approval of a TNF agent for the treatment of soft tissue sarcoma in 1999 (Balkwill 2009). Balkwill's unconventional work in the TNF field was nonetheless supported by ICRF (support which continued when it became Cancer Research UK) and she persevered with a trajectory of work on anti-TNF molecules. Balkwill's work has supported the

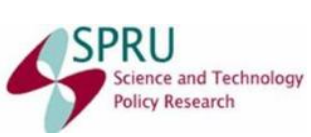


clinical testing of anti-TNFs as anti-cancer agents, such as infliximab (Remicade, developed by Centocor), found other cytokine drug targets such as IL- 6 and the chemokine receptor CCR4 and developed more fundamental understanding of cancers by showing the potential of some cytokines to have a dual role in tumour development, thus revealing the complexity of the tumour microenvironment.

What kind of funding allowed Balkwill's work to develop to produce clinically applicable knowledge?

During the 20 years Balkwill spent at the ICRF at Lincoln Inn Fields in London there was little need to gain access to external funding. However, when Balkwill moved to the Barts Cancer Institute at Queen Mary University of London (then the ICRF Translational Oncology Laboratory) it was necessary to find diverse sources of funding to ensure her group of scientists and their work could be sustained. One of the first things Balkwill did at her new lab was to persuade a commercial partner, Centocor, to fund the preclinical and clinical studies of infliximab, in cancer patients, a stream of funded work that continued for nearly a decade. Balkwill continues to receive funding from diversity of public and private sources reflecting the different streams of research relating to anti-TNF and IL-6 molecules and their clinical applications, to understanding the underlying molecular mechanisms surrounding the activity of TNF and IL- 6 as well understanding the cytokine network in the tumour microenvironment as a whole. She also sees it as vital to have diverse funding support and currently holds both a Cancer Research UK Programme grant and an ERC Advanced Researcher grant.

While such large grants are important for sustaining the group, sub-projects can still require additional support as interesting opportunities arise. Balkwill recalls "I had a Cancer Research UK PhD student who came up with an unexpected observation about a chemokine receptor (CCR4) in renal cancer. I got a Discovery Committee grant from Cancer Research UK for 2 years for target validation. During that time, we were able to access a small molecule inhibitor for CCR4 in a collaboration with AstraZeneca". It is hoped that this drug, previously a shelved Asthma drug-candidate can be repurposed if further grant support is forthcoming. Subsequently this avenue of research targeting CCR4 also has proved of interest to Affitech, a Danish biotech firm identified by CRT, who helped to form a licensing and R\&D agreement which secured Queen Mary's University further research funding to support Affitech - Balkwill said "we've had now 2 years of very substantial industry funding from them for pre-clinical studies of anti-CCR4 antibodies".

\section{Case study 4: Gene hunting provides new cancer diagnostics}

Ian Tomlinson is a Professor of Molecular and Population Genetics, Group Head/PI and Consultant Clinical Geneticist based at the Wellcome Trust Centre for Human Genetics, Oxford. Tomlinson's research is particularly concerned with genetic predispositions to cancers such as colorectal and renal cancers. His research has revealed a series of genetic mutations in several genes related to rare hereditary cancers. During the period 1995 to 1998, as a post-doctoral researcher, Tomlinson carried out several studies to determine the genetic basis for Peutz-

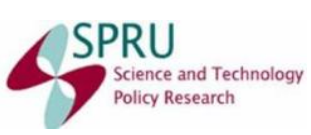


Jeghers syndrome (PJS), a rare inherited disorder causing hyperpigmented patches of mucosa and gastrointestinal polyps that present elevated malignancy risk. Beginning with genetic linkage studies, Tomlinson worked to gain an insight into the pathway linking PJS with a predisposition to cancers, and to find the genetic locus of PJS (see Hemminki, Tomlinson et al. 1997). The discovery of this specific locus rapidly allowed for the development of improved cancer screening for PJS patients (Tomlinson and Houlston 1997).

Tomlinson's work on PJS was facilitated by two grants, from the European Commission and the other from the Cancer Research Campaign (CRC). These grants covered different aspects of the PJS but presented complementary research themes. Tomlinson recalls: "the actual aims of [the grants] were interrelated, as it happened, doing slightly different things within that disease but very much linked". In addition to the work on PJS, the group also received a small exploratory pump priming award working on breast tumours ${ }^{9}$ from the Medical Research Council (MRC).

\section{Cross cutting themes}

The above case studies illustrate how multiple grants and funders are often necessary to generate a breakthrough such as developing a new diagnostic or advancing a new class of drug molecule to the clinic.

In the past, Cancer Research UK has been able to sustain researchers in its own laboratories allowing them over decades to develop controversial hypotheses into applied therapeutic programmes, however this is beginning to change as across the UK scientists are required to raise external grants.

Three interviewees discuss the particular importance of Cancer Research UK programme grants as a basis from which to grow larger teams by gaining additional grants. Although more than one suggested their institution would encourage them to look for other funding rather than Cancer Research UK (due to lack of overheads paid), Cancer Research UK grants were suggested by two of the three to be a "mark of quality" for peer reviewers and that helped to attract further grants. Also it was noted that a "core" grant provided the opportunity to generate the data necessary to develop interesting proposals to win further grants. In this way a core grant can help an investigator to rapidly build on promising research to develop a stronger research line.

Having multiple grants at the same time is also important for hedging and providing for continuity of the group, as there is a constant battle to keep postdoctoral researchers funded. Tomlinson suggests a key aim is to avoid sharp peaks or troughs in group size and instead aim for "a gentle undulation". He noted "There's always a potential crisis looming two years down the road for certain members of the group. In Oxford we are quite lucky in that people with their own fellowships, for example, are not that uncommon....they help to even out the natural cycle of [larger] grants."

\footnotetext{
${ }^{9}$ Pump priming awards are generally given out to research aimed at developing new ideas with promising potential. 
Jackson also emphasised the importance of individual laboratories having multiple sources of funding: "I think it is a sort of healthy way in running a lab where you have at least two funding bodies contributing" although he (and other interviewees) emphasised that they should not be funded twice to do the same work. Balkwill also suggested it was important not to be over-reliant on one funding source, recalling "When I moved from CR-UK we probably had 11-12 people on Cancer Research UK grants, by the time it got to my previous one it was three... they just don't give that kind of money any more, it's also got so expensive". Balkwill was awarded a further Cancer Research UK Programme Grant in 2013 with four posts granted. Balkwill currently aims to have no more than $25-30 \%$ of her group reliant on one funding source.

How do interviewees see today's UK funding environment?

All four interviewed scientists suggested that the UK funding system was better, from their perspective, than the USA. Jackson suggests scientists studying cancer in the UK have a good choice of funders, including charities, government research councils and European funding opportunities. The situation at the present time is better than the USA where key grant funders such as the NIH are having their budgets cut.

Balkwill's perspective on the funding environment for cancer research in the UK is generally positive, exceeding the system much of the rest of Europe and the USA. In the latter case, part of the strength of the UK funding environment is the introduction of the European Research Council.

Jackson also agreed that the UK funding environment remains strong while the US was experiencing funding cuts. Tomlinson observes that the access to funding in the UK is relatively healthy, with a more "streamlined" process of grant applications, than is the case in other countries, particularly the USA. However, Tomlinson also suggests that there are frequently significant changes in directions in the types of research receiving funding. These changes are, perhaps, inevitable, and he likens them to "fashion in science" or "oscillations in how exciting various sorts of research are perceived". Jackson is also concerned that politics is driving UK research councils to be more prescriptive, and focusing too much on seeking economic benefits: "The reality is that innovation and opportunities, and ensuing healthcare companies, in most cases come out from doing good science in a good environment not through translational science in a very applied institute." 


\subsection{Scientometric analysis: Diversity in neoplasm research}

\subsubsection{Diversity of funders and host organisations across scientific disciplines}

One of the questions posed in the proposal was 'Which funders support more interdisciplinary research?' We considered that this question did not sufficiently address any of the three overarching questions posed by Cancer Research-UK, and so we therefore address a different question more related to the main thrust of the analysis - namely, 'which funders support more diversity in research'.

We investigate the diversity of research that funders and research host organisations support using the ISI journal subject categories for the journals their publications are in as a proxy for the disciplines they contribute to. We analyse three dimensions of diversity (Rafols et al. 2012, Stirling 1998) as shown in Figure 3.21.

- Variety: the number of scientific disciplines a funder or research host organisation contributes to by supporting or producing publications. Higher numbers indicate higher variety.

- Balance: the distribution of the publications a funder or research host organisation supported or produced across the scientific disciplines. A value of 1 would indicate each subject category has the same number of publications.

- Disparity: the cognitive distance between the scientific disciplines a funder (host organisation) contributed to by supporting (producing) publications. A value of 1 indicates the highest disparity between supported publications' subject categories, and 0 indicates no disparity.

Figure 3.21: Conceptualisation of diversity measures (based on Rafols and Meyer 2010 and Stirling 1998).

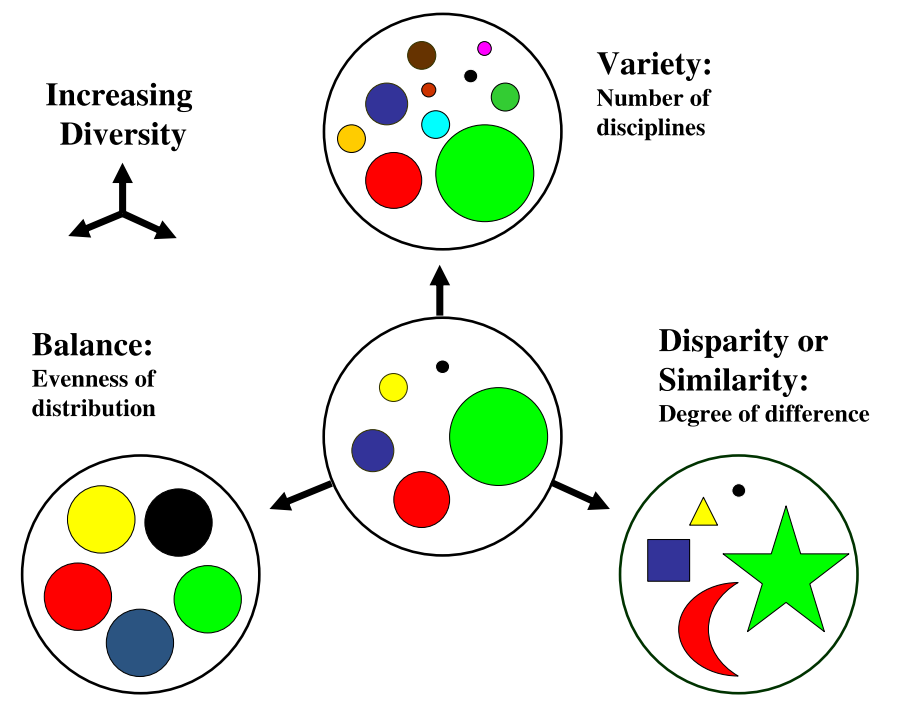


We also consider an 'aggregate' indicator of diversity that considers both the proportion of publications in each discipline and the cognitive distance between those disciplines. This indicator is the Rao-Stirling diversity index (Stirling 2007), with a value closer to 1 indicating higher diversity.

We assessed the diversity of publications for the major funders and research host organisations that contributed to at least $2 \%$ of the UK neoplasm research output in 2011. Table 3.15 and Table 3.16 report the results respectively for funders (based on the 3,914 publications with funder acknowledgements) and research host organisations (based on 7,510 publications in the total sample).

In Table 3.15, Variety refers to the number of subject categories that publications appear in, counted in absolute terms (no threshold) and counting only those subject categories where $>1 \%$ of an organisations' research output is published. When counting without threshold restrictions, the Departments of Health (including NHS and NIHR) and Cancer Research UK support the greatest variety of subject categories, although when a $1 \%$ threshold is imposed, the BBSRC and EPSRC support more diverse research. The BBSRC and EPSRC also perform well in terms of providing a balance in the support they give to publications across subject categories.

In terms of the disparity of publications supported, the Departments of Health and Cancer Research UK support the most disparate publications overall, but the most disparate are not supported often, so that when a threshold is imposed, BBSRC performs more strongly. The BBSRC is also the funder supporting the most diverse publications. Of the top nine funders, Leukaemia and Lymphoma Research and Breakthrough Breast Cancer support the least diverse publications.

Table 3.16 shows diversity measures for the 17 top research host organisations. University College London and Oxford University publish across the highest variety of journal subject categories, however the majority of these do not contribute to $>1 \%$ of the host's output. The University of Sheffield and King's College London contribute $>1 \%$ of their publications to the widest variety of subject categories.

The Universities of Birmingham, Liverpool and Cardiff are the most balanced in terms of their contributions to subject categories, whereas the Institute of Cancer Research is the least balanced.

Disparity in the types of subject categories published in is highest in absolute terms for University College London and King's College London, but when a $1 \%$ threshold is imposed, Liverpool and King's College London publish in the most disparate range of publications. The University of Liverpool is the most diverse of the top 17 research host organisations based on the Rao-Stirling diversity index, and the Institute for Cancer Research is the least diverse. 
Table 3.15: UK funding organisations acknowledged in at least $2 \%$ of the publication sample $(\mathbf{N}=3,914)$ and diversity measures on the supported research (funders sorted by total number of publications)

\begin{tabular}{|c|c|c|c|c|c|c|c|}
\hline & \multirow[b]{3}{*}{ Organisation } & \multicolumn{6}{|c|}{ Diversity Measures } \\
\hline & & \multicolumn{2}{|c|}{ Variety } & \multirow{2}{*}{ Balance } & \multicolumn{2}{|c|}{ Disparity } & \multirow{2}{*}{$\begin{array}{l}\text { Rao-Stirling } \\
\text { diversity }\end{array}$} \\
\hline & & $\begin{array}{c}\text { No } \\
\text { threshold }\end{array}$ & $\begin{array}{c}1 \% \\
\text { threshold }\end{array}$ & & $\begin{array}{c}\text { No } \\
\text { threshold }\end{array}$ & $\begin{array}{c}1 \% \\
\text { threshold }\end{array}$ & \\
\hline 1) & Cancer Research UK & 75 & 16 & 0.682 & 0.818 & 0.623 & 0.557 \\
\hline 2) & Departments of Health (including NHS and NIHR) & 78 & 19 & 0.701 & 0.827 & 0.687 & 0.612 \\
\hline 3) & Medical Research Council (MRC) & 66 & 23 & 0.747 & 0.801 & 0.669 & 0.587 \\
\hline 4) & Wellcome Trust & 44 & 19 & 0.783 & 0.726 & 0.622 & 0.537 \\
\hline 5) & Leukaemia and Lymphoma Research & 28 & 15 & 0.683 & 0.639 & 0.543 & 0.437 \\
\hline 6) & Breakthrough Breast Cancer & 24 & 13 & 0.712 & 0.629 & 0.468 & 0.407 \\
\hline 7) & Breast Cancer Campaign & 29 & 18 & 0.756 & 0.721 & 0.663 & 0.518 \\
\hline 8) & Engineering and Physical Science Research Council (EPSRC) & 42 & 25 & 0.871 & 0.765 & 0.633 & 0.554 \\
\hline 9) & Biotechonolgy and Biological Sciences Research Council (BBSRC) & 41 & 28 & 0.884 & 0.789 & 0.746 & 0.691 \\
\hline
\end{tabular}

Notes. The threshold refers to the proportion of publications in a given SC. Figures from Rafols and Meyer (2010) and Stirling (1998).

Table 3.16: UK organisations contributing to at least $2 \%$ of the publication sample $(\mathrm{N}=7,510)$ diversity measures on the produced research output (organisation sorted by total number of publications)

\begin{tabular}{|c|c|c|c|c|c|c|c|}
\hline & \multirow[b]{3}{*}{ Organisation } & \multicolumn{6}{|c|}{ Diversity Measures } \\
\hline & & \multicolumn{2}{|c|}{ Variety } & \multirow[t]{2}{*}{ Balance } & \multicolumn{2}{|c|}{ Disparity } & \multirow{2}{*}{$\begin{array}{l}\text { Rao-Stirling } \\
\text { diversity }\end{array}$} \\
\hline & & $\begin{array}{c}\text { No } \\
\text { threshold }\end{array}$ & $\begin{array}{c}1 \% \\
\text { threshold }\end{array}$ & & $\begin{array}{c}\text { No } \\
\text { threshold }\end{array}$ & $\begin{array}{c}1 \% \\
\text { threshold }\end{array}$ & \\
\hline 1) & $\begin{array}{l}\text { Institute of Cancer Research, London } \\
\text { (including the following organisation or name variations: Royal Marsden NHS Foundation } \\
\text { Trust) }\end{array}$ & 52 & 19 & 0.667 & 0.765 & 0.669 & 0.537 \\
\hline 2) & $\begin{array}{l}\text { University College London, London } \\
\text { (including the following organisation or name variations: University College London } \\
\text { Hospitals NHS Trust, UCL Cancer Institute, National Hospital for Neurology and } \\
\text { Neurosurgery, Royal Free Hampstead NHS Trust) }\end{array}$ & 83 & 23 & 0.788 & 0.829 & 0.685 & 0.679 \\
\hline 3) & $\begin{array}{l}\text { Imperial College, London } \\
\text { (including the following organisation or name variations: Imperial College Healthcare NHS } \\
\text { Trust, Hammersmith Hospital, Charing Cross Hospital) }\end{array}$ & 66 & 21 & 0.741 & 0.784 & 0.666 & 0.608 \\
\hline 4) & $\begin{array}{l}\text { University of Cambridge, Cambridge } \\
\text { (including the following organisation or name variations: Cancer Research UK Cambridge } \\
\text { Research Institute, Hutchison/MRC Research Centre, Cambridge Biomedical Research } \\
\text { Centre, Addenbrooke's University Hospital, Cambridge University Hospital NHS Trust) }\end{array}$ & 64 & 24 & 0.750 & 0.784 & 0.654 & 0.598 \\
\hline 5) & $\begin{array}{l}\text { Oxford University, Oxford } \\
\text { (including the following organisation or name variations: Gray Institute, John Radcliffe } \\
\text { Hospital, Oxford Radcliffe Hospitals NHS Trust, United Kingdom) }\end{array}$ & 74 & 21 & 0.736 & 0.818 & 0.676 & 0.618 \\
\hline 6) & $\begin{array}{l}\text { King's College London, London } \\
\text { (including the following organisation or name variations: King's College Hospital NHS Trust, } \\
\text { Guy's and St Thomas NHS Trust, Guy's Hospital, Western General Hospital) }\end{array}$ & 69 & 27 & 0.787 & 0.822 & 0.750 & 0.672 \\
\hline 7) & University of Leeds, Leeds & 67 & 22 & 0.750 & 0.816 & 0.709 & 0.642 \\
\hline
\end{tabular}




\begin{tabular}{|c|c|c|c|c|c|c|c|}
\hline & \multirow[b]{3}{*}{ Organisation } & \multicolumn{6}{|c|}{$\begin{array}{l}\text { Diversity Measures } \\
\end{array}$} \\
\hline & & \multicolumn{2}{|c|}{ Variety } & \multirow[t]{2}{*}{ Balance } & \multicolumn{2}{|c|}{ Disparity } & \multirow{2}{*}{$\begin{array}{l}\text { Rao-Stirling } \\
\text { diversity }\end{array}$} \\
\hline & & $\begin{array}{c}\text { No } \\
\text { threshold }\end{array}$ & $\begin{array}{c}1 \% \\
\text { threshold }\end{array}$ & & $\begin{array}{c}\text { No } \\
\text { threshold }\end{array}$ & $\begin{array}{c}1 \% \\
\text { threshold }\end{array}$ & \\
\hline & $\begin{array}{l}\text { (including the following organisation or name variations: Leeds } \\
\text { Cancer Research UK Centre, St James's University Hospital, Leeds } \\
\text { Teaching Hospitals NHS Trust, Leeds General Infirmary) }\end{array}$ & & & & & & \\
\hline 8) & $\begin{array}{l}\text { University of Manchester, Manchester } \\
\text { (including the following organisation or name variations: Cancer } \\
\text { Research UK Paterson Institute, Christie Hospital) }\end{array}$ & 58 & 24 & 0.755 & 0.790 & 0.709 & 0.609 \\
\hline 9) & $\begin{array}{l}\text { Queen Mary University of London, London } \\
\text { (including the following organisation or name variations: St } \\
\text { Bartholomew's Hospital) }\end{array}$ & 47 & 20 & 0.726 & 0.781 & 0.670 & 0.545 \\
\hline 10) & $\begin{array}{l}\text { University of Edinburgh, Edinburgh } \\
\text { (including the following organisation or name variations: Edinburgh } \\
\text { Cancer Research Centre, Western General Hospital) }\end{array}$ & 49 & 24 & 0.793 & 0.782 & 0.740 & 0.634 \\
\hline 11) & $\begin{array}{l}\text { University of Glasgow, Glasgow } \\
\text { (including the following organisation or name variations: NHS } \\
\text { Greater Glasgow and Clyde, Gartnaval General Hospital, Glasgow } \\
\text { Royal Infirmary, Western Infirmary) }\end{array}$ & 57 & 26 & 0.784 & 0.770 & 0.721 & 0.615 \\
\hline 12) & $\begin{array}{l}\text { University of Newcastle, Newcastle Upon Tyne } \\
\text { (including the following organisation or name variations: Northern } \\
\text { Institute of Cancer Research, Newcastle upon Tyne Hospitals NHS } \\
\text { Trust, Royal Victoria Infirmary, Freeman Hospital) }\end{array}$ & 45 & 18 & 0.747 & 0.753 & 0.717 & 0.601 \\
\hline 13) & University of Birmingham, Birmingham & 53 & 23 & 0.822 & 0.780 & 0.694 & 0.631 \\
\hline 14) & $\begin{array}{l}\text { University of Sheffield, Sheffield } \\
\text { (including the following organisation or name variations: Weston } \\
\text { Park Hospital, Sheffield Children's NHS Trust, Sheffield Teaching } \\
\text { Hospitals NHS Trust) }\end{array}$ & 59 & 28 & 0.816 & 0.817 & 0.767 & 0.683 \\
\hline 15) & $\begin{array}{l}\text { Cardiff University, Cardiff } \\
\text { (including the following organisation or name variations: Velindre } \\
\text { NHS Trust) }\end{array}$ & 52 & 24 & 0.817 & 0.775 & 0.741 & 0.647 \\
\hline 16) & $\begin{array}{l}\text { University of Southampton, Southampton } \\
\text { (including the following organisation or name variations: } \\
\text { Southampton General Hospital) }\end{array}$ & 40 & 24 & 0.805 & 0.783 & 0.741 & 0.641 \\
\hline 17) & University of Liverpool, Liverpool & 51 & 23 & 0.821 & 0.806 & 0.790 & 0.716 \\
\hline
\end{tabular}

Notes. The threshold refers to the proportion of publications in a given SC. Figures from Rafols and Meyer (2010) and Stirling (1998). 


\subsubsection{Diversity of funders and host organisations across medical areas}

We further explore the diversity of funders and research host organisations by analysing the variety of, and balance across, the domains of research they support or contributed to using MeSH qualifiers. MeSH qualifiers further qualify the meaning of MeSH descriptors, and unlike MeSH descriptors, which operate in a hierarchical tree structure, MeSH qualifiers can be used to categorise all publications with MeSH codes.

All MeSH qualifiers assigned to at least $10 \%$ of the publications in the total sample are reported in Figure 3.22. These show that pathology and genetics are the most frequently occurring, followed by surgery (green), diagnosis (blue) and drug therapy (orange).

Figure 3.23 profiles the major UK funders according to the most frequent $\mathrm{MeSH}$ qualifiers, i.e. those assigned to at least $10 \%$ of the publications in the total sample. As in the previous analyses on the MeSH descriptors, we report the proportion of publications each funder supported in a domain in relation to the overall number of publications the funder supported (above) and the comparison between the observed and the expected value of publication number (below) the methodology used here is similar to that described in section 3.5.3. It is worth noting that the qualifiers represented in the radar charts describe on average $\sim 90 \%$ of the publications supported by these organisations, but each radar chart does not completely cover the scope of outputs.

Major UK funders strongly focus on supporting studies in genetics and pathology which each account for between $20 \%$ and $40 \%$ of the publications they support. The exception is the EPSRC for which a very small proportion of the supported publications are assigned to genetics. However, more than $20 \%$ of the publications supported by EPSRC are in diagnostics while the remaining major UK funders supported a lower proportion of publications in this domain. Unlike the overall sample, major UK funders neglect surgery. 
Figure 3.22: Top MeSH qualifiers (at least $~ 10 \%$ of the publications) assigned to the descriptors included in the "Neoplasms" branch of the MeSH tree (more than one qualifier can be assigned to a publication; 817 publications have no assigned qualifiers)

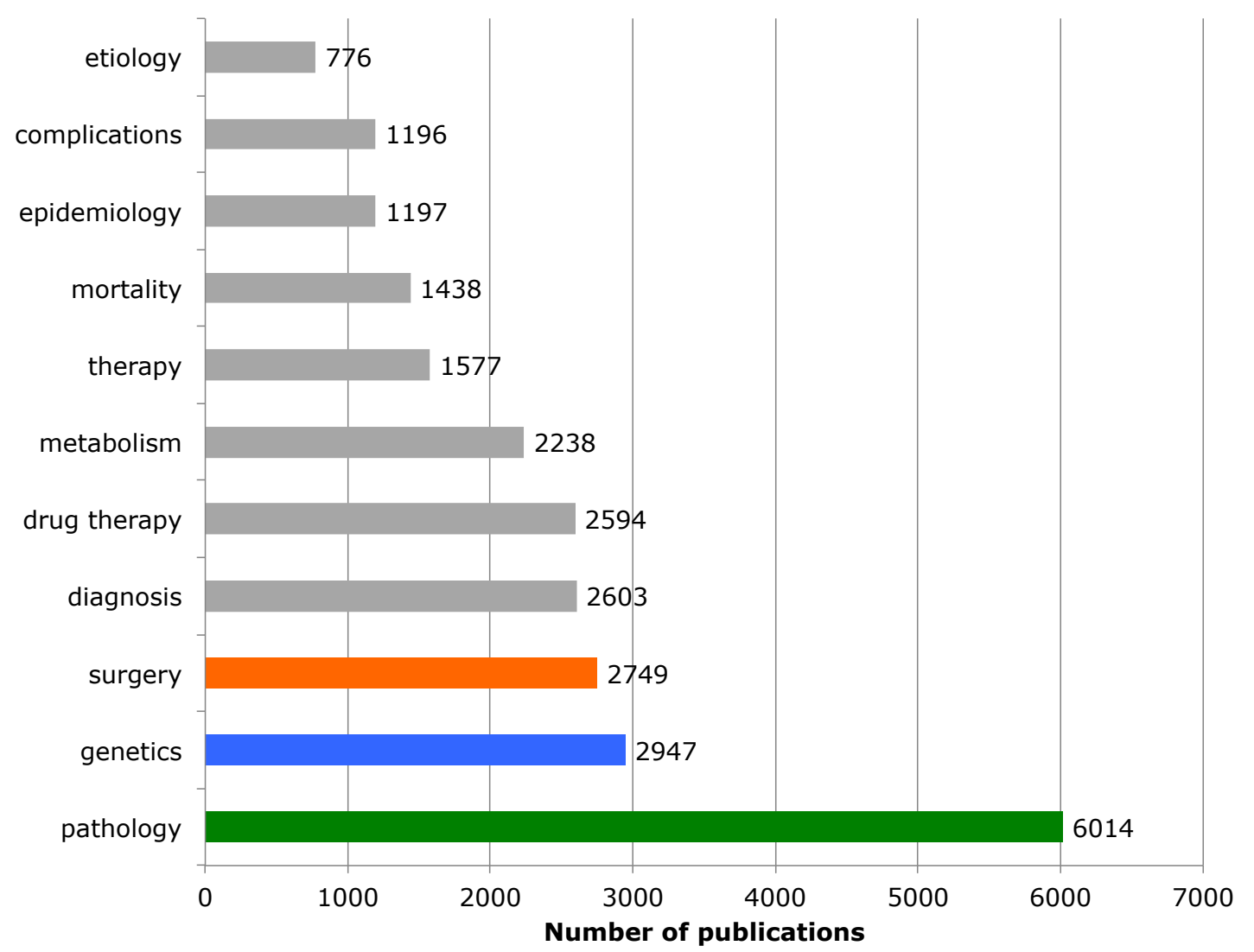


Figure 3.23a: Major UK funders in "Neoplasms" area and proportion of publications across the top MeSH qualifiers (90.6\% of the 3,914 publications with acknowledgements to funders are classified using the reported MeSH qualifiers). Upper charts report the percentage of funders' total publications in different domains. Right charts report whether funders are more $(>1.0)$ or less $(<1.0)$ active in each domain than expected.

1. Cancer Research UK
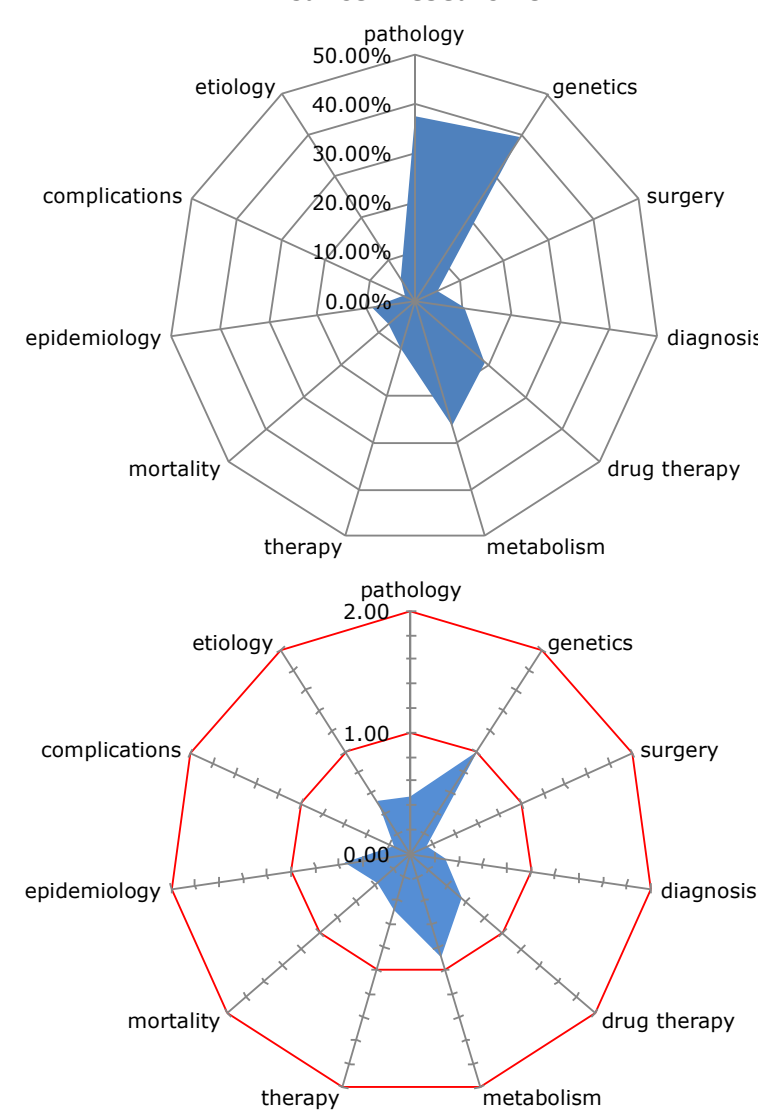

2. Departments of Health

(including NHS and NIHR)
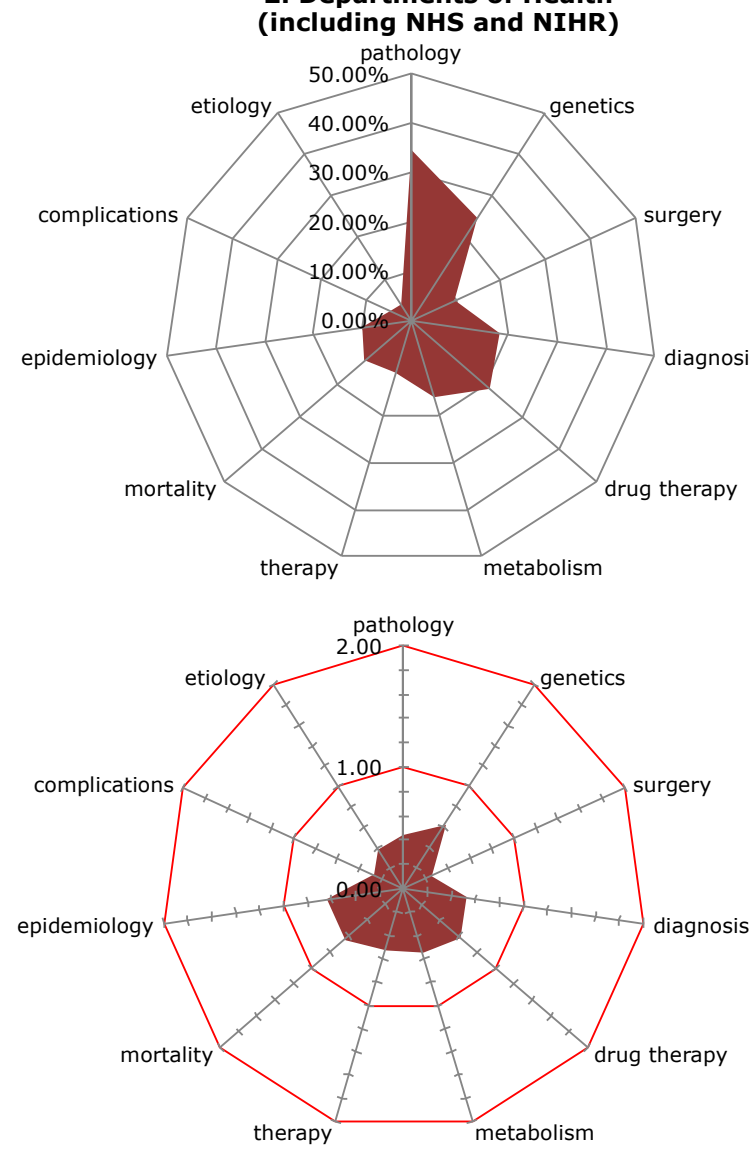

3. Medical Research Council (MRC)
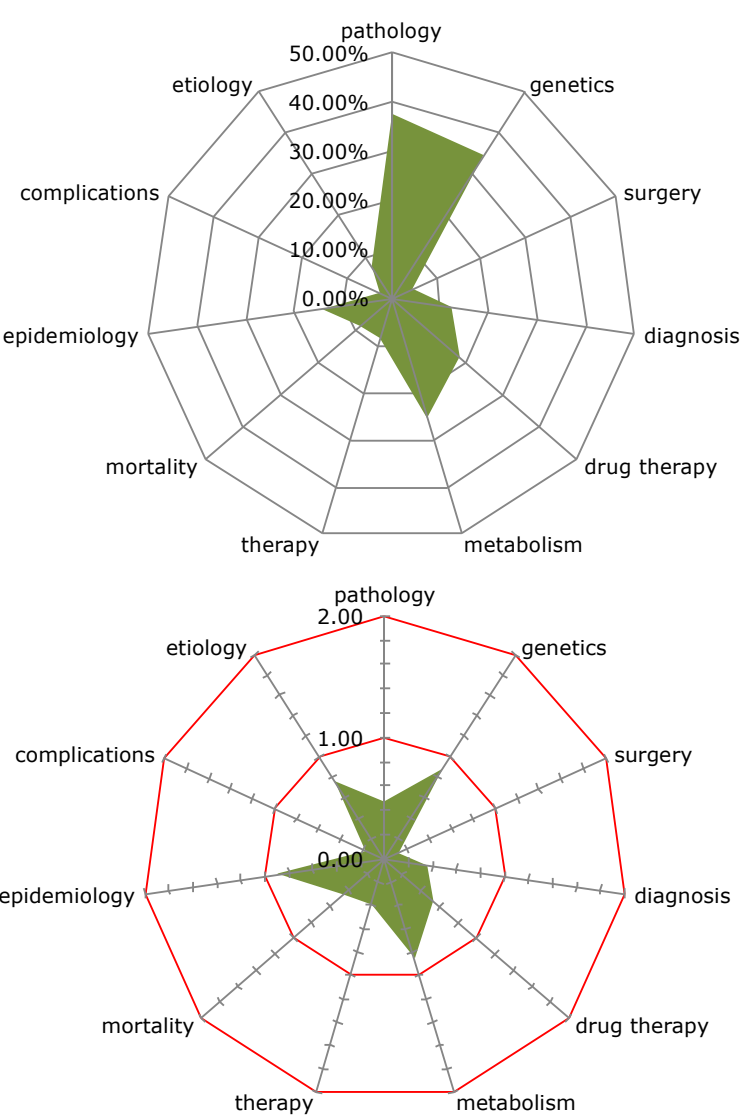
Figure 3.23b: Major UK funders in "Neoplasms" area and proportion of publications across the top MeSH qualifiers (90.6\% of the 3,914 publications with acknowledgements to funders are classified using the reported MeSH qualifiers). Upper charts report the percentage of funders' total publications in different domains. Right charts report whether funders are more $(>1.0)$ or less $(<1.0)$ active in each domain than expected.
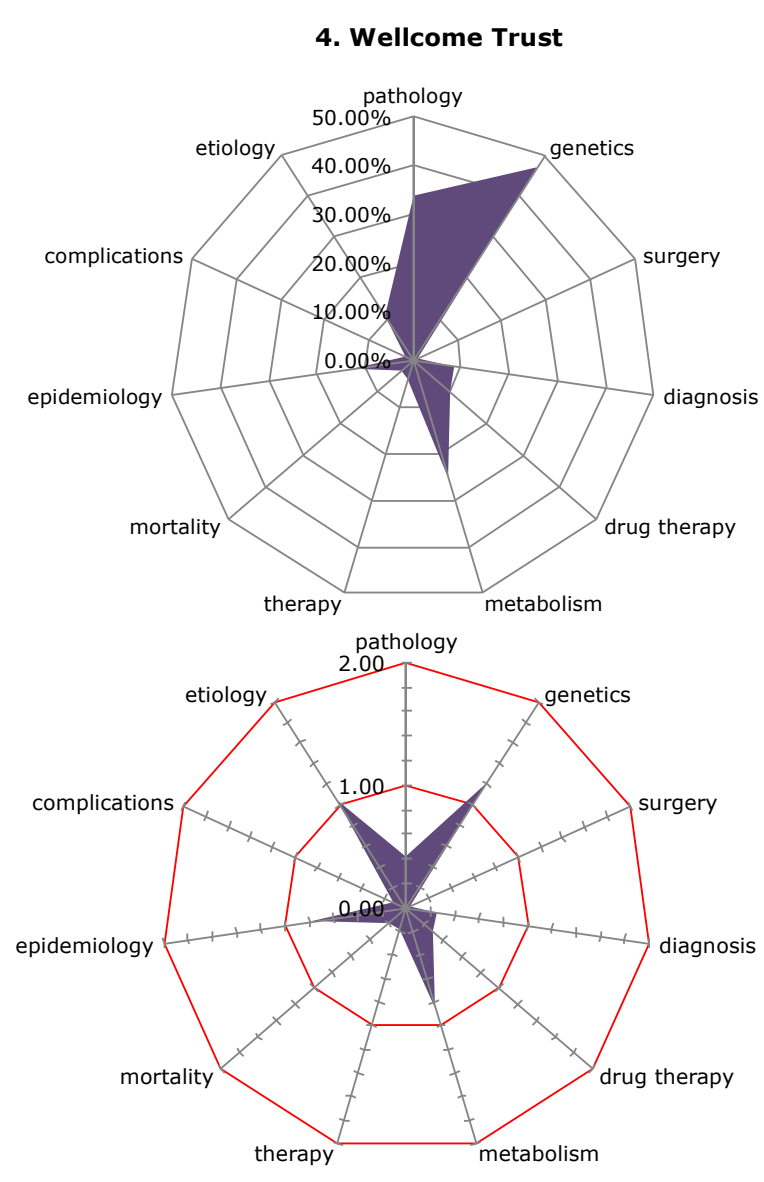

\section{Breakthrough Breast Cancer}
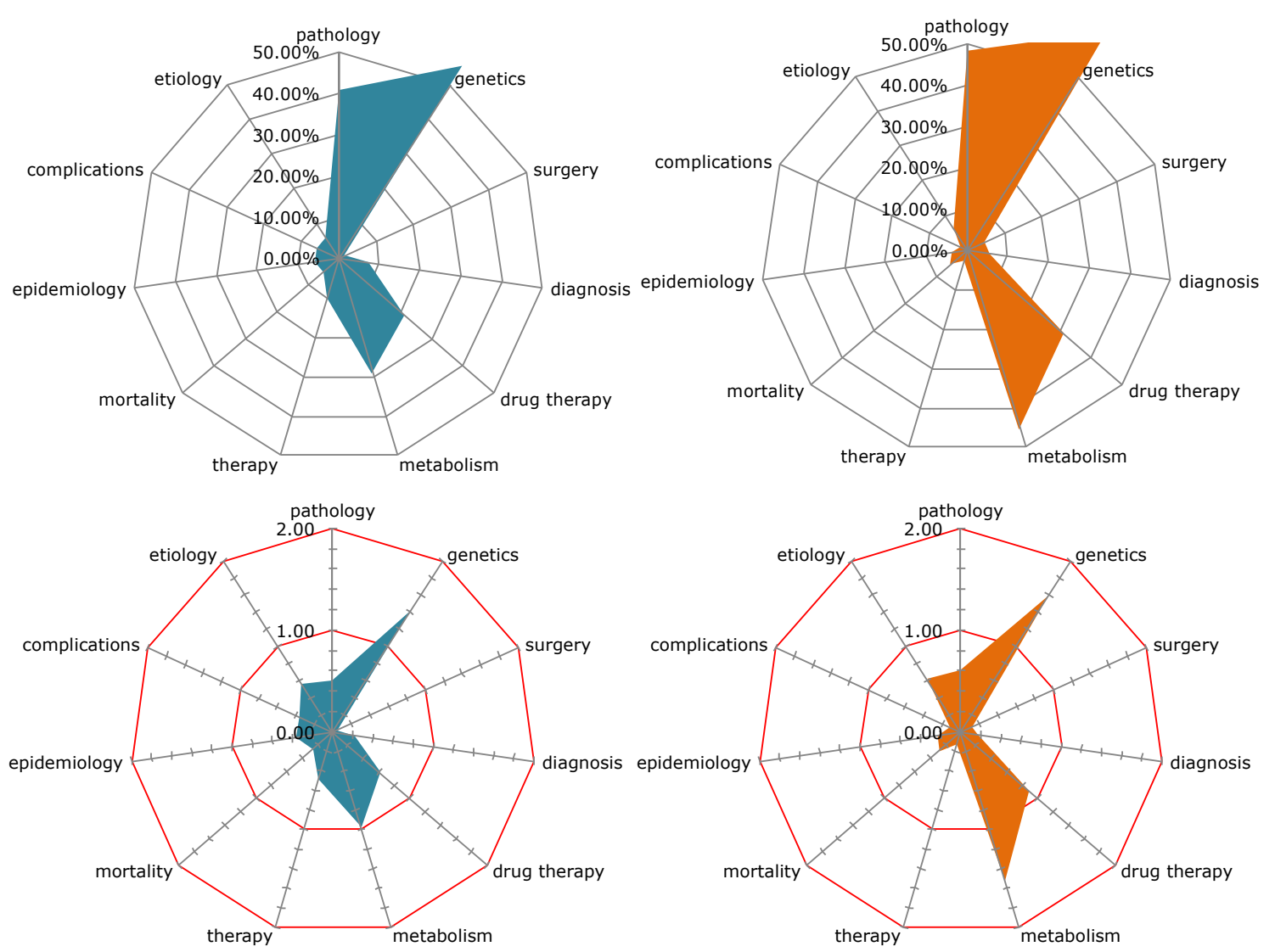
Figure 3.23c: Major UK funders in "Neoplasms" area and proportion of publications across the top MeSH qualifiers (90.6\% of the 3,914 publications with acknowledgements to funders are classified using the reported MeSH qualifiers). Upper charts report the percentage of funders' total publications in different domains. Right charts report whether funders are more $(>1.0)$ or less $(<1.0)$ active in each domain than expected.

\section{Breast Cancer Campaign}
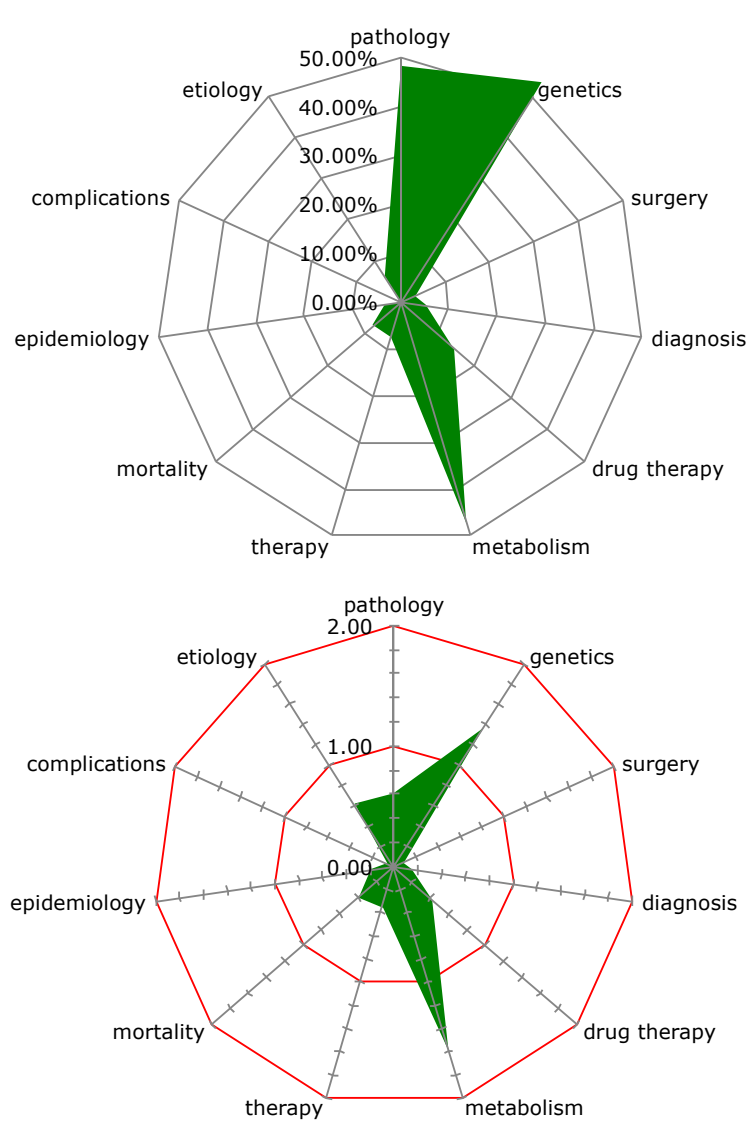

8. Engineering and Physical Science Research Council (EPSRC)
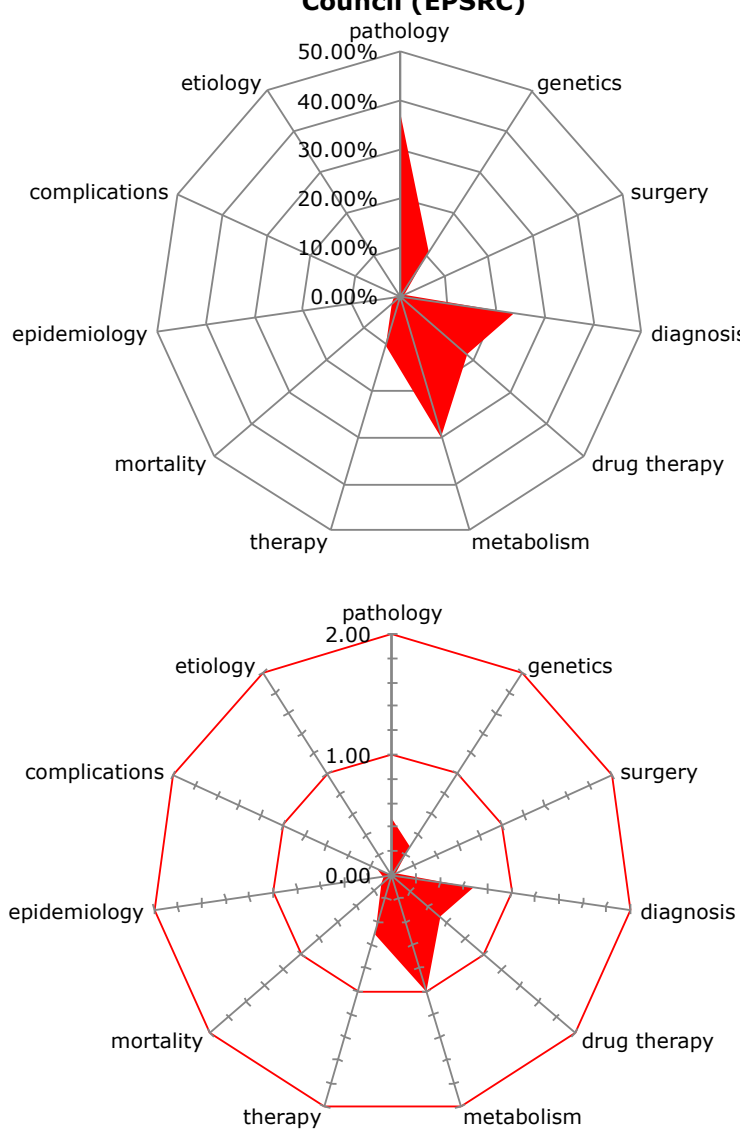

9. Biotechonolgy and Biological Sciences Research Council (BBSRC)
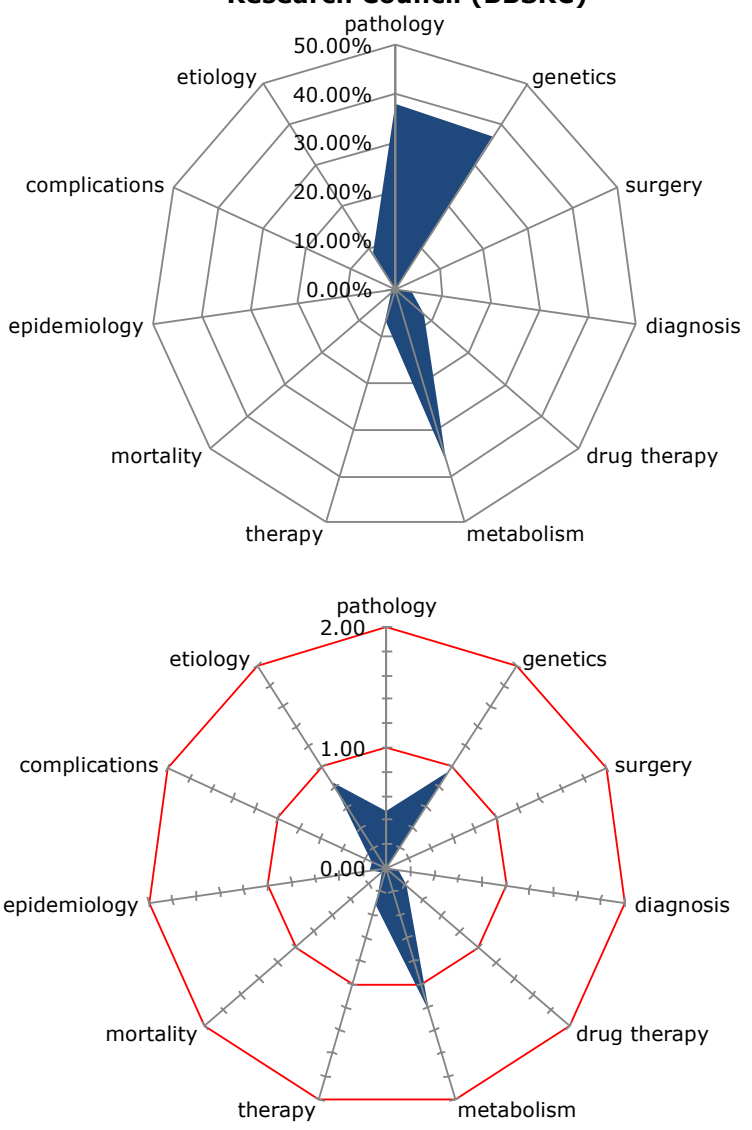


\subsection{Scientometric analysis: Additional perspectives}

In addition to the main questions of the study - related to the interdependency, complementarity and diversity of UK funders and research host organisations, there was opportunity to explore the following questions:

a) Which funders support rapidly cited works?

b) Which funders support international collaborations or public/private collaborations?

\subsubsection{Funder, host organisations and highly-cited publications}

In order to identify the most highly cited publications it is necessary to first control for the different propensity of authors working in different subject categories to cite recent publications. To achieve this, each subject category was considered individually to identify the top $5 \%$ and top $10 \%$ papers by citation (Table 3.17 ). Those papers acknowledging research funding were more highly represented in these top cited papers, suggesting that there is a significant correlation between research funding acknowledgement and citation (Table 3.18).

Table 3.17: Citations and publications $(\mathrm{N}=7,510)$

\section{Number of highly-cited publications \\ Top-5\% cited within a subject category \\ Top-10\% cited within a subject category}

Top-5\% cited normalised by citation rate in subject categories Top-10\% cited normalised by citation rate in subject categories

Note. Since a journal may be assigned to more than one SC, an article is considered highly cited if ranks in the top-cited articles of at least one of the SCs assigned to its journal.

Table 3.18: Funding acknowledgements and highly cited publications (citations count normalised within ISI WoS subject categories)

\begin{tabular}{|c|c|c|c|}
\hline Type of publication & $\begin{array}{l}\text { Number of } \\
\text { publications }\end{array}$ & $\begin{array}{c}\text { Number of } \\
\text { publications within } \\
\text { the top- } 5 \% \text { cited }\end{array}$ & $\begin{array}{c}\text { Number of } \\
\text { publications within } \\
\text { the top-10\% cited }\end{array}$ \\
\hline $\begin{array}{l}\text { Publication with funding data in } \\
\text { acknowledgement sections }\end{array}$ & 3,914 & $\begin{array}{c}268 \\
(6.8 \%)\end{array}$ & $\begin{array}{c}532 \\
(13.6 \%)\end{array}$ \\
\hline $\begin{array}{l}\text { Publications with no } \\
\text { acknowledgements sections or } \\
\text { no funding data in } \\
\text { acknowledgement sections }\end{array}$ & 3,596 & $\begin{array}{c}107 \\
(3.0 \%)\end{array}$ & $\begin{array}{c}219 \\
(6.9 \%)\end{array}$ \\
\hline $\begin{array}{l}\text { Notes. The test on proportion sup } \\
\text { shows that publications acknowl } \\
\text { publications without such funding } \\
\text { cited articles according to the cit } \\
\text { of publication. }\end{array}$ & $\begin{array}{l}\text { sults do not } \\
\text { count norma }\end{array}$ & $\begin{array}{l}\text { d by SCs or focusing } \\
\text { d byen one consider }\end{array}$ & $\begin{array}{l}\mathrm{p}<0.001 \text {, respectively) } \\
\text { highly cited than those } \\
\text { e top-5\% and top-10\% } \\
\text { analysis on 'article' typ }\end{array}$ \\
\hline
\end{tabular}

Table 3.19 shows which research host organisations have the highest citations in their papers. To avoid results that are sensitive to publications that are outliers with very high numbers of citations coming from organisations with very few publications, only those major UK host organisations, i.e. those contributing to at 
least $2 \%$ of the publications sample, are considered. The results show that while the Institute for Cancer Research and Oxford University have the highest number of publications in the top 5\% cited (57 and 46 respectively), when the results are normalised by the size of the publication output of the top organisations, Cardiff University and Queen Mary University have a higher proportion of their output in the top $5 \%$ cited $(8.9 \%$ and $8.67 \%$ respectively vs. $8.15 \%$ for the Institute of Cancer Research and $8.39 \%$ for Oxford University).

Table 3.20 contains the results of the equivalent analysis for funders. It shows that although Cancer Research UK and the Departments of Health support more papers in the top 5\% cited (60 and 59 respectively) than other funders, several funders support a proportionally higher percentage of highly cited publications including Breakthrough Breast Cancer (10\%), Wellcome Trust (7.9\%), MRC (7.8\%) and BBSRC $(7.6 \%)$ - compared with $6.3 \%$ for Cancer Research UK and $6.6 \%$ for DH. Notably, the EPSRC did not fund neoplasms research papers in the highly cited category in this period.

Figure 3.24 explores the relationship between the number of funders acknowledged in publications and the relative proportion of highly cited (top-5\%) publications. As the number of funders increase the proportion of highly cited paper increases up to 6-7 funders when the relationships shows decreasing returns. ${ }^{10}$ The results confirm prior research that suggests papers supported by more funders are more highly cited (Lewison and Dawson 1998).

Table 3.19: UK organisations contributing to at least $2 \%$ of the publication sample $(\mathrm{N}=7,510)$ and number of highly cited (top-5\%) publications

\begin{tabular}{|c|c|c|c|}
\hline & Organisation & $\begin{array}{l}\text { Number of } \\
\text { publications } \\
\text { within the top- } \\
5 \% \text { cited }\end{array}$ & $\begin{array}{l}\text { Number of publications } \\
\text { within the top- } 5 \% \\
\text { cited out the number of } \\
\text { publications produced }\end{array}$ \\
\hline 1) & $\begin{array}{l}\text { Institute of Cancer Research, London } \\
\text { (including the following organisation or name variations: } \\
\text { Royal Marsden NHS Foundation Trust) }\end{array}$ & 57 & $8.15 \%$ \\
\hline 2) & $\begin{array}{l}\text { Oxford University, Oxford } \\
\text { (including the following organisation or name variations: Gray } \\
\text { Institute, John Radcliffe Hospital, Oxford Radcliffe Hospitals NHS } \\
\text { Trust, United Kingdom) }\end{array}$ & 46 & $8.39 \%$ \\
\hline 3) & $\begin{array}{l}\text { University of Cambridge, Cambridge } \\
\text { (including the following organisation or name variations: Cancer } \\
\text { Research UK Cambridge Research Institute, Hutchison/MRC Research } \\
\text { Centre, Cambridge Biomedical Research Centre, Addenbrooke's } \\
\text { University Hospital, Cambridge University Hospital NHS Trust) }\end{array}$ & 41 & $7.37 \%$ \\
\hline 4) & $\begin{array}{l}\text { University of Leeds, Leeds } \\
\text { (including the following organisation or name variations: Leeds } \\
\text { Cancer Research UK Centre, St James's University Hospital, Leeds } \\
\text { Teaching Hospitals NHS Trust, Leeds General Infirmary) }\end{array}$ & 33 & $8.35 \%$ \\
\hline 5) & $\begin{array}{l}\text { Imperial College, London } \\
\text { (including the following organisation or name variations: Imperial } \\
\text { College Healthcare NHS Trust, Hammersmith Hospital, Charing Cross } \\
\text { Hospital) }\end{array}$ & 32 & $5.64 \%$ \\
\hline 6) & $\begin{array}{l}\text { University College London, London } \\
\text { (including the following organisation or name variations: University } \\
\text { College London Hospitals NHS Trust, UCL Cancer Institute, National } \\
\text { Hospital for Neurology and Neurosurgery, Royal Free Hampstead } \\
\text { NHS Trust) }\end{array}$ & 30 & $4.76 \%$ \\
\hline 7) & $\begin{array}{l}\text { University of Manchester, Manchester } \\
\text { (including the following organisation or name variations: Cancer } \\
\text { Research UK Paterson Institute, Christie Hospital) }\end{array}$ & 30 & $7.71 \%$ \\
\hline 8) & $\begin{array}{l}\text { King's College London, London } \\
\text { (including the following organisation or name variations: King's } \\
\text { College Hospital NHS Trust, Guy's and St Thomas NHS Trust, Guy's } \\
\text { Hospital, Western General Hospital) }\end{array}$ & 28 & $5.29 \%$ \\
\hline 9) & Queen Mary University of London, London & 28 & $8.67 \%$ \\
\hline
\end{tabular}

${ }^{10} \mathrm{~A}$ more detailed analysis that controls for additional variables is required to draw explanatory conclusions here. This is beyond the scope of the present study. 


\begin{tabular}{|c|c|c|c|}
\hline & Organisation & $\begin{array}{l}\text { Number of } \\
\text { publications } \\
\text { within the top- } \\
5 \% \text { cited }\end{array}$ & $\begin{array}{l}\text { Number of publications } \\
\text { within the top- } 5 \% \\
\text { cited out the number of } \\
\text { publications produced }\end{array}$ \\
\hline & $\begin{array}{l}\text { (including the following organisation or name variations: St } \\
\text { Bartholomew's Hospital) }\end{array}$ & & \\
\hline 10) & $\begin{array}{l}\text { University of Edinburgh, Edinburgh } \\
\text { (including the following organisation or name variations: Edinburgh } \\
\text { Cancer Research Centre, Western General Hospital) }\end{array}$ & 21 & $7.45 \%$ \\
\hline 11) & $\begin{array}{l}\text { Cardiff University, Cardiff } \\
\text { (including the following organisation or name variations: Velindre } \\
\text { NHS Trust) }\end{array}$ & 17 & $8.90 \%$ \\
\hline 12) & $\begin{array}{l}\text { University of Glasgow, Glasgow } \\
\text { (including the following organisation or name variations: NHS } \\
\text { Greater Glasgow and Clyde, Gartnaval General Hospital, Glasgow } \\
\text { Royal Infirmary, Western Infirmary) }\end{array}$ & 15 & $5.40 \%$ \\
\hline 13) & $\begin{array}{l}\text { University of Sheffield, Sheffield } \\
\text { (including the following organisation or name variations: Weston Park } \\
\text { Hospital, Sheffield Children's NHS Trust, Sheffield Teaching Hospitals } \\
\text { NHS Trust) }\end{array}$ & 15 & $7.08 \%$ \\
\hline 14) & $\begin{array}{l}\text { University of Southampton, Southampton } \\
\text { (including the following organisation or name variations: } \\
\text { Southampton General Hospital) }\end{array}$ & 13 & $7.65 \%$ \\
\hline 15) & University of Liverpool, Liverpool & 12 & $7.23 \%$ \\
\hline 16) & $\begin{array}{l}\text { University of Newcastle, Newcastle Upon Tyne } \\
\text { (including the following organisation or name variations: Northern } \\
\text { Institute of Cancer Research, Newcastle upon Tyne Hospitals NHS } \\
\text { Trust, Royal Victoria Infirmary, Freeman Hospital) }\end{array}$ & 12 & $4.94 \%$ \\
\hline 17) & University of Birmingham, Birmingham & 9 & $4.11 \%$ \\
\hline
\end{tabular}

Notes. Only organizations contributing to at least $2 \%$ of publications are considered. The rank changes marginally when one considers the top-10\% cited articles according to the citation count within SCs or the top- $5 \%$ and top- $10 \%$ cited articles according to the citation count normalised by SCs.

Table 3.20: UK funding organisations acknowledged in at least $2 \%$ of the publication sample ( $N=3,914)$ and number of highly cited (top-5\%) publications

\begin{tabular}{|c|c|c|c|}
\hline & Organisation & $\begin{array}{l}\text { Number of } \\
\text { publications } \\
\text { within the } \\
\text { top- } 5 \% \text { cited }\end{array}$ & $\begin{array}{l}\text { Number of publications } \\
\text { within the top- } 5 \% \text { cited } \\
\text { out the number of } \\
\text { publications produced }\end{array}$ \\
\hline 1) & Cancer Research UK & 60 & $6.3 \%$ \\
\hline 2) & Department of Health (including NHS and NIHR) & 59 & $6.6 \%$ \\
\hline 3) & Medical Research Council (MRC) & 37 & $7.8 \%$ \\
\hline 4) & Wellcome Trust & 16 & $7.9 \%$ \\
\hline 5) & Breakthrough Breast Cancer & 11 & $10.0 \%$ \\
\hline 6) & Biotechonolgy and Biological Sciences Research Council (BBSRC) & 7 & $7.6 \%$ \\
\hline 7) & Leukaemia and Lymphoma Research & 7 & $5.1 \%$ \\
\hline 8) & Breast Cancer Campaign & 6 & $6.3 \%$ \\
\hline 9) & Engineering and Physical Science Research Council (EPSRC) & 0 & $0.0 \%$ \\
\hline
\end{tabular}

We also investigated the citations patterns by following the conceptualisations of funders and publications adopted in Section 3.5. We report in Table 3.21 the number of highly cited papers by categories of funder and relative compositions. We considered both top-5\% and top-10\% highly cited paper as in the previous analysis. Those publications simultaneously supported by all types of funders $(\mathrm{g})$ have a higher proportion of highly cited publications ( $\sim 12 \%$ and $\sim 22 \%$ when considering the top- $5 \%$ and top- $10 \%$ cited). Conversely, those publications supported only by minor funders (b) report a lower proportion of publications ( $\sim 5.2 \%$ and $\sim 10.3 \%$ when considering the top-5\% and top-10\% cited) of highly cited publications. 
Figure 3.24 Number of funders and relative proportion of highly cited (top-5\%) publications.

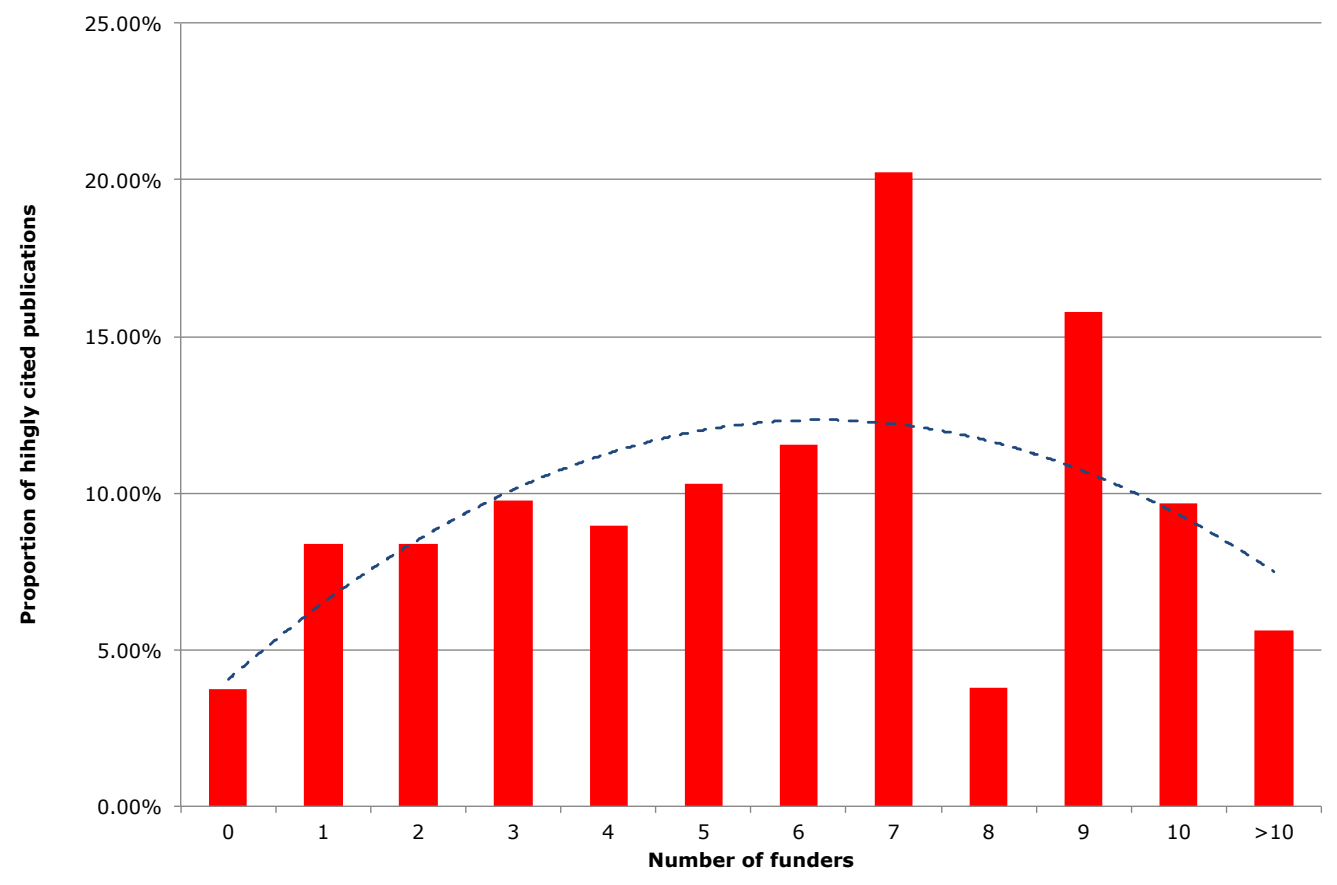

We analysed the proportion of highly cited papers by combining the different categories in three overlapping groups as in previous analyses, i.e. publications supported at least by one major UK funder $(a+d+f+g)$, publications supported by at least one minor UK funder $(b+d+e+g)$, and publications supported at least by one 'other' funder or industry $(c+e+f+g)$. The results are reported in the lower part of Table 3.21. Publications supported by at least one minor UK funder are less likely to be highly cited papers ( $\sim 7 \%$ and $\sim 15 \%$ when considering the top-5\% and top-10\% cited) compared to those publications involving at least one major UK funder ( $~ 9 \%$ and $\sim 17 \%$ when considering the top-5\% and top-10\% cited) and those publications involving at least one industrial actor or any other funders not falling in the previous categories ( $\sim 11 \%$ and $\sim 19 \%$ when considering the top-5\% and top- $10 \%$ cited).

Table 3.21: Funders compositions and number of highly cited publications

\begin{tabular}{|c|c|c|c|c|}
\hline $\begin{array}{l}\text { Publications } \\
\text { supported by }\end{array}$ & Subset & $\begin{array}{l}\text { Number of } \\
\text { publications }\end{array}$ & $\begin{array}{c}\text { Number of } \\
\text { publications within } \\
\text { the top-5\% cited }\end{array}$ & $\begin{array}{c}\text { Number of } \\
\text { publications within } \\
\text { the top-10\% cited }\end{array}$ \\
\hline Major UK funders & $a$ & $\begin{array}{c}697 \\
(17.8 \%)\end{array}$ & $\begin{array}{c}60 \\
(8.6 \%)\end{array}$ & $\begin{array}{c}102 \\
(14.6 \%)\end{array}$ \\
\hline Minor UK funders & c & $\begin{array}{c}426 \\
(10.9 \%)\end{array}$ & $\begin{array}{c}22 \\
(5.2 \%)\end{array}$ & $\begin{array}{c}44 \\
(10.3 \%)\end{array}$ \\
\hline $\begin{array}{l}\text { Other funders and } \\
\text { industry }\end{array}$ & c & $\begin{array}{c}1,344 \\
(34.3 \%)\end{array}$ & $\begin{array}{c}139 \\
(10.3 \%)\end{array}$ & $\begin{array}{c}232 \\
(17.3 \%)\end{array}$ \\
\hline $\begin{array}{l}\text { Major-Minor UK } \\
\text { funders }\end{array}$ & $d$ & $\begin{array}{c}483 \\
(12.3 \%)\end{array}$ & $\begin{array}{c}26 \\
(5.4 \%)\end{array}$ & $\begin{array}{c}55 \\
(11.4 \%)\end{array}$ \\
\hline $\begin{array}{l}\text { Minor UK funder-Other } \\
\text { funders and industry }\end{array}$ & e & $\begin{array}{c}166 \\
(4.2 \%)\end{array}$ & $\begin{array}{c}14 \\
(8.4 \%)\end{array}$ & $\begin{array}{c}32 \\
(19.2 \%)\end{array}$ \\
\hline Major UK funders - & $\mathrm{f}$ & 433 & 47 & 92 \\
\hline $\begin{array}{l}\text { Office of } \\
\text { Health } \\
\text { Economics } \\
\text { Research\&Consulting }\end{array}$ & & 87 & & \\
\hline
\end{tabular}




\begin{tabular}{|c|c|c|c|c|}
\hline $\begin{array}{l}\text { Publications } \\
\text { supported by }\end{array}$ & Subset & $\begin{array}{c}\text { Number of } \\
\text { publications }\end{array}$ & $\begin{array}{c}\text { Number of } \\
\text { publications within } \\
\text { the top-5\% cited }\end{array}$ & $\begin{array}{c}\text { Number of } \\
\text { publications within } \\
\text { the top-10\% cited }\end{array}$ \\
\hline $\begin{array}{l}\text { Other funders and } \\
\text { industry }\end{array}$ & & $(11.1 \%)$ & $(10.8 \%)$ & $(21.2 \%)$ \\
\hline $\begin{array}{l}\text { Major and minor UK } \\
\text { funders - Other } \\
\text { funders and industry }\end{array}$ & $g$ & $\begin{array}{c}365 \\
(9.3 \%)\end{array}$ & $\begin{array}{c}44 \\
(12.0 \%)\end{array}$ & $\begin{array}{c}80 \\
(21.9 \%)\end{array}$ \\
\hline $\begin{array}{l}\text { Major UK funders } \\
\text { (extended) }\end{array}$ & $a+d+f+g$ & $\begin{array}{c}1,978 \\
(50.5 \%)\end{array}$ & $\begin{array}{c}177 \\
(8.9 \%)\end{array}$ & $\begin{array}{c}329 \\
(16.6 \%)\end{array}$ \\
\hline $\begin{array}{l}\text { Minor UK funders } \\
\text { (extended) }\end{array}$ & $b+d+e+g$ & $\begin{array}{c}1,441 \\
(36.8 \%)\end{array}$ & $\begin{array}{c}106 \\
(7.4 \%)\end{array}$ & $\begin{array}{c}211 \\
(14.6 \%)\end{array}$ \\
\hline $\begin{array}{l}\text { Other funders } \\
\text { (extended) }\end{array}$ & $c+e+f+g$ & $\begin{array}{c}2,308 \\
(59.0 \%)\end{array}$ & $\begin{array}{c}245 \\
(10.6 \%)\end{array}$ & $\begin{array}{c}437 \\
(18.9 \%)\end{array}$ \\
\hline
\end{tabular}

In addition, we assess the citations of publications supported by industry (i.e. those publications with at least one author with an industrial affiliation or acknowledging at least one industrial funder. The results, reported in Table 3.22, show that industry supported publications are significantly over-represented in the top $5 \%$ and top $10 \%$ of highly cited publications compared to the sample of publications not involving industrial actors as funders or as host organisations.

Table 3.22: Involvement of industrial actors and highly cited publications (citations count normalised within ISI WoS subject categories)

\begin{tabular}{lccc}
\hline $\begin{array}{l}\text { Type of } \\
\text { publication }\end{array}$ & $\begin{array}{c}\text { Number of } \\
\text { publications }\end{array}$ & $\begin{array}{c}\text { Number of publications } \\
\text { within the top-5\% cited }\end{array}$ & $\begin{array}{c}\text { Number of publications } \\
\text { within the top-10\% cited }\end{array}$ \\
\hline $\begin{array}{l}\text { Industry } \\
\text { involvement }\end{array}$ & 1,084 & 104 & 190 \\
& $(14.4 \%)$ & $(9.6 \%)$ & $(17.5 \%)$ \\
$\begin{array}{l}\text { No-industry } \\
\text { involvement }\end{array}$ & 6,426 & 271 & 561 \\
& $(85.6 \%)$ & $(4.2 \%)$ & $(8.6 \%)$
\end{tabular}

Notes. The test on proportion supported (chi2 $=56.52, p<0.001$ and chi2 $=79.76, p<0.001$, respectively) that publications involving industry are significantly more cited than those not involving industrial actors. Results do not change focusing the analysis on 'scientific article' type of publication.

\subsubsection{Funder, host organisations and intensity of international collaboration}

The average number of countries that research host organisations collaborate with per publication is shown in Table 3.23. The results show that the University of Cambridge, Imperial College London and Oxford University support research that includes notably more international research links than other organisations.

Table 3.24 shows the results of the equivalent analysis for research funders, which show that the Wellcome Trust supports research that is notably more collaborative with international partners than that of other funders.

Table 3.25 reports the average number of countries and the relative standard deviation for the publication sample classified according to the conceptualisation of funders adopted in Section 3.5. Publications supported exclusively by major or minor UK funders $(a, b$, and $d)$ involves on average 1.3 countries. Publications 
supported by other funders or industrial actors involve on average a larger number of countries (3.6). As above, we investigated the involvement of international actors in publications by combining the different categories in three overlapping groups, i.e. publications supported at least by one major UK funder $(a+d+f+g)$, publications supported by at least one minor UK funder $(b+d+e+g)$, and publications supported at least by one 'other' funder or industry $(c+e+f+g)$. The first two groups of publications involves on average 2 different countries per publications. This suggests that major UK funders are not more likely to support researchers to form international links compared to minor UK funders.

Table 3.23: UK organisations contributing to at least $2 \%$ of the publication sample $(N=7,510)$ and international collaborations

\begin{tabular}{|c|c|c|c|c|c|}
\hline & \multirow[t]{2}{*}{ Organisation } & \multicolumn{4}{|c|}{ Number of countries } \\
\hline & & Mean & Std.Dev. & Min & Max \\
\hline 1) & $\begin{array}{l}\text { University of Cambridge, Cambridge } \\
\text { (including the following organisation or name variations: Cancer } \\
\text { Research UK Cambridge Research Institute, Hutchison/MRC Research } \\
\text { Centre, Cambridge Biomedical Research Centre, Addenbrooke's } \\
\text { University Hospital, Cambridge University Hospital NHS Trust) }\end{array}$ & 3.4 & 3.9 & 1 & 25 \\
\hline 2) & $\begin{array}{l}\text { Imperial College, London } \\
\text { (including the following organisation or name variations: Imperial } \\
\text { College Healthcare NHS Trust, Hammersmith Hospital, Charing Cross } \\
\text { Hospital) }\end{array}$ & 3.4 & 3.7 & 1 & 25 \\
\hline 3) & $\begin{array}{l}\text { Oxford University, Oxford } \\
\text { (including the following organisation or name variations: Gray } \\
\text { Institute, John Radcliffe Hospital, Oxford Radcliffe Hospitals NHS } \\
\text { Trust, United Kingdom) }\end{array}$ & 3.2 & 3.6 & 1 & 25 \\
\hline 4) & $\begin{array}{l}\text { Institute of Cancer Research, London } \\
\text { (including the following organisation or name variations: Royal } \\
\text { Marsden NHS Foundation Trust) }\end{array}$ & 2.7 & 3.3 & 1 & 23 \\
\hline 5) & $\begin{array}{l}\text { University of Newcastle, Newcastle Upon Tyne } \\
\text { (including the following organisation or name variations: Northern } \\
\text { Institute of Cancer Research, Newcastle upon Tyne Hospitals NHS } \\
\text { Trust, Royal Victoria Infirmary, Freeman Hospital) }\end{array}$ & 2.6 & 4.1 & 1 & 25 \\
\hline 6) & $\begin{array}{l}\text { University of Sheffield, Sheffield } \\
\text { (including the following organisation or name variations: Weston Park } \\
\text { Hospital, Sheffield Children's NHS Trust, Sheffield Teaching Hospitals } \\
\text { NHS Trust) }\end{array}$ & 2.6 & 3.6 & 1 & 23 \\
\hline 7) & $\begin{array}{l}\text { University of Leeds, Leeds } \\
\text { (including the following organisation or name variations: Leeds } \\
\text { Cancer Research UK Centre, St James's University Hospital, Leeds } \\
\text { Teaching Hospitals NHS Trust, Leeds General Infirmary) }\end{array}$ & 2.5 & 3.0 & 1 & 25 \\
\hline 8) & $\begin{array}{l}\text { University of Glasgow, Glasgow } \\
\text { (including the following organisation or name variations: NHS } \\
\text { Greater Glasgow and Clyde, Gartnaval General Hospital, Glasgow } \\
\text { Royal Infirmary, Western Infirmary) }\end{array}$ & 2.4 & 3.2 & 1 & 25 \\
\hline 9) & $\begin{array}{l}\text { King's College London, London } \\
\text { (including the following organisation or name variations: King's } \\
\text { College Hospital NHS Trust, Guy's and St Thomas NHS Trust, Guy's } \\
\text { Hospital, Western General Hospital) }\end{array}$ & 2.4 & 2.9 & 1 & 23 \\
\hline 10) & University of Liverpool, Liverpool & 2.3 & 3.1 & 1 & 25 \\
\hline 11) & $\begin{array}{l}\text { University of Manchester, Manchester } \\
\text { (including the following organisation or name variations: Cancer } \\
\text { Research UK Paterson Institute, Christie Hospital) }\end{array}$ & 2.3 & 2.5 & 1 & 20 \\
\hline 12) & $\begin{array}{l}\text { Queen Mary University of London, London } \\
\text { (including the following organisation or name variations: St } \\
\text { Bartholomew's Hospital) }\end{array}$ & 2.2 & 2.4 & 1 & 18 \\
\hline 13) & $\begin{array}{l}\text { Cardiff University, Cardiff } \\
\text { (including the following organisation or name variations: Velindre } \\
\text { NHS Trust) }\end{array}$ & 2.2 & 2.1 & 1 & 14 \\
\hline 14) & $\begin{array}{l}\text { University of Edinburgh, Edinburgh } \\
\text { (including the following organisation or name variations: } \\
\text { Edinburgh Cancer Research Centre, Western General } \\
\text { Hospital) }\end{array}$ & 2.2 & 2.2 & 1 & 17 \\
\hline 15) & $\begin{array}{l}\text { University College London, London } \\
\text { (including the following organisation or name variations: University } \\
\text { College London Hospitals NHS Trust, UCL Cancer Institute, National } \\
\text { Hospital for Neurology and Neurosurgery, Royal Free Hampstead } \\
\text { NHS Trust) }\end{array}$ & 2.1 & 2.0 & 1 & 17 \\
\hline 16) & University of Birmingham, Birmingham & 2.0 & 1.7 & 1 & 14 \\
\hline 17) & $\begin{array}{l}\text { University of Southampton, Southampton } \\
\text { (including the following organisation or name variations: } \\
\text { Southampton General Hospital) }\end{array}$ & 2.0 & 2.6 & 1 & 20 \\
\hline
\end{tabular}


Table 3.24: UK funding organisations acknowledged in at least $2 \%$ of the publication sample $(\mathrm{N}=3,914)$ and international collaborations

\begin{tabular}{llccc}
\hline Organisation & \multicolumn{3}{c}{ Number of countries } \\
& Mean & Std.Dev. & Min & Max \\
\hline 1) Wellcome Trust & 3.1 & 3.4 & 1 & 17 \\
2) Medical Research Council (MRC) & 2.6 & 2.9 & 1 & 20 \\
3) Breakthrough Breast Cancer & 2.5 & 3.1 & 1 & 20 \\
4) Cancer Research UK & 2.5 & 3.0 & 1 & 23 \\
5) Breast Cancer Campaign & 2.5 & 3.5 & 1 & 20 \\
6) Department of Health (including NHS and NIHR) & 2.2 & 2.8 & 1 & 23 \\
7) Leukaemia and Lymphoma Research & 1.6 & 0.9 & 1 & 5 \\
8) Biotechonolgy and Biological Sciences Research Council (BBSRC) & 1.6 & 0.8 & 1 & 4 \\
9) Engineering and Physical Science Research Council (EPSRC) & 1.5 & 0.8 & 1 & 4 \\
\hline
\end{tabular}

Table 3.25: Funders composition and international collaborations.

\begin{tabular}{|c|c|c|c|c|}
\hline $\begin{array}{l}\text { Publications } \\
\text { supported by }\end{array}$ & Subset & $\begin{array}{l}\text { Number of } \\
\text { publications }\end{array}$ & $\begin{array}{l}\text { Mean number of } \\
\text { countries per } \\
\text { publication }\end{array}$ & $\begin{array}{c}\text { Std.Dev. of the } \\
\text { number of countries } \\
\text { per publication }\end{array}$ \\
\hline Major UK funders & $\bar{a}$ & $\begin{array}{c}697 \\
(17.8 \%)\end{array}$ & 1.3 & 1.1 \\
\hline Minor UK funders & c & $\begin{array}{c}426 \\
(10.9 \%)\end{array}$ & 1.3 & 0.9 \\
\hline $\begin{array}{l}\text { Other funders and } \\
\text { industry }\end{array}$ & c & $\begin{array}{c}1,344 \\
(34.3 \%)\end{array}$ & 3.6 & 2.8 \\
\hline Major-Minor UK funders & $d$ & $\begin{array}{c}483 \\
(12.3 \%)\end{array}$ & 1.3 & 0.7 \\
\hline $\begin{array}{l}\text { Minor UK funder-Other } \\
\text { funders and industry }\end{array}$ & e & $\begin{array}{c}166 \\
(4.2 \%)\end{array}$ & 2.7 & 2.3 \\
\hline $\begin{array}{l}\text { Major UK funders -Other } \\
\text { funders and industry }\end{array}$ & $f$ & $\begin{array}{c}433 \\
(11.1 \%)\end{array}$ & 2.9 & 2.8 \\
\hline $\begin{array}{l}\text { Major and minor UK } \\
\text { funders- Other funders } \\
\text { and industry }\end{array}$ & $g$ & $\begin{array}{c}365 \\
(9.3 \%)\end{array}$ & 3.4 & 3.7 \\
\hline $\begin{array}{l}\text { Major UK funders } \\
\text { (extended) }\end{array}$ & $a+d+f+g$ & $\begin{array}{c}1,978 \\
(50.5 \%)\end{array}$ & 2.1 & 2.3 \\
\hline $\begin{array}{l}\text { Minor UK funders } \\
\text { (extended) }\end{array}$ & $b+d+e+g$ & $\begin{array}{c}1,441 \\
(36.8 \%)\end{array}$ & 2.0 & 2.3 \\
\hline $\begin{array}{l}\text { Other funders } \\
\text { (extended) }\end{array}$ & $c+e+f+g$ & $\begin{array}{c}2,308 \\
(59.0 \%)\end{array}$ & 3.4 & 2.6 \\
\hline
\end{tabular}

\subsection{Future research}

This study has opened up some areas that may warrant further investigation. Firstly, it is clear that a high proportion of UK neoplasms research is supported by a large number of relatively small funders. The funding priorities of these funders and the ways in which they seek to complement the efforts of the larger funders is relatively unknown. Secondly, are such small funders a prominent contributor to other fields of biomedical research, or are they more strongly clustered in neoplasms? Finally, it is clear that a high proportion of UK research is in some way associated with international collaborations and funding from overseas. How would 
cuts to the budget of UK or overseas funders impact the structure of the dense network or reduce the quality of scientific outputs?

\section{References for Chapter 3}

Freeman LC (1979) Centrality in social networks conceptual clarification. Social Networks, 1(3): 215-239.

HERG, OHE, RAND Europe. (2008) Medical research: what's it worth? London: Medical Research Council, Wellcome Trust, Academy of Medical Sciences.

Hopkins MM, Siepel J (2013) Just how difficult can it be counting up R\&D funding for emerging technologies (and is tech mining with proxy measures going to be any better)? Technology Analysis \& Strategic Management, 25(6): 655-685.

Lewison G, Dawson G (1998) The effect of funding on the outputs of biomedical research. Scientometrics, 41(1-2): 17-27.

Lewison G, Dawson G, Anderson J (1995) The behaviour of scientific authors in acknowledging their funding sources. Proceedings of the fifth international conference of the international society for scientometrics and informetrics.

MacLean M, Davies C, Lewison G, Anderson J (1998) Evaluating the research activity and impact of funding agencies. Research Evaluation, 7(1): 7-16.

Morgan Jones M, Grant J (2011) Complex trauma research in the UK. Product Page http://www.rand.org/pubs/documented_briefings/DB613.html

Rafols I, Leydesdorff L, O'Hare A, Nightingale P, Stirling A (2012) How journal rankings can suppress interdisciplinarity. The case of innovation studies and business and management. Research Policy, 41(7): 1262-1282.

Rafols I, Porter AL, Leydesdorff L (2010) Science overlay maps: A new tool for research policy and library management. Journal of the American Society for Information Science and Technology, 61(9): 1871-1887.

Rotolo D, Rafols I, Hopkins M, Leydesdorff L (2013) Scientometric mappings as strategic intelligence for tentative governance of emerging science and technologies. Working Paper

http://papers.ssrn.com/sol3/papers.cfm?abstract_id=2239835

Stirling A (1998) On the economics and analysis of diversity. SPRU Electronic Working Papers, 28.201

Stirling A (2007) A General framework for analysing diversity in science, technology and society. Journal of The Royal Society Interface, 4(15): 707-719.

UKCRC (UK Clinical Research Collaboration) (2012) UK health research analysis 2009/10. London: UKCRC. 
Wassermann S, Faust K (1994) Social Network Analysis: Methods and Applications. Cambridge, MA: Cambridge University Press. 


\section{COMPLEMENTARITY/SUBSTITUTABILITY OF GOVERNMENT AND CHARITY FUNDING OF CANCER RESEARCH IN THE UK}

\section{Key Points}

- In a web-based survey of 401 members of the UK general public, we asked respondents how they would distribute a hypothetical $£ 100$ allocation of income tax amongst cancer research and other medical research charities under a range of different scenarios regarding changes in government spending on cancer research and other medical research.

- When respondents are asked to suppose that the government has cut (or has increased) funding for cancer research, the overall tendency is to give a larger (smaller) share of the allocation of income tax to cancer research charities. This suggests that, given the opportunity, respondents would try to counteract the hypothetical change in government funding of cancer research by allocating more (less) of their income tax to cancer research, were they given the opportunity. However, most respondents' preferred allocations did not vary much from scenario to scenario.

- The vast majority of respondents stated that their existing personal out-ofpocket donations to cancer research and/or other medical research charities would not be affected by changes in government funding levels or by being given the opportunity to allocate $£ 100$ of their income tax to these charities.

- Respondents' decisions about whether to donate to a cancer research charity are more likely to be driven by personal experience of cancer or by increases in their disposable income than by information about the level of government funding for cancer research.

- Recent additions to the literature suggest that government and charity funding of medical research may be complementary, with some empirical studies reporting that increases in government spending on a particular area may crowd in (rather than crowd out) private donations to charities operating in the same area.

\subsection{Introduction}

This chapter addresses the question: "If there was a cut in government funding for life sciences would other funders (private and public) be able to fill the gap and continue to support research activities?"

In our previous report for Cancer Research UK (OHE, 2011), we examined the likely consequences of a hypothetical reduction in the level of public funding for medical research. For that report we conducted a review of the peer-reviewed and grey literature, identifying 12 key papers that focused on the question of whether government and charity funding of medical research substitute for, or complement, one another. 
The main finding of our 2011 review was that there are theoretical arguments supporting both "crowding out" effects - i.e. decreases in government funding lead to donors increasing their own contributions (Warr, 1982; Roberts, 1984; Bergstrom et al., 1986; Andreoni, 1990; Andreoni and Payne, 2003) and "crowding in" effects - i.e. decreases in government funding lead to donors reducing their own contributions (Rose-Ackerman, 1986; Payne, 2001; Heutel, 2009). However, no empirical evidence specific to the UK medical research environment was found.

The one relevant UK study we identified (Khanna and Sandler, 2000) suggested that government funding of research is more likely to crowd in than to crowd out charitable funding. But the evidence was weak and did not relate specifically to medical research charities. Outside of the UK, most of the studies were undertaken in the US and suggested that whether crowding in or crowding out prevails depends on the nature of the activity undertaken by the charity. For example, Payne (2001) reported evidence that government funding crowds in charity contributions for research universities but not for non-research universities.

Given the limited literature available at the time, we identified as top of the future research agenda: finding UK-specific evidence on the crowding in or crowding out effect of government funding vis-à-vis charitable funding of medical research.

\subsection{Updated literature review}

\subsubsection{Objectives and scope}

Our objective was to update the literature review we undertook for Cancer Research UK in 2011, adopting a similar search strategy to before (OHE, 2011) but limited to the period 2010 to 2013. However, we also identified a strand of the literature that had not previously been explored (experimental economics), so decided to include studies published prior to 2010 that had not been captured in the earlier review but were deemed to be relevant to the research question.

As before, the stated objectives of the review were to:

- identify the economic principles underpinning charity and government contributions to medical research (or research in general);

- investigate whether government and charitable funding of medical research (or research in general) complement and/or substitute each other within the UK research funding system.

\subsubsection{Method}

We used three approaches to identify additional literature:

1. Keyword searches of the major economics, medical and general databases, using an updated version of the search strategy used in our earlier review.

2. Searching for papers published since 2010 that cited one of more of the key papers identified in our earlier review, using Google Scholar's "cited by" feature.

3. Searching for working papers and other unpublished literature using RePEc (Research Papers in Economics; http://repec.org/) and the websites of individuals and organisations who are active in this area of research. 
We began with approach 1 , examining the titles of the 12 key papers identified in our earlier review:

- Impure altruism and donations to public goods: a theory of warm-glow giving (Andreoni, 1990)

- Leadership giving in charitable fund-raising (Andreoni, 2006)

- Do government grants to private charities crowd out giving or fund-raising? (Andreoni and Payne, 2003)

- On the private provision of public goods (Bergstrom et al., 1986)

- Demand for collective goods in private non-profit markets: can fundraising expenditures help overcome free-rider behavior? (Weisbrod and Dominguez, 1986)

- Crowding out and crowding in of private donations and government grants (Heutel, 2009)

- Partners in giving: the crowding-in effects of UK government grants (Khanna and Sandler, 2000)

- Measuring the effect of federal research funding on private donations at research universities: is federal research funding more than a substitute for private donations? (Payne, 2001)

- A positive model of private charity and public transfers (Roberts, 1984)

- The informational value of sequential fundraising (Vesterlund, 2003)

- Pareto optimal redistribution and private charity (Warr, 1982)

- Do government grants to charity reduce private donations? (RoseAckerman, 1986)

We counted the number of times each potential keyword (e.g. "research") appeared in these titles, combining synonymous and related terms where appropriate (e.g. "charity", "charities", "charitable"). We identified the following nine keywords to be the most commonly used amongst the original key papers: private; donations; grants; government; charity/charities/charitable; research; giving; fund-raising/fundraising; crowd/crowding.

In addition, we included two further terms: "experimental" (in order to capture relevant papers in the experimental economics literature) and "medical research". This gave a total of 11 keywords.

We conducted a series of electronic searches of economics, medical and general databases in April 2013 using logical combinations of the 11 keywords. The keyword searches identified 346 potentially relevant English language records, 120 of which had been published since 2010 .

We then proceeded to approach 2, using Google Scholar to identify papers published since 2010 that had cited the key papers from the original review:

- Andreoni (1990) - 777 citations since 2010

- Andreoni (2006) - 54 citations since 2010

- Andreoni and Payne (2003) - 105 citations since 2010

- Bergstrom et al. (1986) - 347 citations since 2010

- Weisbrod and Dominguez (1986) - 66 citations since 2010

- Heutel (2009) - 19 citations since 2010

- Khanna and Sandler (2000) - 41 citations since 2010 
- Payne (2001) - 12 citations since 2010

- Roberts (1984) - 68 citations since 2010

- Rose-Ackerman (1986) - not a journal article therefore no citation statistics available via Google Scholar

- Vesterlund (2003) - 83 citations since 2010

- Warr (1982) - 86 citations since 2010

In total, the key papers (excluding Rose-Ackerman, 1986) were found to have been cited in 1,658 recent articles, although a number of these records were duplicates of each other and of the records identified using approach 1 . Finally, using approach 3 we identified a small number working / occasional papers that had not (yet) been published in peer-review journals and had not been identified using approaches 1 and 2 .

Including all of the identified records would have required reviewing up to 2,000 articles, which was infeasible given the scope of the study. We therefore restricted our attention to the first few pages of results from the searches (where the results were sorted by relevance). We also refined approach 2 by searching the results for the approach 1 keywords to identify the records that were most likely to be relevant to the research question. These steps reduced the results to 55 records.

We then screened each record by examining their titles and abstracts. Records were selected for the review if they were deemed to be directly relevant to the research question. We considered empirical studies, reviews and theoretical papers. Reference lists from included papers were checked to identify further relevant studies.

\subsubsection{Findings}

We organised the relevant studies into three broad categories:

1) studies that focused on or specifically mentioned funding for scientific or health-related research;

2) studies published since 2010 that did not specifically mention research but that focused on the relationship between government spending and private donations to charitable organisations; and

3) studies that used laboratory experiments to investigate private charitable donation behaviour.

\subsubsection{Studies that mention funding for research}

The only study we identified that focused directly on funding for scientific research, and had not been included in our earlier review, was that of Diamond (1999). Diamond begins by noting evidence (from areas other than scientific research) that when the government increases its funding of a given activity, the private funding that had been supporting that activity diminishes. He hypothesises that the converse would also be true: as the government withdraws from funding an activity, private money will enter to partially fill the gap.

Diamond examines 43 years of US data on spending on basic research from four funding sources: the federal government, industry, universities and non-profit institutions. He finds evidence of crowding in, although the economic magnitude of 
the effect is small, suggesting that donors view federal and private spending on basic research as complements rather than substitutes. If this is true both when the government increases and when it reduces spending levels, Diamond suggests that "private funding could not be expected to replace lost federal funding of science".

We also identified an empirical study that distinguished health-related charities from other types of charities. In an examination of panel data covering all registered charities in Sweden between 1989 and 2003, Breman (2006) reported results that overall reject the crowding out hypothesis. She categorised the organisations depending on whether they are related to health (including health research), social services, international aid, or "other"; finding that for health and international aid organisations, zero crowding out cannot be rejected; whereas for social services and other organisations, zero crowding out can be rejected and there is evidence of crowding in.

\subsubsection{Studies published since 2010}

In a review of empirical studies of philanthropy, Bekkers and Wiepking (2011) identified eight factors driving charitable giving: awareness of need, solicitation, costs, benefits, altruism, reputation, psychological benefits, values, and efficacy. In the context of the impact of changes in government funding, altruism and psychological benefits are of particular interest. Purely altruistic motivation would lead to a crowding out effect, as donors reduce their own contributions as they learn about increases in contributions by others. However, there is evidence that charitable giving produces positive psychological consequences for the donor, often labelled "warm glow" or "joy of giving" effects.

In a UK study based on interviews with 60 "committed donors", in general i.e. not limited to medical research charities, Breeze (2010) found that people tend not to give to the most urgent needs but rather to support causes that mean something to them. She reports the following criteria that commonly influence donors' decision-making: their tastes, preferences and passions; their personal and professional backgrounds; their perceptions of charity competence; and their desire to have a personal impact. Regarding the fourth criterion, Breeze notes that the interviewees were "keen to avoid their donations becoming a substitute for government spending", particularly in the area of welfare spending. Rather, they were keen for their contributions to complement rather than to replace the funding available for a particular cause - donors have "higher expectations for their contributions than 'gap plugging'".

Garrett and Rhine (2010) claim that the relationship between government spending and charitable giving depends on the specific categories of spending being studied. This suggests that it is difficult to make inferences about medical research funding using data that is not concerned primarily with medical research funding. The authors also note that no statistical relationship between government spending and charitable contributions would be expected if people are "rationally ignorant" about government activities, which is often likely to be the case.

Andreoni and Payne (2011) distinguish between "classic" and "fundraising" crowding out. Classic crowding out occurs when government grants to charities 
lead donors to reduce their donations because the donors treat their voluntary private contributions as a substitute for their involuntary contributions through taxation. Fundraising crowding out occurs when the charities receiving the grants reduce their fundraising efforts, which results in reduced private donations. The latter is a feasible explanation for crowding out in situations where donors are largely unaware of changes in funding levels. Using a panel of charities in the US, the authors find that "crowding out attributable to classic crowd-out ranges from $30 \%$ to a slight crowd-in effect, while fundraising crowd-out ranges from $70 \%$ to over $100 \%$ of all crowd-out" (the percentages can be interpreted as follows: $30 \%$ crowd-out indicates that every $\$ 1,000$ government grant reduces private giving by $\$ 300$ ). This suggests that the actions of charities themselves are responsible for a large proportion of all observed crowding out.

A more recent study by Andreoni et al. (2013) examines the effect of grants on charities' incomes in the UK. The authors use a sample of charities that applied for a grant from a National Lottery-funded programme. They find that grants do not crowd out other income, with evidence of crowd in for some of the smaller charities.

In an empirical study examining panel data from almost 30,000 charities in the US, Heutel (2012) reports the government grants to charities lead to a crowding in effect, with "a dollar increase in government grants leading to an increase in private donations between 10 and 30 cents". He also finds that the rate of crowding in is larger for younger charities (the effect disappears for the oldest charities). This suggests the existence of a signalling effect as younger charities are less likely to be known by donors, so the signal value of a grant is higher. Heutel calls for further research on signalling effects.

In an empirical study examining the determinants of private donations to USbased non-government organisations engaged in international development cooperation, Herzer and Nunnenkamp (2012) find that government grants crowd in private donations in the long run. However, the authors note that private donors tend to be more familiar with local charities, whereas information asymmetries are likely to exist in the context of large and/or international organisations.

\subsubsection{Experimental economics literature}

An alternative approach to testing the crowding out hypothesis is to use laboratory experiments. Eckel et al. (2005) conducted one such study in which respondents were randomly assigned to an allocation of real money (for example, US\$15 to the respondent and US $\$ 5$ to a charity chosen by the respondent from a list). Respondents were then invited to voluntarily allocate additional money to their chosen charity. One group of respondents was simply informed of the initial allocations between themselves and the charity. The other group was told that their initial allocation had been, say, US $\$ 20$ but that a tax had been levied on this, with the tax revenue being allocated to the charity. In the first group, the size of respondents' voluntary contributions increased as the size of the initial allocation to the charity fell. In the second group, in which "fiscal illusion is eliminated", the size of the voluntary contributions was not found to vary with the size of the initial allocation to the charity. Eckel et al. conclude that "forced contributions crowd out 
private giving when the source of the funding of the forced transfers is apparent to the subjects".

In another experimental study, Crumpler and Grossman (2008) allocated an endowment of US $\$ 10$ to respondents and asked them how they wished to divide the amount between themselves and a charity (again, chosen by the respondent from a list). The respondents were also told that the experimenter would be making a donation to the charity, but that the size of this donation would be reduced by however much the respondent chooses to allocate to the charity. Hence, the charity would receive US $\$ 10$ in all cases, so the respondents' donations would be completely crowded out and a pure altruist would have no incentive to donate. The authors report that over half of the respondents made a donation, which indicates the existence of "warm glow" giving.

\subsubsection{Summary of the literature}

In summary, a number of recent studies have reported evidence of the crowding in effect, which suggests that an increase in government spending in a particular area may result in increased private donations to charities operating in that area. However, the majority of studies report US data and may not be relevant to the UK context. With their US focus, most of the studies examine the impact of direct government grants to charities themselves. There are very few studies that specifically examine funding for research, let alone medical research. Furthermore, most of the studies focus on increases in government spending, whereas given the current economic climate it would be more appropriate to consider the impact of cuts in spending. The lack of relevant UK evidence means that experimental or stated preference studies may be useful in terms of understanding the potential impact of cuts in government funding for cancer research.

\subsection{Stated preference survey}

\subsubsection{Objective}

The aim of this stated preference study was to elicit the views of the general public about how a change in government spending on cancer research might affect people's willingness to donate to cancer research charities. We sought to address a number of gaps in the existing literature on charitable behaviour, which lacks studies that use a stated preference design, and which contains no studies that focus specifically on medical research and charitable giving in the UK.

The survey was designed so as to answer the following key research questions:

- If given the opportunity to allocate $£ 100$ of the income tax they pay this year to one or more medical research charities, how would people choose to distribution the $£ 100$ between cancer research and other medical research charities?

- Would being given the opportunity to allocate $£ 100$ of their income tax to cancer and other medical research charities lead people to change their existing personal out-of-pocket donations to those types of charities?

- Would people's preferred allocations of funds change if they were to learn that the government was cutting or increasing funding for cancer and/or other medical research? 


\subsubsection{Methods}

\subsubsection{Survey instrument}

The main part of the survey comprised five hypothetical scenarios. In each scenario, respondents were asked to imagine that they had the opportunity to allocate $£ 100$ of the income tax they paid this year to one or more medical research charities. They were asked how they wished to allocate the $£ 100$ between cancer research charities and medical research charities concerned with diseases other than cancer. The recipients of the allocation would be unnamed charities of the respondents' choosing. The idea behind the scenarios was loosely based on the situation in Italy, where since 2006 taxpayers have been offered the opportunity to donate $0.5 \%$ of their income tax they pay to non-profit organisations of their choosing (Agenzia delle Entrate, n.d.).

After having been given the opportunity to allocate $£ 100$ in this way, the respondents were then asked if they would want to reduce or increase any personal donations that they already make out of their own pocket to cancer research and non-cancer medical research charities; and if so, by how much. Respondents were only asked about changes to their out-of-pocket personal donations if they had earlier claimed to have made financial donations to one or more medical research charities in the previous year (see below). These questions allowed us to test the extent to which having the opportunity to allocate some of their income tax to medical research charities might affect people's willingness to donate from their own (post-tax) resources.

Table 4.1 summarises the information provided to respondents in the five scenarios. The full survey is reproduced in the Appendix.

In scenario 1, no information was provided about research funding levels. In scenario 2, respondents were presented with rounded estimates of how much the government and charities actually spend on medical research in the UK each year (figures based on data in: NCRI, 2011; UKCRC, 2012). The actual levels of spending on medical research may be very different from what respondents would have been expecting. Comparing scenarios 1 and 2 allows us to test the hypothesis that some respondents would revise their choices of allocations when they become better informed about research funding levels.

In scenario 3, respondents were asked to imagine a hypothetical situation where the government has reduced its annual spending on cancer research from $£ 150$ million (as in scenario 2) to $£ 50$ million, and has spent the $£ 100$ million difference on more research into diseases other than cancer. The crowding out hypothesis suggests that respondents would seek to make up the gap by increasing the amount they give to cancer research charities. Alternatively, respondents may view the government's decision to redirect resources away from cancer research towards other areas of medical research as a signal that cancer research is a relatively low priority for society (hence comparing scenarios 2 and 3 allows us to test the signalling hypothesis). If so, they may follow suit by reducing the amount they give to cancer research charities. 
Table 4.1: Summary of scenarios used in the survey

\begin{tabular}{|c|c|c|c|c|c|}
\hline \multirow[b]{3}{*}{ Scenario } & \multicolumn{4}{|c|}{ Spend on medical research in the UK each year } & \multirow[b]{3}{*}{ Description } \\
\hline & \multicolumn{2}{|c|}{ Funding from government } & \multicolumn{2}{|c|}{ Funding from charities } & \\
\hline & $\begin{array}{l}\text { Cancer } \\
\text { research }\end{array}$ & $\begin{array}{l}\text { Other medical } \\
\text { research }\end{array}$ & $\begin{array}{l}\text { Cancer } \\
\text { research }\end{array}$ & $\begin{array}{l}\text { Other medical } \\
\text { research }\end{array}$ & \\
\hline 1 & \multicolumn{4}{|c|}{ No information provided to respondent } & $\begin{array}{l}\text { Scenario included to capture } \\
\text { respondents' preferences in } \\
\text { absence of information about } \\
\text { medical research funding levels }\end{array}$ \\
\hline 2 & $£ 150 \mathrm{~m}$ & $£ 2,350 \mathrm{~m}$ & $£ 350 \mathrm{~m}$ & $£ 650 \mathrm{~m}$ & $\begin{array}{l}\text { Realistic estimates of actual } \\
\text { spending on medical research }\end{array}$ \\
\hline 3 & $£ 50 \mathrm{~m}$ & $£ 2,450 \mathrm{~m}$ & $£ 350 \mathrm{~m}$ & $£ 650 \mathrm{~m}$ & $\begin{array}{l}\text { Government reduces its spending } \\
\text { on cancer research and spends } \\
\text { that money instead on other } \\
\text { medical research }\end{array}$ \\
\hline 4 & $£ 50 \mathrm{~m}$ & $£ 2,350 \mathrm{~m}$ & $£ 350 \mathrm{~m}$ & $£ 650 \mathrm{~m}$ & $\begin{array}{l}\text { Government reduces its spending } \\
\text { on cancer research; spending on } \\
\text { other medical research remains } \\
\text { unchanged }\end{array}$ \\
\hline 5 & $£ 250 \mathrm{~m}$ & $£ 2,250 \mathrm{~m}$ & $£ 350 \mathrm{~m}$ & $£ 650 \mathrm{~m}$ & $\begin{array}{l}\text { Government increases its spending } \\
\text { on cancer research and reduces its } \\
\text { spending on other medical } \\
\text { research by the same amount }\end{array}$ \\
\hline
\end{tabular}

Scenario 4 replicates scenario 3 except that the government does not increase its spending on other areas of medical research, so total annual government spending on medical research has been reduced by the same $£ 100$ million that has been cut from spending on cancer research.

Finally, in scenario 5 the government has increased its annual spending on cancer research by $£ 100$ million and has found that money by reducing its spending on research into diseases other than cancer by $£ 100$ million. It was hypothesised that if a respondent reacts to hearing that the government has reduced its spending on cancer research by increasing (reducing) the share of the $£ 100$ allocation they give to cancer research charities, then they may react to hearing the government has increased its spending on cancer research by reducing (increasing) the share for cancer research charities.

Information about the levels of funding for research from charities remained constant throughout the scenarios, and was included to provide some context to the respondents.

The questions relating to the five scenarios were preceded by a small number of preliminary questions. First, respondents were presented with a list of well-known cancer research charities and were asked to indicate which of those charities, if any, they had given money to in the past year. An "Other" option was included to allow respondents to specify the name of a cancer research charity that they had given money to and was not included in the list. Respondents were then asked a similar question but about medical research charities focusing on diseases other 
than cancer. When later faced with the five scenarios, respondents were only asked the questions about whether they would change their personal out-ofpocket donations to cancer research and/or other medical research charities if they had already claimed to give money to the relevant types of charities in these preliminary questions.

The respondents were then asked to guess: (1) how much the UK government currently spends on medical research each year, in millions of pounds; and (2) the percentage of total UK government spending on medical research each year that is on cancer research. It was assumed that respondents would not know the answers to either of these questions, but having information on their best guesses helps us to interpret any changes in their responses when moving from scenario 1 (no information on government spending provided) to scenario 2 (realistic estimates of government spending levels provided).

The respondents were then asked to indicate whether they thought that government funding of medical research had been going up, been going down, or remained about the same, over the last three years. They were then asked the same question, but focusing specifically on cancer research.

Following these preliminary questions, the respondents were presented with the five scenarios, as described above. Once they had completed the questions for these scenarios, they were invited to provide comments to support their answers if they so wished. Respondents who had claimed not to have given money to any cancer research charities in the previous year were asked what, if anything, might encourage them to donate to a cancer research charity.

The next question sought to elicit respondents' views more directly, asking them whether hearing that the government has reduced its spending on cancer research would make them more or less likely to donate to a cancer research charity, or to donate more or less than they already do. Alternatively, respondents could indicate that government spending decisions make no difference to their donation decisions.

Finally, the respondents were asked some background questions about the types of charity donations they had made in the last year (to any kind of charity, medical or otherwise); whether the level of their charity donations had been going up, been going down or remained about the same; and whether they had any personal experience of cancer.

\subsubsection{Administration of survey}

The questions were included in a self-completion web-based survey. The survey was administered on a sample of adult members of the UK general public, all of whom were members of a panel managed by Aurora MR, with whom the market research agency Accent partnered for this component of the research. We sought a sample that was representative of the general population in terms of age and gender. We also sought respondents from different socioeconomic grades, choosing to oversample those from the very highest grades ( $A$ and $B$ ) in order to obtain a large subsample comprising individuals who might be expected a priori to be more likely than average to be regular givers of large charity donations (or to become such givers in the future). Screen-in questions, combined with a 
"minimum quota" approach, were used to ensure that the sample comprised individuals with the appropriate characteristics. Respondents were compensated for taking part by way of "reward points" which can be redeemed for gift vouchers.

Information about the scenarios was presented using a combination of text descriptions and diagrams (see Appendix). All responses were recorded via the web-based survey. In order to control for potential ordering effects, the respondents were randomly assigned to one of two blocks that determined the order in which the scenarios were presented to them. Respondents in the first block faced the scenarios in the same order as described above (12345); respondents in the second block were presented with the scenario describing an increase in the government's funding for cancer research before proceeding to the scenarios describing reductions in the government's funding for cancer research (12534).

\subsubsection{Piloting}

The study design was informed by a focus group, which was used to pilot a draft version of the survey and to seek feedback from general public participants. The focus group took place in Hammersmith, London in May 2013. It was moderated by a focus group leader from Accent, with assistance from a member of the study team (KS). Nine members of the general public took part, all of whom claimed to support the principle of giving to charity. The sample was well-balanced with respect to age (three participants under 30 years; three between 30 and 60 years; and three over 60 years) and gender (four males; five females).

The topic was introduced by the focus group leader. This was followed by a group discussion about different reasons for giving to charity, including medical research charities. The participants were then each handed a paper copy of the draft survey and were asked to complete it by hand without conferring with each other. All but one of the participants completed the survey within 15 minutes; the majority required less than 10 minutes. Feedback was sought on all aspects of the survey. The entire session was video recorded.

The comments were largely favourable, with participants describing the scenarios as interesting and easy to understand; and claiming that the survey was straightforward to complete without assistance. However, the participants also criticised the survey for being overly "wordy" and repetitive; and some participants questioned the plausibility of some of the scenarios.

The findings from the focus group informed the design of the final survey in a number of ways, in particular: the reduction of wordiness throughout the survey, with less repetition from scenario to scenario; the use of diagrams (rather than tables) to demonstrate the key pieces of information in the scenarios; the focus on financial donations only, rather than all types of giving (unpaid time, for example); the provision of examples of cancer and other medical research charities at the start of the survey; survey routing based on answers to previous question (e.g. only ask about changes to the respondent's out-of-pocket donations to cancer research charities if the respondent has already claimed to give money to cancer research charities); removal of specific reference to the policy in Italy; and the use 
of features to make the web-based survey more user-friendly than its pen-andpaper counterpart.

\subsubsection{Results}

The survey was carried out in July 2013. Respondents who completed the survey in less than 3.5 minutes were excluded from the sample due to concerns about data quality $(n=74)$, leaving a sample of 401 respondents. The median time taken by these 401 respondents to complete the survey was 6.025 minutes. Table 4.2 presents the background characteristics of the sample. By design, the sample was broadly representative of the general population with respect to age and gender (Office for National Statistics, 2011a), and comprised a larger proportion of individuals in the highest socioeconomic grades (National Readership Survey, 2013).

Table 4.2: Sample background characteristics

\begin{tabular}{|c|c|c|}
\hline & Freq & $\%$ \\
\hline Total & 401 & 100 \\
\hline \multicolumn{3}{|l|}{ Gender } \\
\hline Male & 214 & 53.4 \\
\hline Female & 187 & 46.6 \\
\hline \multicolumn{3}{|l|}{ Age (years) } \\
\hline 18 to 29 & 49 & 12.2 \\
\hline 30 to 39 & 90 & 22.4 \\
\hline 40 to 49 & 63 & 15.7 \\
\hline 50 to 59 & 76 & 19.0 \\
\hline 60 and over & 123 & 30.7 \\
\hline \multicolumn{3}{|l|}{$\begin{array}{l}\text { Social grade (refers to the occupation/responsibilities of the chief wage earner of } \\
\text { the respondent's household) }\end{array}$} \\
\hline A (higher managerial, administrative or professional) & 23 & 5.7 \\
\hline B (intermediate managerial, administrative or professional) & 144 & 35.9 \\
\hline C1 (supervisory or clerical and junior managerial, administrative or professional) & 95 & 23.7 \\
\hline C2 (skilled manual workers) & 52 & 13.0 \\
\hline D (semi-skilled and unskilled manual workers) & 27 & 6.7 \\
\hline E (state pensioners, casual and lowest grade workers, unemployed with state benefits only) & 60 & 15.0 \\
\hline \multicolumn{3}{|l|}{ Types of charity donations made in the last year } \\
\hline Money - regular donation & 127 & 31.7 \\
\hline Money - one-off donation & 241 & 60.1 \\
\hline Money - other (charity events, auctions, etc.) & 126 & 31.4 \\
\hline Non-financial (donation of unwanted goods, volunteering, etc.) & 223 & 55.6 \\
\hline None of the above & 45 & 11.2 \\
\hline \multicolumn{3}{|l|}{$\begin{array}{l}\text { Over the last three years, what has happened to the level of your charity } \\
\text { donations(s)? }\end{array}$} \\
\hline Going up & 66 & 16.5 \\
\hline Going down & 56 & 14.0 \\
\hline About the same & 279 & 69.6 \\
\hline \multicolumn{3}{|l|}{ Personal experience of cancer (respondents could tick multiple boxes) } \\
\hline Yes, self & 34 & 8.5 \\
\hline Yes, close friend or relative & 275 & 68.6 \\
\hline No & 87 & 21.7 \\
\hline No answer given & 22 & 5.5 \\
\hline
\end{tabular}

Just over half of the respondents (53.4\%) said they had given money to Cancer Research UK in the previous year. Donations to Cancer Research UK were more common amongst respondents with personal experience of cancer and those from 
the lower socioeconomic grades (although the question did not specify the size or regularity of the donations).

Figure 4.1 shows the distribution of answers given by respondents when asked: (1) how much the UK government spends on medical research each year, in millions of pounds; and (2) what proportion of the total UK government spending on medical research each year is spent on cancer research. The vast majority $(96.3 \%)$ of respondents underestimated the total government spending on medical research (median guess $=£ 24$ million; actual figure $\approx £ 2,500$ million), and a similarly large majority overestimated the proportion of government spending on medical research that is spent on cancer research (median guess $\approx 30 \%$; actual figure $\approx 6 \%$ ) (actuals based on NCRI, 2011 and UKCRC, 2012). Over four-fifths of the respondents $(82.5 \%)$ guessed that total government spending on medical research was less than or equal to $£ 100$ million, with three evident peaks at $£ 10$ million (12.9\%), £50million (9.0\%) and $£ 100$ million $(12.2 \%)$. The majority of respondents guessed that government funding of cancer research had either been going down $(33.7 \%)$ or remained about the same $(35.2 \%)$ over the past three years, with most of the remainder selecting the "don't know" option.

\section{Figure 4.1: Distribution of guesses of levels of government spending}

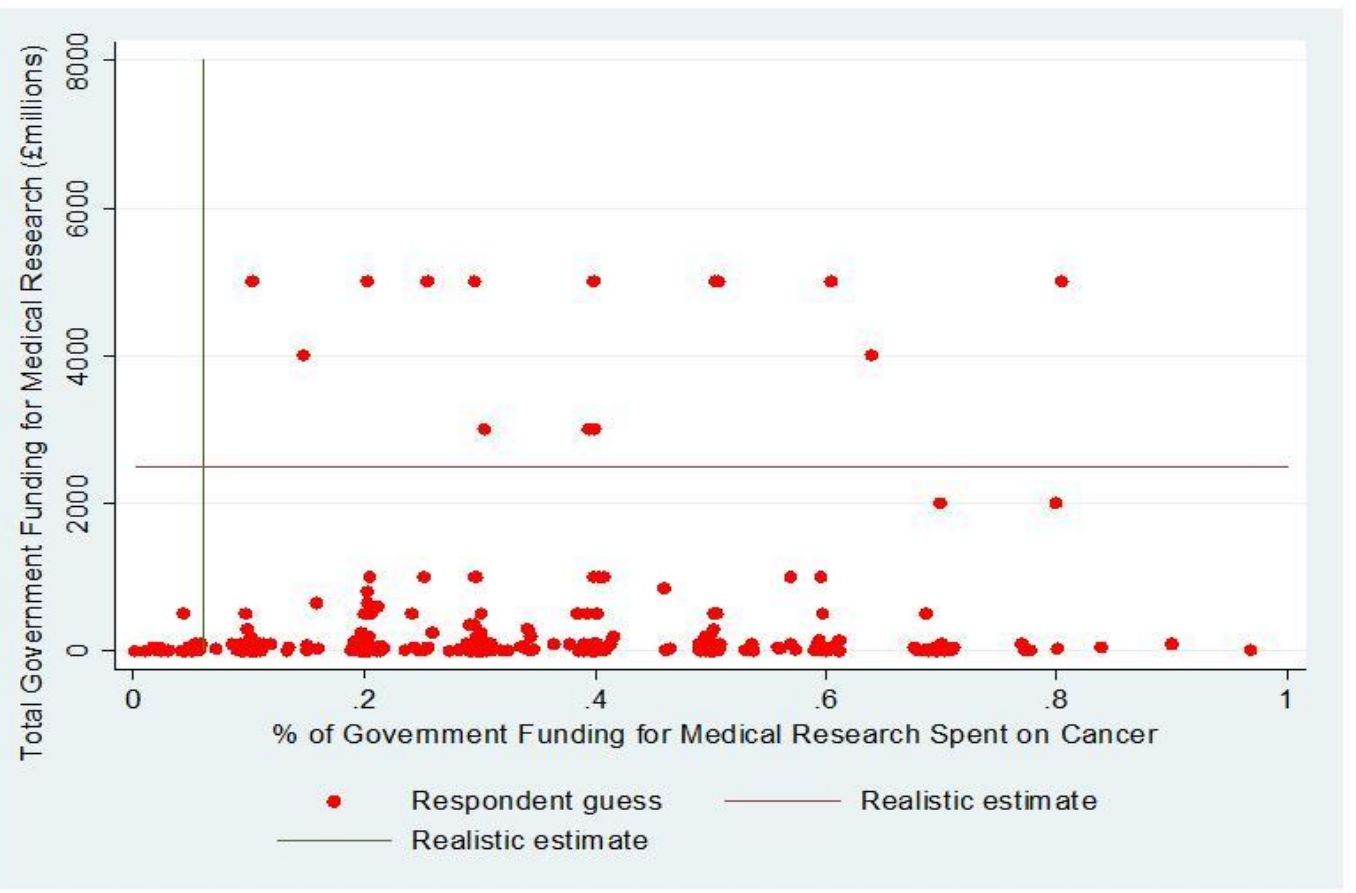

Table 4.3 reports the aggregate response data for the five scenarios. In scenario 1 , in which no information about actual levels of medical research funding was provided, the respondents were fairly equally split between giving the majority of the $£ 100$ allocation to cancer research charities (38.2\%), giving the majority to non-cancer medical research charities $(27.9 \%)$, and splitting the allocation equally between cancer research and non-cancer medical research charities (33.9\%). In all of the subsequent scenarios, the proportion of respondents giving the majority of the allocation to cancer research charities was greater than in scenario 1 . Respondents were mostly likely to give the majority of the allocation to cancer research charities in scenarios 3 and 4, when they were asked to imagine that the 
government had reduced its spending on cancer research. One hundred and fiftythree respondents (38.2\%) opted for the same split between cancer research and other medical research charities in all five scenarios, including 48 respondents $(12.0 \%)$ who chose a 50:50 split on every occasion.

Table 4.3: Aggregate response data for scenarios 1-5

\begin{tabular}{|c|c|c|c|c|c|}
\hline & \multicolumn{5}{|c|}{ Scenario } \\
\hline & $\begin{array}{r}1 \\
\text { No info }\end{array}$ & $\begin{array}{r}2 \\
\text { Realistic } \\
\text { estimates }\end{array}$ & $\begin{array}{r}3 \\
+ \text { cancer } \\
\text { research; } \\
\text { I other } \\
\text { medical } \\
\text { research }\end{array}$ & $\begin{array}{r}4 \\
+ \text { cancer } \\
\text { research }\end{array}$ & $\begin{array}{r}5 \\
{ }^{1} \text { cancer } \\
\text { research; } \\
\text { ' other } \\
\text { medical } \\
\text { research }\end{array}$ \\
\hline $\begin{array}{l}\text { Allocation to cancer research charities } \\
\text { (out of notional } £ 100 \text { tax deducted } \\
\text { sum) }\end{array}$ & $27.9 \%$ & $27.9 \%$ & $26.9 \%$ & $25.7 \%$ & $29.4 \%$ \\
\hline$<£ 50$ & $33.9 \%$ & $22.2 \%$ & $16.5 \%$ & $19.7 \%$ & $25.4 \%$ \\
\hline 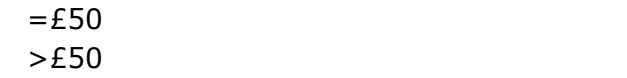 & $38.2 \%$ & $49.9 \%$ & $56.6 \%$ & $54.6 \%$ & $45.1 \%$ \\
\hline $\begin{array}{l}\text { Mean allocation to cancer research } \\
\text { charities }\end{array}$ & $£ 53.60$ & $£ 58.19$ & $£ 63.15$ & $£ 62.35$ & $£ 56.47$ \\
\hline $\begin{array}{l}\text { Change in personal out-of-pocket } \\
\text { donations to cancer research charities }\end{array}$ & & & & & \\
\hline Would reduce & $4.0 \%$ & $1.8 \%$ & $2.6 \%$ & $2.2 \%$ & $5.8 \%$ \\
\hline Would increase & $4.7 \%$ & $9.1 \%$ & $11.7 \%$ & $9.5 \%$ & $5.1 \%$ \\
\hline Would not change & $91.2 \%$ & $89.1 \%$ & $85.8 \%$ & $88.3 \%$ & $89.1 \%$ \\
\hline $\begin{array}{l}\text { Mean change in personal out-of-pocket } \\
\text { donation to cancer research charities }{ }^{2}\end{array}$ & $-£ 0.10$ & $+£ 1.12$ & $+£ 1.54$ & $+£ 1.51$ & $-£ 0.21$ \\
\hline $\begin{array}{l}\text { Change in personal out-of-pocket } \\
\text { donations to other medical research } \\
\text { charities }^{3}\end{array}$ & $5.4 \%$ & $8.3 \%$ & $7.8 \%$ & $5.4 \%$ & $4.4 \%$ \\
\hline Would reduce & $2.5 \%$ & $2.0 \%$ & $3.9 \%$ & $3.9 \%$ & $5.4 \%$ \\
\hline $\begin{array}{l}\text { Would increase } \\
\text { Would not change }\end{array}$ & $92.2 \%$ & $89.7 \%$ & $88.2 \%$ & $90.7 \%$ & $90.2 \%$ \\
\hline $\begin{array}{l}\text { Mean change in personal out-of-pocket } \\
\text { donations to other medical research } \\
\text { charities }\end{array}$ & $-£ 0.52$ & $-£ 0.78$ & $-£ 0.37$ & $+£ 0.09$ & $+£ 0.02$ \\
\hline
\end{tabular}

${ }^{1}$ Questions asked only to respondents who had given money to one or more cancer research charities in the previous year

${ }^{2}$ Excludes outlier (individual who claimed that they would increase their personal donations by £250)

${ }^{3}$ Questions asked only to respondents who had given money to one or more non-cancer medical research charities in the previous year

On average, from the $£ 100$ of income tax they were able to allocate to medical research, respondents chose to give $£ 58.19$ to cancer research charities and $£ 41.81$ to other medical research charities in scenario 2 , in which they were presented with realistic estimates of government spending levels. In the scenarios in which the government had reduced its spending on cancer research, the average amount from within the $£ 100$ of income tax to be allocated to medical research that would be given to cancer research charities increased by $£ 4.96$ and $£ 4.16$ (scenarios 3 and 4, respectively). In the scenario in which the government had increased its spending on cancer research, the average amount given to cancer research charities from within the $£ 100$ of income tax to be allocated fell by $£ 1.72$ per person, on average (scenario 5).

In all five scenarios, of the respondents who had earlier claimed to have given money to medical research charities in the previous year, the vast majority 
(ranging from $88.2 \%$ in scenario 3 to $92.2 \%$ in scenario 1 ) said that they would not change the level of their personal out-of-pocket charity donations even after being given the opportunity to give an extra $£ 100$ out of their income tax. These respondents were most likely to increase their out-of-pocket donations to cancer research charities in scenarios 3 and 4, when they were asked to assume that the government had reduced its spending on cancer research; and were most likely to increase their out-of-pocket donations to non-cancer medical research charities in scenario 5, when they were asked to assume that the government had increased its spending on cancer research and had found that money by reducing its spending on research into diseases other than cancer.

Sixty-eight point three per cent (274/401) of respondents said they had donated to cancer research charities in the last year. Among that group of respondents, Table 4.3 shows that the mean personal out-of-pocket donation to cancer research charities would be greater in scenario 4 than in scenario 2 , but by just $£ 0.39$ per existing donor. If replicated across $68.3 \%$ of the total 50 million UK adult population this would amount to extra out-of-pocket donations totalling $£ 13$ million. Relative to the hypothetical $£ 100 \mathrm{~m}$ cut in government spending on cancer research in this scenario, this would imply a net $£ 87$ million reduction in combined government and charity annual spending on cancer research.

Figure 4.2 shows the distributions of the allocations given to cancer research charities in each of the five scenarios. The tendency to choose an even split between cancer research and other medical research charities in greatest in scenario 1. After being provided with information about the levels of government spending on medical research (scenarios 2 to 5 ), many respondents switch to giving the entire allocation to cancer research charities. This tendency is strongest in the scenarios that describe cuts in government spending on cancer research. It is notable that the distributions for scenarios 2 and 5 are near-identical.

Across all scenarios, respondents with personal experience of cancer were less likely to choose even splits than those without personal experience of cancer. The differences in the population means between the experience/no experience groups are statistically significant in four of the five scenarios (ANOVA analysis). The differences in the distributions of the allocations between these groups are statistically significant in scenarios 3 and 4 (Kolmogorov-Smirnov test), where respondents with personal experience of cancer are more likely than those without personal experience of cancer to give a larger share of the allocation to cancer research. No statistically significant differences were found between the allocations of respondents in the highest socioeconomic grades and those of respondents in the lower grades. 
Figure 4.2: Distributions of the allocations given to cancer research charities
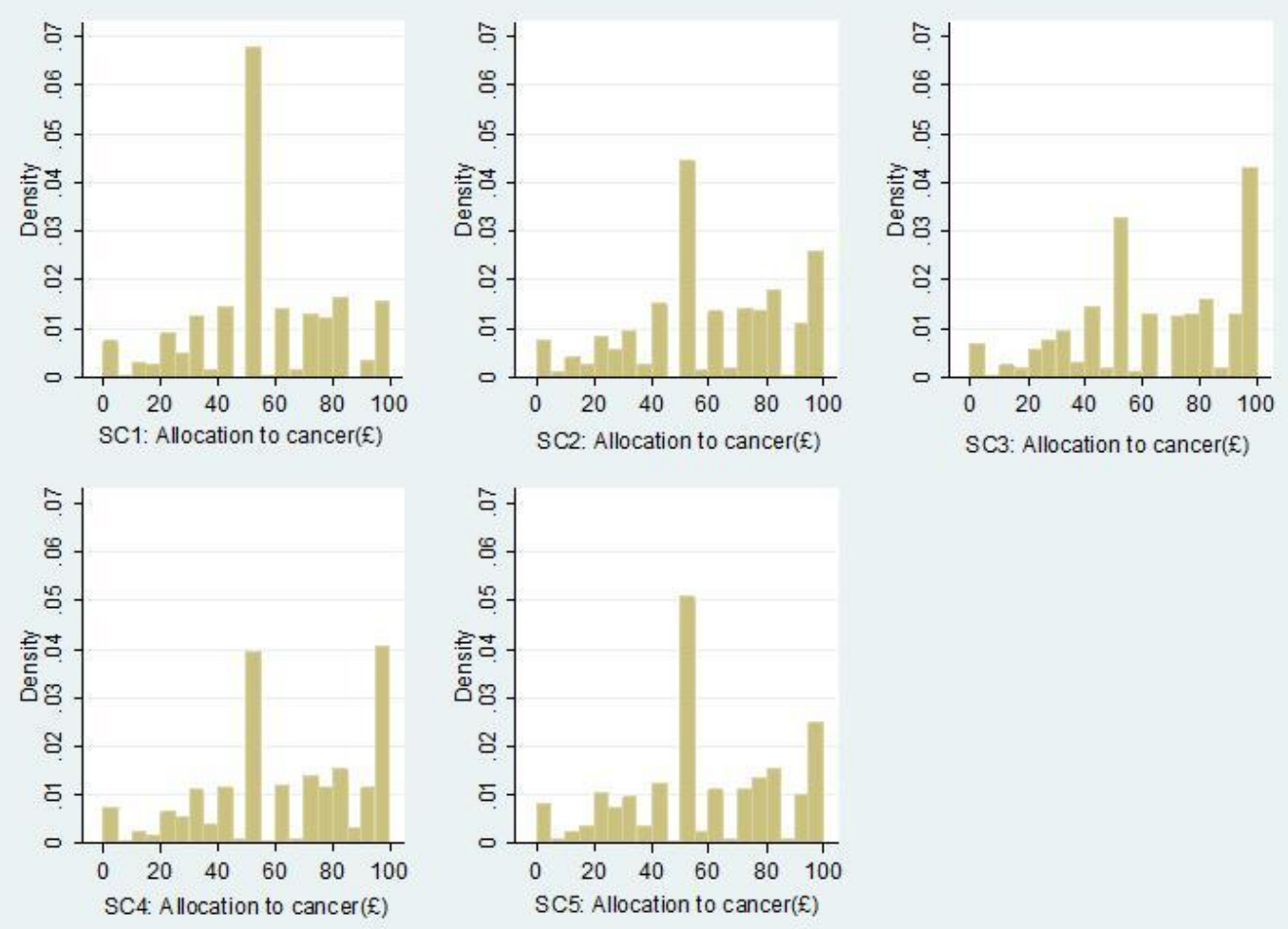

Figure 4.3 shows the extent to which respondents changed their allocation choices from one scenario to another (for selected pairs of scenarios). Compared to scenario 2 (the scenario presenting realistic government spending estimates), respondents were more likely to give an increased share of the allocation to cancer research charities in scenarios 3 and 4 (the scenarios describing cuts to government funding for cancer research); and were slightly more likely to give a reduced share in scenario 5 (the scenario describing an increase in government funding for cancer research). 
Figure 4.3: Changes in allocations from one scenario to another (for selected pairs of scenarios)
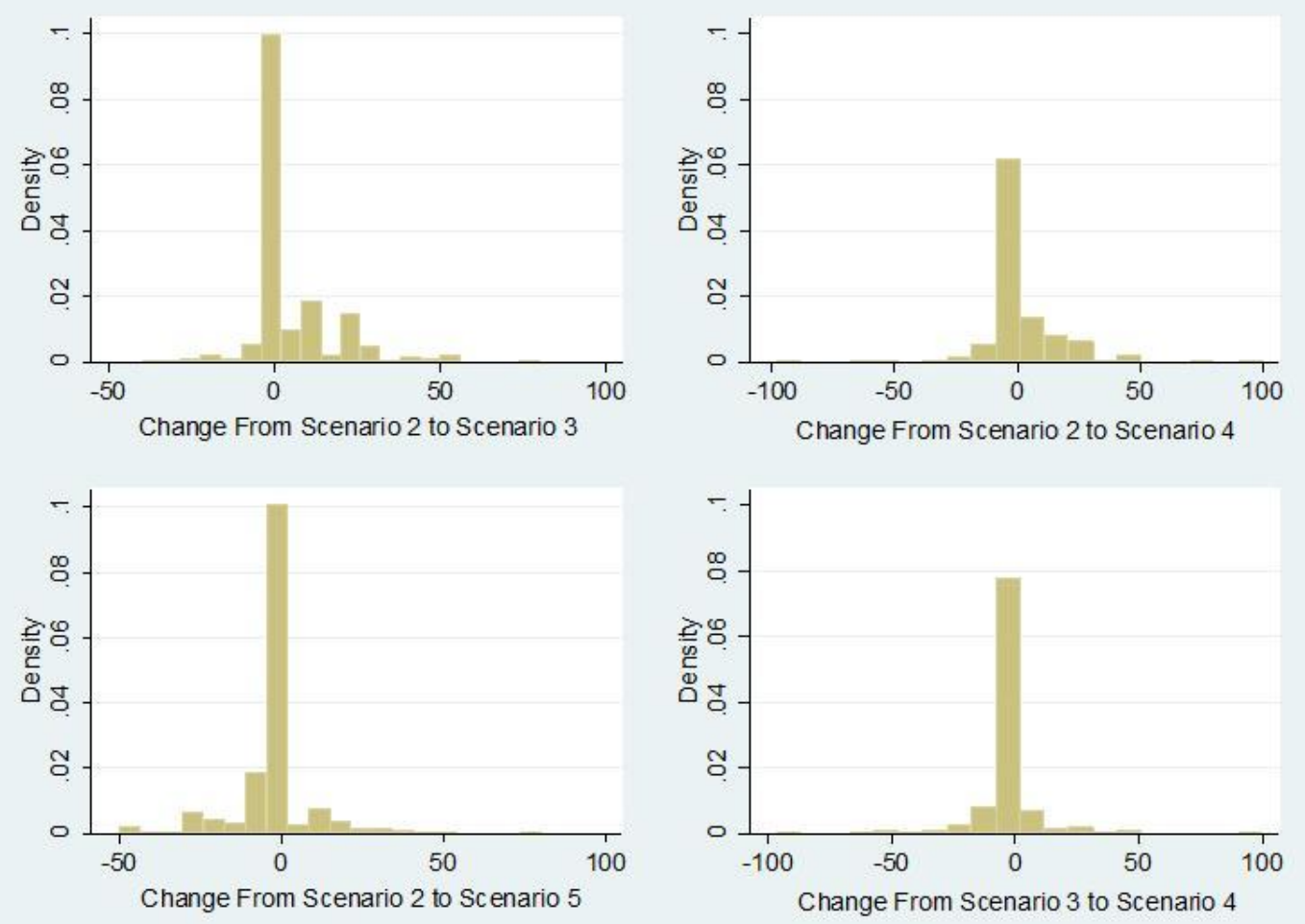

Comparing the preferred allocations in scenarios 2, 3 and 5: over three-quarters of the respondents either gave the same amount to cancer research charities in all three scenarios $(49.4 \%)$ or gave a larger amount to cancer research charities in scenario 3 than in scenarios 2 or 5 (28.2\%). This is shown in Table 4.4.

Table 4.4: Comparison of scenarios 2, 3 and 5 - in which was the largest amount allocated to cancer research charities?

\begin{tabular}{|l|r|r|}
\hline Scenario(s) in which the largest amount was given to cancer research charities & Freq & $\%$ \\
\hline Same allocation in all three scenarios & 198 & $49.4 \%$ \\
\hline Scenario 2 & 20 & $5.0 \%$ \\
\hline Scenario 3 & 113 & $28.2 \%$ \\
\hline Scenario 5 & 18 & $4.5 \%$ \\
\hline Scenarios 2 and 3 & 30 & $7.5 \%$ \\
\hline Scenarios 2 and 5 & 7 & $1.7 \%$ \\
\hline Scenarios 3 and 5 & 15 & $3.7 \%$ \\
\hline
\end{tabular}

Figure 4.4 shows, for each of the five scenarios, the relationship between respondents' preferred allocations of the $£ 100$ of their income tax and the amount they say that being given the opportunity to allocate that $£ 100$ of their income tax would cause them to reduce or increase their personal out-of-pocket donations to cancer research charities (excluding those who would not change their personal donations and a small number of outliers who claimed that they would increase their personal donations by more than $£ 100$ ). Figure 4.5 shows the stated changes in personal out-of-pocket donations to non-cancer medical research charities. 
Figure 4.4: Relationship between allocation and change in personal outof-pocket donation to cancer research charities
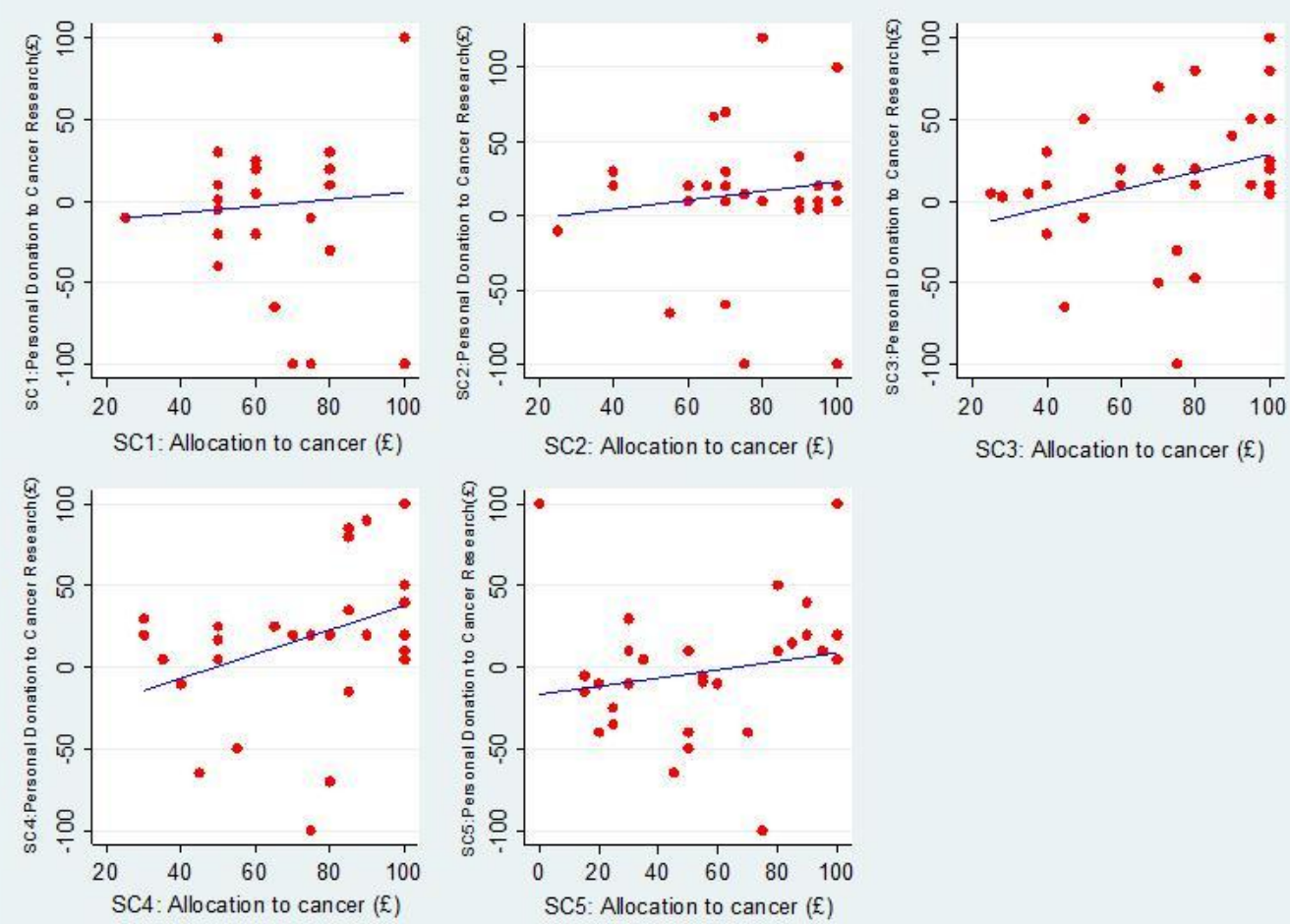

Figure 4.5: Relationship between allocation and change in personal outof-pocket donation to non-cancer medical research charities
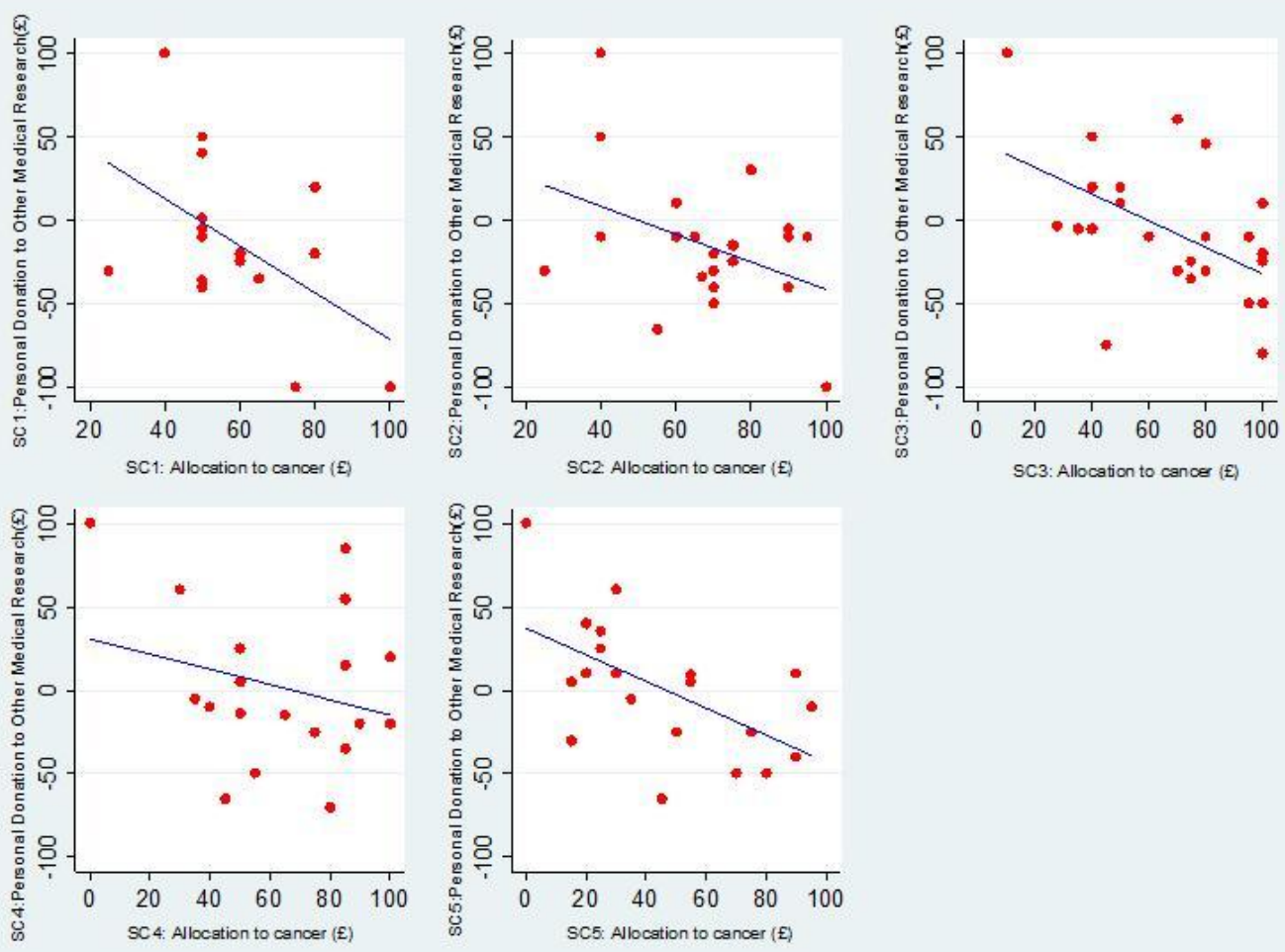
The linear trend lines in Figures 4.4 and 4.5 respectively indicate that the larger a respondent's allocation to cancer research charities, the more likely that respondent is to increase their personal out-of-pocket donations to cancer research charities as a result of being given the opportunity to allocate some of their income tax; and the more likely they are to reduce their personal out-ofpocket donations to non-cancer medical research charities. The relationship between respondents' preferred allocations and the changes in their personal donations to cancer research charities appears to be strongest in scenarios 3 and 4.

The order in which the scenarios are presented in the survey appears to affect the way in which respondents' preferred allocations of the $£ 100$ of income tax vary across the scenarios. Figure 4.6 shows that respondents who were presented with scenario 5 prior to scenarios 3 and 4 (order 2) were more likely to choose the same allocation in scenarios 2 and 5 than those who were presented with scenario 5 last (order 1).

\section{Figure 4.6: Order effects}

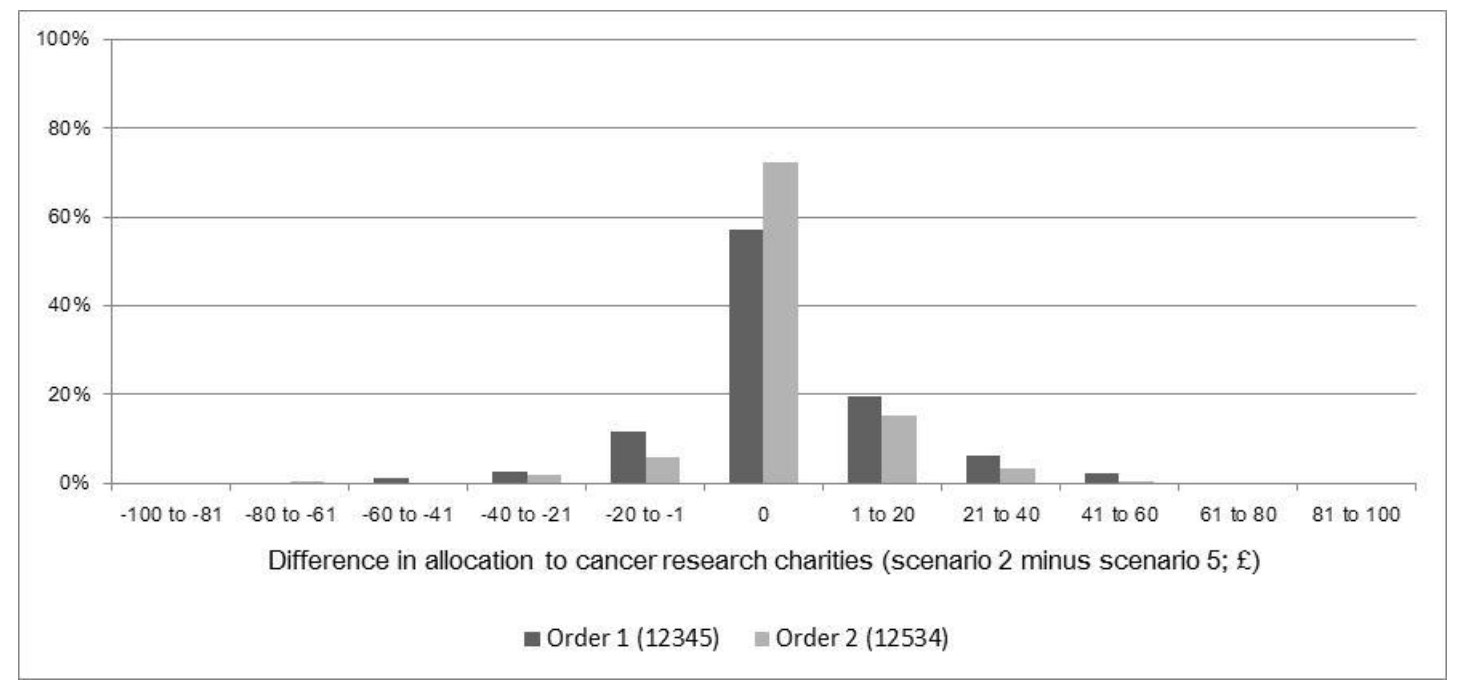

When asked directly if they were to hear that the government had reduced its spending on cancer research whether that would make them more or less likely to donate to a cancer research charity (or to donate more or less than they already do), the majority of respondents (70.8\%) claimed that government spending decisions make no difference to their decision about whether or not (or how much) to donate to a cancer research charity. Of the remainder, most claimed that it would make them more likely to donate, whereas only eight respondents $(2.0 \%)$ claimed that it would make them less likely to donate. Table 4.5 provides a crosstabulation of respondents' answers to this question and their answers to the question regarding scenario 4 when they were asked if they would change the level of their personal out-of-pocket donations to cancer research charities when faced with a situation whereby the government had reduced its spending on cancer research by $£ 100$ million (the wording of this scenario most closely matches the wording of the direct attitudinal question).

The majority of respondents who claimed that government spending decisions make no difference to their decision about whether to donate to a cancer research 
charity also stated that they would not wish to change the level of their existing out-of-pocket donations to cancer research charities were they to hear that the government had reduced its spending on cancer research.

Table 4.5: Cross tabulation - question regarding scenario 4 about impact on personal out-of-pocket donations vs. direct attitudinal question

\begin{tabular}{|c|c|c|c|c|c|}
\hline & & \multicolumn{4}{|c|}{ Direct attitudinal question } \\
\hline & & $\begin{array}{r}\text { Less likely to } \\
\text { donate }\end{array}$ & $\begin{array}{r}\text { Makes no } \\
\text { difference }\end{array}$ & $\begin{array}{r}\text { More likely to } \\
\text { donate }\end{array}$ & Total \\
\hline \multirow{3}{*}{$\begin{array}{l}\text { Question } \\
\text { regarding } \\
\text { scenario } 4 \\
\text { (impact on } \\
\text { out-of-pocket } \\
\text { donations) }\end{array}$} & $\begin{array}{l}\text { Would } \\
\text { reduce }\end{array}$ & 0 & 2 & 4 & 6 \\
\hline & $\begin{array}{c}\text { Would not } \\
\text { change }\end{array}$ & 6 & 171 & 65 & 242 \\
\hline & $\begin{array}{c}\text { Would } \\
\text { increase }\end{array}$ & 1 & 8 & 17 & 26 \\
\hline \multicolumn{2}{|c|}{ Total } & 7 & 181 & 86 & 274 \\
\hline
\end{tabular}

All respondents were invited to leave comments about their answers to scenario questions. The comments were coded and organised into categories by Accent. Table 4.6 shows the proportion of respondents who made each type of comment. Note that some respondents made comments that belong to multiple categories, so the numbers sum to more than $100 \%$. 
Table 4.6: Summary of comments made by respondents about their answers

\begin{tabular}{|l|r|}
\hline Category of comment & $\%$ \\
\hline No comment & $80.5 \%$ \\
\hline Other charities are just as important (general) & $0.5 \%$ \\
\hline Other medical research is just as/more important & $3.0 \%$ \\
\hline Surprised/disgusted at how little cancer research receives from government & $2.2 \%$ \\
\hline My personal donations would not be affected by changes to government policy/funding & $3.0 \%$ \\
\hline The government should prioritise funding for education/preventative measures & $0.7 \%$ \\
\hline People/I tend to donate to a cause they're connected to (e.g. family members affected) & $2.2 \%$ \\
\hline Would support a campaign for increased government funding for medical research & $0.7 \%$ \\
\hline Government funding for medical research should be as transparent as possible & $0.5 \%$ \\
\hline Ability to donate to charity is affected by low income/current economic climate & $1.2 \%$ \\
\hline My preference is to support lesser known charities & $0.7 \%$ \\
\hline Concerns over how funding for research is spent (e.g. ineffective, bureaucracy, poor results) & $0.7 \%$ \\
\hline The government allocations look out of proportion (unspecified) & $0.5 \%$ \\
\hline Generally critical of all cancer treatment/mainstream medicine & $0.5 \%$ \\
\hline Strongly opposed to animal testing & $0.5 \%$ \\
\hline Problems with the form of the survey - confusing, complicated, repetitive & $2.7 \%$ \\
\hline Lack of information/specialist knowledge to provide meaningful responses & $1.2 \%$ \\
\hline Other & $1.7 \%$ \\
\hline
\end{tabular}

Respondents who had not earlier claimed to have given money to cancer research charities in the previous year were asked what might encourage them to do so. The responses were coded and organised into categories by a member of the study team (KHV). Table 4.7 shows the proportion of respondents who gave each type of response. Responses that suggested that having a larger disposable income would encourage donations to a cancer research charity were made predominantly by respondents in the lower socioeconomic grades, while responses that mentioned personal experience of cancer were made predominantly by those in the highest grades. None of the respondents who were asked this question gave a response that mentioned the level of government funding for cancer (or any other type of) research.

Table 4.7: Summary of responses made by respondents when asked what would encourage them to donate to a cancer research charity

\begin{tabular}{|l|r|}
\hline Category of response & \% \\
\hline No response & $56.7 \%$ \\
\hline Personal experience of cancer (self, friends or family) & $11.8 \%$ \\
\hline Larger disposable income & $10.2 \%$ \\
\hline Greater levels of information and transparency & $8.7 \%$ \\
\hline Nothing (would encourage me to donate to a cancer research charity) & $7.1 \%$ \\
\hline Other & $5.5 \%$ \\
\hline
\end{tabular}




\subsubsection{Discussion}

This study has elicited the views of a sample of the UK general public about how (hypothetical) changes in government spending on cancer research might affect people's willingness to donate to cancer research charities. The main findings are as follows:

- Almost all respondents (96.3\%) underestimate the amount that the government spends on medical research, and most overestimate the proportion of government spending on medical research that is for cancer research. When presented with actual government spending figures, the overall tendency is to give a larger share of the allocation ( $£ 100$ of their income tax) to cancer research charities (at the expense of medical research charities concerned with diseases other than cancer).

- When respondents are asked to suppose that the government has cut funding for cancer research, the overall tendency is to give a larger share of the allocation to cancer research charities.

- When respondents are asked to suppose that the government has increased funding for cancer research, the overall tendency is to give a smaller share to the allocation to cancer research charities, although the impact is somewhat smaller than that of when the government has cut funding for cancer research.

- Notwithstanding the above findings, most respondents' preferred allocation splits did not vary much from scenario to scenario; and a sizeable minority $(38.2 \%)$ of respondents chose the same allocation split in all five scenarios.

- In all five scenarios, the vast majority (88.2-92.2\%) of respondents said that they would not take the opportunity to change the levels of their existing personal out-of-pocket donations to cancer research and/or other medical research charities, despite the fact that these charities would be receiving additional funding by way of the $£ 100$ allocation. For those respondents who said that they would change their personal donations, the larger their preferred allocation to cancer research charities, the more likely they are to increase their personal donations to cancer research charities.

Overall, the results from the scenario questions suggest that most people's private donation decisions are not (or only slightly) affected by information about government spending. This finding is further supported by the responses to the direct attitudinal question, in which approximately two-thirds of respondents claimed that hearing that the government had reduced its spending on cancer research would not affect their decision about whether to donate to a cancer research charity, or the size of their donation.

The open-ended comments made by respondents paint a similar picture. Few of the comments mentioned government funding for research as a factor affecting their decisions, with respondents claiming that personal experience of cancer, or increases in their disposable income, would be the main drivers behind any future decision to donate to a cancer research charity. Of the respondents who left a comment about their answers to the scenario questions, $15 \%$ took the opportunity to reiterate the fact their personal donations would not be affected by changes in government policy or funding levels. 
Nevertheless, there are some respondents whose preferred allocations varied substantially from scenario to scenario. Overall, the results suggest that crowding out effects outweigh any possible crowding in or signalling effects. Of the respondents who amended their allocation splits upon being given new information about government spending levels, the majority tended to move in the opposite direction to the government - increasing the share for cancer research charities when government funding for cancer research is cut, and reducing the share for cancer research charities when government funding for cancer research is increased.

On average, when moving from scenario 2 (realistic estimates of government spending) to scenario 4 ( $£ 100$ million cut to in government funding for cancer research with no increase in government funding for other medical research), respondents increased the share of the $£ 100$ of income tax allocated to cancer research by $£ 4.16$. Given that the adult population of the UK is approximately 50million (Office for National Statistics, 2011b) and assuming that the wider population would behave in accordance with the stated preferences elicited in this study, then if the government were to cut funding for cancer research by $£ 100$ million and gave each individual $£ 100$ of income tax to allocate to cancer research and other medical research charities of their choosing, then cancer research charities would between them receive $£ 208$ million from such a policy. In other words the general public would rebalance tax spending back to cancer research, given the chance, if government were to cut its planned spending on cancer research. The direction of intent is clear. However not much can be read into the magnitude of the additional allocation to cancer research owing to the hypothetical nature of the exercise and the fact that the magnitude is likely to be strongly affected by the size of the amount that the individual is given discretion over to allocate.

In addition, since the mean change in personal out-of-pocket donation to cancer research charities is greater in scenario 4 than in scenario 2, cancer research charities might also expect to receive a small amount of further donations from the pockets of individuals who already give money to these types of organisations, should the government cut its spending on cancer research. Comparing scenario 4 with scenario 2, the additional $£ 0.39$ per person saying they already donate to cancer research charities, who make up $68.3 \%$ of our survey respondents (274/401), suggests that if replicated across $68.3 \%$ of the 50 million UK adult population this would amount to extra out-of-pocket donations of $£ 13$ million. This would not go far towards offsetting the hypothetical $£ 100$ million cut in government spending on cancer research.

However, we would urge caution when scaling up in this way: in reality, even the better-informed members of the public would be unlikely to have access to information about government spending levels as presented in the scenarios. Furthermore, means tend to be skewed by extreme values (such as respondents who claim that they would give an additional $£ 100$ to cancer research charities after already having been given the opportunity to allocate $£ 100$ of income tax to those charities) that may not accurately reflect what would happen if the scenario were actually to occur. It is perhaps more telling that the median change in 
personal out-of-pocket donations to both cancer research and other medical research charities was zero in all five scenarios.

It is not surprising that the respondents were largely uninformed about current levels of government spending on medical research. A recent survey of public views about science and biomedical research reported that, when asked which groups they are aware of that carry out medical research in the UK, only $6 \%$ mentioned the government, $18 \%$ the NHS, and $23 \%$ mentioned universities; and $16 \%$ said that they did not know ( $48 \%$ mentioned medical research charities) (Clemence et al., 2013).

Most respondents guessed that government spending on medical research is far more concentrated on cancer research than is actually the case. This may explain the large shares of the allocations given to cancer research at the expense of other medical research (in each of the scenarios, the mean amount given to cancer research charities was greater than $£ 50$ of the $£ 100$ to be allocated). However, the fact that cancer research was clearly the main subject of the survey (and the fact that respondents were informed that the study was funded by Cancer Research UK) is likely to have resulted in a focusing effect whereby respondents placed more importance on cancer than they otherwise might have done. In terms of the purpose of this study, however, the actual amounts given to cancer research charities in any given scenario are less important than the ways in which those amounts change from scenario to scenario.

After having been given the opportunity to allocate $£ 100$ of income tax to medical research charities of their choosing, very few respondents then said that they would take the opportunity to reduce the size of their existing personal out-ofpocket donations. Most existing donors to medical research charities said that they would not change the size of their personal donations. This is particularly the case in scenario 1 , in which respondents were not given any information about government funding levels. This means that their answers regarding personal donations under scenario 1 would not have been driven by concerns that the government is spending too little (or too much) on medical research.

However, a drawback of stated preference studies is that they only elicit data on what respondents say that they would do/prefer - we do not know whether they would behave in the same way if the hypothetical scenarios were to actually happen. Survey respondents may exaggerate claims about their positive behaviour (i.e. giving to charity) either to appease or impress the researcher, or because they have a deluded view of themselves. Future research could combine the stated preference design with an experimental lab-based study in order to test whether people act on their claims when given real money to allocate.

\section{References for Chapter 4}

Agenzia delle Entrate. (n.d.) 5 per mille 2013 - Scheda informative. (in Italian) Available at:

http://www.agenziaentrate.gov.it/wps/content/Nsilib/Nsi/Home/CosaDeviFare/Rich 
iedere/Iscrizione + elenchi $+5+$ per + mille $+2013 /$ Scheda + informativa $+5 \times$ mille +2013 $\angle$ [Accessed 8 Aug 2013]

Andreoni, J. (1989) Giving with impure altruism: Applications to charity and Ricardian equivalence. Journal of Political Economy. 97(6), 1447-1458.

Andreoni, J. (1990) Impure altruism and donations to public goods: A theory of warm-glow giving. The Economic Journal. 100(401), 464-477.

Andreoni, J. (2006) Leadership giving in charitable fundraising. Journal of Public Economic Theory. 8(1), 1-22.

Andreoni, J. and Payne, A. (2003). Do government grants to private charities crowd-out giving or fund-raising? The American Economic Review. 93(3), 792-812.

Andreoni, J. and Payne, A.A. (2011) Is crowding out due entirely to fundraising? Evidence from a panel of charities. Journal of Public Economics. 95(5), 334-343.

Andreoni, J., Payne, A. and Smith, S. Do grants to charities crowd out other income? Evidence from the UK. CMPO Working Paper No. 13/301. Bristol: Centre for Market and Public Organisation.

Bekkers, R. and Wiepking, P. (2011) A literature review of empirical studies of philanthropy: Eight mechanisms that drive charitable giving. Nonprofit and Voluntary Sector Quarterly. 40(5), 924-973.

Bergstrom, T., Blume, L. and Varian, H. (1986) On the private provision of public goods. Journal of Public Economics. 29(1), 25-49.

Breeze, B. (2010) How donors choose charities: Findings of a study of donor perceptions of the nature and distribution of charitable benefit. CGAP Occasional Paper 1. Kent: Centre for Charitable Giving and Philanthropy.

Breman, A. (2006) The economics of altruism, paternalism and self-control. PhD thesis. Stockholm: Stockholm School of Economics.

Clemence, M., Gilby, N., Shah, J., et al. (2013) Wellcome Trust Monitor Wave 2: Tracking public views on science, biomedical research and science education. London: Wellcome Trust.

Diamond, A.M. (1999) Does federal funding "crowd in" private funding of science? Contemporary Economic Policy. 17(4), 423-431.

Eckel, C.C., Grossman, P.J. and Johnston, R.M. (2005) An experimental test of the crowding out hypothesis. Journal of Public Economics. 89(8), 1543-1560.

Garrett, T. and Rhine, R. (2010) Government growth and private contributions to charity. Public Choice. 143(1-2), 103-120.

Herzer, D. and Nunnenkamp, P. (2012) Private donations, grants, commercial activities, and fundraising: Cointegration and causaility for NGOs in international development cooperation. Kiel Working Paper No. 1769. Kiel: Kiel Institute for the World Economy. 
Heutel, G. (2009) Crowding out and crowding in of private donations and government grants. NBER Working Paper No. 15004. Boston: The National Bureau of Economic Research.

Heutel, G. (2012) Crowding out and crowding in of private donations and government grants. Public Finance Review. Published online. DOI:

$10.1177 / 1091142112447525$

Khanna, J. and Sander, T. (2000) Partners in giving: The crowding-in effects of UK Government grants. European Economic Review. 44(8), 1543-1556.

National Readership Survey (2013). Lifestyle data 2012-2013. Available at: http://www.nrs.co.uk/lifestyle-data/ [Accessed 11 Aug 2013]

NCRI (National Cancer Research Institute) (2011) Celebrating a decade of progress through partnership in cancer research. London: NCRI.

Office for National Statistics. (2011a) Census: neighbourhood statistics (England and Wales). Available at:

http://www.neighbourhood.statistics.gov.uk/dissemination/ [Accessed 11 Aug 2013]

Office for National Statistics. (2011b) 2011 Census: Population Estimates for the United Kingdom, 27 March 2011. Available at@

http://www.ons.gov.uk/ons/dcp171778 292378.pdf [Accessed 22 Aug 2013]

OHE (Office of Health Economics). (2011) Exploring the interdependency between public and charitable medical research. London: Cancer Research UK.

Payne, A. (2001) Measuring the effect of federal research funding on private donations at research universities: Is federal research funding more than a substitute for private donations? International Tax and Public Finance. 8(5-6), 731-751.

Roberts, R. (1984) A positive model of private charity and public transfers. Journal of Political Economy. 92(1), 136-148.

Rose-Ackerman, S. (1986) Do government grants to charity reduce private donations? In: The Economics of Non-Profit Institutions. New York and Oxford: Oxford University Press.

Shang, J. and Croson, R. (2009) A field experiment in charitable contribution: The impact of social information on the voluntary provision of public goods. The Economic Journal. 119(540), 1422-1439.

UKCRC (UK Clinical Research Collaboration) (2012) UK health research analysis 2009/10. London: UKCRC.

Vesterlund, L. (2001) The informational value of sequential fundraising. Journal of Public Economics. 87(3-4), 627-657.

Warr, P.G. (1982) Pareto optimal redistribution and private charity giving. Journal of Public Economics. 19(1), 131-138. 


\section{APPENDIX TO CHAPTER 3}

\section{A1.1 Identification of the publication sample}

To map the UK cancer funding landscape it is necessary to take a snapshot of the research and funder organisational 'ecosystem' as a whole. To ensure comprehensive coverage a window of one full calendar year was selected based on the assumption that research active scientists would author at least one published paper per year and that even relatively small funding organisations would have been likely to have publications stemming from their work published during a given year. The year 2011 was selected so that at the outset of the project (in early 2013) the lag between publication of papers in journals and complete indexing by publication databases would minimally affect data collection, whilst allowing the study to be as up-to-date as possible. The sample aims to capture all papers with an electronic publication date for $2011 .^{11}$

Delineating a broad topic such as cancer for scientometric analysis from first principles, without creating biases in data collection, is often challenging. In particular, approaches using ad hoc searches for keywords (e.g. in titles and abstracts of papers) or those that rely on author-defined keywords will often yield many false positives and false negatives (Leydesdorff et al. 2012). In order to benefit from prior expertise in building the sample, the Medical Subject Headings (MeSH) controlled vocabulary indexing system was used. MeSH classification is the basis of the US National Library of Medicine (NLM) of the National Institutes for Health (NIH) PubMed/MEDLINE collection where papers are classified in a standardised process by indexers according to the main themes and subject matter of the paper. ${ }^{12}$ The coding system allows each paper to be categorised using sets of terms drawn from over 26,000 MeSH descriptors organised in a tree like branching structure. ${ }^{13}$ The descriptors describe the disease and anatomical focus, the techniques used and any drugs or other molecules discussed in the paper. This coding system is such that very specific terms are located within broader topics.

To capture the study of cancer - itself a broad set of diseases - the highest available level in the tree-like MeSH coding system was used: "C04 - Neoplasms". $\mathrm{MeSH}$ notes the scope of the term neoplasm as: "New abnormal growth of tissue. Malignant neoplasms show a greater degree of anaplasia and have the properties of invasion and metastasis, compared to benign neoplasms". The search therefore includes benign and malignant neoplasms. Table A2 (at the end of this section) shows a full list of the disease sub-categories captured within C04.

PubMed/MEDLINE returned 115,101 publications, to which examiners at NLM assigned as descriptor "Neoplasms" or relative sub-levels in the tree structure of the coding system, globally for year 2011.

\footnotetext{
${ }^{11}$ The electronic date provided by PubMed/MEDLINE was used.

12 For further details see www.nlm.nih.gov/mesh

${ }^{13}$ The tree is organized in 16 branches reported in the followings: "Anatomy", "Organisms", "Diseases", "Chemical and Drugs", "Analytical, Diagnostics and Therapeutic Techniques and Equipment",

"Psychiatry and Psychology", "Phenomena and Processes", "Disciplines and Occupations",

"Anthropology, Education, Sociology and Social Phenomena", "Technology, Industry and Agriculture",

"Humanities", "Information Science", "Named Groups", "Health Care", "Publication Characteristics", and "Geographicals". 


\section{A1.2. Data on authors' addresses and identification of UK publications}

Although PubMed/MEDLINE provides the MeSH indexing system to retrieve papers, it does not provide the full data on affiliations or full addresses of all authors involved on a given publication. However this data is required to fulfil the aims of this study. We therefore matched the data from PubMed/MEDLINE in the above step with data from SCOPUS. The match was performed by using the PubMed/MEDLINE publication unique identifier, namely "PMID", and the publication DOI. This match covered $98.1 \%$ of the global publication production. ${ }^{14}$ All the data were then arranged into a relational database. We identified UK publications as those involving at least one author affiliated to a UK organisation. We specifically searched for UK in the "Affiliation" field provided by SCOPUS. ${ }^{15}$ Records from PubMed/MEDLINE that were unmatched with SCOPUS records using PMID (1.9\%) were manually screened and added to the dataset when a UK organisation was found involved in the given publication. The final dataset includes 7,922 UK publications.

\section{A1.3. Data sample and scientific discipline coverage}

The 7,922 UK publications composing our sample were distributed across 1,480 journal titles. Due to publisher restrictions in electronic access to journal titles we were not able to access publications from 130 journals. However, access to full text of 7,510 publications was obtained. This provides coverage of $94.8 \%$ of the initial publication sample.

Figure A1 depicts a web of 224 scientific disciplines (shown as nodes) as defined by ISI Web of Science (WoS) 'Subject Categories' (SCs). ${ }^{16}$ The network structure reflects the propensity of publications in the journals that make up each subject category to cite publications in journals in other subject categories (see Rafols, Porter, Leydesdorff 2010). The size of each node is proportional to the number publications that are published within each subject category. Leading nodes only are labelled. The smallest node size depicts nodes with no publications.

The broad range of scientific disciplines (135 of 224) demonstrates that the use of the $\mathrm{CO} 4$ search does not exclude research in relevant domains. ${ }^{17}$ Table 3.1 reports

\footnotetext{
${ }^{14}$ The lag in the indexing process of the two databases does not allow for a full match of the records. For example, when the matched was performed, SCOPUS did not provide the PMID for some of the records listed in PubMed/MEDLINE while the latter did not provide the DOI for of some records for which SCOPUS did.

${ }^{15}$ We build a query that searched for: "\%United Kingdom\%", "\% UK;", " U.K.;", " U.K.,", "U.K.", "\% UK,", "\% UK.", "\%Scotland\%", "\%England\%", "\%Wales\%", "\%Great Britain\%", "\%Northern Ireland\%". The "\%" represents the wild card/ jolly characters. The query returned a sample of 8,347 publications. Yet, this sample still included false positives (e.g. articles by authors at the "University of New South Wales"). These records were eliminated by manual screening returning a sample of 7,922 publications.

${ }_{16}$ The map was produced by using VOSviewer Version 1.5.4.

${ }^{17}$ The SCs not covered by the publication sample are reported in the followings: Agricultural Economics \& Policy; Agricultural Engineering; Agriculture, Dairy \& Animal Science; Agriculture, Multidisciplinary; Agronomy; Anthropology; Area Studies; Astronomy \& Astrophysics; Automation \& Control Systems; Business; Business, Finance; Computer Science, Cybernetics; Computer Science, Hardware \& Architecture; Computer Science, Software Engineering; Construction \& Building Technology; Criminology \& Penology; Crystallography; Cultural Studies; Demography; Electrochemistry; Energy \& Fuels; Engineering, Aerospace; Engineering, Chemical; Engineering, Civil; Engineering, Geological; Engineering, Industrial; Engineering, Marine; Engineering, Mechanical; Engineering, Ocean; Engineering, Petroleum; Entomology; Environmental Studies; Ergonomics; Fisheries; Forestry; Geochemistry \& Geophysics; Geography; Geography, Physical Geology; Geosciences, Multidisciplinary; Office of 
the top-20 SCs in terms of number of publications. These SCs represent $\sim 80 \%$ of the publication sample. Table 3.1 reveals that $33 \%$ of the sampled publications are published in specialist oncology journals. The other major categories are closely associated with clinical disciplines led by Surgery $\left(2^{\text {nd }}\right)$, Haematology $\left(3^{\text {rd }}\right)$, Radiology $\left(4^{\text {th }}\right)$, and Gastroenterology and Hepatology $\left(7^{\text {th }}\right)$, although basic sciences are well represented too such as Cell biology $\left(5^{\text {th }}\right)$, Biochemistry and Molecular Biology $\left(6^{\text {th }}\right)$ and Genetics and Heredity $\left(11^{\text {th }}\right)$.

Using the MeSH categorisation 'neoplasms' will inevitably miss some of those publications that might be deemed by researchers or funders to be associated with neoplasms. Coding is a subjective process and opinions may differ on whether a paper should be included or excluded. For example, a funder or researcher may consider studies of angiogenesis in healthy tissue to be relevant for understanding how tumours develop a blood supply, but if these papers are not considered to actually study cancerous tissue they may not be understood as within the study of neoplasms per se, and they will not be coded using the MeSH term 'C04'. The publications recovered by the searches employed in this study are therefore referred to as a 'sample', reflecting the fact that the search is exhaustive within the $\mathrm{CO} 4$ field, but not comprehensive of neoplasms by other definitions.

\section{Table A1: ISI WoS Subject Categories (SCs) representing 80\% of the publication sample.}

\begin{tabular}{rlc}
\hline & ISI WoS Subject Categories & Number of publications \\
\hline 1) & Oncology & 2,405 \\
2) & Surgery & 669 \\
3) & Hematology & 432 \\
$4)$ & Radiology, Nuclear Medicine and Medical Imaging & 412 \\
5) & Cell Biology & 405 \\
6) & Biochemistry and Molecular Biology & 369 \\
7) & Gastroenterology and Hepatology & 295 \\
$8)$ & Medicine, General and Internal & 287 \\
$9)$ & Public, Environmental and Occupational Health & 272 \\
$10)$ & Pathology & 247 \\
$11)$ & Genetics and Heredity & 242 \\
$12)$ & Obstetrics and Gynecology & 227 \\
$13)$ & Clinical Neurology & 203 \\
$14)$ & Urology and Nephrology & 193 \\
$15)$ & Pharmacology and Pharmacy & 169 \\
$16)$ & Health Care Sciences and Services & 163 \\
$17)$ & Medicine, Research and Experimental & 146 \\
$18)$ & Endocrinology and Metabolism & 136 \\
$19)$ & Biology & 129 \\
20) & Dermatology & 125 \\
\hline
\end{tabular}

Note. A journal can be assigned to more than one SC.

History; History Of Social Sciences; Horticulture; Hospitality, Leisure, Sport \& Tourism; Industrial Relations \& Labour; Information Science \& Library Science; International Relations; Law; Limnology; Management; Marine \& Freshwater Biology; Materials Science, Ceramics; Materials Science, Characterization \& Testing; Materials Science, Coatings \& Films; Materials Science, Composites; Materials Science, Paper \& Wood; Materials Science, Textiles; Mathematics; Mathematics, Applied; Mechanics; Metallurgy \& Metallurgical Engineering; Meteorology \& Atmospheric Sciences; Mineralogy; Mining \& Mineral Processing; Oceanography; Operations Research \& Management Science; Ornithology; Palaeontology; Physics, Fluids \& Plasmas; Physics, Mathematical; Physics, Multidisciplinary; Physics, Nuclear; Physics, Particles \& Fields; Planning \& Development; Plant Sciences; Political Science; Psychology, Applied; Psychology, Educational; Psychology, Mathematical; Psychology, Psychoanalysis; Public Administration; Remote Sensing; Robotics; Social Sciences, Mathematical Methods; Soil Science; Spectroscopy; Telecommunications; Thermodynamics; Transportation; Transportation Science \& Technology; Urban Studies; Water Resources; Women. 
Figure A1: Distribution of the publication sample over the ISI WoS SC - size of each node equal to log $\operatorname{lof}_{2}$ the number of publications in each SC; the map is based on 7,260 out 7,510 publications for which a SC can be identified.

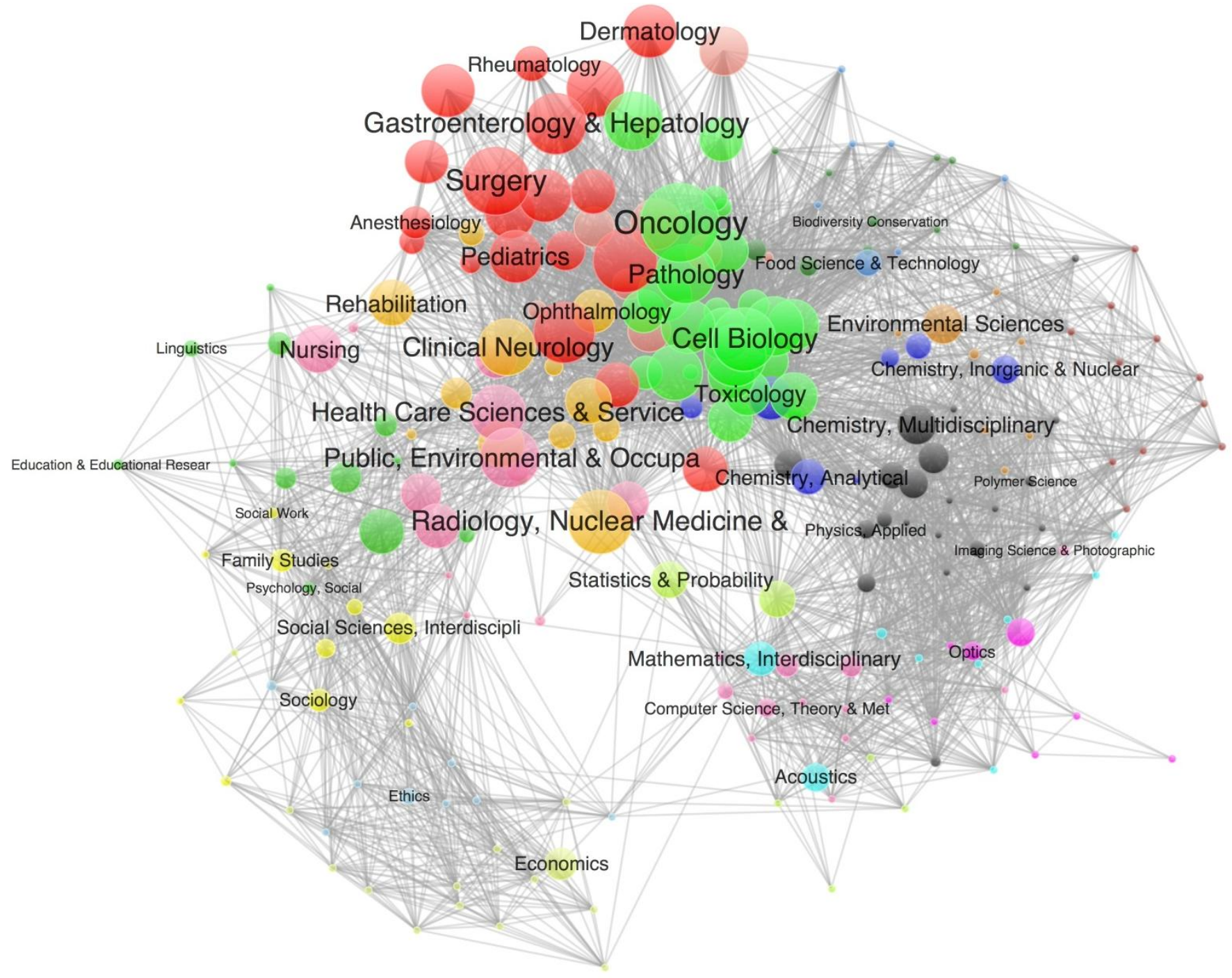

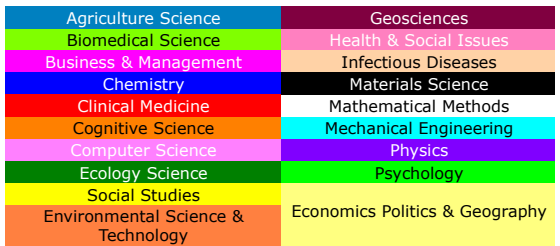

Office of 
Figure A2: SCOPUS classification of publications and coverage of funding data $(N=7,510)$

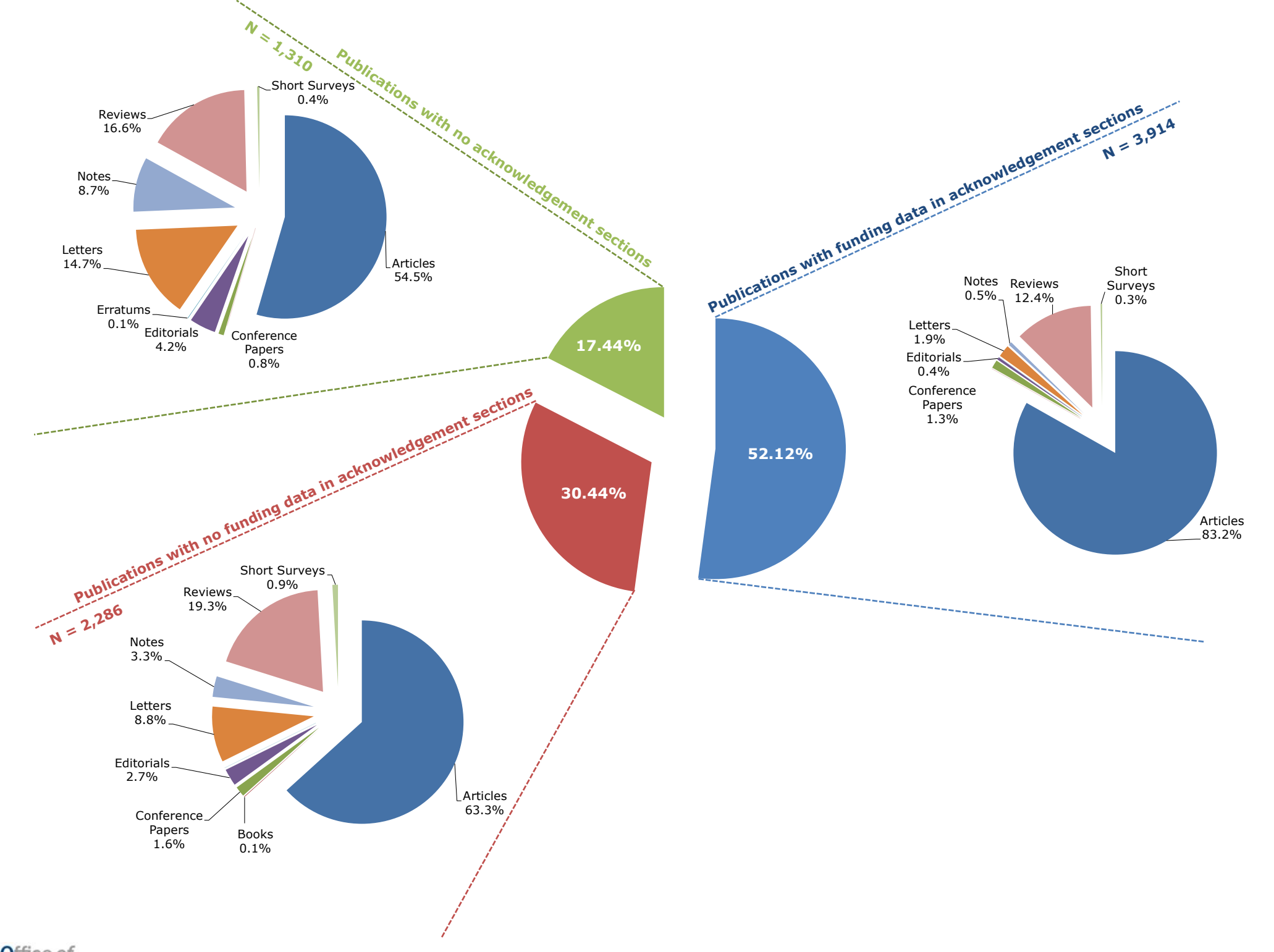




\section{A1.4 Extraction of information on acknowledgements}

The study relies on searches undertaken using automated software routines to read from the html code of publishers' web pages and where necessary to selectively download PDFs of the publications. The routines were designed to extract information under the following headings: (i) "Acknowledgements", (ii) "Funding", (iii) "Conflicts of Interest", (iv) "Financial Disclosure", (v) "Role of Funding Sources", (vi) "Financial Supports", (vii) "Competing Financial Interests", and (ix) "Statement of interests". We refer to all of the above wordings as 'acknowledgements' henceforth. The automated searches allowed the collection of acknowledgements from the majority of publications with manual checks of remaining papers. At completion the acknowledgements sections from $~ 83 \%$ of the publications in the sample were found, while the remaining $\sim 17 \%$ of papers had no acknowledgement sections (see Figure A2).

\section{A1.5 Identification of funders from acknowledgements in publications}

Acknowledgements were manually read by the research team to establish whether they mentioned the support of funders. A detailed protocol established guidelines for interpretation and coding of funding data, which was undertaken manually by a team of coders.

All sources of funding were recorded where authors indicated financial support for work leading to a publication. Other forms of support (colleagues reading drafts, helpful comments) were not coded. Declarations of conflicts of interest stemming from historic support, unrelated to the current publication, were excluded where possible.

These searches revealed 3,914 publications (52.1\%) that disclosed at least one funder in an acknowledgements section, and 2,286 (30.4\%) that did not acknowledge funding support but did make other forms of acknowledgement. A further 1,310 (17.4\%) of publications had no acknowledgement sections (see Figure A2).

\section{A1.6 Why do so many publications not acknowledge research funding?}

Around $48 \%$ of the 7510 publications in the sample do not directly disclose a source of funding. Prior studies of funding acknowledgements in UK biomedical research have found $39 \%$ of papers have no acknowledgement to a funder (Lewison et al. 1995), so this figure is high, but it is not unexpected for a large proportion of papers not to have acknowledgements to funders. There are several possible explanations for this:

a) The publications required little or no financial support to produce.

b) The publication required research funding but these details were omitted from the publication either by the author(s) or the publisher.

c) The publications were supported by the author(s) employer, who is acknowledged indirectly through the author(s) affiliation.

Reseach by Lewison et al. (1995) would lead us to expect that in the majority of casesreason (c) would be the most common explanation.

Figure A2 shows of the sample of 7,510 publications divided according to their disclosure or funders as well as by publication type. Publication type is an important distinction to make since some publications rely on more laboratory work or other research-intensive activity than others. SCOPUS makes the distinction between "Articles" and what are 
often less cost intensive publications to produce, such as "Reviews", "Letters", "Editorials" and "Notes".

The categorisation of publications by SCOPUS definition provides some evidence supporting explanation (a) as a higher proportion of publications with acknowledgements but no named funders are less cost intensive (37\%) than is the case for those with acknowledgements (17\%).

The NLM's MeSH descriptors for publication types allow further more detailed classification within the category of publications that SCOPUS defines as 'articles'. Again we searched for those publications that were perceived to be less cost intensive - such papers defined by MeSH descriptors as "Comments", "Case Reports", "Reviews", "Comparative Study", "Editorials", "Consensus Development Conferences", "Practical Guidelines", "English Abstract", and "Introductory Journal Articles". As with the SCOPUS typology above, the proportion of less cost intensive publications differs significantly between the subsamples of publications where acknowledgements contain funders and those that do not contain funders, with $27 \%$ of SCOPUS defined "Articles" with funding acknowledgements being classified as less cost intensive by MeSH descriptors while $67 \%$ of SCOPUS defined "Articles" without acknowledgement sections were of the less cost intensive types. This provides further evidence to support the high relevance of explanation (a).

To establish whether publications were omitting acknowledgements to funding sources due to explanations (b) and (c), it was necessary to directly investigate a sample of publications in more detail.

$2,286 / 7,510$ or $30.44 \%$ of the sample's publications have acknowledgements but no stated funders. Of these, $69 \%$ explicitly state they did not benefit from financial support. Of the remaining 31\%, 89 were selected at random for investigation (over $10 \%$ ). Of these, $14 / 89(\sim 16 \%)$ were deemed to be case reports and therefore it was assumed no funding (beyond the author's employer) was necessary to fund the publication. No further investigation was carried out for these publications. The remaining 75 were queried by e-mail to the corresponding author, and 28 responses obtained ( $37 \%$ response rate). Only $4 / 28$ ( $14 \%$ of respondents) revealed contribution by funders other than authors' employers in publications. However $14 / 28$ respondents suggested the research had been supported by their employer. We therefore cautiously conclude that explanation (c) is more frequently accurate than explanation (b).

Further enquires were needed for the distinct subset of publications in formats where some publishers do not permit author acknowledgements or in cases where authors may omit an acknowledgement section. $1,310 / 7,510$ or $17.44 \%$ of the sample's publications contained no acknowledgement sections. Of these, $208(\sim 16 \%)$ were selected at random for investigation. 79/208 (38\%) were classified as case reports and therefore it was assumed no funding (beyond the author's employer) was necessary to fund the publication. The remaining 129 were queried via email to the corresponding author, and 49 replies obtained ( $38 \%$ response rate). In $9 / 49$ responses $(18 \%)$, a funding contribution to the publication other than the authors' employers was revealed, although it is notable that $30 / 40$ revealed a contribution by their employer. Again this suggests that explanation (b) is less frequently accurate while explanation (c) is more commonly accurate. This is consistent with the findings of Lewison et al. (1995). 


\section{A1.7 Assumptions on funding disclosures and analytical implications}

A high-level quantitative analysis such as that described here will necessarily make strong assumptions about the consistency of the data.

From the above investigations it is concluded that in the vast majority of cases UK-based authors are disclosing external funders appropriately and therefore that the majority of publications resulting from cost intensive research acknowledge external funding.

Publications that do not contain acknowledgements are likely to be the result of less costly research and/or paid for by the author(s) host institution or employer. It is also important to note (as discussed above) that when prompted by email, authors frequently acknowledge the financial contribution of their employer, but it is clearly not an established practice to acknowledge the host organisation in an acknowledgement section. One interviewee gave some insight into this norm: "I think in general the acknowledgements, as I'm sure you know... if your employer mostly fund[s] your work it seems a bit strange to thank them for giving you a job, which in a sense is true but it sounds a bit odd."

Where a paper contains no funding acknowledgements, it is therefore appropriate to assume that the authors' employer or host organisation is funding the work. Indeed even where there is an external funder acknowledged, the employer (or otherwise host) institution should be thought of, if not acknowledged, as a funder because, as explained in Chapter 2, the costs of research are borne by external funders and host organisations albeit to different extents. For example UK research councils reimburse research grant holders $80 \%$ of the full economic cost of research they undertake, while charities reimburse typically around $60 \%$, with HEI support in England topping this up to $80 \%$ FEC (UKCRC 2012 p.20).

One major exception is that contributions by HEFCE, which distributes funding to researchers via their universities on the basis of quality performance of researchers in each institution as measured by exercises such as the Research Excellence Framework. Outputs stemming from HEFCE funding are not recorded because researchers rarely acknowledge this source of funding (even though 40 universities receive HEFCE funding for biological sciences alone). ${ }^{18}$

Taking the above limitations into account it is theoretically possible to undertake three analytical perspectives for the analysis of outputs from research funding support:

1) Publications supported fully or partially by one or more external funders

2) Publications fully or partially supported by one or more host organisations

3) Publications supported by a combination of host organisations and external funders

However, given that in some substantial cases external funders also fund host organisations, the third perspective is likely to produce results that are less robust and transparent than (1) and (2) individually. An exception is the case where industrial funding is concerned, due to higher transparency in the UK over recent years in the disclosure of industry support for research. The analysis presented in this study has for

18 http://www.hefce.ac.uk/whatwedo/rsrch/howfundr/mainstreamar/ 
the most part therefore will focused on either the contributions of host organisations, or the contributions of external funders.

\section{A1.8 Standardisation of funders names, author affiliations and aggregation of related organisations}

Where funders are acknowledged, this may often be directly by name of organisation (in full or abbreviated form), section, funding scheme or even by grant number alone. To address the three above-discussed analytical perspectives, it was necessary to harmonise all funder names. ${ }^{19}$ All funders were also geographically coded.

The same process was followed for the authors' affiliations (research host organisations). All authors routinely report at least one affiliation and related address details in each publication. This information allows publications to be organisationally and geographically classified. However, to count data consistently it is necessary to harmonise organisations' names and relative addresses. This is often challenging given that address details may describe teams/groups, departments, sites, organisations and clusters of organisations. Some detail levels may also be missing. For example, a researcher at the "Royal Free Hospital in London" may describe their affiliation as such or use the higher level affiliation, "University College London Hospitals NHS Trust". Furthermore individuals may not be consistent and individuals within the same organisation will often observe different practices. It is therefore appropriate to use higher level affiliation details for consistency, even though this results in the loss of some granularity of the data.

Manual identification of organisational linkages and aggregation to the highest level of organisational group was undertaken using Google-based web searches as well as the Cancer Research UK list of organisational groups for clusters of UK research institutions.

\section{Table A2: MeSH Descriptors 2013 (source: PubMED/MEDLINE)}

Note: Each band denotes a distinct $3^{\text {rd }}$ level heading. Codes within a band are subsections of the first code in the band

\begin{tabular}{ll}
\hline MeSH Heading & Tree Number \\
\hline Neoplasms & C04 \\
Cysts & C04.182 \\
Arachnoid Cysts & C04.182.044 \\
Bone Cysts & C04.182.089 \\
Bone Cysts, Aneurysmal & C04.182.089.265 \\
Jaw Cysts & C04.182.089.530 \\
Nonodontogenic Cysts & C04.182.089.530.660 \\
Odontogenic Cysts & C04.182.089.530.690 \\
Basal Cell Nevus Syndrome & C04.182.089.530.690.150 \\
Dentigerous Cyst & C04.182.089.530.690.310 \\
Odontogenic Cyst, Calcifying & C04.182.089.530.690.605 \\
Periodontal Cyst & C04.182.089.530.690.790 \\
Radicular Cyst & C04.182.089.530.690.790.820 \\
Branchioma & C04.182.117 \\
Breast Cyst & C04.182.156 \\
Bronchogenic Cyst & C04.182.195 \\
Chalazion & C04.182.197 \\
Choledochal Cyst & C04.182.198 \\
Colloid Cysts & C04.182.199 \\
Dermoid Cyst & C04.182.201 \\
Epidermal Cyst & C04.182.254 \\
Esophageal Cyst & C04.182.281 \\
Follicular Cyst & C04.182.300 \\
\hline
\end{tabular}

19 The harmonisation process was manually conducted with the support of "The Vantage Point" software.
Office of
Health
Economics
Research\&Consulting 
Hodgkin Disease

Immunoproliferative Small Intestinal Disease

Lymphoma, Non-Hodgkin

Burkitt Lymphoma

Lymphoma, B-Cell

Burkitt Lymphoma

Lymphoma, AIDS-Related

Lymphoma, B-Cell, Marginal Zone

Lymphoma, Large B-Cell, Diffuse

Lymphoma, Primary Effusion

Lymphomatoid Granulomatosis

Lymphoma, Follicular

Lymphoma, Large-Cell, Anaplastic

Lymphoma, Large-Cell, Immunoblastic

Lymphoma, Mantle-Cell

Lymphoma, T-Cell

Enteropathy-Associated T-Cell Lymphoma

Lymphoma, Extranodal NK-T-Cell

Lymphoma, Large-Cell, Anaplastic

Lymphoma, T-Cell, Cutaneous

Lymphoma, Primary Cutaneous Anaplastic Large Cell

Lymphomatoid Papulosis

Mycosis Fungoides

Pagetoid Reticulosis

Sezary Syndrome

Lymphoma, T-Cell, Peripheral

Neoplasms, Complex and Mixed

Adenolymphoma

Adenoma, Pleomorphic

Adenomyoepithelioma

Adenomyoma

Adenosarcoma

Carcinoma, Adenosquamous

Carcinosarcoma

Carcinoma 256, Walker

Composite Lymphoma

Hepatoblastoma

Mesenchymoma

Mixed Tumor, Malignant

Mixed Tumor, Mesodermal

Mixed Tumor, Mullerian

Myoepithelioma

Wilms Tumor

Denys-Drash Syndrome

WAGR Syndrome

Nephroma, Mesoblastic

Pulmonary Blastoma

Rhabdoid Tumor

Sarcoma, Endometrial Stromal

Thymoma

Neoplasms, Connective and Soft Tissue

Neoplasms, Adipose Tissue

Angiolipoma

Angiomyolipoma

Lipoma

Lipoblastoma

Liposarcoma

Liposarcoma, Myxoid

Myelolipoma

Neoplasms, Connective Tissue

Chondroblastoma

Chondroma

Chondromatosis

Chondrosarcoma

Chondrosarcoma, Mesenchymal

Endometrial Stromal Tumors

Gastrointestinal Stromal Tumors

Giant Cell Tumors

Giant Cell Tumor of Bone

Mastocytosis

Mast-Cell Sarcoma

Mastocytoma

Mastocytoma, Skin

Mastocytosis, Cutaneous

Mastocytoma, Skin

Urticaria Pigmentosa

Mastocytosis, Systemic

Leukemia, Mast-Cell

Myofibroma

Myxoma

Carney Complex
C04.557.386.355

C04.557.386.390

C04.557.386.480

C04.557.386.480.100

C04.557.386.480.150

C04.557.386.480.150.165

C04.557.386.480.150.450

C04.557.386.480.150.570

C04.557.386.480.150.585

C04.557.386.480.150.592

C04.557.386.480.150.600

C04.557.386.480.350

C04.557.386.480.487

C04.557.386.480.493

C04.557.386.480.525

C04.557.386.480.750

C04.557.386.480.750.099

C04.557.386.480.750.199

C04.557.386.480.750.399

C04.557.386.480.750.800

C04.557.386.480.750.800.507

C04.557.386.480.750.800.528

C04.557.386.480.750.800.550

C04.557.386.480.750.800.550.600

C04.557.386.480.750.800.775

C04.557.386.480.750.825

C04.557.435

C04.557.435.075

C04.557.435.090

C04.557.435.108

C04.557.435.110

C04.557.435.135

C04.557.435.250

C04.557.435.290

C04.557.435.290.210

C04.557.435.295

C04.557.435.380

C04.557.435.500

C04.557.435.525

C04.557.435.530

C04.557.435.540

C04.557.435.585

C04.557.435.595

C04.557.435.595.220

C04.557.435.595.950

C04.557.435.600

C04.557.435.675

C04.557.435.710

C04.557.435.775

C04.557.435.850

C04.557.450

C04.557.450.550

C04.557.450.550.100

04.557 .450 .550 .125

C04.557.450.550.400

C04.557.450.550.400.500

C04.557.450.550.420

C04.557.450.550.420.425

C04.557.450.550.710

C04.557.450.565

C04.557.450.565.250

C04.557.450.565.265

C04.557.450.565.265.270

C04.557.450.565.280

C04.557.450.565.280.280

C04.557.450.565.325

C04.557.450.565.370

C04.557.450.565.380

C04.557.450.565.380.380

C04.557.450.565.465

C04.557.450.565.465.124

C04.557.450.565.465.249

C04.557.450.565.465.249.500

C04.557.450.565.465.500

C04.557.450.565.465.500.500

C04.557.450.565.465.500.850

C04.557.450.565.465.750

C04.557.450.565.465.750.500

C04.557.450.565.540

C04.557.450.565.550

C04.557.450.565.550.312 
Neurothekeoma

Myxosarcoma

Neoplasms, Bone Tissue

Fibroma, Ossifying

Giant Cell Tumor of Bone

Osteoblastoma

Osteochondroma

Osteochondromatosis

Exostoses, Multiple Hereditary

Osteoma

Osteoma, Osteoid

Osteosarcoma

Osteosarcoma, Juxtacortical

Sarcoma, Ewing

Neoplasms, Fibrous Tissue

Fibroma

Fibroma, Desmoplastic

Fibroma, Ossifying

Fibromatosis, Abdominal

Fibromatosis, Aggressive

Fibrosarcoma

Dermatofibrosarcoma

Neurofibrosarcoma

Histiocytoma

Histiocytoma, Benign Fibrous

Histiocytoma, Malignant Fibrous

Myofibromatosis

Neoplasms, Fibroepithelial

Adenofibroma

Cystadenofibroma

Brenner Tumor

Fibroadenoma

Solitary Fibrous Tumors

Solitary Fibrous Tumor, Pleural

Sarcoma, Clear Cell

Sarcoma, Small Cell

Sarcoma, Synovial

Neoplasms, Muscle Tissue

Granular Cell Tumor

Leiomyoma

Angiomyoma

Leiomyoma, Epithelioid

Leiomyomatosis

Leiomyosarcoma

Myoma

Rhabdomyoma

Myosarcoma

Rhabdomyosarcoma

Rhabdomyosarcoma, Alveolar

Rhabdomyosarcoma, Embryonal

Sarcoma, Alveolar Soft Part

Smooth Muscle Tumor

Perivascular Epithelioid Cell Neoplasms

Angiomyolipoma

Lymphangioleiomyomatosis

Sarcoma

Adenosarcoma

Carcinosarcoma

Carcinoma 256, Walker

Chondrosarcoma

Chondrosarcoma, Mesenchyma

Desmoplastic Small Round Cell Tumor

Endometrial Stromal Tumors

Sarcoma, Endometrial Stromal

Fibrosarcoma

Dermatofibrosarcoma

Neurofibrosarcoma

Hemangiosarcoma

Histiocytoma, Malignant Fibrous

Leiomyosarcoma

Liposarcoma

Liposarcoma, Myxoid

Lymphangiosarcoma

Mixed Tumor, Mesodermal

Myosarcoma

Rhabdomyosarcoma

Rhabdomyosarcoma, Alveolar

Rhabdomyosarcoma, Embryonal

Myxosarcoma

Osteosarcoma

Osteosarcoma, Juxtacortical
C04.557.450.565.550.625

C04.557.450.565.560

C04.557.450.565.575

C04.557.450.565.575.400

C04.557.450.565.575.420

C04.557.450.565.575.600

C04.557.450.565.575.610

C04.557.450.565.575.610.615

C04.557.450.565.575.610.615.325

C04.557.450.565.575.625

C04.557.450.565.575.625.625

C04.557.450.565.575.650

C04.557.450.565.575.650.655

C04.557.450.565.575.650.800

C04.557.450.565.590

C04.557.450.565.590.340

C04.557.450.565.590.340.345

C04.557.450.565.590.340.360

C04.557.450.565.590.340.400

C04.557.450.565.590.340.410

C04.557.450.565.590.350

C04.557.450.565.590.350.320

C04.557.450.565.590.350.590

C04.557.450.565.590.425

C04.557.450.565.590.425.350

C04.557.450.565.590.425.360

C04.557.450.565.590.550

C04.557.450.565.590.595

C04.557.450.565.590.595.050

C04.557.450.565.590.595.050.500

C04.557.450.565.590.595.150

C04.557.450.565.590.595.350

C04.557.450.565.590.797

C04.557.450.565.590.797.750

C04.557.450.565.800

C04.557.450.565.825

C04.557.450.565.835

C04.557.450.590

C04.557.450.590.350

C04.557.450.590.450

C04.557.450.590.450.125

C04.557.450.590.450.455

C 04.557 .450 .590 .450 .465

C04.557.450.590.455

C04.557.450.590.540

C04.557.450.590.540.700

C04.557.450.590.550

C04.557.450.590.550.660

C04.557.450.590.550.660.665

C04.557.450.590.550.660.675

C04.557.450.590.775

C04.557.450.590.800

C04.557.450.692

C04.557.450.692.249

C04.557.450.692.500

C04.557.450.795

C04.557.450.795.135

C04.557.450.795.290

C04.557.450.795.290.210

C04.557.450.795.300

C04.557.450.795.300.280

C04.557.450.795.315

C04.557.450.795.332

C04.557.450.795.332.500

C04.557.450.795.350

C04.557.450.795.350.320

C04.557.450.795.350.590

C04.557.450.795.390

C04.557.450.795.400

C04.557.450.795.455

C04.557.450.795.465

C04.557.450.795.465.425

C04.557.450.795.480

C04.557.450.795.530

C04.557.450.795.550

C04.557.450.795.550.660

C04.557.450.795.550.660.665

04.557 .450 .795 .550 .660 .675

C04.557.450.795.560

C04.557.450.795.620 C04.557.450.795.620.655 
Sarcoma, Ewing

Phyllodes Tumor

Sarcoma, Alveolar Soft Part

Sarcoma, Clear Cell

Sarcoma, Experimental

Sarcoma 37

Sarcoma 180

Sarcoma, Avian

Sarcoma, Yoshida

Sarcoma, Kaposi

Sarcoma, Myeloid

Sarcoma, Small Cell

Sarcoma, Synovial

Neoplasms, Germ Cell and Embryonal

Carcinoma, Embryonal

Chordoma

Germinoma

Dysgerminoma

Seminoma

Gonadoblastoma

Mesonephroma

Endodermal Sinus Tumor

Neuroectodermal Tumors

Craniopharyngioma

Neoplasms, Neuroepithelial

Ganglioneuroma

Glioma

Astrocytoma

Glioblastoma

Optic Nerve Glioma

Ependymoma

Glioma, Subependymal

Ganglioglioma

Gliosarcoma

Medulloblastoma

Oligodendroglioma

Optic Nerve Glioma

Neurocytoma

Neuroectodermal Tumors, Primitive

Medulloblastoma

Neuroectodermal Tumors, Primitive, Peripheral

Neuroblastoma

Esthesioneuroblastoma, Olfactory

Ganglioneuroblastoma

Pinealoma

Retinoblastoma

Neuroectodermal Tumor, Melanotic

Neuroendocrine Tumors

Adenoma, Acidophil

Adenoma, Basophil

Adenoma, Chromophobe

Apudoma

Carcinoid Tumor

Malignant Carcinoid Syndrome

Carcinoid Heart Disease

Carcinoma, Neuroendocrine

Carcinoma, Medullary

Carcinoma, Merkel Cell

Somatostatinoma

Vipoma

Melanoma

Hutchinson's Melanotic Freckle

Melanoma, Amelanotic

Melanoma, Experimenta

Neurilemmoma

Neuroma, Acoustic

Neurofibromatosis 2

Paraganglioma

Paraganglioma, Extra-Adrenal

Carotid Body Tumor

Glomus Jugulare Tumor

Glomus Tympanicum Tumor

Pheochromocytoma

Teratocarcinoma

Teratoma

Dermoid Cyst

Struma Ovarii

Trophoblastic Neoplasms

Choriocarcinoma

Choriocarcinoma, Non-gestationa

Trophoblastic Tumor, Placental Site
C04.557.450.795.620.800

C04.557.450.795.650

C04.557.450.795.775

C04.557.450.795.800

C04.557.450.795.830

C04.557.450.795.830.760

C04.557.450.795.830.780

C04.557.450.795.830.800

C04.557.450.795.830.850

C04.557.450.795.850

C04.557.450.795.853

C04.557.450.795.870

C04.557.450.795.875

C04.557.465

C04.557.465.200

C04.557.465.220

C04.557.465.330

C04.557.465.330.300

C04.557.465.330.800

C04.557.465.420

C04.557.465.510

C04.557.465.510.350

C04.557.465.625

C04.557.465.625.200

C04.557.465.625.600

C04.557.465.625.600.355

C04.557.465.625.600.380

C04.557.465.625.600.380.080

C04.557.465.625.600.380.080.335

C04.557.465.625.600.380.080.667

C04.557.465.625.600.380.290

C04.557.465.625.600.380.290.390

C04.557.465.625.600.380.350

C04.557.465.625.600.380.400

C04.557.465.625.600.380.515

C04.557.465.625.600.380.590

C04.557.465.625.600.380.795

C04.557.465.625.600.580

C04.557.465.625.600.590

C04.557.465.625.600.590.500

C04.557.465.625.600.590.650

C04.557.465.625.600.590.650.550

C04.557.465.625.600.590.650.550.150

04.557 .465 .625 .600 .590 .650 .550 .300

C04.557.465.625.600.657

C04.557.465.625.600.725

C04.557.465.625.630

C04.557.465.625.650

C04.557.465.625.650.025

C04.557.465.625.650.075

C04.557.465.625.650.095

C04.557.465.625.650.135

C04.557.465.625.650.200

C04.557.465.625.650.200.500

C04.557.465.625.650.200.500.205

C04.557.465.625.650.240

C04.557.465.625.650.240.315

C04.557.465.625.650.240.325

C04.557.465.625.650.240.695

C04.557.465.625.650.240.847

04.557 .465 .625 .650 .510

C04.557.465.625.650.510.385

C04.557.465.625.650.510.515

C04.557.465.625.650.510.525

C04.557.465.625.650.595

C04.557.465.625.650.595.610

C04.557.465.625.650.595.610.500

C04.557.465.625.650.700

C04.557.465.625.650.700.705

C04.557.465.625.650.700.705.220

C04.557.465.625.650.700.705.340

C04.557.465.625.650.700.705.360

C04.557.465.625.650.700.725

C04.557.465.900

C04.557.465.910

C04.557.465.910.250

C04.557.465.910.850

C04.557.465.955

C04.557.465.955.207

C04.557.465.955.207.750

C04.557.465.955.207.875 
Gestational Trophoblastic Disease

Choriocarcinoma

Trophoblastic Tumor, Placental Site

Hydatidiform Mole

Hydatidiform Mole, Invasive

Neoplasms, Glandular and Epithelial

Adenoma

ACTH-Secreting Pituitary Adenoma

Adenoma, Acidophil

Adenoma, Basophil

Adenoma, Bile Duct

Adenoma, Chromophobe

Adenoma, Islet Cell

Insulinoma

Adenoma, Liver Cell

Adenoma, Oxyphilic

Adenoma, Pleomorphic

Adenoma, Sweat Gland

Acrospiroma

Poroma

Hidrocystoma

Syringoma

Adenoma, Villous

Adenomatoid Tumor

Adenomatosis, Pulmonary

Adenomatous Polyps

Adenomatous Polyposis Coli

Gardner Syndrome

Adrenal Rest Tumor

Apudoma

Cystadenoma

Cystadenoma, Mucinous

Cystadenoma, Papillary

Cystadenoma, Serous

Growth Hormone-Secreting Pituitary Adenoma

Mesothelioma

Mesothelioma, Cystic

Prolactinoma

Carcinoma

Adenocarcinoma

Adenocarcinoma, Bronchiolo-Alveolar

Adenocarcinoma, Clear Cell

Adenocarcinoma, Follicular

Carcinoma, Papillary, Follicular

Adenocarcinoma, Mucinous

Adenocarcinoma, Papillary

Carcinoma, Papillary, Follicular

Adenocarcinoma, Scirrhous

Linitis Plastica

Adenocarcinoma, Sebaceous

Adrenocortical Carcinoma

Carcinoid Tumor

Malignant Carcinoid Syndrome

Carcinoid Heart Disease

Carcinoma, Acinar Cel

Carcinoma, Adenoid Cystic

Carcinoma, Ductal

Carcinoma, Ductal, Breast

Carcinoma, Pancreatic Ductal

Carcinoma, Endometrioid

Carcinoma, Hepatocellular

Carcinoma, Intraductal, Noninfiltrating

Paget's Disease, Mammary

Carcinoma, Islet Cell

Gastrinoma

Glucagonoma

Carcinoma, Lobular

Carcinoma, Mucoepidermoid

Carcinoma, Neuroendocrine

Carcinoma, Medullary

Carcinoma, Merkel Cell

Somatostatinoma

Vipoma

Carcinoma, Renal Cell

Carcinoma, Signet Ring Cell

Krukenberg Tumor

Carcinoma, Skin Appendage

Cholangiocarcinoma

Choriocarcinoma

Choriocarcinoma, Non-gestationa

Trophoblastic Tumor, Placental Site
C04.557.465.955.416

C04.557.465.955.416.202

C04.557.465.955.416.202.875

C04.557.465.955.416.812

C04.557.465.955.416.812.500

C04.557.470

C04.557.470.035

C04.557.470.035.012

C04.557.470.035.025

C04.557.470.035.075

C04.557.470.035.085

C04.557.470.035.095

C04.557.470.035.100

04.557 .470 .035 .100 .852

C04.557.470.035.120

C04.557.470.035.140

C04.557.470.035.155

C04.557.470.035.175

C04.557.470.035.175.125

C04.557.470.035.175.125.600

C04.557.470.035.175.375

C04.557.470.035.175.800

C04.557.470.035.185

C04.557.470.035.200

C04.557.470.035.210

C04.557.470.035.215

C04.557.470.035.215.100

C04.557.470.035.215.100.500

C04.557.470.035.232

C04.557.470.035.250

C04.557.470.035.320

C04.557.470.035.320.225

C04.557.470.035.320.230

C04.557.470.035.320.240

C04.557.470.035.415

C04.557.470.035.510

C04.557.470.035.510.515

C04.557.470.035.625

C04.557.470.200

C04.557.470.200.025

C04.557.470.200.025.030

C04.557.470.200.025.045

C04.557.470.200.025.060

C04.557.470.200.025.060.225

C04.557.470.200.025.075

C04.557.470.200.025.085

C04.557.470.200.025.085.225

C04.557.470.200.025.095

C04.557.470.200.025.095.410

C04.557.470.200.025.105

C04.557.470.200.025.152

C04.557.470.200.025.200

C04.557.470.200.025.200.500

C04.557.470.200.025.200.500.205

C04.557.470.200.025.215

C04.557.470.200.025.220

C04.557.470.200.025.232

C04.557.470.200.025.232.500

C04.557.470.200.025.232.750

C04.557.470.200.025.240

C04.557.470.200.025.255

C04.557.470.200.025.275

C04.557.470.200.025.275.625

C04.557.470.200.025.290

C04.557.470.200.025.290.500

C04.557.470.200.025.290.750

C04.557.470.200.025.305

C04.557.470.200.025.340

C04.557.470.200.025.370

C04.557.470.200.025.370.315

04.557 .470 .200 .025 .370 .325

C04.557.470.200.025.370.695

C04.557.470.200.025.370.847

C04.557.470.200.025.390

C04.557.470.200.025.415

C04.557.470.200.025.415.410

C04.557.470.200.025.420

04.557 .470 .200 .025 .450

C04.557.470.200.025.455

C04.557.470.200.025.455.750 C04.557.470.200.025.455.875 
Cystadenocarcinoma

Cystadenocarcinoma, Mucinous

Cystadenocarcinoma, Papillary

Cystadenocarcinoma, Serous

Eccrine Porocarcinoma

Klatskin's Tumor

Paget Disease, Extramammary

Pulmonary Adenomatosis, Ovine

Carcinoma, Adenosquamous

Carcinoma, Basal Cell

Basal Cell Nevus Syndrome

Carcinoma, Basosquamous

Carcinoma, Ehrlich Tumor

Carcinoma, Giant Cell

Carcinoma in Situ

Cervical Intraepithelial Neoplasia

Prostatic Intraepithelial Neoplasia

Carcinoma, Krebs 2

Carcinoma, Large Cell

Carcinoma, Lewis Lung

Carcinoma, Papillary

Carcinoma, Small Cell

Carcinoma, Squamous Cell

Bowen's Disease

Carcinoma, Transitional Cell

Carcinoma, Verrucous

Buschke-Lowenstein Tumor

Neoplasms, Adnexal and Skin Appendage

Adenocarcinoma, Sebaceous

Adenoma, Sweat Gland

Acrospiroma

Poroma

Hidrocystoma

Syringoma

Carcinoma, Skin Appendage

Neoplasms, Basal Cell

Carcinoma, Basal Cell

Basal Cell Nevus Syndrome

Carcinoma, Basosquamous

Pilomatrixoma

Neoplasms, Cystic, Mucinous, and Serous

Adenocarcinoma, Mucinous

Carcinoma, Mucoepidermoid

Carcinoma, Signet Ring Cell

Krukenberg Tumor

Cystadenocarcinoma

Cystadenocarcinoma, Mucinous

Cystadenocarcinoma, Papillary

Cystadenocarcinoma, Serous

Cystadenofibroma

Cystadenoma

Cystadenoma, Mucinous

Cystadenoma, Papillary

Cystadenoma, Serous

Mucoepidermoid Tumor

Pseudomyxoma Peritonei

Neoplasms, Ductal, Lobular, and Medullary

Carcinoma, Ductal

Carcinoma, Ductal, Breast

Carcinoma, Pancreatic Ductal

Carcinoma, Intraductal, Noninfiltrating

Paget's Disease, Mammary

Carcinoma, Lobular

Carcinoma, Medullary

Paget Disease, Extramammary

Papilloma, Intraductal

Neoplasms, Fibroepithelial

Adenofibroma

Cystadenofibroma

Brenner Tumor

Fibroadenoma

Neoplasms, Mesothelial

Adenomatoid Tumor

Mesothelioma

Mesothelioma, Cystic

Neoplasms, Neuroepithelial

Ganglioneuroma

Glioma

Astrocytoma

Glioblastoma

Optic Nerve Glioma
C04.557.470.200.025.480

C04.557.470.200.025.480.225

C04.557.470.200.025.480.230

C04.557.470.200.025.480.240

C04.557.470.200.025.500

C04.557.470.200.025.540

C04.557.470.200.025.660

C04.557.470.200.025.715

C04.557.470.200.150

C04.557.470.200.165

C04.557.470.200.165.150

C04.557.470.200.170

C04.557.470.200.200

C04.557.470.200.220

C04.557.470.200.240

C04.557.470.200.240.250

C04.557.470.200.240.500

C04.557.470.200.255

C04.557.470.200.260

C04.557.470.200.280

C04.557.470.200.360

C04.557.470.200.380

C04.557.470.200.400

C04.557.470.200.400.130

C04.557.470.200.430

C04.557.470.200.450

C04.557.470.200.450.500

C04.557.470.550

C04.557.470.550.105

C04.557.470.550.175

C04.557.470.550.175.125

C04.557.470.550.175.125.600

C04.557.470.550.175.375

C04.557.470.550.175.800

C04.557.470.550.420

C04.557.470.565

C04.557.470.565.165

C04.557.470.565.165.150

C04.557.470.565.170

C04.557.470.565.625

C04.557.470.590

C04.557.470.590.075

C04.557.470.590.340

C04.557.470.590.415

C04.557.470.590.415.410

C04.557.470.590.480

C04.557.470.590.480.225

C04.557.470.590.480.230

C04.557.470.590.480.240

C04.557.470.590.482

C04.557.470.590.485

C04.557.470.590.485.225

C04.557.470.590.485.230

C04.557.470.590.485.240

C04.557.470.590.580

C04.557.470.590.782

C04.557.470.615

C04.557.470.615.132

C04.557.470.615.132.500

C04.557.470.615.132.750

C04.557.470.615.275

C04.557.470.615.275.625

C04.557.470.615.305

C04.557.470.615.315

C04.557.470.615.660

C04.557.470.615.670

C04.557.470.625

C04.557.470.625.050

C04.557.470.625.050.500

C04.557.470.625.150

C04.557.470.625.350

C04.557.470.660

C04.557.470.660.200

C04.557.470.660.510

C04.557.470.660.510.515

C04.557.470.670

C04.557.470.670.355

C04.557.470.670.380

C04.557.470.670.380.080

C04.557.470.670.380.080.335

C04.557.470.670.380.080.667 
Ependymoma

Glioma, Subependymal

Ganglioglioma

Gliosarcoma

Medulloblastoma

Oligodendroglioma

Optic Nerve Glioma

Neurocytoma

Neuroectodermal Tumors, Primitive

Medulloblastoma

Neuroectodermal Tumors, Primitive, Peripheral

Neuroblastoma

Esthesioneuroblastoma, Olfactory

Ganglioneuroblastoma

Pinealoma

Retinoblastoma

Neoplasms, Squamous Cell

Acanthoma

Carcinoma, Papillary

Carcinoma, Squamous Cell

Bowen's Disease

Carcinoma, Verrucous

Buschke-Lowenstein Tumor

Papilloma

Papilloma, Inverted

Neoplasms, Gonadal Tissue

Gonadoblastoma

Sex Cord-Gonadal Stromal Tumors

Granulosa Cell Tumor

Luteoma

Sertoli-Leydig Cell Tumor

Leydig Cell Tumor

Sertoli Cell Tumor

Thecoma

Neoplasms, Nerve Tissue

Meningioma

Nerve Sheath Neoplasms

Neurilemmoma

Neurofibroma

Neurofibroma, Plexiform

Neurofibromatoses

Neurofibromatosis 1

Neurofibromatosis 2

Neurofibrosarcoma

Neurofibrosarcoma

Neuroma

Neurilemmoma

Neuroma, Acoustic

Neurofibromatosis 2

Neurothekeoma

Neuroectodermal Tumors

Craniopharyngioma

Neoplasms, Neuroepithelial

Ganglioneuroma

Glioma

Astrocytoma

Glioblastoma

Optic Nerve Glioma

Ependymoma

Glioma, Subependymal

Ganglioglioma

Gliosarcoma

Medulloblastoma

Oligodendroglioma

Optic Nerve Glioma

Neurocytoma

Neuroectodermal Tumors, Primitive

Medulloblastoma

Neuroectodermal Tumors, Primitive, Peripheral

Neuroblastoma

Esthesioneuroblastoma, Olfactory

Ganglioneuroblastoma

Pinealoma

Retinoblastoma

Neuroectodermal Tumor, Melanotic

Neuroendocrine Tumors

Adenoma, Acidophil

Adenoma, Basophil

Adenoma, Chromophobe

Apudoma

Carcinoid Tumor
C04.557.470.670.380.290

C04.557.470.670.380.290.390

C04.557.470.670.380.350

C04.557.470.670.380.400

C04.557.470.670.380.515

C04.557.470.670.380.590

C04.557.470.670.380.795

C04.557.470.670.580

C04.557.470.670.590

C04.557.470.670.590.500

C04.557.470.670.590.650

C04.557.470.670.590.650.550

C04.557.470.670.590.650.550.150

C04.557.470.670.590.650.550.300

C04.557.470.670.657

C04.557.470.670.725

C04.557.470.700

C04.557.470.700.040

C04.557.470.700.360

C04.557.470.700.400

C04.557.470.700.400.130

C04.557.470.700.450

C04.557.470.700.450.500

04.557 .470 .700 .600

C04.557.470.700.600.610

C04.557.475

C04.557.475.395

C04.557.475.750

C04.557.475.750.656

C04.557.475.750.751

C04.557.475.750.847

C04.557.475.750.847.249

C04.557.475.750.847.500

C04.557.475.750.875

C04.557.580

C04.557.580.520

04.557 .580 .600

C04.557.580.600.290

C04.557.580.600.580

C04.557.580.600.580.585

C04.557.580.600.580.590

C04.557.580.600.580.590.650

C04.557.580.600.580.590.655

C04.557.580.600.580.795

C04.557.580.600.590

C04.557.580.600.610

C04.557.580.600.610.595

C04.557.580.600.610.595.610

C04.557.580.600.610.595.610.500

C04.557.580.600.625

C04.557.580.625

C04.557.580.625.200

C04.557.580.625.600

C04.557.580.625.600.355

C04.557.580.625.600.380

C04.557.580.625.600.380.080

C04.557.580.625.600.380.080.335

C04.557.580.625.600.380.080.667

C04.557.580.625.600.380.290

C04.557.580.625.600.380.290.390

C04.557.580.625.600.380.350

C04.557.580.625.600.380.400

C04.557.580.625.600.380.515

C04.557.580.625.600.380.590

C04.557.580.625.600.380.795

C04.557.580.625.600.580

C04.557.580.625.600.590

C04.557.580.625.600.590.500

C04.557.580.625.600.590.650

C04.557.580.625.600.590.650.550

C04.557.580.625.600.590.650.550.150

C04.557.580.625.600.590.650.550.300

C04.557.580.625.600.657

C04.557.580.625.600.725

C04.557.580.625.630

C04.557.580.625.650

C04.557.580.625.650.025

C04.557.580.625.650.075

C04.557.580.625.650.095

C04.557.580.625.650.135

C04.557.580.625.650.200 
Malignant Carcinoid Syndrome

Carcinoid Heart Disease

Carcinoma, Neuroendocrine

Carcinoma, Medullary

Carcinoma, Merkel Cell

Melanoma

Hutchinson's Melanotic Freckle

Melanoma, Amelanotic

Melanoma, Experimental

Neurilemmoma

Neuroma, Acoustic

Paraganglioma

Paraganglioma, Extra-Adrena

Carotid Body Tumor

Glomus Jugulare Tumor

Glomus Tympanicum Tumor

Pheochromocytoma

Neoplasms, Plasma Cell

Multiple Myeloma

Leukemia, Plasma Cell

Plasmacytoma

Waldenstrom Macroglobulinemia

Neoplasms, Vascular Tissue

Angiofibroma

Angiokeratoma

Glomus Tumor

Hemangioma

Central Nervous System Venous Angioma

Hemangioendothelioma

Hemangioendothelioma, Epithelioid

Hemangioma, Capillary

Hemangioblastoma

Hemangioma, Cavernous

Hemangioma, Cavernous, Central Nervous System

Kasabach-Merritt Syndrome

Sturge-Weber Syndrome

Hemangiopericytoma

Hemangiosarcoma

Meningioma

Sarcoma, Kaposi

Nevi and Melanomas

Melanoma

Hutchinson's Melanotic Freckle

Melanoma, Amelanotic

Melanoma, Experimenta

Nevus

Dysplastic Nevus Syndrome

Nevus, Halo

Nevus, Intradermal

Nevus, Pigmented

Mongolian Spot

Nevus, Blue

Nevus of Ota

Nevus, Spindle Cell

Nevus, Epithelioid and Spindle Cell

Nevus, Sebaceous of Jadassohn

Odontogenic Tumors

Ameloblastoma

Cementoma

Odontogenic Cyst, Calcifying

Odontogenic Tumor, Squamous

Odontoma

\section{Neoplasms by Site}

Abdominal Neoplasms

Peritoneal Neoplasms

Retroperitoneal Neoplasms

Sister Mary Joseph's Nodule

Anal Gland Neoplasms

Bone Neoplasms

Adamantinoma

Femoral Neoplasms

Skull Neoplasms

Jaw Neoplasms

Mandibular Neoplasms

Maxillary Neoplasms

Palatal Neoplasms

Nose Neoplasms

Orbital Neoplasms

Skull Base Neoplasms

Spinal Neoplasms

Breast Neoplasms
C04.557.580.625.650.200.500

C04.557.580.625.650.200.500.205

C04.557.580.625.650.240

C04.557.580.625.650.240.315

C04.557.580.625.650.240.325

C04.557.580.625.650.510

C04.557.580.625.650.510.385

C04.557.580.625.650.510.515

C04.557.580.625.650.510.525

C04.557.580.625.650.595

C04.557.580.625.650.595.610

C04.557.580.625.650.700

C04.557.580.625.650.700.705

C04.557.580.625.650.700.705.220

C04.557.580.625.650.700.705.340

C04.557.580.625.650.700.705.360

C04.557.580.625.650.700.725

C04.557.595

C04.557.595.500

C04.557.595.500.500

C04.557.595.600

C04.557.595.925

C04.557.645

C04.557.645.100

C04.557.645.115

C04.557.645.350

C04.557.645.375

C04.557.645.375.185

C04.557.645.375.370

C04.557.645.375.370.380

C04.557.645.375.380

C04.557.645.375.380.370

C04.557.645.375.385

C04.557.645.375.385.500

C04.557.645.375.617

C04.557.645.375.850

C04.557.645.380

C04.557.645.390

C04.557.645.520

C04.557.645.750

C04.557.665

C04.557.665.510

C04.557.665.510.385

C04.557.665.510.515

C04.557.665.510.525

C04.557.665.560

C04.557.665.560.260

C04.557.665.560.580

C04.557.665.560.590

C04.557.665.560.615

C04.557.665.560.615.530

C04.557.665.560.615.550

C04.557.665.560.615.585

C04.557.665.560.615.625

C04.557.665.560.615.625.585

C04.557.665.560.700

C04.557.695

C04.557.695.065

C04.557.695.210

C04.557.695.605

C04.557.695.607

C04.557.695.610

\section{C04.588}

C04.588.033

C04.588.033.513

C04.588.033.731

C04.588.033.740

C04.588.083

C04.588.149

C04.588.149.030

C04.588.149.276

C04.588.149.721

C04.588.149.721.450

C04.588.149.721.450.583

C04.588.149.721.450.601

C04.588.149.721.450.692

C04.588.149.721.600

C04.588.149.721.656

C04.588.149.721.828

C04.588.149.828

C04.588.180 
Breast Neoplasms, Male

Carcinoma, Ductal, Breast

Hereditary Breast and Ovarian Cancer Syndrome

Inflammatory Breast Neoplasms

Digestive System Neoplasms

Biliary Tract Neoplasms

Bile Duct Neoplasms

Common Bile Duct Neoplasms

Gallbladder Neoplasms

Gastrointestinal Neoplasms

Esophageal Neoplasms

Intestinal Neoplasms

Cecal Neoplasms

Appendiceal Neoplasms

Colorectal Neoplasms

Adenomatous Polyposis Coli

Gardner Syndrome

Colonic Neoplasms

Adenomatous Polyposis Coli

Gardner Syndrome

Sigmoid Neoplasms

Colorectal Neoplasms, Hereditary Nonpolyposis

Rectal Neoplasms

Anus Neoplasms

Anal Gland Neoplasms

Duodenal Neoplasms

Ileal Neoplasms

Jejunal Neoplasms

Stomach Neoplasms

Liver Neoplasms

Adenoma, Liver Cell

Carcinoma, Hepatocellular

Liver Neoplasms, Experimental

Pancreatic Neoplasms

Adenoma, Islet Cell

Insulinoma

Carcinoma, Islet Cell

Gastrinoma

Glucagonoma

Somatostatinoma

Vipoma

Carcinoma, Pancreatic Ductal

Peritoneal Neoplasms

Endocrine Gland Neoplasms

Adrenal Gland Neoplasms

Adrenal Cortex Neoplasms

Adrenocortical Adenoma

Adrenocortical Carcinoma

Multiple Endocrine Neoplasia

Multiple Endocrine Neoplasia Type 1

Multiple Endocrine Neoplasia Type 2a

Multiple Endocrine Neoplasia Type 2b

Ovarian Neoplasms

Granulosa Cell Tumor

Hereditary Breast and Ovarian Cancer Syndrome

Luteoma

Meigs Syndrome

Sertoli-Leydig Cell Tumor

Thecoma

Pancreatic Neoplasms

Adenoma, Islet Cell

Insulinoma

Carcinoma, Islet Cell

Gastrinoma

Glucagonoma

Somatostatinoma

Vipoma

Carcinoma, Pancreatic Ductal

Paraneoplastic Endocrine Syndromes

Parathyroid Neoplasms

Pituitary Neoplasms

ACTH-Secreting Pituitary Adenoma

Nelson Syndrome

Growth Hormone-Secreting Pituitary Adenoma

Prolactinoma

Testicular Neoplasms

Sertoli-Leydig Cell Tumor

Leydig Cell Tumor

Sertoli Cell Tumor

Thyroid Neoplasms

Thyroid Nodule
C04.588.180.260

C04.588.180.390

C04.588.180.483

C04.588.180.576

C04.588.274

C04.588.274.120

C04.588.274.120.250

C04.588.274.120.250.250

C04.588.274.120.401

C04.588.274.476

C04.588.274.476.205

C04.588.274.476.411

C04.588.274.476.411.184

C04.588.274.476.411.184.290

C04.588.274.476.411.307

C04.588.274.476.411.307.089

C04.588.274.476.411.307.089.393

C04.588.274.476.411.307.180

C04.588.274.476.411.307.180.089

C04.588.274.476.411.307.180.089.500

C04.588.274.476.411.307.180.800

C04.588.274.476.411.307.190

C04.588.274.476.411.307.790

C04.588.274.476.411.307.790.040

C04.588.274.476.411.307.790.040.040

C04.588.274.476.411.445

C04.588.274.476.411.501

C04.588.274.476.411.523

C04.588.274.476.767

C04.588.274.623

C04.588.274.623.040

C04.588.274.623.160

C04.588.274.623.460

C04.588.274.761

C04.588.274.761.249

C04.588.274.761.249.500

C04.588.274.761.500

C04.588.274.761.500.124

C04.588.274.761.500.249

C04.588.274.761.500.500

C04.588.274.761.500.750

C04.588.274.761.750

C04.588.274.780

C04.588.322

C04.588.322.078

C04.588.322.078.265

C04.588.322.078.265.500

04.588 .322 .078 .265 .750

C04.588.322.400

C04.588.322.400.500

C04.588.322.400.505

C04.588.322.400.510

C04.588.322.455

C04.588.322.455.398

C04.588.322.455.431

C04.588.322.455.464

C04.588.322.455.531

C04.588.322.455.648

C04.588.322.455.765

C04.588.322.475

C04.588.322.475.249

C04.588.322.475.249.500

C04.588.322.475.500

C04.588.322.475.500.124

04.588 .322 .475 .500 .249

C04.588.322.475.500.500

C04.588.322.475.500.750

C04.588.322.475.750

C04.588.322.490

C04.588.322.525

C04.588.322.609

C04.588.322.609.145

C04.588.322.609.145.500

C04.588.322.609.292

C04.588.322.609.792

C04.588.322.762

C04.588.322.762.500

C04.588.322.762.500.249

C04.588.322.762.500.500

C04.588.322.894

C04.588.322.894.800 
Eye Neoplasms

Conjunctival Neoplasms

Orbital Neoplasms

Paraneoplastic Syndromes, Ocular

Retinal Neoplasms

Retinoblastoma

Uveal Neoplasms

Choroid Neoplasms

Iris Neoplasms

Head and Neck Neoplasms

Esophageal Neoplasms

Facial Neoplasms

Eyelid Neoplasms

Mouth Neoplasms

Gingival Neoplasms

Leukoplakia, Oral

Leukoplakia, Hairy

Lip Neoplasms

Palatal Neoplasms

Salivary Gland Neoplasms

Parotid Neoplasms

Sublingual Gland Neoplasms

Submandibular Gland Neoplasms

Tongue Neoplasms

Otorhinolaryngologic Neoplasms

Ear Neoplasms

Laryngeal Neoplasms

Nose Neoplasms

Paranasal Sinus Neoplasms

Maxillary Sinus Neoplasms

Pharyngeal Neoplasms

Hypopharyngeal Neoplasms

Nasopharyngeal Neoplasms

Oropharyngeal Neoplasms

Tonsillar Neoplasms

Parathyroid Neoplasms

Thyroid Neoplasms

Thyroid Nodule

Tracheal Neoplasms

Hematologic Neoplasms

Bone Marrow Neoplasms

Mammary Neoplasms, Animal

Mammary Neoplasms, Experimental

Nervous System Neoplasms

Central Nervous System Neoplasms

Brain Neoplasms

Cerebral Ventricle Neoplasms

Choroid Plexus Neoplasms

Papilloma, Choroid Plexus

Infratentorial Neoplasms

Brain Stem Neoplasms

Cerebellar Neoplasms

Neurocytoma

Pinealoma

Supratentorial Neoplasms

Hypothalamic Neoplasms

Pallister-Hall Syndrome

Pituitary Neoplasms

Central Nervous System Cysts

Arachnoid Cysts

Colloid Cysts

Meningeal Neoplasms

Meningeal Carcinomatosis

Meningioma

Spinal Cord Neoplasms

Epidural Neoplasms

Cranial Nerve Neoplasms

Optic Nerve Neoplasms

Optic Nerve Glioma

Paraneoplastic Syndromes, Nervous System

Anti-N-Methyl-D-Aspartate Receptor Encephalitis

Lambert-Eaton Myasthenic Syndrome

Limbic Encephalitis

Myelitis, Transverse

Opsoclonus-Myoclonus Syndrome

Paraneoplastic Cerebellar Degeneration

Paraneoplastic Polyneuropathy

Peripheral Nervous System Neoplasms

Cranial Nerve Neoplasms

Neuroma, Acoustic

Optic Nerve Neoplasms
C04.588.364

C04.588.364.235

C04.588.364.659

C04.588.364.738

C04.588.364.818

C04.588.364.818.760

C04.588.364.978

C04.588.364.978.223

C04.588.364.978.400

C04.588.443

C04.588.443.353

C04.588.443.392

C04.588.443.392.500

C04.588.443.591

C04.588.443.591.402

C04.588.443.591.545

C04.588.443.591.545.500

C04.588.443.591.550

C04.588.443.591.692

C04.588.443.591.824

C04.588.443.591.824.695

C04.588.443.591.824.882

C04.588.443.591.824.885

C04.588.443.591.925

C04.588.443.665

C04.588.443.665.312

C04.588.443.665.481

C04.588.443.665.650

C04.588.443.665.650.693

C04.588.443.665.650.693.575

C04.588.443.665.710

C04.588.443.665.710.485

C04.588.443.665.710.650

C04.588.443.665.710.684

C04.588.443.665.710.684.800

C04.588.443.680

C04.588.443.915

C04.588.443.915.800

C04.588.443.925

C04.588.448

C04.588.448.200

C04.588.531

C04.588.531.500

C04.588.614

C04.588.614.250

C04.588.614.250.195

C04.588.614.250.195.205

C04.588.614.250.195.205.200

C04.588.614.250.195.205.200.500

C04.588.614.250.195.411

C04.588.614.250.195.411.100

C04.588.614.250.195.411.211

C04.588.614.250.195.648

C04.588.614.250.195.766

C04.588.614.250.195.885

C04.588.614.250.195.885.500

C04.588.614.250.195.885.500.299

C04.588.614.250.195.885.500.600

C04.588.614.250.387

C04.588.614.250.387.100

C04.588.614.250.387.200

C04.588.614.250.580

C04.588.614.250.580.150

C04.588.614.250.580.500

C04.588.614.250.803

C04.588.614.250.803.342

C04.588.614.300

C04.588.614.300.600

C04.588.614.300.600.600

C04.588.614.550

C04.588.614.550.112

C04.588.614.550.225

C04.588.614.550.450

C04.588.614.550.550

C04.588.614.550.600

C04.588.614.550.650

C04.588.614.550.700

C04.588.614.596

C04.588.614.596.240

C04.588.614.596.240.015

C04.588.614.596.240.240 
Optic Nerve Glioma

Pelvic Neoplasms

Skin Neoplasms

Acanthoma

Sebaceous Gland Neoplasms

Muir-Torre Syndrome

Sweat Gland Neoplasms

Soft Tissue Neoplasms

Muscle Neoplasms

Vascular Neoplasms

Splenic Neoplasms

Thoracic Neoplasms

Heart Neoplasms

Carney Complex

Mediastinal Neoplasms

Respiratory Tract Neoplasms

Lung Neoplasms

Bronchial Neoplasms

Carcinoma, Bronchogenic

Carcinoma, Non-Small-Cell Lung

Small Cell Lung Carcinoma

Multiple Pulmonary Nodules

Pancoast Syndrome

Pulmonary Blastoma

Pulmonary Sclerosing Hemangioma

Solitary Pulmonary Nodule

Pleural Neoplasms

Pleural Effusion, Malignant

Solitary Fibrous Tumor, Pleural

Tracheal Neoplasms

Thymus Neoplasms

Thymoma

Urogenital Neoplasms

Genital Neoplasms, Female

Fallopian Tube Neoplasms

Uterine Neoplasms

Endometrial Neoplasms

Carcinoma, Endometrioid

Uterine Cervical Neoplasms

Vaginal Neoplasms

Vulvar Neoplasms

Genital Neoplasms, Male

Penile Neoplasms

Prostatic Neoplasms

Testicular Neoplasms

Sertoli-Leydig Cell Tumor

Leydig Cell Tumor

Sertoli Cell Tumor

Urologic Neoplasms

Kidney Neoplasms

Carcinoma, Renal Cell

Wilms Tumor

Denys-Drash Syndrome

WAGR Syndrome

Nephroma, Mesoblastic

Ureteral Neoplasms

Urethral Neoplasms

Urinary Bladder Neoplasms

Venereal Tumors, Veterinary

Neoplasms, Experimental

Carcinoma 256, Walker

Carcinoma, Brown-Pearce

Carcinoma, Ehrlich Tumor

Carcinoma, Krebs 2

Carcinoma, Lewis Lung

Leukemia, Experimental

Avian Leukosis

Leukemia L1210

Leukemia L5178

Leukemia P388

Liver Neoplasms, Experimental

Mammary Neoplasms, Experimental

Melanoma, Experimental

Sarcoma, Experimental

Sarcoma 37

Sarcoma 180

Sarcoma, Avian

Sarcoma, Yoshida

Tumor Virus Infections

Avian Leukosis

Epstein-Barr Virus Infections

04.588 .614 .596 .240 .240 .50

C04.588.699

C04.588.805

C04.588.805.040

C04.588.805.578

C04.588.805.578.500

C04.588.805.776

C04.588.839

C04.588.839.500

C04.588.839.750

C04.588.842

C04.588.894

C04.588.894.309

C04.588.894.309.500

C04.588.894.479

C04.588.894.797

C04.588.894.797.520

C04.588.894.797.520.109

C04.588.894.797.520.109.220

C04.588.894.797.520.109.220.249

C04.588.894.797.520.109.220.624

C04.588.894.797.520.237

C04.588.894.797.520.734

C04.588.894.797.520.867

C04.588.894.797.520.933

C04.588.894.797.520.966

C04.588.894.797.640

C04.588.894.797.640.700

C04.588.894.797.640.800

C04.588.894.797.760

C04.588.894.949

C04.588.894.949.500

C04.588.945

C04.588.945.418

C04.588.945.418.365

C04.588.945.418.948

C04.588.945.418.948.585

C04.588.945.418.948.585.124

C04.588.945.418.948.850

C04.588.945.418.955

C04.588.945.418.968

C04.588.945.440

C04.588.945.440.715

C04.588.945.440.770

C04.588.945.440.915

C04.588.945.440.915.500

C04.588.945.440.915.500.249

C04.588.945.440.915.500.500

C04.588.945.947

C04.588.945.947.535

C04.588.945.947.535.160

C04.588.945.947.535.585

C04.588.945.947.535.585.220

C04.588.945.947.535.585.950

C04.588.945.947.535.790

C04.588.945.947.940

C04.588.945.947.945

C04.588.945.947.960

C04.588.945.956

\section{C04.619}

C04.619.045

C04.619.124

C04.619.169

C04.619.214

C04.619.230

C04.619.531

C04.619.531.216

C04.619.531.594

C04.619.531.602

C04.619.531.782

C04.619.540

C04.619.590

C04.619.600

C04.619.857

C04.619.857.573

C04.619.857.656

C04.619.857.800

C04.619.857.82

C04.619.935

C04.619.935.120

C04.619.935.313 


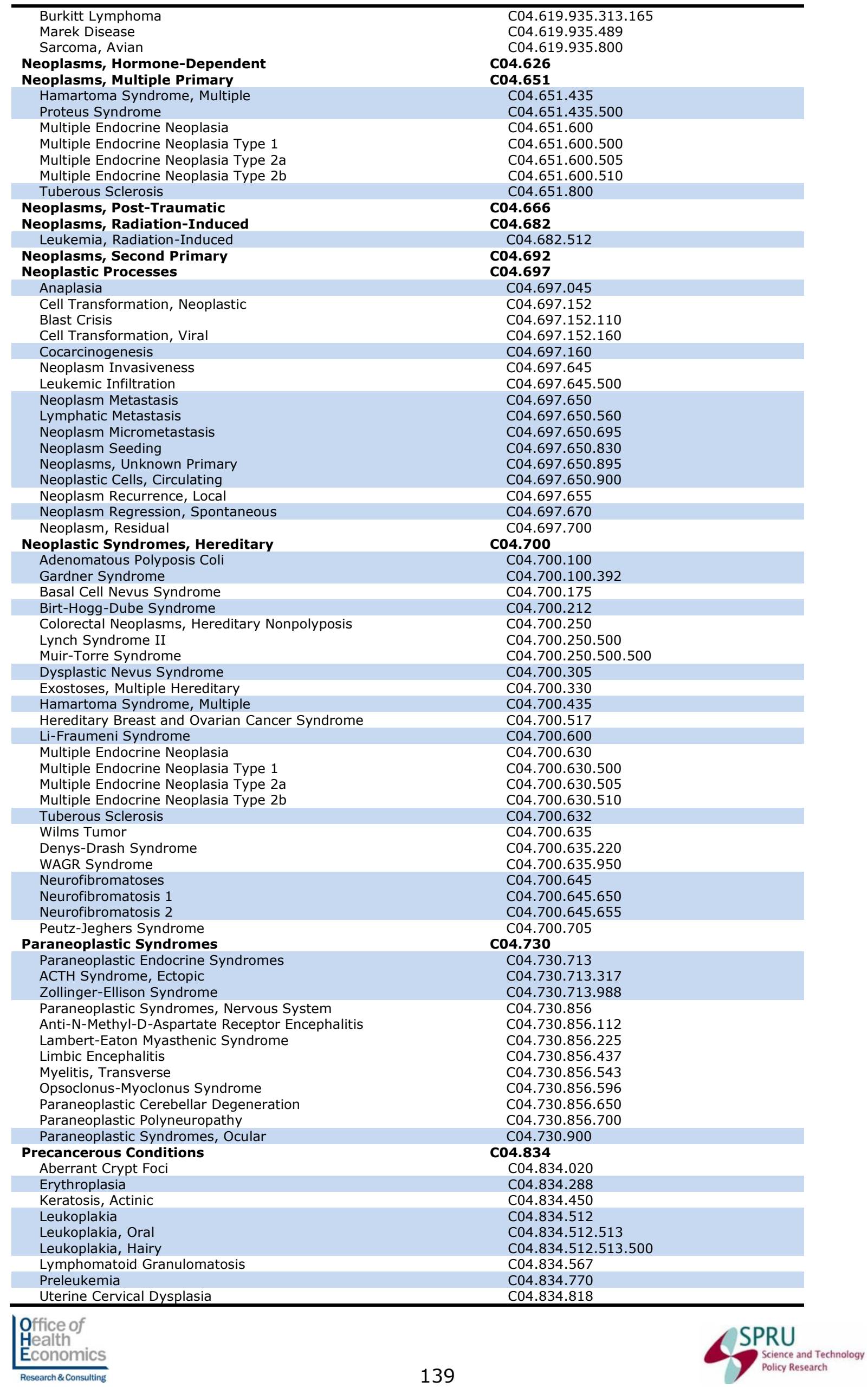


OHE and SPRU Report for Cancer Research UK March 2014

Xeroderma Pigmentosum

Pregnancy Complications, Neoplastic

Trophoblastic Neoplasms

Gestational Trophoblastic Disease

Choriocarcinoma

Trophoblastic Tumor, Placental Site

Hydatidiform Mole

Hydatidiform Mole, Invasive

Tumor Virus Infections

Avian Leukosis

Carcinoma, Merkel Cell

Epstein-Barr Virus Infections

Burkitt Lymphoma

Marek Disease

Sarcoma, Avian

Warts

Epidermodysplasia Verruciformis
C04.834.867

C04.850

C04.850.908

C04.850.908.416

C04.850.908.416.186

C04.850.908.416.186.875

C04.850.908.416.750

C04.850.908.416.750.500

C04.925

C04.925.120

C04.925.216

C04.925.313

C04.925.313.165

C04.925.489

C04.925.700

C04.925.744

C04.925.744.500 


\section{Appendix to Chapter 4 - Screenshots from survey}

\section{Introduction}

Thank you for agreeing to take part in this research study which is conducted by Accent, on behalf of OHE (an economics research organisation). The purpose of the study is to find out how a change in Government support for medical research might affect your willingness to donate to medical research charities. The study is being funded by Cancer Research UK

You will be asked to answer a series of questions involving hypothetical scenarios. There are no right or wrong (or better or worse) answers - we are simply seeking your views. You will also be asked some general questions about yourself and how you feel about giving to charity.

The results of the study will be written up in a report for Cancer Research UK, and may be published in academic journals and presented at conferences. You will not be identified in any reports or publications. The anonymised data collected during the course of the study may be used for additional or subsequent research and analysis

This research is conducted under the terms of the MRS code of conduct and is completely confidential. If you would like to confirm Accent's credentials please call the MRS free on 0500396999.

We will just ask you a couple of questions to check that you are eligible to take part in this research.

\section{Scoping questions}

Are you:
$\ominus$ Male
$\ominus$ Female 
Which of the following age groups do you fall into?
Under 18
18-29
(9)-39
० $40-49$
๑ $50-59$
60 or over
Do not wish to say

Please indicate to which occupational group the Chief Income Earner in your household belongs, or which group fits best.

This could be you: the Chief Income Earner is the person in your household with the largest income.

If the Chief Income Earner is retired and has an occupational pension please answer for their most recent occupation.

If the Chief Income Earner is not in paid employment but has been out of work for less than 6 months, please answer for their most recent occupation.

\section{PLEASE TICK ONLY ONE ANSWER}

Semi or unskilled manual work.

(e.g. manual workers, all apprentices to be skilled trades, caretaker, park keeper, non-HGV driver, shop assistant)

Skilled manual worker

(e.g. skilled bricklayer, carpenter, plumber, painter, bus/ ambulance driver, HGV driver, AA patrolman, pub/bar worker, etc)

Supervisory or clerical/ junior managerial/ professional/ administrative

(e.g. office worker, student doctor, foreman with $25+$ employees, salesperson, etc)

Intermediate managerial/ professional/ administrative

(e.g. newly qualified (under 3 years) doctor, solicitor, board director in small organisation, middle manager in large organisation, principal officer in civil service/local government) Higher managerial/ professional/ administrative

(e.g. established doctor, solicitor, board director in a large organisation $(200+$ employees, top level civil servant/public service employee)

$\odot$ Student

Casual worker, not in permanent employment

- Housewife/Homemaker

Retired and living on state pension

Unemployed or not working due to long-term sickness

- Full-time carer of other household member

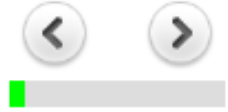




\section{Main Questionnaire}

Thank you, I can confirm you are in scope for the survey. The questionnaire will take about 10 minutes to complete. You do not have to answer questions you do not wish to and you can terminate the interview at any point. For convenience you can stop and return to complete the questionnaire as many times as you wish, although once submitted you will not be able to enter again.

In the last year, to which of the following cancer research charities have you given money?

Please tick all that apply

British Association for Cancer Research

$\checkmark$ Cancer Research UK

$\ominus$ Children with Cancer UK

$\ominus$ Leukaemia \& Lymphoma Research

Marie Curie Cancer Care

$\ominus$ Ovarian Cancer Action

$\ominus$ Pancreatic Cancer Research Trust

Prostate Cancer UK

The Brain Tumour Charity

Other, specify

None of these 
In the last year, to which of the following medical research charities have you given money?

Please tick all that apply

Alzheimer's Research UK

Arthritis Research UK

British Heart Foundation

9 Diabetes UK

Motor Neurone Disease Association

ㄱ. Parkinson's UK

Scope

Sense, the National Deafblind and Rubella Association

The Multiple Sclerosis Society of Great Britain and Northern Ireland

Other medical research charities (excluding cancer research charities), specify

None of these

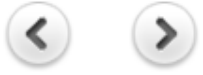

How much do you think the UK Government currently spends on medical research each year? Please note that we're interested in your best guess even if you don't know.

(in millions of pounds)

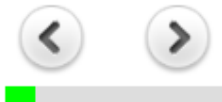

Office of

Health

Economics 
And, of the total amount that the UK Government is currently spending on medical research each year, what percentage do you think is spent on cancer research? Again, we're interested in your best guess

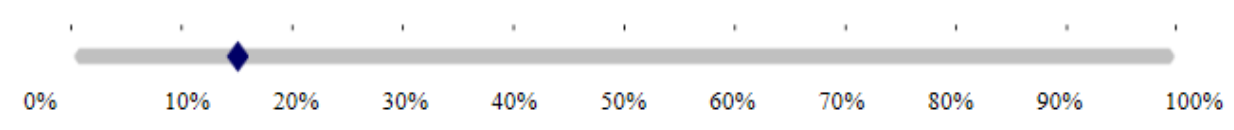

Over the last three years, do you think that Government funding of medical research:
Has been going up
Has been going down
$\odot$ Has remained about the same
I I don't know

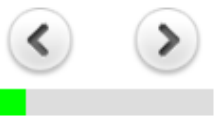


And, over the last three years, do you think that Government funding of cancer research:
$\odot$ Has been going up
$\odot$ Has been going down
○ Has remained about the same
○I don't know

\section{INTRO SCENARIOS}

Now we would like you to imagine that you have the opportunity to allocate $£ 100$ of the income tax you pay this year to one or more medical research charities.

You could give none, some or all of the $£ 100$ to cancer research charities and the remainder (if any) to medical research charities (of your choosing) concerned with diseases other than cancer.

The following questions will ask you how you would distribute your £100 allocation under various scenarios. 
How would you distribute your $£ 100$ allocation?

to cancer research charities

I

to non-cancer medical research charities

Having been given the opportunity to allocate $£ 100$ in this way, would you want to reduce or increase any personal donations that you currently make out of your own pocket to any cancer research charities?

๑ Would reduce by $£ \ldots . .$. (type in)

Would increase by $£ \ldots . .$. (type in)

Would not change 
Please consider the diagram below, which shows approximately how much the Government and charities currently spend on medical research in the UK each year.

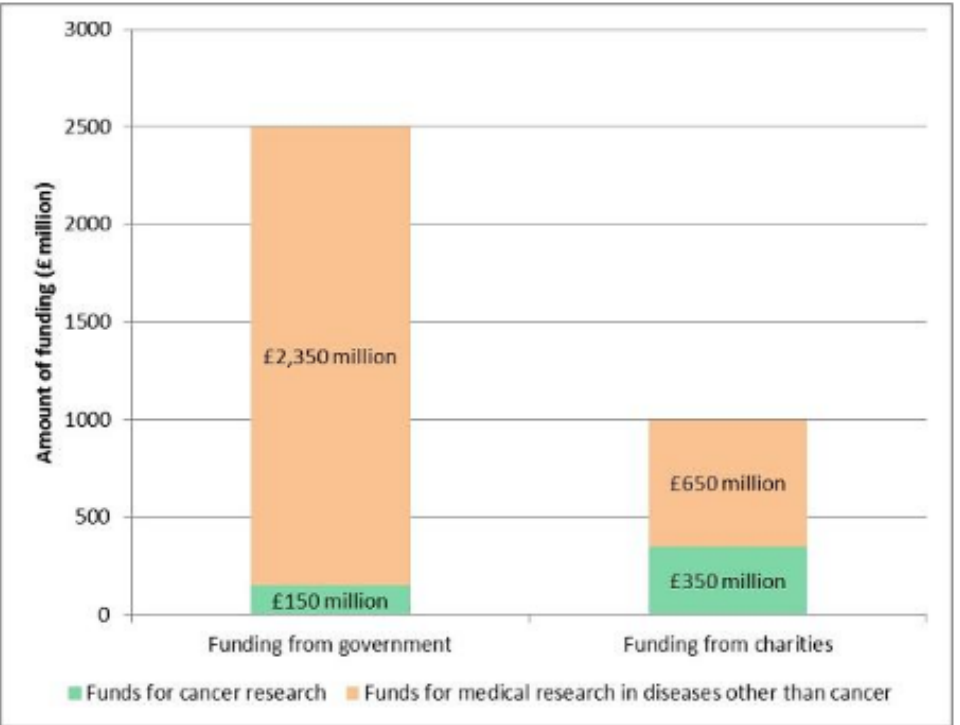

In the light of that information, please consider again what you would do if you have the opportunity to allocate $£ 100$ of the income tax you pay this year to one or more medical research charities.

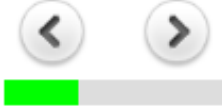

How would you distribute your $£ 100$ allocation?

to cancer research charities

to non-cancer medical research charities 
Having been given the opportunity to allocate $£ 100$ in this way, would you want to reduce or increase any personal donations that you currently make out of your own pocket to any cancer research charities?
๑ Would reduce by $£ . .$. (type in)
๑ Would increase by £.... (type in)
- Would not change

Please consider the diagram below, which shows a scenario of what medical research spending in the UK might look like in the future. In this case, the Government has reduced its spending on cancer research by $£ 100$ million per year and is spending that money instead on more research into diseases other than cancer.

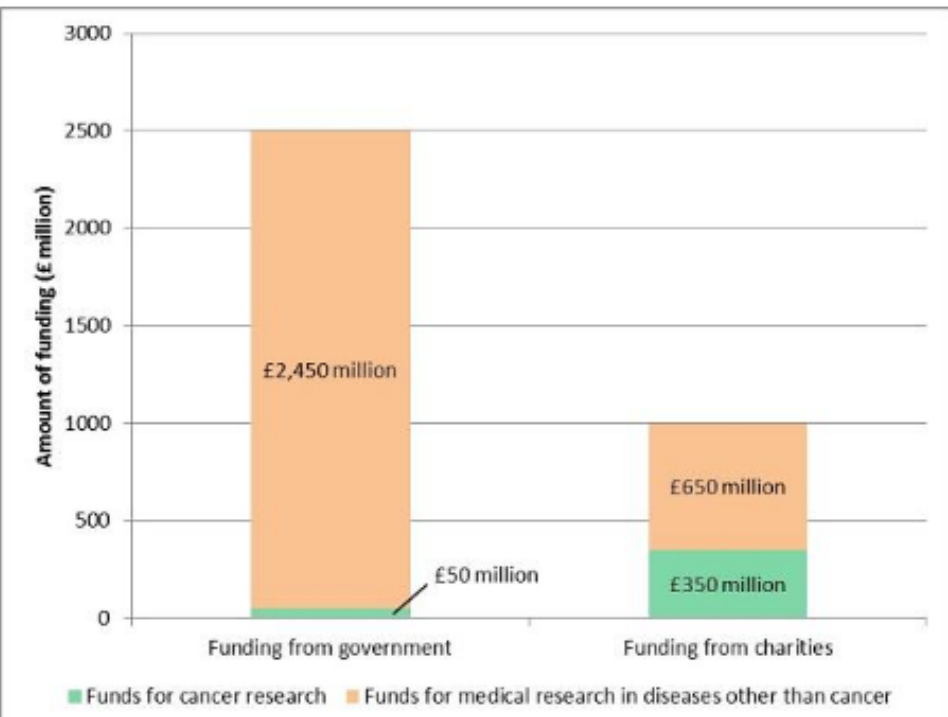

In the light of that information, please consider again what you would do if you have the opportunity to allocate $£ 100$ of the income tax you pay this year to one or more medical research charities.

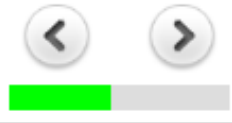


Please consider the diagram below, which shows another scenario of what medical research spending might look like in the future. In this case, the Government has reduced its spending on cancer research by £100 million per year and is NOT increasing its spending on any other area of medical research, so total Government spending on medical research has been reduced by the same $£ 100$ million.

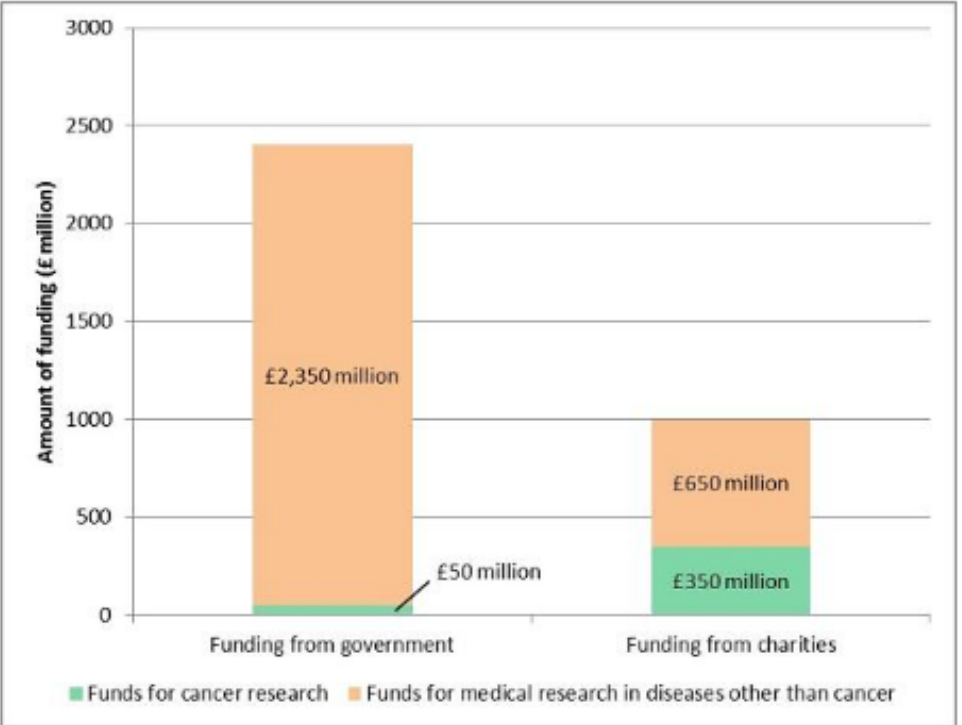

In the light of that information, please consider again what you would do if you have the opportunity to allocate $£ 100$ of the income tax you pay this year to one or more medical research charities.

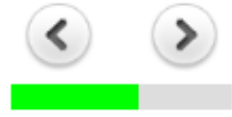


Please consider the diagram below, which show another scenario of what medical research spending might look like in the future. In this case, the Government has increased its spending on cancer research by £100 million per year and has found that money by reducing its spending on research into diseases other than cancer by £100 million.

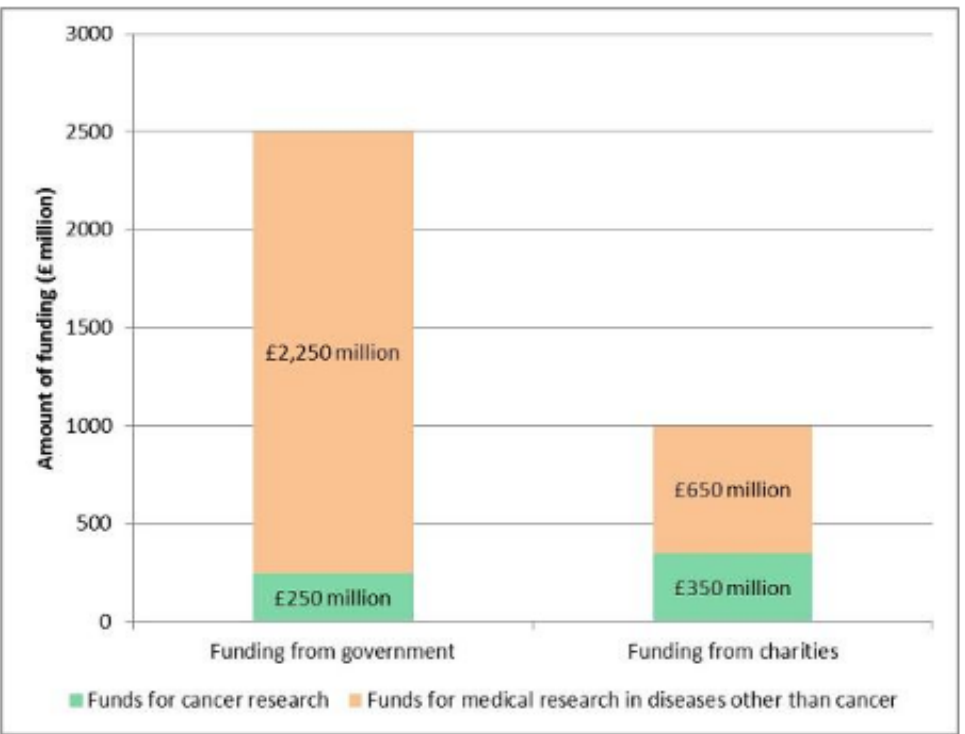

In the light of that information, please consider again what you would do if you have the opportunity to allocate $£ 100$ of the income tax you pay this year to one or more medical research charities.

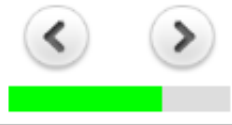

If you have any comments that you would like to make about your answers to the previous questions, please enter them in the box below.

WRITE IN:

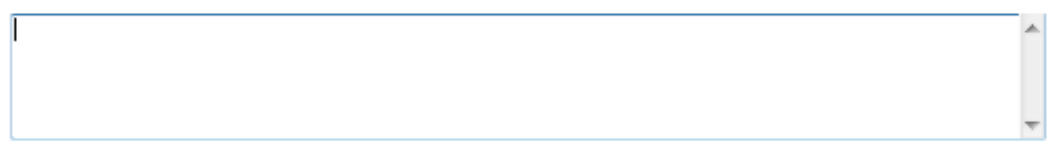

№ comment 
Which of the following statements best reflects your personal view?

I would be more likely to donate to a cancer research charity, or to donate even more than I already do, if I were to hear that the Government has reduced its spending on cancer research

I would be less likely to donate to a cancer research charity, or to donate less than I already do, if I were to hear that the

Government has reduced its spending on cancer research

๑ Government spending decisions make no difference to my decision about whether or not to donate to a cancer research charity

Which of the following types of charity donation have you made in the last year? We are interested in your donations to any kind of charity, medical or otherwise. Please tick all boxes that apply.

Please tick all that apply

B Money - regular donation

日 Money - one-off donation

Money - other (charity events, auctions, etc.)

$\ominus$ Non-financial - e.g. donation of unwanted goods, volunteering

$\theta$ None of the above 
Over the last three years, has the level of your charity donation(s) been going up or going down, or has it remained about the same?
Going up
Going down
$\ominus$ About the same

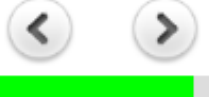

Do you have personal experience of cancer or have a close friend or family member who has had cancer?

Please tick all that apply

Yes, self

Yes, friend or relative

$\exists$ No

I would rather not answer this question 
We really appreciate the time that you have given us today. Would you be willing to be contacted again for clarification purposes or be invited to take part in other research for Office of Health Economics or Cancer Research UK?

Yes, for both clarification and further research

Yes, for clarification only

Yes, for further research only

$\odot$ No

\section{End of Survey}

THANK YOU FOR YOUR HELP IN THIS RESEARCH

This research was conducted under the terms of the UK Market Research Society code of conduct and is completely confidential.

Office of 